
10 VINVS?

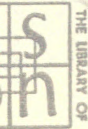

aivin 캐응

VINVS

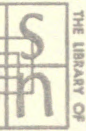

and 채 0

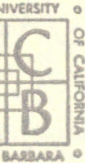

ne vinvs o

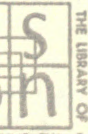

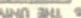
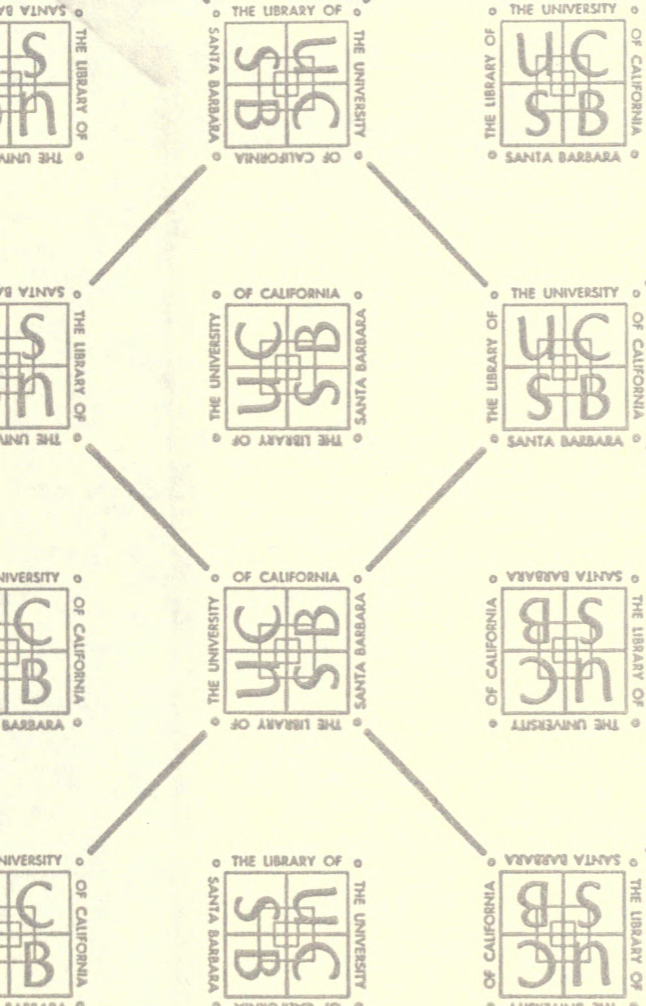

- OF CALIFORN

- vineosinvs so

- Santa Barekea.

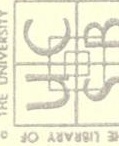

- THE UBRARY

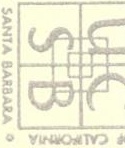

- SANTA Mashea

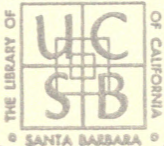

a Voverve VinNes o
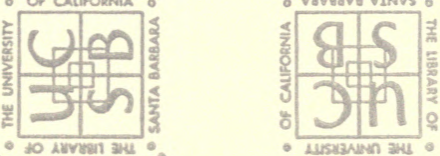

THE LIRAMY

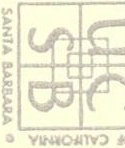

- OF CALFORN

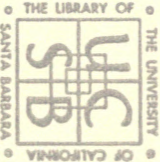

noverve yiars o
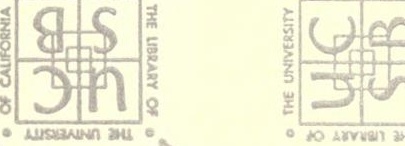

THE UNNESSTr d

OF CALHOL:
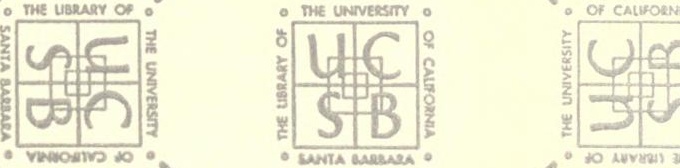
$x$ 




\section{DICTIONARY OF \\ BRITISH SCIENTIFIC INSTRUMENTS}






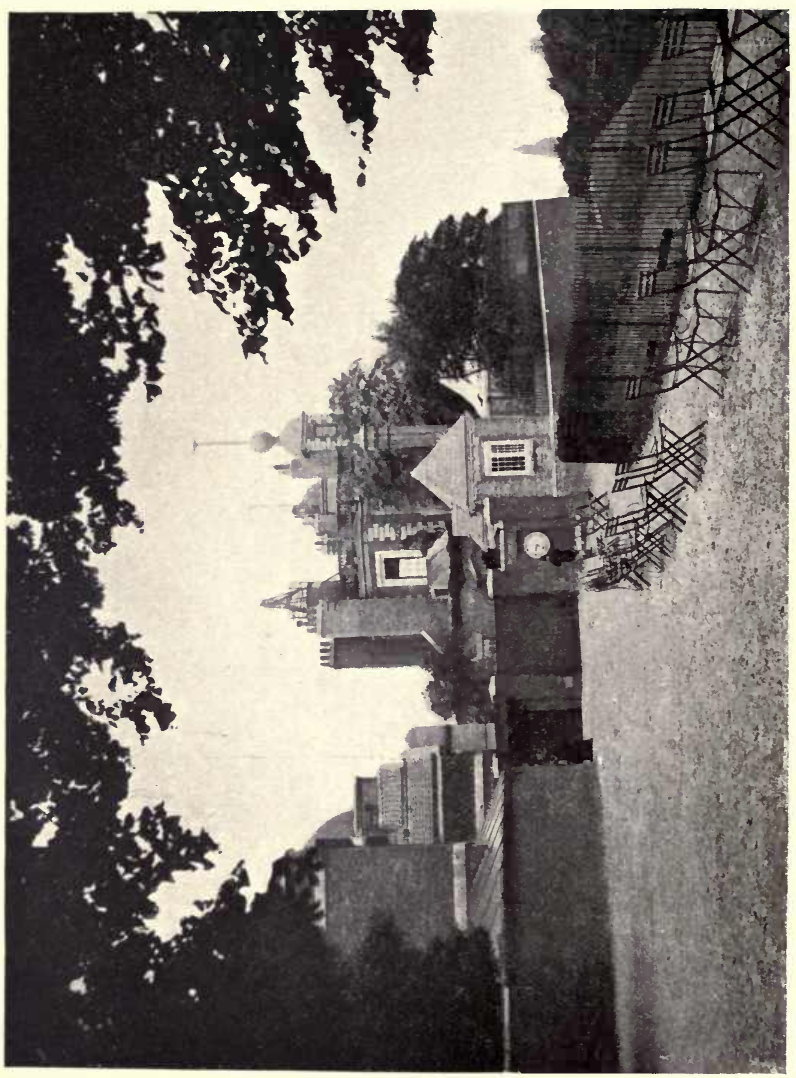

17. 


\section{Soientific Instrument manutalon of Great
"ASsoclation of
DICTIONARY OF
BRITISH SCIENTIFIC INSTRUMENTS}

ISSUED BY THE

BRITISH OPTICAL INSTRUMENT MANUFACTURERS' ASSOCIATION

\section{LONDON}

CONSTABLE AND COMPANY LTD. 

The key number of Messrs. Adam Hilger, Ltd., should be included after the names of the following instruments :-
Absorption Apparatus. Collimator.
Colorimeter.
Colour Perception Ap- paratus.
Concave Lens. " Mirror.
Direct Vision Spectro- scope.
Double Image Prism.
Erecting Prism.
Eyepiece.

" Diagonal.
Huyghenian.
" Positive.
Ramsden.
Fabry \& Perot Inter- ferometer. Filter, Light.
Galvanometer Mirrors. Gas Analysis Apparatus. Rutherford Prism.

\begin{tabular}{|l|} 
Interferometer, Fabry \\
\& Perot. \\
Interferometer, Lum- \\
mer \& Gehrcke. \\
Lens, Achromatic. \\
Mica Wave Plates. \\
Micrometer Eyepiece. \\
Mirror. Screw. \\
Nicol Prism. \\
Object Glasses. \\
Ocular. \\
Optical Mirror. \\
Parabolic Mirror. \\
Photometer. \\
Polarising Apparatus. \\
Positive Eyepiece. \\
Prism, Foucault. \\
", Nicol's. \\
", Tutherford's. \\
Ramsden Eyepon. \\
Rutherford Prism.
\end{tabular}
Schumann Plates.
Screen, Filter.
Solar Diagonal Eye- piece.
Spectrograph, Concave Grating.
Spectrograph, Fery. Spectrograph, Quartz, Arc Form.
Spectrograph, Quartz, Littrow.
Spectroscope, Direct Vision.
Spectroscope, Evershed.
Spherometer.
Strain-Measurer.
Telespectroscope.
Tension Meter.
Tetragonal Prism.
Thermo-couple.
Thermopile.
Viscometer.

The address of the British Optical Instrument Manufacturers Association should read :-

Duke Street, London, S.W.I. 



\section{PREFACE.}

THE nomenclature of a science is one of the most im. portant portions of its structure, and the Science of Instruments requires a good dictionary as a basis. It is believed that a concise definition of each instrument, together with illustrations of the most important types, will be of real service to scientific men and the industry.

This book is not only a means of information and reference respecting scientific instruments of every description, but also exhibits the great variety of such instruments that are produced in Great Britain. Key numbers corresponding with a numbered list of manufacturers are attached to the dictionary descriptions.

The British Optical Instrument Manufacturers' Association, under whose auspices the book is issued, is composed of the leading Optical Instrument Manufacturers of Great Britain, the names of whom will be familiar throughout the world. From these houses have emanated in years gone by the original types of which the presentday highly developed, and often complex, instruments are the outcome, and these houses have throughout maintained that high standard of excellence and fine working quality for which British instruments are famed.

The British Optical Industry succeeded in meeting the increased requirements of the War to an extent that was not considered possible, and to-day with greatly enlarged factories, equipped with mechanical machinery of the most suitable and modern description, with supplies of optical glass constantly increasing in quality and variety, and aided by a Research Association adequately financed, it is in a position to give its supporters a service in brains and goods that has never before been available.

The Association issues this book with the full assurance of the ability of its members to meet the demands of all who are interested in the promotion and maintenance of the supremacy of the British Optical Instruments, and invites their confidence and support. 



\section{LIST OF CONTENTS.}

The British Optical Instrument Industry
List of Members -





\section{LIST OF ILLUSTRATIONS.}

FIG.

I Aeroplane Instrument

PAGE

Board

2 Air Meter, Biram' $\cdots$...

4 Anemograph (Recorder and Transmitter) ... ...

5 Artificial Horizon, Admiralty Pattern $\quad$... $\quad 183$

6 Alidade and Abney Level...

7 Altazimuth for Surveying

8 Azimuth Mirror ... ...

9 Azimuth Mirror ... ...

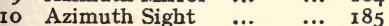

I I Adjusting Dial $\quad . . \quad \ldots \quad$... 185

12 Azimuth Dial, Course Corrector ... ... I86

I3 Azimuth Dial, Pelorus ... 186

I4 Balance, Chemical f.. 187

I5 Barocyclonometer... ...

I6 Barograph ... $\quad . . \quad \ldots . . \quad$ I88

I7 Barometer, Aneroid $\quad \ldots$. r89

18 Barometer, Aneroid, Surveying Pattern ... ... r 89

19 Barometer, Aneroid (Pocket Size) $\quad \ldots \quad \ldots \quad$ rgo

20 Barometer, Aneroid (Hunter Case) ... ... r 90

21 Barometer, Aneroid, Surveying Pattern ... ...

22 Barometer, Fitzroy Pediment ... ... ... r 9 I

23 Barometer, Marine ... $\quad$ I9I

24 Barometer, Fortin Standard

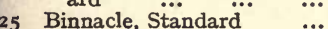

26 Binnacle, Trawler Standard

27 Binocular, Prism, Marine...

28 Binocular, Galilean, EyeFocussing Marine ...

29 Binocular, Galilean, Marine Night Glass ... ...

30 Binocular, Galilean, Marine Night and Day Glass ...

31 Calorimeter, Bunsen's Ice...

32 Calorimeter, Glazebrook's

33 Calorimeter, Mahler Cook...
Camera, Hand ... ...

Camera, Reflex $\quad .$. ...

Camera, Stand $\quad \ldots$... 195

I95

I96

г96

I97

198

r99

199
FIG.

PAGE

37 Camera Lucida, Vertical ... 200

$3^{8}$ Camera Lucida, Wollaston's $\quad \ldots \quad \ldots . \quad \ldots \quad 200$

39 Camera Lucida, Abbé ... 200

40 Camera Lucida, Sketching 200

4r Cardiograph ... ... 20r

42 Capillary Electrometer ... 202

43 Cymograph $\quad$... $\quad$... 202

44 Cathetometer $\quad$... $\quad$... 203

45 Cathetometer ... $\quad$... 203

46 Centrifuge ... $\quad$... $\quad$... 204

47 Chronograph ... ... 204

48 Chronometer Deck Watch 205

49 Chronograph Watch ... 205

50 Chronometer, Marine ... 206

5I Chart Protractor, XY $\quad$... 207

52 Chart Protractor ... ... 207

53 Chart Dividers, Parallel ... 207

54 Chart Dividers ... $\quad$... 207

55 Chart Dividers, OneHanded ... ... ... 207

56 Cinematograph $\quad$... $\quad$... 208

57 Clinometer, Marine Mercury $20 y$

58 Clinometer, Marine Dial ... 209

59 Clinometer, Rule and Compass $\quad . . . \quad \ldots \quad \ldots 2$ Io

60 Clinometer and Prismatic Compass ... ... 2 Io

6r Colorimeter, Nutting's ... 2 II

62 Circumferentor ... ... 2 I2

63 Comparator $\quad . . . \quad \ldots \quad 2$ I 2

64 Comparator, Co-ordinate ... 212

65 Comparator, Ten-Link ... 213

66 Compass, Azimuth ... 214

67 Compass, Aeronautical ... 2 I5

68 Compass, Creagh-Osborne 216

69 Compass, Creagh-Osborne 216

70 Gyroscopic Compass in Binnacle $\quad . . . \quad \ldots 2 \mathrm{I}_{7}$

7 Gyroscope Compass removed from the Binnacle

72 Gyroscope Compass, Steering Repeater ... ... 218

73 Compass, Lifeboat $\quad$... 2 219

74 Compass Magnifier $\quad$... 2 2 9

75 Compass, Pocket ... ... 220

76 Compass, Box ... ... 220

77 Compass, Pocket, Liquid... 220

78 Compass, Tell Tale $\quad$... 220 


\section{LIST OF ILLUSTRATIONS-cont.}

FIG.

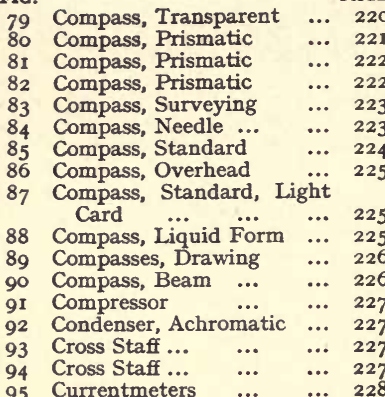

1427. Currentmeter, Tidal Log.

1 494. Currentmeter.

I 495. Amsler Currentmeter, Pattern III.

1496. Ditto, Pattern I.

I 498. Ditto, Pattern IV.

I 499. Ditto, Pattern VI.

96 Dichroiscope $\quad .$. ...

97 Dip Needle... ... ... 229

98 Deflector ... $\quad$... $\quad \ldots .229$

99 Deflector, Kelvin Pattern

I00 Dip Needle, Kelvin Pattern (Vertical Force Instru-

IoI

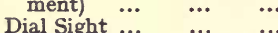

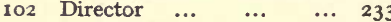

I03 Divider, Hair $\quad \ldots \quad \ldots .233$

I04 Eectrometer, Dolezalek ... 234

I05 Dotting Pen ... ... 234

106 Electrometer, Laby String

107 Electrometer (Wilson

Kaye's Tilted Gold Leaf)

108 Endless Tangent Screw on Sextant ...

109

Extensometer

$$
\text { ... } \quad \cdots
$$

I Io Episcope ... ... ...

I I Eyeglasses, Folding Pattern

I 2 Forceps for Microscope ...

I13 Forceps, 3-prong ... ...

I 4

I I 5

I 6

117

I 18

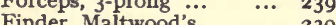

Finder Telescope $\quad . . .239$

Field Glass, Prism $\quad$... 240

Field Glass, Galilean ... 240

Fuller Calculating SlideRule
FIG.

I 9

I 20

I2I

122

123

Fog Horn ...

Geometric Pen ...

Growing Cell for Microscopes $\quad . . \quad \ldots \quad$...

Growing Cell for Microscopes $\quad . . \quad \ldots \quad \ldots \quad \ldots 4^{2}$

Goniometer, Dr. Hutchinson's $\quad \ldots \quad \quad \ldots \quad \quad \ldots \quad 24$

124

125

126

Goniometer for Microscope

Grating, Diffraction ... 24

Grating, Etalon ... $\quad$... 24

127 Galvanometer, AyrtonMather ... ... ... 245

128 Galvanometer, Telescope and Scale $\quad \ldots \quad$... 246

129 Galvanometer, Thompson 246

I 30 Galvanometer, Broca ... 247

I31 Galvanometer, Paschen ... 248

132 Galvanometer, Einthoven String $\quad \ldots \quad \ldots \quad \ldots \quad 24$

133 Grating, Échelon ... … 25

I $34 a$ Gauges, Vacuum and

$\begin{array}{lllll} & \text { and } b & \text { Pressure ... } & \ldots & \ldots\end{array}$

I35 Indicator, Richards's $\quad \ldots .25$

136 Indicator, High Speed $\ldots .25$

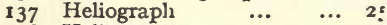

138 Heliostat ... $\quad \ldots \quad \ldots .2$

I39 Hygrometer, with Humidity Tables

I 40 Hygrometer, Ämiralty Pattern ... $\quad$... $\quad$... 25

I4I Iris Diaphragm $\quad . . \quad \ldots .254$

I 42 Sorby's Parabolic Illuminator $\quad . . \quad \ldots \quad$... 254

I43 Illuminator, Vertical ... 254

I44 Illuminator Prism $\quad \ldots .254$

I45 Integrator $\quad \ldots \quad \ldots .254$

I46 Michelson's Interferometer 255

147 Keratometer ‥ $\quad$... 255

I 48 Lamp, Lighthouse $\quad$... 256

I 49 Lamp, Signalling ... ... 256

I50 Lantern, Enlarging $\quad$... 257

I5I Lantern, Optical ... ... 257

I52 Lens, Photographic ... 25 ह

153 Lens, Photographic, Cooke's $25 \varepsilon$

154 Lens, Telephoto ... $\quad$... $25^{8}$

155 Lens, Telephoto $\quad . . \quad$... $25^{8}$

I 56 Lamp Lens... $\quad$... $\quad$... 259

157 Linen Prover $\quad$... $\quad$... 259

158 Live Trap ... $\quad . . \quad \ldots \quad 25$ s

I59 Live Box ... $\quad \ldots \quad$... 25

160 Lieberkuhn $\quad . . \quad \ldots .25$

I6I Lummer-Gehrcke Plate ... 2 2:

241 162 Laryngoscope ... 


\section{LIST OF ILLUSTRATIONS-cont.}

FIG.

163

I 64

\section{5}

\section{6}

167

I68

169

170

I7 1

172

I 73

I 74

I 75

I 76

177

I 78

179

180

I8I

182

183

184

185

186

187

I 88

189

190

191

193

194

195

196

197

I98

199

200

201

202

$\begin{array}{lcc}\text { Laryngoscope } & \ldots & \ldots \\ \text { Land Chain } & \ldots & \ldots \\ \text { Level, Spirit } & \ldots & \ldots \\ \text { Level, Plain Reflecting } & \ldots \\ \text { Level, Abney } & \ldots & \ldots \\ \text { Level, Abney, Micrometer } & \end{array}$

PAGE FIG.

$260 \quad 207$

260

$26 I$

26 I

261

Pattern

Level, Surveyor's ...

26r

Levelling Staff ...

… 262

Level, Surveyor's ...

Log, Towing Pattern

Log, The Cherub Register...

Log, Excelsior, for Motorboats

$\cdots, \quad \ldots \quad \ldots$

Log, Bridge Connection ...

Log, Bridge Indicator Dial

Magnetometer

Magnifying Lenses, Hand and Pocket

Map Measurer $\quad . . . \quad$...

Morse Signalling Lamp and Tapper ... $\quad . . \quad$...

Mathematical Instruments Mathematical Instruments

Megaphone

Microscope, Bacteriological

Microscope, Binocular ...

Microscope, Metallurgical

Microscope, Research ...

Microscope, Standard ...

Micromanometer, Chattock Tilting

Microscope Nosepiece, Revolving $\ldots \quad \ldots \quad \ldots$

Micro-Spectroscope ...

Micromanometer, Threlfall

Micrometer, Bi-Filar ...

Micrometer, Boys' Radio...

Micrometer, Star Photographic ... ... ...

Micrometer Filar ... $\quad \ldots \quad 278$

Microtome, Rocking $\quad \ldots$

Mining Compass, Luminous Scales

Mining Dial

... $\quad \ldots$

Navigraph Instrument $\ldots .28 \mathrm{I}$

Omnimeter Theodolite $\quad \ldots \quad 282$

Optical Bench, Lens Testing

Optical Bench $\quad \ldots . \quad \ldots .283$

Ophthalmoscope ...

Ophthalmoscope ...

Optical Square
... 284

... 284

... 284
207 Parallel Ruler, Metal, Field's Rolling ... $\quad \ldots \quad 285$

208 Parallel Ruler, Metal, Field's Pattern ... ... 285

209 Parallel Ruler, Field's Pat$\begin{array}{lllll}\text { tern } & \ldots & \ldots & \ldots & 285\end{array}$

2xo Parallel Ruler $\quad \ldots \quad \ldots \quad 285$

2 I I XY Rolling (Field's) Paral$\begin{array}{llll}\text { lel Rule ... } & \ldots & \ldots & 285\end{array}$

2I 2 Pantograph $\quad \ldots . \quad \ldots .286$

213 Passometer... ... $\quad . . .286$

2I 4 Pedometer... $\quad \ldots \quad \ldots . .286$

215 Optical Square $\quad \ldots \quad \ldots \quad$... 287

216 Photometer Wedge $\quad . . \quad 287$

21 7 Proportional Dividers $\quad \ldots \quad 287$

2I 8 Perimeter ... $\quad \ldots \quad \ldots \quad \ldots \quad 288$

219 Photometer, Ritchie's $\quad \ldots \quad 289$

220 Periscope, with Prism Binoculars $\ldots . \quad \ldots \quad \ldots \quad$... 289

221 Periscope, Trench $\quad \ldots \quad 289$

222 Planimeter $\quad \ldots \quad \ldots \quad \ldots 289$

223 Photometer Bench _.. 290

224 Photometer, Nutting's ... 290

225 Polarimeter $\quad . . \quad \ldots \quad \ldots \quad 291$

226 Protractor ... $\quad . . \quad \ldots \quad$... 291

227 Protractor ... $\quad \ldots \quad \ldots \quad$... 291

228 Picket Poles $\quad \ldots . \quad \ldots .292$

229 Pitchometer $\quad \ldots \quad \ldots \quad$... 292
A. The Instrument.
B. As Applied on Ship.
C. As Applied in Shop.

230 Plane Table $\quad \ldots \quad \ldots . \quad 293$

23I Pyrometer, Féry Radiation 293

232 Rain Gauge, Metallurgical,

Office Pattern ... $\quad$... 294

233 Rain Gauge, Tilting Bucket 294

234 Range-Finder, Navigational 295

235 Range-Finder, Naval $\quad \ldots \quad 295$

236 Range-Finder, Infantry ... 296

237 Range-Finder,Anti-Aircraft 296

238 Refractometer, Pulfrich ... 297

239 Sea Wave Counter $\quad . . \quad 298$

240 Slide-Rule, Calculating $\begin{array}{lllll}\text { Circle } & \ldots & \ldots & \ldots & 298\end{array}$

24I Refractometer, Abbé $\quad \ldots \quad 299$

242 Sauver's Bridge (Microscope Object-holder) $\ldots . \quad \ldots \quad 299$

243 Semi-Circumferenter $\quad . . .299$

244 Saccharimeter $\quad \ldots \quad \ldots . \quad 300$

245 Shutter, Photographic $\quad \ldots \quad 300$

246 Spot Lens (Microscope) $\ldots .300$

247 Salinometer $\ldots . \ldots .301$

$24^{8}$ Sea-Water Hydrometer,

B.T. Pattern $\quad . . \quad$... 301 


\section{LIST OF ILLUSTRATIONS-cont.}

FIG.

249 Searchlight

250 Searchlight

25 I Sextant, Box

252

253

254

255

256

257

258

259

260

26 I

262

263

264

265

266

267

268 Stage, Warm, for Microscope $\quad . . \quad$... ...

269 Stereoscope $\quad . . . \quad \ldots$

270 Star Globe, Paget... ...

271 Station Pointer, Admiralty Pattern ... ... ...

272 Station Pointer, XY Pattern ... ... ...

273. Station Keeper, Bell's ...

274 Stewart's Distance-Finder

275 Submarine Sentry Winch, Fairlead and Sinker ...

276 Submarine Sentry, The Kite ... ... ...

277 Sundial, Equatorial ... 31

278 Sunshine Recorder $\quad . . .318$

279 Telescope, Officer of the Watch ... $\quad . . \quad$... 319

280 Telescope, Naval ... $\quad \ldots .3$ 3I9

281 Telescope, Naval Signalling

282 Telescope, Altazimuth ... 32

283 Telescope, Equatorial ... 32 I

284 Theodolette $\quad . . \quad \ldots .322$
FIG.

285 Theodolite, Transit, for General Surveying $\quad$... 323

286 Theodolite, Micrometer ... 324

287 Theodolite, Photo ... 325

288 Theodolite, Recording ... 326

289 Thermometer, Copper Case 327

290 Thermometer Screen $\quad$... 327

291 Thermograph $\quad . . \quad \ldots . \quad 327$

292 Thermometer (Six's Maximum and Minimum) ... 328

293 Thermometer, Window ... 328

294 Thermometer, Solar Radiation ... $\quad . . . \quad \ldots .328$

295 Thermometer, Clinical ... 328

296 Thermometer (in Scottish pattern Frame) ... ... 329

297 Thermometer (in Wooden Mount, ascending) $\quad . .329$

298 Thermometer (in Wooden Mount, descending) $\quad$.. 329

Deep Sea Water-Bottle ... 329

300 Thermometer, Reversing Frame ... ... ... 329

301 Thermometer (Terrestrial Radiation) (... ... 330

302 Thermometer (Terrestrial Radiation) $\quad \ldots \quad \quad \ldots \quad 330$

303 Thermometer (Deep-Sea, Reversing Type) ... 330

304 Thermometer (Deep-Sea, Reversing Type) ... 330

305 Thermometer (Maximum and Minimum) ... $\quad . .330$

306 Tide-Gauge, India Office Pattern ... ... ... 33I

307 Tide-Recorder, Field and Cust $\quad . .6 \quad \ldots . \quad \ldots$ 33I

308 Transit Instrument $\quad$... 332

309 Tape Measure $\quad$... $\quad$... 332

3ro Trial Sight Frame... ... 333

3I I Trial Sight Case ... $\quad \ldots .333$

3 I2 X-Ray Apparatus $\quad . .3334$

3I3 Valvograph $\quad . . \quad \ldots . \quad 334$ 


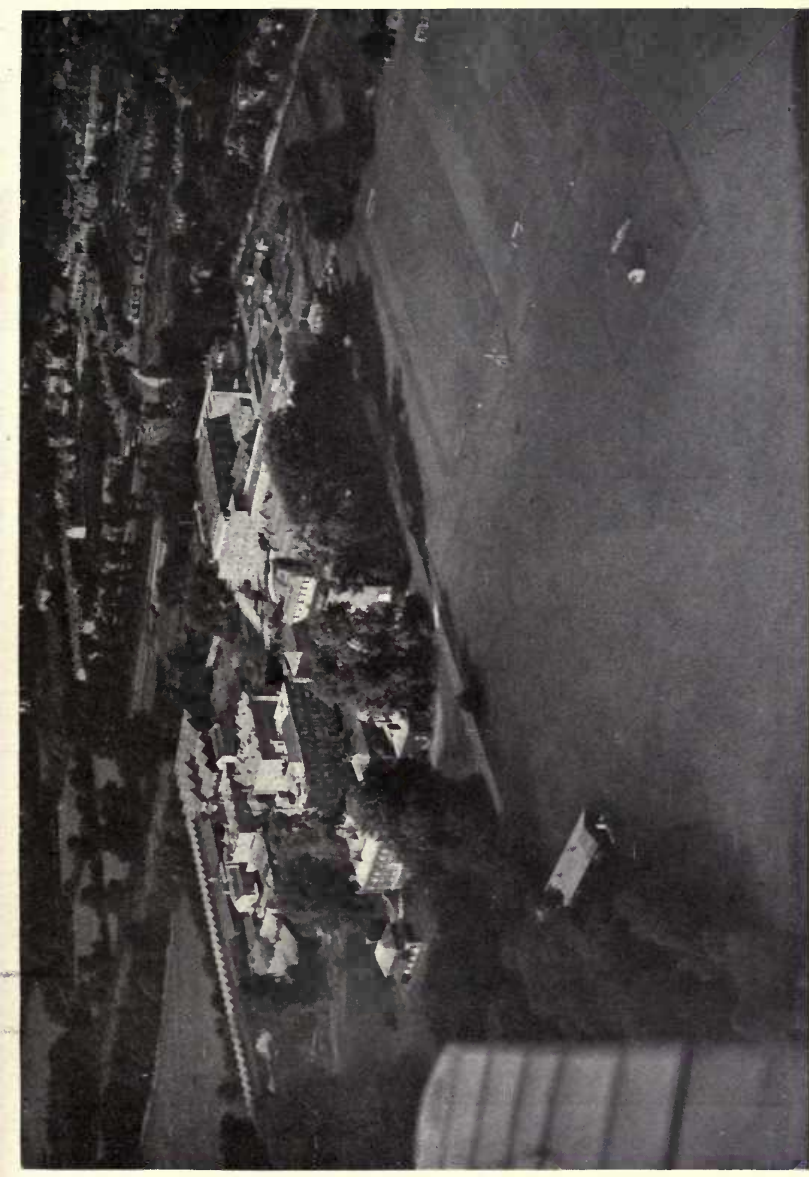

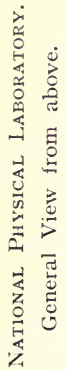




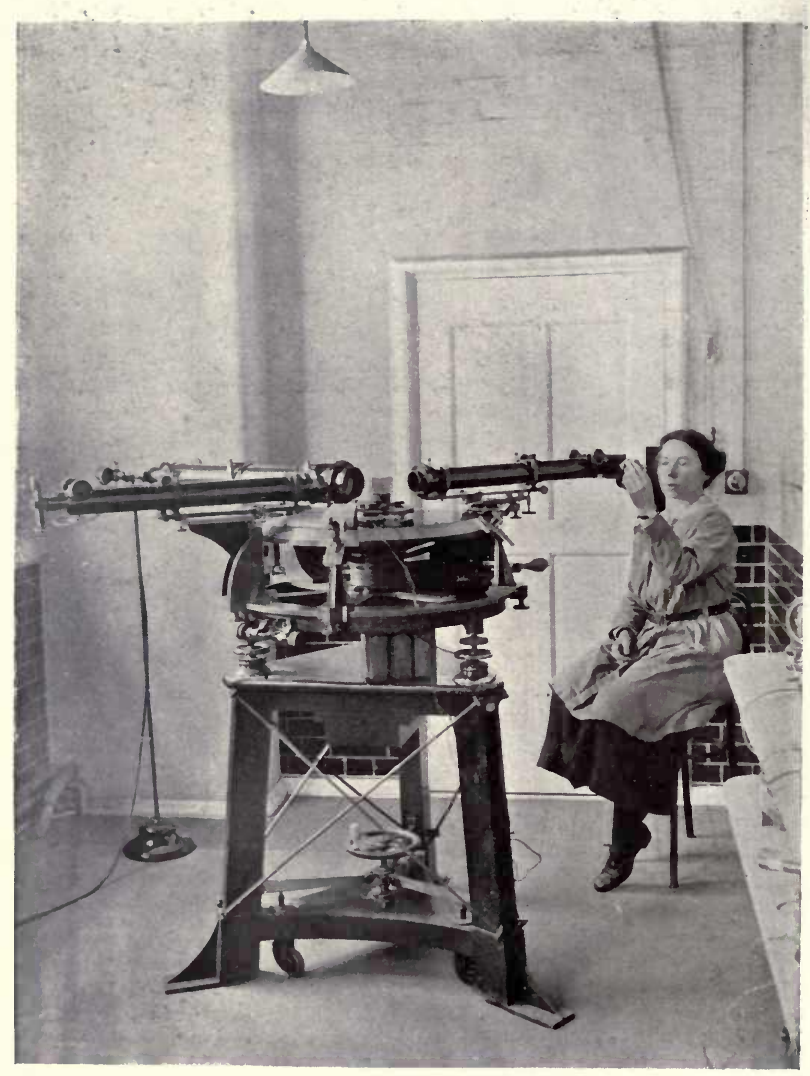

National Physical Laboratory.

Prism Measurements on Spectrometer. 


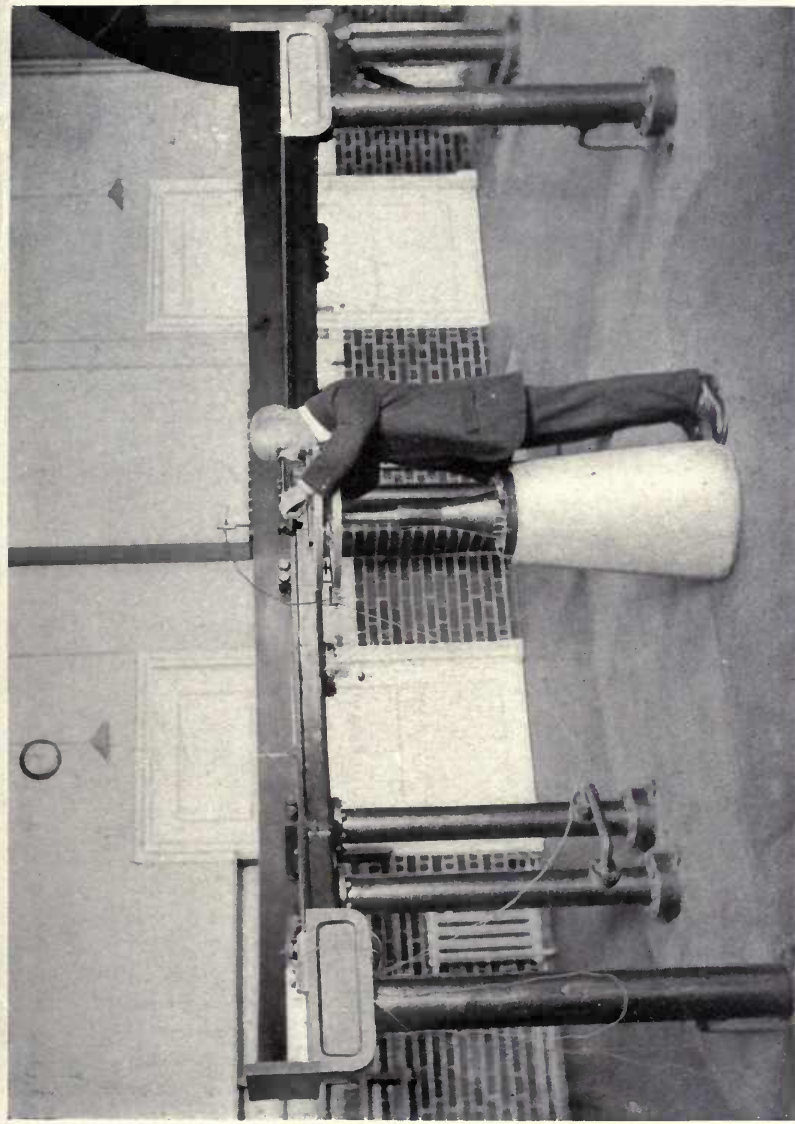

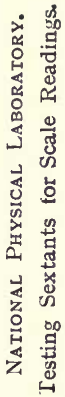




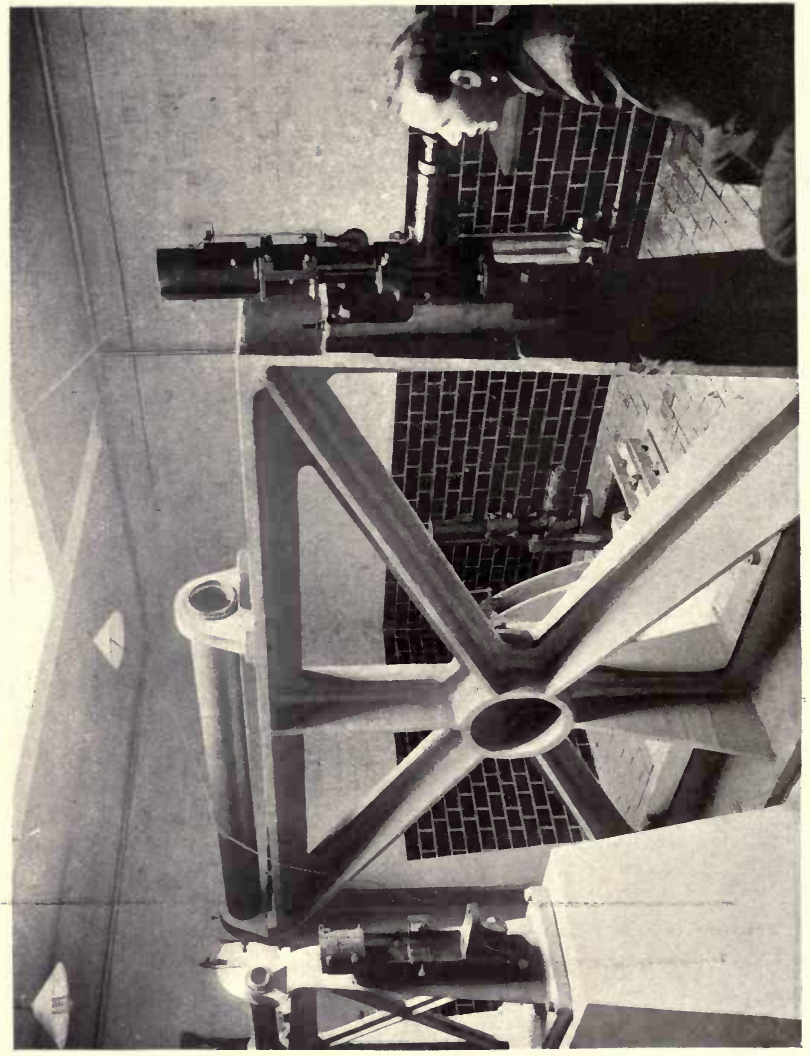

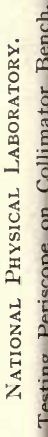




\section{THE BRITISH OPTICAL INSTRUMENT INDUSTRY.}

GREAT BRITAIN is proud of her predominant share in creating the science underlying the manufacture of optical instruments.

It is only necessary to mention such names as Newton, Young, Brewster, Herschel, Airey, Dollond, Lister, Maxwell, and Rayleigh to realise to what a great extent this country has been responsible for the instrument-making of the world.

The British-made instruments illustrated in this book indicate the perfection of design and workmanship that may be looked for in this department of our national industry.

An enormous demand for military instruments fostered the industry in the past in those countries which possessed large standing armies. It is, therefore, not surprising that the great establishments for making optical instruments found in continental Europe did not exist in this country. The advent of the war, however, found the optical industry of Great Britain in such a healthy state of activity that within a short space of time it increased to the necessary extent to equip a new army of five million men, and supplied many million pounds' worth per annum of the highest grade scientific instruments; and it may be safely asserted that in no direction has the creation of the Army been hindered by the lack of the best optical instruments. Many optical inventions have been produced by the trade for Military and Naval purposes during the war, and the rapid development has been in accordance with the well-earned traditions of the past.

The Surveying and Nautical Instruments, Photographic Lenses, Telescopes, Microscopes, Range-finders and Gunsights, invented and developed in this country, have not been surpassed elsewhere, and with a greatly improved plant of machinery and extended factories, obtained for War purposes, there seems little doubt that the Industry will greatly extend its scope in the future.

The British Optical Instrument Manufacturers' Association is a compact body, representing the most important manufacturers. It is devoted to furthering the interests of 
the Trade. Its address is Duke Street, E.C.2, and it is under its auspices that this book is published.

The key numbers printed in the dictionary, after the descriptions of the best known instruments, represent firms who either manufacture or factor such instruments. A list of the key numbers is given below, with the names and addresses of the firms they refer to.

\section{LIST OF MEMBERS.}

I. Aldis Bros., Messrs., Sare Hole Road, Sparkhill, Birmingham.

2. Baker, Charles, 244, High Holborn, London, W.C.I

3. BEсK, R. \& J., LTD., 68, Cornhill, London, E.C.3.

4. Cambridge Scientific Instrument Co., Ltd., The, Chesterton Road, Cambridge.

5. Casartelli, Joseph, \& Son, Messrs., 43, Market Street, Manchester.

6. Casella, C. F., \& Co., Lrd., Wansey Street Works, Walworth, London, S.E.I7.

7. Chance Bros. \& Co., Lrd., Glass Works, Smethwick, Birmingham.

8. Dallmeyer, J. H., Ltd., Church End Works, Willesden, London, N.W.ro.

9. Dollond \& Co. 44, Kirby Street, Hatton Garden, E.C.I.

io. Endacott Scientific Instrument Co., Verulam Street, Gray's Inn Road, W.C.r.

II. Grubb, Sir Howard, \& Sons, Ltd., Rathmines, Dublin.

12. United Kingdom Optical Co., LidD., The, White Hart Lane, Tottenham, London, N.I7.

13. Heath \& Co., LtD., New Eltham Scientific Instrument Works, New Eltham, London, S.E.9.

14. Hilger, Adam, Ltd., 75A, Camden Road, London, N.W.I.

15. Hughes \& Son, Lrd., Henry, 59, Fenchurch Street, London, E.C.3.

16. Kelvin, BotTomley, \& BaIRD, Ltd., Cambridge Street, Glasgow.

17. Negretti \& Zambra, Messrs., Holborn Circus, London, E.C.I.

18. Otтway \& Co., Lrd., W., Orion Works, Ealing, London, W.5.

I9. Pye \& Co., W. G., Messrs., Granta Works, Montague Road, Cambridge. 
20. Ross, Lrd., Clapham Common, London, S.W.4.

21. Stanley \& Co., Ltd., W. F., 286, High Holborn, London, W.C.I.

22. Swift \& Son, Ltd., James, 81, Tottenham Court Road, London, W.I.

23. TAYlor, TAYlOR, \& Hobson, LTD., Stoughton Street Works, Leicester.

24. Thornton, LtD., A. G., Paragon Works, King Street West, Manchester.

25. Troughton \& Simms, Ltd., 340, Woolwich Road, Charlton, London, S.E.7.

26. Watson \& Sons, Ltd., W., 313, High Holborn, London, W.C.I.

27. Watts \& Son, E. R., Messrs., 123, Camberwell Road, London, S.E.5.

28. John Lilley \& Sons, LtD. (Wilson \& Gillie), Messrs., The New Quay, North Shields. 


\section{NAVIGATING INSTRUMENTS.}

THE art of finding the latitude dates from early times. In the process it is necessary to find the altitude of some heavenly body whose position has been determined. The first known instrument of any accuracy for this purpose was the Astrolabe (Gr. astron $=\mathrm{a}$ star, lambano $=$ to receive). It was used by the Greeks and Arabians about B.c. Ioo, and is said to have been first made by Hipparchus, who flourished about I60-145 B.C. Chaucer, in his "Treatyse on the Astrolabye," I39r, gives an excellent description of this instrument, which consists of a heavy graduated metal circle constructed to hang plumb from a ring at the top: "Thine Astrolabye hath a ryng to putten on thy thombe on thy righte honde in taking the heyght of thynges " (Chaucer). It was still in use at the time of the Spanish Armada, specimens having been found from the wrecked vessels, of which there is an example among the collection of instruments at the South Kensington Museum. Sir Jonas Moore, in his "New Systeme of the Mathematicks," I68I, also describes it.

Quadrants, with sights upon the side and a plummet hung from the centre to pass the graduated arc and so to denote the altitude, were also used.

Fore Staff or Cross Staff.-This instrument, according to Seller in his "Practical Navigation" (edition I7II), was of some antiquity, and at that date was probably much used, as it is illustrated in most of the manuals of navigation of that period. The staff was graduated either arithmetically, by the table of natural tangents, or geometrically, from the divisions of a quarter of a circle, and was fitted with crosses or vanes, four in number, made to slide smoothly on the staff. On one side of the staff the graduation began about $3^{\circ}$ and proceeded to $10^{\circ}$ toward the eye end, upon which the $10^{\circ}$ cross is used. The next is called the $30^{\circ}$ cross and belongs to the side of the staff where the graduations begin at $10^{\circ}$ and end at $30^{\circ}$. The next is called the $60^{\circ}$ cross and works on the side where the graduation begins at $20^{\circ}$ and ends at $60^{\circ}$; the longest is called the $90^{\circ}$ cross for the last side, where the divisions begin at $30^{\circ}$ and end at $90^{\circ}$. In use the eye was placed at the end of the staff and the cross moved until the top touched the sun or star and the other end the horizon; the altitude was then read off from the graduated side of the staff. (For article on the construction 
of this instrument see Sir Jonas Moore's work, before referred to, which also gives descriptions of the Demi Cross Bow and Plough, which were all modifications of the cross staff.)

Back Staff, Sea Quadrant or Daris's Quadrant.-Called Back Staff because the back of the observer was turned to the sun or star when observing, and Davis's Quadrant from its inventor, Captain John Davis, who discovered the strait bearing his name and who died in 1605 (described and illustrated by John Seller in his "Practical Navigation," of which there are several editions, I672-1720). The instrument consists of two graduated arcs, one of $30^{\circ}$ connected by radii to a centre, and a second of smaller radius measuring $60^{\circ}$ on the side of it. To the $30^{\circ}$ arc a sight vane is attached, and on the $60^{\circ}$ arc another for the purpose of carrying the ray of the sun to the vertex of the instrument, where there is a horizontal vane with a slit in it, through which the horizon can be seen; the altitude is read off by adding the amounts shown on the two arcs.

Hadley's Quadrant or Octant (this being the form of the instrument) was invented by John Hadley in I730, and was the first reflecting instrument of any note that had been made; it has been in general use since the time it was invented, and, with very small modifications, is practically of the same construction as the sextant in use to-day. The original is thoroughly described by Benjamin Martin in his "Theory of Hadley's Quadrant Demonstrated." The first examples were made of mahogany, of 20 inches radius, with the arc divided by a diagonal scale of boxwood, with a wooden index bar; later examples were of mahogany or ebony, with ivory scale, with a nonius or vernier reading to one minute. The invention of this instrument was also claimed for Newton, but the Royal Society examined the claims and decided that the invention belonged to John Hadley. As time went on it was found desirable to make a more extended arc, and sextants reading to $\mathrm{I}^{\circ} 0^{\circ}$ were made, and of smaller size, some of only 3 inches radius, for the use of travellers. During the $\mathrm{I} \delta$ th century splendid specimens of the sextant were made by J. Ramsden, B. Martin, P. Dollond, G. Adams, J. Carey and others, which, as examples of handwork, have never been excelled, and which show that no care or trouble was spared to produce the best possible instrument. A specimen of Ramsden's Pillar Sextant, now in a private collection, is divided to $5^{\prime \prime}$; the arcs were frequently divided on gold and in platinum. There are many varieties of sextants, among which may be mentioned the 
double sextant, for bringing two objects to the horizon-glass at the same time and so measuring both angles. One of these sextants, in box form, was invented by Captain George, and another, in open form, by Captain Beechy. (For description see Raper's " Navigation," early editions.)

Repeating and Reflecting Circles.-The first reflecting circle was invented by Tobias Mayer, 1723-62; another was by Chevalier de Borda, and known as Borda's Repeating Circle; another, by Mendoza Rios, is described in his treatise on "An improved reflecting Circle," which was read before the Royal Society in ISOI : a good illustration of it is given in Norie's "Navigation" of I8Io. Dollond and Troughton also made excellent reflecting circles, the idea being that, having the whole circle whereby observations could be repeated and a mean taken, the centreing and other errors were eliminated. In the Troughton Circle, three arms were attached to the index, which gave readings on three different parts of the circle from which the mean of the three readings was obtained. (For description see Raper's "Navigation," I843, and Simms's " Mathematical Instruments," I849).

Artificial Horizons.-When the natural horizon is not available, it is necessary to make use of an artificial one, and many different instruments have been introduced for this purpose. Some had mechanical devices which were fixed to the sextant for obtaining a level for use on board ship, but were never found very satisfactory. The only form found to be accurate is a trough of some fluid, which is obviously unsuitable for shipboard; quicksilver is most commonly used, with a plate-glass cover to protect it from the wind; but treacle, oil, or even water in a saucer, gives an excellent result. Captain George invented one to get rid of the vibration of quicksilver by using a disc of black glass floating in a pan of mercury. Captain Beecher's instrument is a mechanical contrivance with a counter-balance working in oil to prevent rapid motion. Newey's has a disc hung in gimbals with two sight vanes. Troughton invented one with a black glass disc set in a frame, with adjusting screws and spirit level.

EDgar TARRY ADAMS, Lieutenant, R.N.V.R.

April, I918. 


\section{ROYAL METEOROLOGICAL SOCIETY.}

\section{President: Sir NAPIER Shaw, Sc.D., F.R.S.}

THE Society has enjoyed a continuous existence for nearly 70 years, having been founded as the "British Meteorological Society" on the 3 rd April, I850. More than one previous attempt had been made to form a society of members interested in meteorological questions, and a rather ambitious volume of Transactions had been published in I839, but sufficient support had not been forthcoming to maintain a permanent organisation. The new Society had the advantage of securing as its first Honorary Secretary Mr. James Glaisher, F.R.S., "who nursed it through its infancy and youth and left it to other hands only when it was old enough and strong enough to walk alone." He retained the office, in fact, until 1873 , having seen the Society established the previous year in rooms of its own, with an office and library for the use of the Fellows, and with a paid Assistant Secretary in charge.

Meanwhile the progress made by the Society had justified an application being made for a Charter of Incorporation, which was granted in 1866 , the name being altered at the same time to the "Meteorological Society," while in I882 authority was obtained to use the prefix of " Royal."

The appointment in 1872 of Mr. W. Marriott as Assistant Secretary enabled a considerable enlargement of the sphere of work of the Society to be undertaken and was followed soon afterwards by the establishment of a number of observation stations of the second order-i.e., where observations are taken twice daily-and the publication of their observations in the form of Quarterly Reports on the Meteorology of England as an Appendix to the Journal.

At that period the Meteorological Office maintained a very limited number of stations of its own, other than the telegraphic reporting stations used for the Daily Weather Reports; so that there was ample scope for the operations of the Society in collecting systematic data of the climatology of the country. In I880 a large number of additional stations were established, with a less elaborate scheme of observations, which were made at 9 a.m. only and did not include barometric pressure or wind. In the following year 
the results were issued as a separate quarterly publication known as the Meteorological Record, which had a sequence of $3 \mathrm{r}$ annual volumes, the last being issued in IgIr. By this time the Meteorological Office also had a large network of observing stations, the results from which were published in the Monthly Weather Report, so that there was a good deal of overlapping and duplication of work, and the Society felt that, if they handed over their stations to the Meteorological Office, they could devote their funds and energies to other branches of work to better advantage.

The number of observing stations maintained during this long period had been about Ioo, including a few in Ireland and the Channel Islands, and although there had necessarily been changes from time to time in the individual stations, the same scheme of tabulation had been adhered to throughout, and the volumes contain a remarkably homogeneous and reliable series of data for the study of the Climatology of England and Wales.

It has long been recognised that, however complete the instructions which are issued to observers may be, satisfactory uniformity can only be attained by regular inspection of the stations by a competent officer, and this inspection formed an important part of Mr. Marriott's work, each station being visited as a rule every third year. In this way instrumental errors were kept in check and the proper exposure and maintenance of the instruments was assured, while the personal contact between the observer and the inspector did much to ensure the high standard of accuracy which it was the object of the Society to maintain.

Mr. Marriott retained his office for nearly four years after the discontinuance of the stations, and retired from the service of the Society on the Ist October, I9I5, after the long period of 43 years' assiduous and successful work. He did not long survive to enjoy his well-earned retirement, and died suddenly on the 28 th December, Igr6.

It has been the practice of the Society for its Presidents to hold office for two years, so that the roll of those who have passed the chair is becoming a long one, but to none of them is it more indebted than to Mr. G. J. Symons, F.R.S., the founder of the British Rainfall Organisation. He held office as President in I880 and I88I and also served as Honorary Secretary for a long period of years after the retirement of Mr. Glaisher, and placed his great organising abilities fully at the disposal of the Society. He had been an assiduous collector of rare meteorological books, many of 
which passed into the Society's possession on his death, together with an elaborate Bibliography of Meteorology, to the compilation of which he devoted much time and labour, and which has since been kept up to date-by the Society. On the approach of the Jubilee of the Society in Igoo he was again elected to the office of President, as the most fitting person to occupy the chair on that important occasion; but a sudden illness supervened and he passed away a few weeks before the event took place. He had, however, prepared an Address for the occasion, which was read by Dr. C. Theodore Williams, who was elected to fill his place. The celebration was attended by representatives of many learned Societies and was a great success.

The memory of Mr. Symons's name is kept before the Society by the establishment of a memorial Gold Medal, which is awarded every alternate year, irrespective of sex or nationality, for distinguished work done in connection with Meteorological Science. The list of recipients includes the most eminent meteorologists in the world, the last name thereon being that of Dr. H. R. Mill, F.R.S.E., who has succeeded to Mr. Symons's work as Director of the British Rainfall Organisation.

In the early days there was little uniformity in the patterns of instruments employed, in the methods of their exposure, or in the instructions for their use, and the Society took a full share in securing improvements in these matters The adoption of the Stevenson screen for thermometers at the Society's stations was an important step in the desired direction, and a convenient handbook of instructions and tables; under the title Hints to Meteorological Observers, was prepared by Mr. Marriott and has passed through a number of editions. For the encouragement of improvements in instruments, exhibitions have been arranged from time to time, on which occasions an address on the history of some class of instrument or some cognate subject has been given, and an opportunity afforded for illustrating results of observations by means of charts and diagrams. Since the Science of Meteorology is almost entirely cooperative in its methods, it finds itself in a peculiar position with regard to the development of instruments. It is very important that observers in different parts of the country should use standardised instruments if possible, and, when the instruments are not standardised, it is often better for observers to use similar instruments than for each observer to alter his equipment in order to take advantage of simprovements 
in the design or finish of instruments. When once an instrument has come into general use a long period of preparation is necessary before the introduction of an improved form can be recommended. Consequently the cooperation of instrument makers with the Society is necessary for the satisfactory development of the Science. The Journal of the Society shows that attention has been given to standardising rain-gauges and thermometer screens, and to the improvement of anemometers, sunshine-recorders, and instruments determining the minor fluctuations of atmospheric pressure, \&c. There is still scope for further development by the instrument makers, notably in the direction of recording apparatus for night observations. It is hoped that every endeavour will be made to satisfy requirements in this respect. Within recent years meteorology has entered upon a new sphere in the investigation of the upper air. The instruments for these researches are at present made, for the most part, at the observatories where the work is undertaken, and have not yet taken their place with the instrument makers.

A system of Phenological Observations was established in I875, and annual reports, extending over more than 40 years, have been published in the Journal.

The Quarterly Journal has been issued in its present form since 1872 , and has taken a very high place among the meteorological publications of the world. It contains the papers read at the meetings, with the discussions, also notes, correspondence, reviews and a current Meteorological Bibliography, which goes far to supply the want left by the suspension of the issue of the International Catalogue of Scientific Literature. During the term of office of the last President, Lt.-Col. H. G. Lyons, F.R.S., considerable improvements were made in the Journal, notably in the introduction of a series of illustrated articles on climatological and other subjects, calculated to appeal to those Fellows to whom the more mathematical side of the Science does not constitute the main interest, and, to provide for these, the size of the volume for I9I7 was considerably increased. The largely increased cost of publication under existing conditions has, however, rendered it necessary to curtail the size of the numbers for the present. The issue of a Journal at quarterly intervals often entails considerable delay in the publication of a communication after its presentation to the Society, and the substitution of a monthly issue would very much enhance its value. Material for such a publication exists in abund- 
ance; the cost is the only obstacle. It may be hoped that the increasing interest which is likely to be taken in the Science in the near future may render such an advance financially possible.

From 1872 to 1899 the Soclety was housed in Great George Street, Westminster, first at No. 30, afterwards at No. 22. When these buildings were taken over by the Government to make way for the erection of new Public Offices, the Society moved to their present home at 70 , Victoria Street, where they occupy a commodious flat on the second floor, which, while fairly convenient to their general needs, has become inadequate for the growing demands of the Library, which will probably necessitate removal to larger quarters at no very distant date.

The Library is a valuable one, containing some 25,000 books and pamphlets and a considerable number of MSS. It includes a number of rare early books, many of which were collected by the late Mr. G. J. Symons.

By I880 the number of Fellows had reached 500 and in recent years has exceeded 700. Naturally the war has led to a certain number of withdrawals, some of which may be only temporary, but, thanks to the interest which war conditions have aroused in the Science, there have been many elections, so that on the whole the Fellowship has been well maintained. Though the publication of recent meteorological information has come under the ban of the Censor, and the withdrawal of weather reports and forecasts from the Daily Press has removed the interest in the subject from the public eye, the great importance of the Science to our fighting forces has been fully established, and a large staff has been employed in discussing the climatology of the various theatres of war, in preparing forecasts for many parts of the globe at all hours of the day and night, and in studying the conditions of the upper air for the benefit of our Air Forces. Meteorology has, in fact, come into its own, and this must result in a largely increased interest in the Science when peace once more returns. The extension of the Fellowship which it is hoped will then result will render possible a largely increased work and usefulness on the part of the Society.

Death has laid a heavy hold on the senior Fellows in recent years and in a period of barely I8 months no less than five ex-Presidents of the Society, in addition to Mr. Marriott, have passed away. These included Sir J. K. Laughton, Dr. Robert H. Scott, F.R.S., for many years Director of the 
Meteorological Office, Mr. W. Ellis, F.R.S., Mr. E. Mawley, and Mr. Baldwin Latham.

The meetings of the Society are held monthly during the session, which lasts from November to June. At the annual meeting in January it is the custom for the President to deliver an Address, while at the meeting in March either a lecture is delivered by some well-known man of science on a subject cognate to Meteorology, or an exhibition is held. At the other meetings communications are read and discussed. The supply of papers has been well kept up during the war, but difficulties of travel and the pressure of other occupations have necessarily interfered with the attendance of many of the Fellows.

In addition to the work of individual Fellows the Society has been able to organise enquiries into many questions of interest, either by the work of committees or the collection of observations. Among subjects which have been dealt with in the past may be mentioned :-

The appointment, in conjunction with other societies, of a Lightning Rod Conference, of which Mr. Symons was Secretary, and which reported in 1882 , and issued a code of rules for the erection of Lightning Conductors which has stood the test of time.

Systematic investigations of the thunderstorms of 1888 and 1889 .

The classification of the various forms of lightning.

The expression of Beaufort's scale of Wind Force in terms of velocity in miles per hour.

Inquiry into the phenomena of the Helm Wind of Crossfell, Cumberland.

Investigations of the Upper Air by means of kites and balloons, in cooperation with other organisations.

Lectures of an educational nature have also been arranged from time to time in connection with local natural history societies, schools, and other bodies.

On the discontinuance of the maintenance of the observing stations the Society took in hand, in association with the Meteorological Office, a comprehensive discussion of the large mass of climatological data which has become available for the British Isles, with the view of its presentation in cartographical form in an Atlas, and some progress had been made with the work when activities had to be suspended on account of the war. It is hoped to renew this work as soon as circumstances permit. There are also many other problems awaiting discussion and vast masses of data 
available. What is wanting is more workers, with leisure for the task, larger funds to provide paid assistance, and more attractive publications to keep the subject under public notice. It is confidently expected that the increased interest and importance of the Science will ensure more activity in this direction and the organisation of the Society will be ready to avail itself of the opportunities.

May, rgi8.

70, Victoria Street, London, S.W.I. 


\section{BRITISH OPTICAL GLASS.}

\section{SOME NOTES ON ITS HISTORY, MANUFACTURE, DEFECTS AND THEIR DETECTION.}

THE glass industry, as developed in Egypt, is of great antiquity, and can be traced back for more than 4,000 years. The insolubility of the material in water, its transparency and general mechanical properties at ordinary temperatures, and the changes which result with heating, give it a unique character, which must have been recognised at a very early date. The material was consequently manufactured for working into vessels for use and ornament and, at a later date, for windows.

In the strictest scientific parlance, glass is an extremely viscous liquid which, even at ordinary temperatures, slowly changes its shape under the action of force and becomes increasingly fluid as the temperature is raised. In the absence of stress, it is isotropic, amorphous, and shows no transition temperatures of melting and solidification, such as characterise true solids. It is rather a highly cooled, unstable liquid which, in the absence of suitable nuclei, has escaped crystallisation. The separation of crystalline constituents is always tending to occur; and, at suitable elevated temperatures, in a longer or shorter time, such crystalline growths will appear, giving the phenomenon of devitrification.

All but a very small fraction of the glass at present manufactured is used on account of its valuable properties as a material which is rigid, hard, transparent or selectively transparent to light, highly resistent to chemical action, and which gradually softens on heating, thus becoming amenable to change of shape by running, pressing, drawing or blowing.

A small amount of glass is manufactured for the sake of its optical properties of refraction and dispersion, occasionally together with that of selective absorption; and when the nature of the use to which this glass is put necessitates the employment of a strictly homogeneous material, it is spoken of as "optical " glass.

\section{HISTORY.}

The glass from which are fashioned the lenses and prisms of telescopes, microscopes and other scientific instruments is made in a different way trom any other kind of glass. In the case of the more common material, which is made into sheet or plate glass, bottles, globes, etc., the substance is 
obtained by melting the necessary constituents an a suitable container and the liquid mass is withdrawn from time to time by gathering or pouring, and brought by appropriate methods of working, casting, rolling, etc., to the required shape.

Optical glass, on the other hand, is left, when melted and refined, to solidify in the pot. The block that results, or fragments of it, are reduced by reheating into forms suitable for the completing work of the opticians. The manufacture is of great nicety and difficulty, demanding the utmost care and patience. It was first undertaken in England some 70 years ago by Messrs. Chance Brothers \& Co., of Birmingham, and, until quite recently, it has remained in the hands of them alone in the United Kingdom.

The function of lenses and prisms is to refract or reflect the rays of light that traverse them. In order that they may perform this function perfectly, the glass must be uniform and homogeneous, so that the rays are not distorted in their passage.

In the early days of the telescope, very thin lenses were used, and for this purpose selected sheet glass was sufficiently satisfactory. On account of the chromatic effects of single object-glasses, the refractor became completely displaced by the reflector for large astronomical instruments, and it was not until Moor Hall in 1724, and Dollond independently in I757, invented the achromatic objective that the manufacture of large refracting telescopes became possible. A demand then arose for homogeneous pieces of glass of much larger size than had previously been required.

The method by which such glass could be produced was discovered through the work of a Swiss joiner, Pierre Louis Guinand, at the end of the eighteenth century. Guinand found that he could equalise the density of his molten glass throughout its mass, and so attain his end, by long-continued stirring. After slow cooling of the whole, he broke the pot away and obtained his block of glass if not completely homogeneous, at least homogeneous in parts that could be selected.

He himself failed to render his process reliable. Working with scientific men at Munich, among them the celebrated Fraunhofer, he was able to produce from time to time discs suitable for working into object-glasses, one or two as much as 13 or 15 inches in diameter. But, for their regular needs, opticians for many years still had to depend on the rare discovery of suitable fragments of ordinary glass.

Faraday stated in his Bakerian lecture of 1829 , in which 
he detailed the work of the Committee of the Royal Society appointed to investigate the subject:- "Mr. Dollond, one of the first of our opticians, has not been able to obtain a disc of flint glass $4 \frac{1}{2}$ inches in diameter, fit for a telescope, within the last five years, or a suitable disc of 5 inches diameter within the last ten years." After eulogising the labours of Guinand and Fraunhofer, he went on to say :-" . . . whether it is that the knowledge they acquired was altogether practical and personal, a matter of minute experience and not of a nature to be communicated; or whether other circumstances were connected with it : it is certain that the public are not in possession of any instruction, relative to the method of making a homogeneous glass fit for optical purposes, beyond what was possessed before their time."

However, Guinand's process was by that time being brought to give regular results. His elder son was working upon it in Switzerland, and his younger son, Henri, in conjunction with Bontemps, in France. In 1828 there were exhibited discs, made at Choisy-le-Roi, of I2 inches and 0 inches diameter. From that time, says Bontemps, production went on regularly, if for a period without great activity.

Mr. R. L. Chance, of Birmingham, who was well acquainted with Bontemps, took out an English patent for Guinand's process in 1838 , and Messrs. Chance Brothers then commenced the manufacture of homogeneous glass. It was not, however, until r848, when Bontemps left Choisy in consequence of the French Revolution and came to Messrs. Chance's works, that they were able to surmount the difficulties which surrounded the manufacture of optical glass.

When John Dollond presented to the world his great invention of the achromatic lens, he had but two glasses from which to shape its twin components-the ordinary crown and flint. These names survived for the half-dozen standard types of optical glass made at Birmingham and elsewhere a century later. The different densities of these were obtained by the use of oxide of lead in varying quantities; the "flint" glasses being those into whose composition no lime entered.

$\mathrm{Up}$ to the time of the introduction of the new Jena varieties, some six types of glass had sufficed for the use of opticians. These had been termed-hard crown, soft crown, light flint, dense flint, extra dense flint, and double extra dense flint.

Such progress was made with the production of large meltings of uniform optical glass that the firm quickly gained 
a very high reputation-such as the future rival German firm was never able to achieve-for the manufacture of large discs of optical glass of the finest quality for astronomical work. A few instances may be mentioned of the successful production of large telescope discs, that most severe test of the skill of the optical glass manufacturer.

At the Great Exhibition of $185 \mathrm{I}$ the firm showed a 20-inch disc of light flint "for daguerreotype apparatus" and a 29 -inch disc of dense flint, weighing 200 lbs., for which a Council Medal was awarded.

In 1855 a companion crown disc was shown at Paris, and this Foucault pronounced to be the finest piece of glass he had ever seen. Sir David Brewster states that he did his best to persuade the British Government to buy the pair and " construct with them the greatest achromatic telescope that was ever contemplated by the most sanguine astronomer," but he could arouse no interest.

Discs of 24 inches and 29 inches were produced in 1856 , and a pair of I8-inch discs sold to Messrs. Alvan Clark \& Sons in I860 resulted, during their testing, in the discovery of the companion to Sirius. A pair of 26 -inch discs, produced in 1862, were worked by Messrs. Cooke \& Son, York, for Mr. R. S. Newall, into the largest refractor then in existence, and this was later given to Cambridge University.

In 1871 and 1874 Messrs. Clark worked pairs of $26 \frac{1}{2}$-inch discs, the former being used for the Washington refractor with which the satellites of Mars were discovered. The 28-inch objective for Greenwich was finished by Sir Howard Grubb in 1887. The flint disc was completed at once, but the crown disc took five years to obtain.

For a number of years from about I880, during which period the discs for the great Lick and Yerkes telescopes were manufactured, Britain took a place second to that of France. A few years before the war, however, a number of orders for big discs were again placed in England, the production of which has been interrupted by war requirements.

\section{MANUfacture.}

As the manufacture of optical glass is an industry with which most people, even those who are greatly interested in its use, are somewhat unfamiliar-owing, partly, to the reticence and secrecy observed respecting many of the operations-it may be of interest to give some account of the different processes involved.

In following the course of manufacture from the com- 
mencement, a few words may be said about the pots or crucibles in which the materials are melted.

Seeing that clay is composed chiefly of silica and alumina (the former oxide being almost essentially, and the latter not infrequently, a constituent of glass), it might be thought that this material would be readily absorbed by the glass. To some extent solution does actually take place; but no other container has ever been employed with success on a large scale, and, if clay of suitable composition is used, the attack by the glass may be diminished to a comparatively small amount.

The clay is mixed with a proportion of burnt clay which is ground to a suitable size, in order to diminish the contraction of the crucible in drying. If this burnt clay or "grog " were not used, the drying of the pots, which in any case takes some six months, would have to occupy a longer time, and there would be much greater danger of cracking in the furnace. Innumerable minute fissures form as the clay contracts round the particles of " grog," but when the pot is slowly brought to a high temperature, before the materials are added, the fine particles of clay sinter or weld together into a hard mass, which is comparatively resistant to the glass.

The burning of the pots-that is, the operation of bringing the cold crucibles to a red heat previous to their introduction into the glass-making furnace-occupies at least a week and must be very carefully carried out, particularly in the early stages.

The constituents from which the glass is made are carefully weighed out, and thoroughly mixed together, and shovelled into the crucible. Successive fillings are necessary to fill the pot; and when the mass is molten, it must be allowed to stand at a high temperature for a sufficient time to enable the bubbles of gas produced during the operation to find their way to the surface. When a sample of the glass, taken on a rod, shows it to be "plain "-that is, free from bubbles-the stirring process is allowed to commence. This operation has not been modified in principle since its original discovery in 1800 by Guinand.

The process is by no means simple. We are not dealing here with a liquid contained in a vessel which is completely insoluble in the liquid; the case, on the other hand, is more nearly analogous to that of an acid solution in a metal vessel which is slowly dissolving in the liquid, which, in addition, attacks the stirrer used to produce complete admixture. 
The liquid also is somewhat viscous-and this prevents the development of any considerable eddy currents, which, in the stirring of ordinary liquids, have such an important effect in producing homogeneity. The viscosity of the liquid has a still more harmful influence in delaying the process of diffusion, which eventually brings about homogeneity in all liquids by the exchange of material between two adjacent layers of slightly different composition. Above all, the very high temperature at which the operation has to be carried out severely restricts the mechanical devices which can be adopted.

In view of the above considerations, it is almost a matter for wonder that any homogeneous glass is obtained from the pot - especially when one remembers the possibility of attack on the pot continuing after the stirring is complete, and of the products of attack being carried by convection currents to other parts of the mass.

When the stirring process is finished, the pot is removed from the glass-making furnace, and is then placed in another furnace, in which it is allowed to cool.

When cold, the crucible and the glass are usually found to be considerably fractured. Occasionally almost the entire mass of glass will be in one single lump, and in such a case is under a condition of great stress, and when broken with a hammer flies into inconveniently small pieces.

The blocks of glass are broken up by workpeople into lumps of the particular size desired, and are roughly sorted for obvious defects. The pieces are moulded into the required shape by being slowly heated to the softening point and then either pressed into shape or allowed to run by gravity into a suitable clay mould.

The blocks so obtained must then be cooled very slowly, in order to avoid a condition of serious internal stress being set up in the glass. When such stress is present in a glass block, it causes the glass to develop optical properties similar to those of many crystalline substances. Iight, on passing through the glass, travels with slightly different velocity according to its plane of vibration-or, in other words, the glass may be said to differ very slightly in refractive index towards light-waves having different planes of vibration. This results in the familiar phenomenon of double refraction when the strained glass is examined in polarised light, and, when present in unduly large amount, renders the material unfit for optical instruments.

The development of this stress is due to the contraction 
of the glass on cooling. If we consider, say, a sphere of glass which is cooling from a temperature at which it is appreciably plastic, we can realise how these internal forces arise.

The outer portions of the sphere cool and harden first, whilst the inner parts are at a higher temperature. As cooling proceeds, the inner parts in turn reach a lower temperature and endeavour to contract; this contraction is, to some extent, prevented by the outer layers which are already comparatively hard and rigid, and, in consequence, a condition of tension is set up in the inner portions of the sphere, which produces in the outer layers a balancing state of compression. If any minute bubbles are present in the glass, high tension does not develop, because the air bubbles, under the diminished pressure, expand considerably and relieve the stress. A large mass of glass which has been quickly cooled always exhibits bubbles of considerable size near the centre; but when subjected to a slow annealing process these bubbles of rarefied gas shrink to a negligible size.

It may be seen, therefore, that the forces set up in a block of glass on cooling are due to the fact that the state of cooling necessitates a falling temperature gradient from the centre outwards; and that, as the mass acquires rigidity under this unequal temperature distribution, forces are set up in the mass when the ordinary temperature, uniform throughout, is reached. The perfection of annealing is, therefore, dependent on the time which is allowed to elapse during the cooling operation, and the amount of strain present can only be reduced so much as to be harmless and can never be entirely avoided.

Small plates of glass, moulded lenses, etc., may be cooled comparatively rapidly without serious stress being developed; but the largest blocks, telescope discs, etc., must pass through the operation known as " fine annealing," in order to reduce the stress to an amount which is not harmful in the optical instrument.

In this process, the glass blocks are reheated to a temperature at which incipient softening occurs. All stress originally present in the glass becomes removed by slight flow of different parts of the mass; and the rate of cooling of the furnace is regulated to a great nicety so that harmful stresses shall not be reintroduced during cooling. This operation occupies some weeks; and, for exceptionally large pieces of glass, it may require months. 
Some Properties of Optical Glass.

When a ray of light, passing through air, falls on a glass surface, it becomes bent on passing into the glass by an amount which depends upon the nature of the glass, the angle of incidence and the colour or wave-length ot the light. A ray falling exactly perpendicular to the glass surface sulfers no deviation; but all other rays are bent to an extent increasing with the obliquity of incidence, and in accordance with the following fundamental law of retraction discovered by Snell :-

The sine of the angle between the incident ray and the perpendicular to the surface is always in a constant ration to the sine of the angle between the refracted ray and the perpendicular for a given glass and colour of light, this constant ratio being called the "index of refraction," and denoted by $n$ or $\mu$.

A parallel beam of light, that is, a plane wave of light, after refraction, still remains parallel, though moving in a different direction. If, however, the beam of light falls upon a convex surface, the rays become convergent, approximately, to a single point or focus, at which an image of the source of light is tormed.

The phenomenon of refraction, therefore, enables us to make optical systems by which images are formed, and in many cases magnified, resulting in the varieties of telescopes, microscopes, photographic lenses, etc., with which the optician has to deal. It is, therefore, obvious that, in the design of lens systems, an accurate knowledge of the indices of refraction of the glasses used is essential. It is found that for light of different colours the index varies greatly, and theretore the index for a definite colour must be precisely defined. Fraunhofer first realised that this coula be done by making use of the monochromatic light which is given off by various luminous vapours, and this method is universally adopted.

The indices of refraction of a glass are almost always given for the homogeneous red, green and violet radiations trom a low-pressure nydrogen vacuum tube, which are styled respectively $C, F$ and $G^{\prime}$, and for the yellow light from a Bunsen flame containing sodium vapour. Since the sodium flame is the most readily obtainable light which is approximately monochromatic, the "mean" index of refraction of a glass is always stated in terms of this particular radiation and denoted by the symbol $n_{\mathrm{D}}$-the sumix referring to the designation $\mathrm{D}$ of the sodium lines in the spectrum. 
The variation in refractive index for different colours results in the breaking up of a beam of white light into its constituent colours when it suffers refraction at a glass surface. The phenomenon is spoken of as the " dispersion" of the light; and the extent to which a glass of given index will produce this dispersion is alluded to as the "dispersive power " of the glass.

A single lens, therefore, under the most favourable conditions can only bring light of one particular colour to a focus at a particular point-with the result that, when an object is examined in ordinary light with such a lens, the image is ill-defined and heavily fringed with colour. To correct this fundamental defect in all refracting media, it is necessary to make use of the device of combining convex and concave lenses of different glasses. The dispersion and deviation produced by the two lenses are thus opposed. With crown and flint glasses it may be arranged that the dispersion of the concave flint lens balances and neutralises that of the crown lens, whilst the deviation due to the flint only partially balances that of the convex crown lens. The two lenses together, therefore, form a system which converges rays of all colours to the same focus without dispersion, giving an achromatic image practically free from all colour fringes.

It will, therefore, be seen from this rough indication of the use of optical glass that, besides the " mean " index of refraction, it is essential in the design of lens systems that the computer should be acquainted accurately with the dispersion for different rays of light which is produced by the glass under consideration.

It is usual for the difference between refractive indices for the red and green rays, $\mathrm{C}$ and $\mathrm{F}$, to be stated; $n_{\mathrm{F}}-n_{\mathrm{C}}$ being spoken of as the " mean," " middle," or "medium" dispersion of the glass.

From what has been said above, it will be seen that it is of importance to know the relation between the deviation and dispersion produced in optical glass, and it is, therefore, frequently convenient to have stated the value of the number which results by dividing the mean index minus I by the mean dispersion; this quantity, which is the reciprocal of the dispersive power of the glass, is spoken of as $v$, and has sometimes been called the "reciprocal dispersive power." We, therefore, have the relation

$$
v=\frac{n_{\mathrm{D}}-\mathrm{I}}{n_{\mathrm{F}}-n}
$$


When Dollond first commenced the manufacture of lenses formed of two components, to correct the chromatic defects of a single lens, there were available only two types of glass, called respectively "crown" and "flint" glass, and these glasses are all that are usually required to produce ordinary telescopic objectives and eye-pieces.

Perfect achromatism cannot be secured by these two older types of glass, which are not exactly matched in dispersion so as to give complete compensation for colour, and therefore leave minute outstanding colour fringes or uncorrected "secondary spectrum." The improvement of optical glass from this point of view was first systematically investigated by Harcourt in I834, this experimenter being, later, joined by Stokes. They discovered the effect of boric and phosphoric acids in reducing dispersion, but the prisms of their glasses were not sufficiently homogeneous to allow accurate measurement of dispersions, though they proved the possibility of reducing secondary spectrum. A trial melting of one of their glasses was made by Messrs. Chance Brothers with somewhat disappointing results. The researches of Schott and Abbe achieved more in this direction and resulted in the production of "telescope" flint, which effected a decided reduction of the secondary spectrum. A glass of similar properties has recently been produced by Messrs. Chance Brothers.

In the case of the telescope, it is necessary that the object-glass should produce an image which, over a small area, should be as free as possible from aberrations; but, in the case of other lens systems, particularly photographic lenses, the image has to cover an area which subtends a considerable angle to the lens, and with any great departure from the axis of the lens system defects in the image appear, which are not met with in the case of the telescope. Further, the image must be as flat as possible, so that it may be as nearly as possible coincident with the photographic plate.

The production of a sharp image, flat over a considerable area, necessitates the use of glasses differing considerably in their optical constants from the simple crown and flint types. In particular, it is desirable to have two glasses differing considerably in the value for $v$, but not very widely in mean index of refraction.

Abbe was the first to realise the types of glass desired to achieve the requisite corrections of the image in the more complex optical systems, and his inspiration was of the greatest possible assistance to the early German experi- 
menters in the new varieties of optical glass, just at the time when dry-plate photography was coming extensively into vogue.

Much work was done with a view to the production of such glasses, and this resulted in the manufacture of a number of barium glasses, which have an index of refraction comparable to that of a flint glass, but a dispersion similar to that of a crown glass.

In this country the investigation of barium glasses was commenced in 1897 , and a long series of experiments were put in hand with a view to producing these glasses on a commercial scale. Great difficulties were experienced in obtaining suitable materials, and the many new problems which presented themselves to the glass manufacturer proved very costly and, for a time, could not be successfully solved, though the investigations were carried out under the superintendence of a highly-qualified chemist. There was also the difficulty of having to meet the requirements of opticians who had, for some years, been using glass of particular optical constants and required these matched before they could be expected to change their source of supply.

Commercially, there was no inducement to carry on the manufacture; but it was felt that, in the national interest, the manufacture of optical glass was one which should not be dropped, and it was, therefore, persevered in, though with the most discouraging results and without any Government assistance. Eventually, however, some success was obtained, and various types of barium glasses were gradually introduced, so that at the outbreak of war there were a number of the newer types of glasses which could be manufactured in this country suitable for the use of opticians.

The outbreak of war brought about an entire change in the position of affairs, and an appreciation of the fact that the manufacture of optical glass is a " key" industry.

Great efforts were made to increase the output of the types of glasses required for war instruments, and such requirements were successfully met. It was found, as a matter of fact, that the types of glasses manufactured by Messrs. Chance Brothers at the outbreak of war were for most purposes sufficient to cover the varieties demanded for optical munitions. Towards the end of I9I7, however, it became necessary to extend the types of barium and other special glasses, to meet the requirements of photographic lenses for the Air Board. It was also found that it was not only desirable, but essential, that research work should be 
undertaken on an extended basis, with the result that a fine Research Laboratory for the full investigation of optical glasses was, under Government auspices, fitted up by Messrs. Chance Brothers. Here, during the past year, extremely successful research work has been carried out on the production of new glasses, on the development of new methods for testing the same, and on the investigation of their various properties.

it may be mentioned that among the glasses which have recently been produced on a commercial scale, as a result of work carried out in the Research Department, three have optical constants rather more extreme than any previously available for the use of opticians. These are a fluor crown of $n_{\mathrm{D}} \mathrm{I} \cdot 4785, v 70 \cdot 5$; and dense barium crowns of $n_{\mathrm{D}} \mathrm{I} \cdot 588 \mathrm{I}$, $v 6 \mathrm{r} \cdot \mathrm{x}$ and $n_{\mathrm{D}} \mathrm{I} \cdot 6 \mathrm{r} 30, v 59^{\circ} 0$.

The investigation of certain coloured glasses which may be required of optical quality is another branch of research to which attention has been devoted, and formulæ have been arrived at for the production of uranium and didymium glasses; but the manufacture of these has not, of course, been possible under the restrictions imposed by the then existing war conditions.

Messrs. Chance Brothers have also further equipped themselves for the special testing work involved in order to be able to guarantee that lens-blanks or prism blocks shall be of any desired standard of homogeneity, measured by the distortion in wave-lengths of the wave front when parallel light is passed through the component in question. Many opticians have been pleased to make use of these opportunities of testing optical material which is required for work of specially high precision.

\section{Defects of Optical Glass.}

The efforts of the optical glass manufacturer to produce glasses of more extreme optical qualities than those at present known are chiefly limited by the occurrence of devitrification and opalescence, and by lack of durability in the glasses which escape these two vital changes.

As already explained, devitrification is caused by the separation of definite chemical compounds from the glass in a crystalline state, usually spheroidal in shape. All glasses on long standing are subject to this defect, which, in the case of the commoner glasses made in tanks, may appear in the form of large globular masses of crystalline material up to 2 or 3 inches in diameter. In such unstirred liquid glass, 
devitrification frequently develops in localised patches, the appearance of which is evident from photograph.

Optical glasses usually develop devitrification as small spherical particles, more or less evenly distributed throughout the mass. These particles increase in size comparatively rapidly at high temperatures, and at a rate appreciable in the course of many years even at ordinary temperatures. In exceptional cases the change may take place with great rapidity, and a glass which is being stirred may, within a minute or two, go practically solid, owing to sudden devitrification having taken place throughout the mass, resulting in blocks having the appearance of marble.

Opalescence is a trouble which usually develops during the slow cooling of glass when the founding is completed, and is particularly liable to occur in glasses of high borate and fluorine content.

Imperfect durability is not quite so vital a trouble, in that, if it is essential for a particular purpose to utilise glasses of very special optical constants, such glasses, if not properly durable, may often be protected in use by cementing between some more durable components.

From the point of view of the user of optical glass, the chief defects are :-

I. Imperfection in annealing.

2. Imperfection in homogeneity.

3. Striæ or "veins."

(These defects distort the light to a greater or less extent in its passage through the glass, thereby affecting definition.)

4. Bubbles or "seed."

5. Bad metal or "feather."

6. Flaws.

7. Imperfect durability.

I. Imperfection in annealing affects glass in two ways. The more obvious effect is that it causes it to exhibit to some extent the property of "double refraction "- -thus producing a retardation of one part of the incident light relative to the remaining part which is vibrating in a different plane. This effect is not nearly so serious as has often been supposed to be the case, and considerable departure from perfect annealing could be tolerated, even in instruments of precision, but for a concomitant effect produced in the glass by the stresses which give rise to the phenomenon of bi-refringence. A block of glass is always, to a greater or less extent according to the 
perfection of annealing, in a state of compression in the outer parts and of tension near the centre, and these stresses affect the refractive index of the glass, causing it to assume a condition of pseudo-heterogeneity, with index of refraction diminishing towards the centre.

By means of the application of the interferometer, as developed by Messrs. Hilger, in figuring prisms, etc., with a view to the correction of departure from homogeneity, this effect may in many cases be cured, and the remaining effect of double-refraction, unless unusually severe, is then not important-but it is naturally desirable to have a glass which has a proper degree of perfection in annealing, so that correction for any departure from homogeneity caused by stress is unnecessary.

The most sensitive way of detecting stress in a plate of glass is to pass approximately parallel polarised light through it and examine it by means of an analysing nicol. If the light is intense, no block of glass ever produced will appear free from stress-though it may be so free from this defect that the greatest amount of double-refraction observed is that due to pressure on the block of glass at the points at which it is supported. Obviously, such perfection in annealing is a refinement which is unnecessary, even in the finest instruments.

For general purposes, a less sensitive test is more useful. The polarised light, after passage through the specimen, passes through a wave-plate (giving a relative retardation of one wave for sodium light) and then through the analysing nicol. The specimen thus viewed against a background of the sensitive first-order violet colour, any departure from perfection in annealing is made evident by a change in colour towards red to yellow or blue to green. The particular tint observed is a direct indication of the extent of doublerefraction.*

2. It is essential that the glass employed in an optical instrument should exhibit a proper degree of homogeneity, so that it may not vitiate the performance of the instrument.

For certain purposes, where, from the nature of the optical system, great perfection in homogeneity is not essential, such as the manufacture of lenses of eyepieces, very cheap object-glasses, etc., selected plate glass may be used, provided light passes in a direction perpendicular to the

* The apparatus for this test was shown by Messrs. Chance Brothers, at the Optical Society's Exhibition, January, I9I7. 
original surface of the plate. In a direction parallel to the plate the glass is seen to be very strongly veined; and, in any case, unless cheapness is an important factor, it is undesirable to put optical work on a glass of this quality.

3. The defects of heterogeneity and veins differ only in degree. In the latter case, the change in index is sufficiently sharp to distort the rays passing through the glass so that the distortion is readily visible to the unaided eye.

Considerable difference of opinion exists as to whether the very broad and subtle forms of homogeneity asserted by some workers do actually exist. It has been held by some that, if a piece of optical glass is free from visible veins and in a properly annealed condition, it is only necessary to work the block accurately flat, or to the proper curvature, to produce perfect results. Others assert that all glass is subject to inherent want of homogeneity, which, in work of the highest precision, may necessitate correction by figuring the otherwise perfect surfaces.

These two views are not completely contradictory, owing to the fact that want of homogeneity (certainly when it exists in the grosser form of veins) is very frequently accompanied and made evident by stress, which is produced in the glass owing to difference in coefficiency of expansion between adjacent portions of the material. It is probable that the truth lies somewhere between the two statements, and that, whilst gradual slight changes in index sometimes exist, in many cases the distortion of the wave front produced by some blocks of glass, which has been put down to inherent heterogeneity, is really due to variation of index produced by the stress which has not been removed to a sufficient extent by the annealing operation.

Three photographs are given of a large pentagonal block which contains rather broad veins, which, however, can only be detected by the unaided eye on very careful examination and with previous knowledge of their exact location.

The first photograph makes the veins evident by the condition of double-refraction set up in the block owing to the stresses produced in the annealing of the non-homogeneous material.

The second photograph is taken without the intervention of polarised light, utilising Töpler's "Schlieren Methode" for the examination of fine departures from homogeneity in a medium. In this method, light from a small source is brought to focus by a suitable optical system (a concave 
mirror may be conveniently used for this purpose),* and the block to be examined is placed in the path of the rays. The image will be distorted by any heterogeneity of the glass; and when the eye is placed at the focus, or just behind a shutter which is partly cutting off the light at the focus, a variable light-and-shade effect indicates departure from uniformity of index. The very pronounced effect observed in the photograph illustrates the extreme sensitiveness of this method, which will, in fact, detect distortions of the wave front of less than one-quarter of a wave-length, such as would indeed have no influence whatever on the definition of an optical instrument.

The third photograph shows the irregularity of a plane wave front after passage through the prism block, and is really the most satisfactory method of examining the performance of a block so as to sum up the whole optical effect due to heterogeneity, double-refraction and pseudo-heterogeneity caused by stress. The broadest changes of index are most readily detected by this instrument, which, in the ingenious method worked out by Messrs. Hilger, may be used to indicate exactly how to figure a block of glass to correct this trouble where it cocurs in small amounts.

A very fine vein causes an altogether inappreciable disturbance of the optical image due to diffraction effects, and merely affects the instrument in the same way as small bubbles, that is, by occasioning a minute loss or scattering of light. In fact, the catalogue of optical glass published by Schott \& Gen, Jena, stated : "The glass is selected carefully by its naked-eye appearance, and is not rejected on account of the occurrence of fine isolated striæ."

4. Small bubbles which are occasionally present in optical glass, and unavoidably so in certain barium glasses, have no effect on the performance of the instrument but to obstruct a minute portion of the light-unless, indeed, they should occur close to the focal plane, as, for example, in the field glass of an eyepiece, in which case they may have an appreciable effect in obstructing a certain portion of the view.

By a short-sighted policy, much otherwise perfect optical glass has been rejected for minute bubbles which, in the particular position in which the glass is employed, have no effect on the instrument which can possibly be perceived.

5. "Feather" in a glass, which is made evident by a sheet of minute bubbles occurring locally, near to the edge of

* The apparatus for this test was shown by Messrs. Ross, at the Optical Society's Exhibition, January, I917. 
a moulded block, is due to some folding of the block during the early stage of the moulding operation, and as a rule has no real effect in distorting the passage of the beam through the block. It is, however, an unsightly defect, which may possibly obstruct an appreciable amount of light, and one which a glass manufacturer would not think of expecting a purchaser to tolerate.

Occasionally small "feathers," isolated from the outside of the block, are met with. These are due to the imperfect closing up during moulding of a flaw, which was not detected in the glass previous to this operation, thus resulting in the imprisoning of a small amount of air as a sheet of very minute bubbles.

However desirable may be the optical properties of a glass, it is unsuitable for use if it will not withstand the action of the various climatic and other influences to which it is subjected.

6. The durability of optical glass is a subject in connection with which much work has been done, with rather uncertain results. The only completely satisfactory method of testing the durability of a glass is the subjection of the glass to exactly those conditions under which it will be used and for such length of time as the instrument may be expected to resist deterioration of its surfaces. This being in almost every case a test which it is impossible to apply, it becomes necessary to hasten up the "weathering " of glass surfaces, or to devise some other kind of test, in order to achieve results within a reasonable time.

Great attention was paid by Schott \& Gen to what is known as the "iodeosin " test, which consists in measuring the extent of alkaline efflorescence which occurs when a clean surface of the glass is exposed for a given length of time, under certain conditions, to the attack of water contained in a moist ether solution.

It has, however, been shown that this test by no means strictly measures the amount of deterioration of a glass surface which will occur in the ordinary conditions of use; at the present time greater importance is attached to the "autoclave" test, which also has the advantage that it can be carried out readily by one who is unskilled in delicate chemical manipulations.

In this test, the glass samples are heated in steam at a pressure of 2 to 4 atmospheres for a few hours (no specified pressure and time have been chosen yet as standards by a competent authority), and it is then found that the surface 
of the glass becomes more or less attacked. The nature of the attack, however, varies considerably in different glasses; some develop a general opacity of surface (a bad form of attack), others show peculiar markings or exhibit tarnishing or iridescence. The exact interpretation of the " autoclave" test is, therefore, itself uncertain; but treatment of glasses in this way does undoubtedly give valuable comparative information and will certainly indicate if a glass is very unsuitable to withstand the attack of moisture.

Some glasses, whilst very resistant in the "autoclave" test, may be particularly susceptible to attack by special re-agents. Thus specially dense flints are rapidly tarnished by exposure to hydrogen sulphide, and extreme barium crowns are appreciably soluble in strong acids and should not be cleaned by such re-agent. 


\section{THE ROYAL OBSERVATORY, GREENWICH.}

THE first object of the foundation of Greenwich Observatory was not research in pure science, but practical usefulness.

Until the end of the I5th century, navigation had been confined to the closed waters of the Mediterranean and its annexes, and to coasting voyages beyond its limits. But with the voyage of Columbus to the Bahamas in I 492 and that of Vasco da Gama to India round the Cape in I498, the scope of navigation was enlarged to the open ocean. Here the seaman was confronted with a problem of a new order, one that at first sight seemed insoluble. How could he determine the position of his ship when for weeks and even months together he had been far out of sight of land? The problem became more insistent as the new oceanic navigation developed, and by the end of the I6th century the need for a solution was urgently felt. In I598, Philip III. of Spain offered a prize of 100,000 crowns to anyone who would devise a method by which the captain of a vessel could determine his position when on the open ocean, and Holland followed very shortly after with the offer of the reward of 30,000 florins. During the Middle Ages, Europe had, commercially, faced eastward, and the great centres of maritime trade were the Mediterranean seaports, especially Venice and Genoa. With the discovery of the New World, commercial Europe began to face westward; and the five countries on the Atlantic seaboard-Spain, Portugal, France, Britain, and Holland-entered into competition for ocean supremacy. Spain and Portugal were the first to enter the field; but England, under Elizabeth, had challenged Spain, and the nation kept the importance of the development of navigation well in view through all changes of rulers, policies, and forms of government. In I674, a Frenchman, Le Sieur de St. Pierre, applied to Charles II. for a reward for a method of determining the longitude of a ship at sea which he claimed to have invented. The method was submitted to a provincial clergyman, well known for his mathematical and astronomical ability, the REV. JoHn FlAMSTEED (I646-I7I9), who reported that the method was sound in principle, but that it required knowledge of the motions of the moon and of the places of the fixed stars far more accurate than was then possessed. The king was much impressed by this report, and appointed Flamsteed his "astronomical observator" and ordered an 
observatory to be built for him on the hill in Greenwich Park. The foundation stone of the Observatory was laid August ro, I675, and Flamsteed retained his office until his death, which occurred on the last day of I7Ig.

This period of a little more than 44 years may be divided into two parts, during the earlier of which Flamsteed worked practically single-handed. Nevertheless, in 13 years he had made 20,000 observations and had revised the whole of the theories and tables of the heavenly bodies then in use. In I688 he was joined at Greenwich for the second time by ABRAHAM SHARP (I653-I742), a most skilful instrumentmaker as well as an excellent astronomer and computer. Sharp furnished Flamsteed with a new mural arc, $140^{\circ}$ in range and seven feet in radius, with which he commenced observation on December I2, I679, and used as his chief instrument for the remainder of his life. During these 30 years he determined the places of some 3,000 stars, and prepared a great catalogue, the Historia Coelestis, which won from Airy the high praise: "This work may shame any other collection of observations in this or any other country." Toward the other side of his great task-the determination of the movements of the moon-he revised and improved by far the best lunar theory then existing, viz., that due to JEREMIAH HORROX (I6I9-I64I), the wonderfully gifted curate of Hoole, whose premature death in his twenty-second year was so great a loss to science. Incidentally to these, the two chief items of the official programme, Flamsteed had determined the latitude of his Observatory, the obliquity of the ecliptic, the position of the equinoctial points, the time in which the sun rotates on its axis and the position of that axis, and had observed an apparent movement of the stars in the course of the year, the explanation of which had to wait till it was afforded by Bradley, the third Astronomer Royal.

Flamsteed was succeeded in I720 by Edmund Halley (1656-I742), then in the 64th year of his age. Halley's chief services to astronomy were rendered before he came to Greenwich. The greatest claim which he has upon our gratitude is that he succeeded in inducing ISAAC NEWTON (1642-I727) to publish his Principia, and undertook to guarantee the expense of publication. But his own services to astronomy were of high importance. He computed the orbits of a number of comets and, in so doing, discovered that one of them-which now bears his name-had returned on two or three occasions, and he predicted that it would 
again be seen after his death. "Wherefore, if it should return according to our prediction about the year 1758 , impartial posterity will not refuse to acknowledge that this was first discovered by an Englishman." When only 2r years of age he undertook a voyage to St. Helena in order to determine the places of the stars of the southern hemisphere. He remained there a year and a half, and, though the weather was very unfavourable, he succeeded in making a catalogue of 34I stars. Terrestrial magnetism had early attracted his attention, and he constructed the first magnetic chart of the world, on which he joined together, by smooth curves, places of equal magnetic variation. To carry out this work he made a couple of long voyages, besides several shorter ones, in which he made numerous hydrographic surveys and tidal observations. His work as Astronomer Royal was begun too late in life to be of much moment, nor was he, as a practical astronomical observer, the equal of his predecessor. Nevertheless he determined the positions of the moon throughout a complete I9-year cycle.

Halley died on January I4, I742, in the 86th year of his age, and was succeeded in a few days by JAMES BRADLEY (I693-I762), who was clearly marked out for the appointment by the high reputation which he had already earned for himself as a practical and theoretical astronomer, and by the great help which he had given to Halley during his last years, Bradley had already furnished an explanation of the curious fact that the stars appear to move in orbits which they complete in the course of a year. This is due to the fact that the velocity of light is about I0,000 times that of the velocity of the earth in her orbit. The maximum apparent displacement of the position of a star is, therefore, equal to the apparent diameter of an object seen from a distance of I0,000 times that diameter. As Astronomer Royal, Bradley's great achievement was that he raised the practical work of observation to a far higher standard than any one had attained before him. The great catalogue of the places of more than 3,200 stars, prepared by Bessel from his observations, is the earliest which is still used for reference in modern astronomy, and it forms the basis of our knowledge of the actual movements of individual stars. Beside his discovery of this " aberration of light" and the determination of its amount, he discovered a second cause of apparent changes in stellar positions, that known as "Nutation," due to the action of the moon, and running its course in a period of I9 years. Further, he determined errors due to his instruments, and to the 
effect of refraction, and introduced corrections for both. He may justly be termed the founder of the modern astronomy of precision.

He was succeeded by the Rev. Nathaniel Bliss (I700I765), who, however, only survived him by three years, and on May 7, I765 Nevil Maskelyne (I732-I8II), who had already made the improvement of the practical business of navigation his chief aim, was appointed in his place. None of all the Astronomers Royal kept the original charter of the office- " to find the so-much desired longitude at sea for the perfecting the art of navigation "-so closely before him as did Nevil Maskelyne.

The problem was solved in two ways. The offer by the Government of the reward of $f_{20,000}$ for a clock or watch which could keep its rate so perfectly at sea that the navigator might, at any moment, learn the true Greenwich time from it, had brought out the invention of the Chronometer by JOHN HARRISON (I693-I776), and the method of lunar distances suggested I30 years earlier by Morin, and fraudulently claimed as his own by Le Sieur de St. Pierre in I674, had now become practicable. For Bradley's places of the stars possessed the needful accuracy, and the lunar tables, prepared by TOBIAS MAYER (I723-I762), and published in London under Maskelyne's direction in I770, gave the means for predicting the place of the moon.

Before his appointment to Greenwich, Maskelyne had undertaken a voyage to St. Helena, in which he had given the method of "lunars" a very thorough testing and found it satisfactory. Part of its success was due to the improvement by JoHN HADLEY (ob, I744) of the instrument chiefly used at sea, the Octant, as it then was, the Sextant as it became a little later.

In I763 Maskelyne published the British Mariner's Guide, a Handbook for the Determination of the Longitude at Sea by the Method of Lunars; and in I765 he published the first number of the Nautical Almanac, together with a volume of Tables Requisite to be Used with the Nautical Ephemeris, the value of which was so instantly appreciated that ro,000 copies were sold at once. The preparation and publication of the Nautical Almanac was continued by Maskelyne up to his death in I8rr.

To Maskelyne, therefore, we owe the first practical solution of the problem of determining the longitude at sea, and the method was promptly put into use by men of remarkable energy and skill. Of these, one was CharLes GREen, 
Maskelyne's assistant at Greenwich, and the other was JAMES Cook (I728-I779), the celebrated explorer. The two men were associated in the first of Captain Cook's three great voyages, that of $I 768$ to I77I, the object of which was part astronomical - to determine the distance of the sun by observation of the transit of Venus of I769, June I-and partly for discovery and maritime survey.

Cook had already earned a high reputation as a navigator, having in I759 been employed as master of the Mercury, in which ship he rendered important service to General Wolfe. then attacking Quebec, by taking soundings in the River St. Lawrence so as to enable the fleet to take up safe positions. He made a complete survey of the intricate channels of the river below Quebec, and for many years his chart was the guide for navigation there. Sir WILIIAM WHARTON (I843-I905), the late Hydrographer of the Admiralty, wrote of this work: "Cook was indeed a born surveyor. Before his day charts were of the crudest description, and he must have somehow acquired a considerable knowledge of trigonometry, and possessed an intuitive faculty for practically applying it, to enable him to originate, as it may truly be said he did, the art of modern marine surveying." The survey of the island of Newfoundland followed and employed him for several years. The accuracy of his charts of this coast is truly astonishing, and they are not yet wholly superseded by the more detailed surveys of modern times.

The second method of determining the longitude at sea, namely, by means of watches that can be trusted to keep a steady rate for long periods, had already been solved by the invention of John Harrison's "timekeeper," and this had passed a successful test, in I76I, in the course of a voyage to Jamaica. In I763 Charles Green had accompanied Maskelyne, who shortly afterwards became Astronomer Royal, in a voyage to Barbados in order to test another of Harrison's " timekeepers"; but none of these were supplied to Cook and Green in I768, and therefore they had to rely entirely upon the methods of lunars. Wharton remarks that "In these observations, Green was indefatigable. Cook, an excellent observer himself, frequently took part in them, but it was Green's especial business, and no doubt to him is due the major part of the determinations of accurate longitude which is one of the very remarkable points of this voyage."

One of the most striking points, when we consider the surveys executed by Cook on his three voyages, is the way 
in which they delimited what is now the Colonial Empire of Great Britain. The one striking exception is that of the island of Tahiti, and there it should be noted that the French Government did not find it necessary to supersede Cook's charts of the Society Group by more recent and elaborate surveys until I20 years after his death.

Early in the Restoration period English clockmakers had achieved pre-eminence in their art, and THOMAs TOMPION (I638-I713), "the father of English watchmaking," who had made the first two clocks possessed by Flamsteed, was the acknowledged leader in horology. He was followed by his nephew, GEORGE GRAHAM (I673-I75I), whose great skill and ingenuity were directed chiefly-especially in the later part of his life-to astronomy and astronomical instruments, and especially to the production of a perfectly astronomical clock. After the success of Harrison's chronometer had been established, the English chronometer-makers at the end of the I8th century, JOHN ARNOLD (I736-I799), THOMAS EARNSHAW (I749-I829), and others, created an equal reputation for their branch of horology; and, a little later on, the care of the chronometers for the use of the Royal Navy became an important part in the routine of Greenwich Observatory.

Great as Maskelyne's main work was, he was able to devote much time and thought to other important problems-the determination of the distance of the sun, through observations of the transits of Venus in I76I and I769; and of the density of the earth, by noticing the deviation produced in the plumbline by the attraction of the mountain Schiehallion.

JoHN POND (I767-I836), who succeeded him, was a skilful observer, and, in I833, brought out a standard catalogue of I,II3 stars, at that date the fullest of any catalogue prepared on the same scale of accuracy. His chief merit was the introduction of several new instruments and the multiplication of observations of stars with different instruments and under different conditions.

Pond retired in 1835 and was succeeded by GEORGE BIDDELl AIRY (I80I-I892). Up to his time the problem of navigation had been dominant; during his time and onward other inquiries, arising naturally out of the actual work of the Observatory or linking themselves on to it, have claimed an ever-increasing attention. Previous to Airy, the Astronomer Royal had himself practically been the Observatory, and such assistants as he employed might rather be described as his personal secretaries and clerks. Under him the institution developed slowly but steadily into a distinct Govern- 
ment department, with an organised and responsible staff, recognised members, like their chief, of the established Civil Service. But throughout the great development which has taken place in the Observatory since r835 the essential continuity of the institution has always been borne in mind. As Airy himself expressed it, "The Observatory was expressly built for the aid of astronomy and navigation, for promoting methods of determining longitudes at sea, and (as the circumstances that led to its foundation show) more especially for the determination of the moon's motions. All these imply, as their first step, the formation of accurate catalogues of stars, and the determination of the fundamental elements of the solar system. These objects have been steadily pursued from the foundation of the Observatory." It is to this recognition of the essential continuity of Greenwich Observatory that its high reputation is chiefly due, winning from Simon NEwcomb (I835-I909), the great American astronomer, the striking comment: "The most useful branch of astronomy has hitherto been that which, treating of the positions and motions of the heavenly bodies, is practically applied to the determination of geographical positions on land and sea. The Greenwich Observatory has, during the past century, been, so far, the largest contributor in this direction as to give rise to the remark that, if this branch of astronomy were entirely lost, it could be reconstructed from the Greenwich Observations alone.'

Airy was succeeded in I88I by his Chief Assistant, W. H. M. Christie, who held office for 30 years, and was followed by the present Astronomer Royal, Frank W. Dyson, who had already held the position of Chief Assistant at Greenwich from I894 to I906, and had been Astronomer Royal for Scotland from 1906 to IgIr. The rule of these three Astronomers Royal cover the modern period of the Observatory.

Perhaps the readiest way of gathering a general impression of the activities of Greenwich Observatory will be to examine one of the Annual Reports, presented by the Astronomer Royal to the official Board of Visitors on the occasion of the annual visitation. This Board, first established in I7I0, received its present constitution in 1830 , and represents the Royal and the Royal Astronomical Societies, the two Universities of Oxford and Cambridge, and the Admiralty, of which the Observatory is a department. The last Report presented before the outbreak of the war, namely, that read on June 6, I9I4, may conveniently be taken as indicating 
the lines on which the present energies of the Observatory are directed in normal times.

Sir Frank Dyson's account of the Astronomical Observations of the year with which his Report is concerned, begins inevitably with the work of the Transit Circle, the fundamental instrument of the establishment, that by means of which " the rectifying the places of the fixed stars," mentioned in the original warrant to John Flamsteed, is still carried out. This Transit Circle, which was first brought into use in I85I, was a great advance upon its predecessors, three in number, the tubes of which are still preserved on the walls of the transit room.

The first of these was due to Halley, and was in use down to I743; but it was followed, six years later, by Bradley's transit, a much more efficient instrument, constructed by JoHN BIRD (I709-I776), pupil of George Graham, and, after his master's death, the most skilful astronomical instrumentmaker of his day, in 1749 and I750, and was 8 feet in focal length. Its original object-glass was $I_{2} \frac{1}{2}$ inches in diameter, but after JoHn Dollond (I706-I76r) had begun to make achromatic object-glasses, one of these, 2.7 inches in aperture, was inserted and a power of 80 was used with it. Bradley used a fixed eyepiece and generally only one wire, noting the time to the nearest second. Maskelyne introduced a sliding eyepiece, observed over five wires, and estimated the time to a tenth of a second.

The third transit instrument is known as "Troughton's," inasmuch as it was made by the great instrument-maker, EDWARD TROUGHTON (I753-I835). It is only right that it should bear his name, for the great instrument-makers and opticians, as likewise the great clockmakers and chronometermakers have played an indispensable part in the progress of astronomy equally with the observers and the mathematicians. This was Yond's chief instrument, and was fitted with a 5-inch object-glass by Dollond of 5 feet focal length. It carried seven fixed vertical wires, and a micrometer frame carrying two parallel movable wires, and a magnifying power of I 70 was usually employed. Another fine instrument, also by Troughton, was used in connection with this transit. This was the mural circle, ordered by Maskelyne, but not delivered until after his death.

But the mural circle was open to the objection that, being attached on one side only to its pier, the errors to which it was exposed tended all to be of the same direction. But, in I824, Pond was able to add a second mural circle to his 
equipment, and he introduced the custom of observing a star directly with one circle, but by reflection from the surface of mercury in the other.

The present Transit Circle, the fourth of this memorable series, is, in effect, a combination of the mural circle with the old form of transit, but is more powerful and capable of a greater delicacy of observation than its predecessors, while its errors of adjustment and form can be far better ascertained and allowed for. Its object-glass is $8 \cdot I$ inches in diameter, figured by WILLIAM SimMS (I793-I860), partner of Edward Troughton (Troughton AND Simms), and the instrument itself was constructed by RANSOMES AND MAY, the specification requiring that the pivots should be true to $\frac{1}{3000}$ th of an inch. The divided circle is 6 feet in diameter, and is read by seven microscopes, fixed in the west pier. By the use of the chronograph the mean time of the transit of an equatorial star can be determined to about a hundredth of a second of time, and its zenith distance, to the tenth part of a second of arc.

These are refinements quite outside anything that is required for the practical purposes of navigation, and far beyond the possibilities of observation with the sextant at sea. The work of the Observatory, therefore, in this direction would have entirely passed beyond its purely maritime purposes even if the great improvement in the performance of chronometers had not superseded the use of "lunars" in ordinary navigation.

The progress in the numbers of the stars of which the places are determined is even more remarkable than the advance in precision. Maskelyne's observing list included only some 36 stars, but during the course of the Igth century programmes of stellar observation were set on foot on a scale some 20,000 times as extensive. Argelander at the Bonn Observatory observed the places of 324,000 stars north of South Dec. $2^{\circ}$, and Schönfeld, Gould and Thome extended it to the South Pole. These catalogues embraced stars down to those only half as bright as the 9th magnitude, but some astronomers found it necessary to observe stars still fainter and surveyed portions of the sky down to the I4th magnitude. But the Milky Way is so rich in the fainter orders that here the number of stars claiming record baffled all the accustomed means of observation. The application of gelatine plates to photography, however, supplied the solution of the difficulty, and in 1887 a great conference of astronomers met at Paris to determine upon an international 
scheme for photographing the heavens. The work was to be divided between I 8 Observatories of different nationalities, of which number Great Britain and her Dominions in the Southern Hemisphere have furnished six. It was planned to result in a photographic chart extending to the I4th magnitude and probably embracing some 40 millions of stars, and to furnish a catalogue, made from measures of the photographs down to the IIth magnitude, which would probably include between two and three million.

Referring again to the Astronomer Royal's IgI4 Report, we find that 16,423 transits and 16,455 circle observations were made within the year by means of the transit circle, beside many hundred determinations of the adjustment of the instrument itself. The bulk of these observations were for the completion of a catalogue of all stars down to the 9 th magnitude in brightness in the zone lying between $24^{\circ}$ and $32^{\circ}$ north of the equator. This catalogue was to contain the places of some 12,400 stars in the zone which has been assigned to the University of Oxford in the great international scheme for photographing the entire heavens, the places of the stars being intended to afford reference points for the Oxford plates. The "probable error" of a single observation of a star is $\frac{1}{25}$ th of a second of time in Right Ascension, that is in the determination of the time of the transit of a star across the meridian, and less than $\frac{1}{2}$ a second of arc in the determination of the distance of a star from the North Pole of the heavens.

The Observatory of Greenwich, like that of the Oxford University, took part in the great international scheme, and the region assigned to it was that round the North Pole and extending $26^{\circ}$ from it. Hence one of its most important instruments of late years has been the Astrographic Telescope, a double-barrelled instrument, one barrel being the photographic telescope of 13 inches aperture and focal length of II feet 3 inches, and the other a guide telescope of Io inches aperture, the whole having been designed and constructed by Howard GRubB of Dublin. The main work of the Astrographic Telescope has been completed for some years, and it is now devoted to subsidiary researches of a minor character, those reported in I9I4 relating partly to the standardisation of the magnitudes of the stars shown on the photographs.

The original method proposed for ascertaining the longitude at sea required that the motions of the moon should be so thoroughly known that its place at any required epoch 
could be accurately predicted for years in advance: a knowledge which, as we have seen, was not in existence when Greenwich Ubservatory was founded. It followed, therefore, naturally that the observation of the moon's place on every possible occasion became a necessary item in the Greenwich programme, and eventually, by the common consent of astronomers, this duty of the continuous observation of the moon has been entrusted wholly to the Royal Observatory. To carry out this duty more fully the Transit Circle has been supplanted by the "Altazimuth," this last being at the present time a second Transit Circle of similar aperture to the tirst, but dittering from it in that, on occasion, it can be fixed in other positions than in the meridian, for, as the tirst Transit Circle is confined to the meridian, the moon cannot be observed with it for several days in each month near the time of conjunction with the sun. In the year referred to in the I9I4 Report, 79 observations of the moon were secured by the Altazimuth, of which I2 were taken out of the meridian.

But something more is required than mere observation of the moon to render it possible for its future movements to be predicted with accuracy. The observations must be discussed, and the amounts and periods of apparent irregularities in its motion must be ascertained and reduced to system. In recent years this great work has been undertaken by PHILIP CowELL, appointed second Chiet Assistant at the Observatory in I896, a post which he held until he was made superintendent of the Nautical Almanac in IgIo. Cowell undertook the enormous task of analysing the outstanding discordances between the adopted tables of the moon and the long series of Greenwich Ubservations, for the double purpose of correcting the coefficients of the periodic terms which had been used for the construction of the tables and of detecting the existence of other periodic terms which had not been thus employed. In this examination, the Greenwich Ubservations for the latter half of the Igth century were most minutely considered, and for an important part of it the observations trom 1750 to 185 I were also included. In other words, the inquiry covered more than a century and a half of the Greenwich observations of the moon. No work in this particular branch of practical and mathematical astronomy has ever been carried out on so great and comprehensive a scale at any other observatory.

This enterprise of employing the moon as the assistant of man in the navigation of the ocean was purely utilitarian 
in its origin, but has thus been carried far beyond utilitarian requirements. But the same mathematical skill was applied to other allied problems which were entirely in the domain of pure science. The occasion for one of these was the discovery, by Philibert Melotte of the Greenwich staff, of a very faint and distant satellite of Jupiter, the eighth in order of discovery, and, as it proved, revolving round its primary in the reverse direction to the seven previously known. The calculation of the orbit of this satellite presented peculiar difficulties because, owing to the distance of the satellite from its primary, the disturbing influence of the sun was relatively very large. Another problem was presented at about the same time by the expected return of Halley's comet, and the need for determining in advance the date of the approaching perihelion passage. These two inquiries were undertaken by Cowell in close association with ANDREw Crommelin, Superintendent of the Altazimuth Department. By their combined labours the orbit of Jupiter's eighth satellite was determined and Halley's comet was followed backwards through its revolutions for more than 2,000 years. Incidentally, a most important result accrued from Cowell's part in these inquiries in that he was able to devise new methods of dealing with such problems, much shorter, more efficient and more easily controlled than those which had previously been known.

The 8th satellite of Jupiter had been first detected on a photograph taken on February 28 , 1908, with a reflector of 30 inches aperture. This mirror is mounted in the largest and most recent of the Greenwich buildings, and is carried by the same mounting as three refractors. The largest of these has an aperture of 26 inches and focal length of $22 \frac{1}{2}$ feet, and is corrected for the photographic rays. The smallest is of 9 inches aperture and 9 feet focal length, and is also designed for photographic work. Both of these were presented by the late Sir Henry Thompson to the Royal Observatory, and, with the equatorial stand and electrically-controlled driving clock, are the work of HowARD GRUBB of Dublin. The third refractor, used as a guide for the 26 -inch, possesses an object-glass of $I 2 \frac{3}{4}$ inches aperture and 18 feet focal length, and was, from 1859 to $I 892$, the largest telescope in the Observatory. These two powerful instruments, the 30 -in. mirror and the 26-in. photographic refractor, are used for photographing faint satellites of planets, faint minor planets, comets, nebulæ and double stars, and for the determination of stellar parallaxes. The 30 -in. mirror is specially suitable 
for photographing faint extended objects, such as comets and nebulæ; the 26-in. refractor, for the parallax work. In the IgI4 Report it is mentioned that " the method adopted for the parallax observations consists in an exposure of the same plate at two different epochs, approximately six months apart, on the star whose parallax is required, and the surrounding field. During the year the first exposure has been given to 292 plates, and a second exposure to 219 plates."

The largest refractor in the Observatory, and in the British Isles, is mounted in the "South-East Dome." The mounting, which, like the Transit Circle, was constructed by Ransomes AND MAY, is quite unlike that of any of the other telescopes, being of what is known as the "English" torm, the polar axis being supported at both its northern and southern end. The mounting was originally set up for the 123 -in. refractor, now used as the guiding telescope to the 26 -in. Thompson telescope, but has proved strong enough to carry the present much larger and heavier instrument, which has been mainly devoted to measures of double stars, and a catalogue of the observations of 3,000 of these, made since the year 1893 , is to be published at the first opportunity.

The Astrographic Equatorial already mentioned and a smaller telescope known as the Six-inch Astrographic Triplet, have been devoted to obtaining standards for the determination of the photographic magnitudes of stars. Thus, in I9I4, a catalogue was published giving the photographic magnitudes of 2,329 stars within $15^{\circ}$ of the North Pole, and believed to be complete down to magnitude 9. Parallel with this work, and closely associated with 1t, have been the "counts" of an immense number of stars on plates taken by the late JoHN FRANKLIN-ADAMS (I843-I9I2), with a triple lens of Io inches aperture (since purchased by the Royal Observatory), made by DENNIS TAYLOR of COOKE AND SONS, of York, the constructors of the mounting of the telescope. FranklinAdams bequeathed the plates of his photographic chart of the entire heavens to Greenwich Observatory, which has undertaken their reproduction by photography. From the "counts" of the stars of these plates, formulæ have been inferred for deducing the total number of luminous stars in our system, and also their general distribution with respect to the Milky Way.

As one of the chief purposes for which Greenwich Observatory was tounded was the "rectifying " the places of the fixed stars," it has followed that the preparation and issue 
at intervals of a few years of fresh catalogues of star-places has long been a staple item of the Observatory programme. The necessity for the continued renewal of these celestial surveys became evident from the time of Halley, who pointed out, in I7I8, that the title " fixed stars" was a misnomer, as applied to at least four of the brightest of the heavenly host, for Sirius, Arcturus, Betelgeux and Aldebaran were in motion on the celestial sphere. The place of a star, therefore, could not be determined once for all and assumed to be unchangeable; it must be continually revised.

The next stage in this enquiry was reached when the elder Herschel drew the inference from the proper motions of I4 stars that there was an apparent drift of the stars in general towards the constellation Canis Major, such as would be caused by an actual motion of the sun and its attendant planets towards the opposite point of the heavens, namely, the constellation Hercules. And in the latter half of the Igth century a number of astronomers, of whom Airy was one, made fresh determinations of the place of the "Apex of the Sun's Way." By this time the proper motions of many hundreds of stars had been ascertained, Bradley's observations, made more than one hundred years earlier, affording the groundwork for that evaluation in a large number of cases. A third stage was reached when a number of stars were seen to be in associated motion; one of the most familiar instances of such association being given by five of the seven stars of the Plough; another by the stars of the Pleiades; and a third by those in the head of Taurus.

Early in the present century the study of proper motions entered on its fourth stage, by the discovery of JACOBUS CORNElius Kapteyn that these motions were by no means haphazard, but, when treated in the mass, showed a strongly marked tendency to alignment in two directions. The later development of this investigation has been due to Arthur Stanley Eddington, Chief Assistant at Greenwich (I906-Igr3). Looked at from the point of view of the centre of gravity of the stars considered, the two star-streams must be moving in directions exactly opposite to one another. "The direction of relative motion of the two streams is a very important and fundamental axis, for it is an axis of symmetry of distribution of stellar motions." It lies accurately in the plane of the Milky Way. "If, as seems to be the case, the number of stars belonging to the two streams is the same, the velocities of the two streams referred to the mean of the stars must be equal. The results, regarded 
from this new standpoint, can be given numerically. Each star has a stream-velocity of about 26 kilometres per second, directed towards R.A. 5 h. $44 \mathrm{~m}$., Dec. $24^{\circ}$, or towards the opposite point according as it belongs to Stream I. or Stream II. ; in addition it has its own peculiar motion, equally likely to be in any direction, and averaging about 28 kilometres per second."*

The above discussions have been concerned with stars of large proper motions, that is to say, with stars that are relatively near to us. But the inquiry has recently been extended to the proper motions of the Greenwich Catalogue for rgro,* alluded to above, and seems to indicate that the two great star-streams extend to the nearer borders of the Milky Way.

Two small telescopes still remain to be noticed, the first of which is devoted to a problem which might almost be described as the inverse of those just noticed, dealing with the dimensions of the universe of stars and the currents in the great stellar ocean. The Cookson Floating Zenith Telescope does not belong to Greenwich, but has been lent by the Observatory of Cambridge University for seven years, now extended to fourteen. It was devised by the late BRYAN Cookson (r874-I909), and carries an object-glass of 61 inches aperture and 65.4 inches focal length, one of Dennis Taylor's triple combinations. The telescope rotates round a vertical axis, the position of which is assured by the support of the telescope being made to float in a ring-trough containing mercury. The instrument, which was made by the Cambridge Scientific Instrument Company, has been devoted to the determination of the latitude of the Observatory, and at the date of the I9I4 Report, 387 latitude plates had been obtained. Tust as the apparent place of a star is not invariable, but suffers change from many causes, so the apparent latitude of an observatory suffers change, the axis of rotation of the earth appearing to move round its mean position at a distance from it of about 60 feet. Very accurate determinations of the latitude of the Observatory are derived from photographs, taken with the Cookson telescope, of pairs of stars, equal in zenith distance, and the apparent change of a very few feet in the place of the North Pole of the earth is indicated by observations made at a distance from that Pole of 2,700 miles. At the

* "The systematic Motions of the Stars between Dec. $24^{\circ}$ and $42^{\circ}$ " by Sir F. W. Dyson and Mr. W. G. Thackeray. Monthly notices of the R.A.S. for r9r7, June; Vol. Ixxvii., p. 581 . 
same time, a very precise determination has been made of the constant of that "aberration of light" which was discovered by Bradley.

The remaining small telescope is the Photoheliograph, also a photographic telescope, made by DALLMEYER AND Son, for the Transit of Venus Expedition to New Zealand in 1874. Its aperture is 4 inches, usually stopped down to $2 \cdot 9$, and it gives an image of the sun of 8 inches diameter on the photographic plate. With this photoheliograph, or with others of similar construction, photographs of the sun have been regularly taken, day by day, whenever possible, since April 1874, and the series obtained at Greenwich has been supplemented by similar photographs taken at the Royal Observatory, Cape of Good Hope, and at Observatories in India and in Mauritius. In this way a continuous record has been secured of the changes in the surface of the sun through four complete II-year cycles of sunspot activity. The year I9I3 proved memorable as the one in which the sun's surface was least disturbed for a whole century, while the month of August I9I7 showed the greatest extent of sun-spots since the Greenwich record began. From these photographs the rotation periods of the sun for different latitudes have been determined, and also the position of the sun's axis. Also a curious relation has been detected between the area of a spot and its position east and west of the central meridian of the disc, groups being both more numerous and larger before reaching the central meridian than afterwards. Another relation between the sun and the earth has also been established in that disturbances of the earth's magnetism tend to recur with the return of a meridian of the sun to the centre of the disc, proving that such disturbances were due to the impact of streams of particles driven off from restricted areas of the sun's surface.

This discovery was one of the fruits of the establishment by Airy of a Magnetical Department. Initiated almost at the beginning of his administration he greatly increased its efficiency by enlisting the aid of photography, then in its infancy, for the registration of the variations of terrestrial magnetism. Greenwich, therefore, possesses a magnetic record by photography continuous from I848 onward, and, in I822, Christie commenced the publication in the annual Greenwich Volumes of reproductions of the photographic traces, for the days of greatest disturbance, and it was these reproductions which led directly to the discovery that the disturbances so frequently occurred with the return of the 
same solar meridian to the centre of the sun's disc. In IgI3, which, as noted above, was a year in which the sun's surface was almost completely free from spots, there were no days of great magnetic disturbance, and only one was classified as of small disturbance.

The Magnetical Department has had a close bearing upon the science of navigation. Thus, when steamships were substituted for sailing vessels, and ships built of iron for those of wood, it fell to Airy to investigate several important problems arising from the effect of these changes on the magnetic compass, and in quite recent years the introduction into ships of powerful dynamos for the generation of electricity has rendered it necessary to investigate the effect of these on the behaviour of chronometers carried in the same vessels. This inquiry was carried out at Greenwich in the years I9IIIgr2. Lastly, just as Halley, the second Astronomer Royal, prepared the first magnetic chart of the world, so at the present time it is at the Royal Observatory that the latest magnetic chart of the world is in course of preparation.

The Report of Igr4 makes reference to the completion of the new Magnetograph House. This has been set up at a considerable distance from the main Observatory buildings, in the same enclosure as the Magnetic Pavilion erected by Christie. The Magnetograph House consists of a small room inside a larger one, the inner room being fitted with an automatic arrangement for securing a uniform temperature throughout the year. As the photographic sheets of the self-recording instruments have to be changed every day, provision is made by means of shutters in the walls of the inner room that this can be done without the observer actually entering it. The new instruments installed in the room, and the recording apparatus, were constructed by the CAmbridge Scientific Instrument Company.

The Meteorological Department is closely connected with the Magnetical, and it is only necessary to say here that no other meteorological observatory in the British Isles of the same full equipment possesses so long and continuous a record.

Two other departments of Greenwich Observatory, the fundamental importance of which will be recognised by every one, call for mention. These are the departments of Chronometers and of Clocks and Time Service. All the chronometers for the Royal Navy are tested and rated at Greenwich, and are returned thither for re-examination at the end of every time of service abroad. The Clock Department is concerned 
with the daily rating of certain standard clocks"by comparison with the observations of the times of suitable?stars, and the work of the Time Service involves the daily issue of time-signals to the General Post Office for distribution throughout the country, and the dropping of time-balls at Deal, and indirectly at Portsmouth, Portland and Devonport, for signalling to ships at sea.

The activities of Greenwich Observatory have extended far beyond the grounds of the Observatory itself. The expeditions in which the assistant, Charles Green, took part have already been noticed, and later expeditions have been quite on the same lines. Thus in the Igth and 2oth centuries, not a few expeditions have been sent out from Greenwich, or have come to Greenwich, in connection with the determination of the longitudes of various observatories overseas, while the special opportunities presented by total eclipses of the sun for extending our knowledge of solar physics have been taken full advantage of in recent years. The IgI4 Report refers to the preparations for the latest of these expeditions, namely that to observe the eclipse of August 2I, I9I4, which was successfully observed, though under war conditions, in Minsk, in Russia.

"It will be seen then that fundamentally, Greenwich Observatory was founded and has been maintained for distinctive practical purposes, chiefly for the improvement of the eminently practical science of navigation. Other inquiries relating to navigation, as, for instance, terrestrial magnetism and meteorology, have been added since. The pursuit of these objects has of necessity meant that the Observatory is equipped with powerful and accurate instruments, and the possession of these again has led to their use in fields which lay outside the domain of the purely utilitarian, fields from which the only harvest which could be reaped was that of the increase of our knowledge."*

It is hoped that the preceding pages, though they give but a hint of its present activities, will have proved that Greenwhich Observatory is a living institution. But the first law of life is growth, and if the administrators of the Observatory had been content at any time to restrict its development rigidly to the purely utilitarian purposes for which it was founded, it would have failed to have accomplished these, and would have imperilled its own existence. But it has been p. 316.

* "The Royal Observatory, Greenwich, its History and Work," 
fortunate in its administrators, who have understood that the opportunity for carrying out researches of pure science involves with it the duty, and that the chief reward of faithful work in science is the ability which it confers of accomplishing yet larger and better work in the future. 


\section{Dictionary of \\ British Scientific Instruments}

ISSUED BY

\section{The British Optical Instrument Manufacturers' Association.}

The indax numbers refer to the Manufacturers, see pages 2 and 3.

Abacus.-An ancient apparatus, consisting of beads sliding on wires, used for casting up accounts or performing arithmetical calculations.

Abbe Condenser.-See Condenser. $[2,3,9,17,20,21,22,26$.

Abbe Refractometer.-See Refractometer. [14.]

Abbot's Silver Disc Pyrheliometer.-See Pyrheliometer.

Abel-Pensky's Flash-point Apparatus.-See Flash-point Apparatus. $[13,15,17,21$.

Abel's Petroleum Test Apparatus.-See Flash-point Apparatus. $[13,15,17,21$.

Abney's Clinometer.-See Clinometer. $[2,5,9,10,13,15,17$, $18,20,24,25,26,27$.

Abney Level.-See Level. $[2,5,6,9,10,13,15,17,18,20,21$, $24,25,26,27$.

Abraham Projection Rheograph.-See Rheograph. [4.]

Absorption Apparatus.-An apparatus for observing the relative quantities of coloured rays absorbed by a medium of given th ckness.

Absorptionmeter.-An instrument for measuring the absorption power of gases.

Accelerometer. - An instrument for determining the acceleration of a moving body. [17.]

Accumulator.-A cell or series of cells capable of being charged with electricity and of yielding electric current in turn, as the result of chemical action. Also called a storage or secondary cell.

Acetimeter.-An instrument for estimating the amount of acetic acid in liquids. $[5,13,15,17,21$.

Acetometer.-A hydrometer (q.v.) graduated for determining the strength of acetic acid. See Hydrometer. $[5,6,13,15,17,21$, 26 .]

Achromatic Condenser.-See Condenser. $[2,3,9,11,17,20,22$, 26.]

Achromatic Lens.-See Lens. $[2,3,8,9,10,11,12,13,14,15$, $17,18,20,21,22,23,21,26,27$.]

Achromatic Prism.-See Prism. [15.] 
Achromatic Telescope.-See Telescope. $[2,3,8,9,10,11,13,15$, $17,18,20,21,22,23,25,26,27,28$.

Acidimeter.-An instrument for determining acidity in cheese or butter. $[5,8,13,15,17,21$.

Acidimeter. - See Hydrometer.

Ackermann's Calculating Disc.-For the rapid determination of alcohol and extract contained in beer.

Acoumeter.-An instrument for measuring the acuteness of the sense of hearing.

Acousimeter.-An acoumeter.

Actinograph.-An instrument for recording the variations of chemical influence of the solar rays.

Actinometer.-An instrument for measuring the actinic powers of the sun's rays. In photography for determining the sensitivity of a photographic plate or paper. $[17,20,21,26$.

Acu-puncturator.-An instrument used in the examination and treatment of the skin.

Acutometer.-An instrument for determining the degree of vision with exactness and rapidity. It consists essentially of a device whereby a straight black line can be gradually widened, $[2,9$.

Adding Machine (Burrough's).-A machine which prints a column of figures in $\hbar$ s. $d$. and automatically their sum. $[15,20$.

Adeney's Apparatus.-For experiment with and analysis of dissolved gases.

Adeney's Apparatus,-For recording the rate of absorption of oxygen by polluted water, and generally for the extraction and collection of gases dissolved in water.

Adjusting Cone.-An instrument for measuring the distance between the axes of the eyes.

Adjusting Dial.-See Dial and Pelorus. $[13,15,16,17,28$.

Admuralty Chart Table. - The special form used on ships of the Royal Navy. $[13,15,16,17$.

Admiraity Clinometer.-See Clinometer. $[13,15,16,17,21$.

Aero Clunmeter.-See Clinometer. $[6,9,15,16,17,21$.

Aero Compass.-See Compass. $[13,15,16,20$.

Aerodynamic Balance.-Siee Balance. [4.]

Aerograph.-(I) A general term for any instrument recording any of the properties of the air. (2) An instrument or tool for spraying with colour, enamel, eıc., a surface or object by means of air pressure. Termed also an Aerograph Brush or Pencil. $[16,17,21,27$.

Aerometer.-Any instrument for measuring the weight and density of air and gases. $[15,17,21$.

Aerophone.-An invention of Edison for amplifying sound.

Aeroplane Instrument Board.-A light and compact aluminium trame or board carrying the various instruments used on the aeroplane. $[4,6,15,16,17,19$.

Aeroplane Revolution Indicator. - See Indicator. $[4,6,9,15,17$ ? 
Aeroplane Speed Indicator.-See Indicator. $[4,9,15,17$. Aeroplane Speedometer.-See Speedometer. $[9,15$.

Aerorthometer.-An instrument for use at gas-testing stations. [21.]

Aeroscope.-An instrument for collecting spores, germs, and bacteria from the air.

Aesthesiometer.-An instrument to determine at how short a distance two impressions on the skin can be distinguished, generally consisting of two pricking instruments whose distance apart can be varied and measured. [8.]

Aethrioscope.-An instrument to determine the radiation of the sky. $[17,21$.

Agate.-(I) A pivot of a mariner's compass, a knife-edge or plane for balance, etc. (2) A tool made of agate for burnishing. $[13,15,16,26,27$.

Agate Cap.-A metal cap with an agate setting used as the pivot in magnetic compasses. $[13,15,16,21,24,26,27,28$.

Ahrens Prism.-See Prism. [2, 3, 22, 26.]

Aim Corrector.-An instrument used to correct the sighting and elevation of a gun when being fired. $[13,15$.

Aim Teacher.-A device to facilitate the instruction of recruits in laying a rifle correctly.

Air Condenser.-See Air Pump.

Air Meter.-An instrument for measuring the velocity of air currents for testing ventilation or draught of furnace flues, etc. See Anemometer and Air Gauge. $[4,5,6,13,16,17$, $20,21,24,27$.]

Air Poise.-An instrument for measuring the weight of the atmosphere. See also Barometer. $[13,16$.

Air Pressure Gauge.-See Gauge. $[5,15,16,17,21$.

Air Pressure Gauge (Admiralty pattern).-See Gauge. $[5,15,16$, $17,21$.

Air Pressure Gauge, Self-recording.-See Gauge. [5.]

Air Pump.-Any form of pump used for the compression or exhaustion of the air or other gas in an enclosed space. $[2,6,17,21$.

Air Pump, Bianchi's.-A double action air pump.

Air-Speed Indicator.-See Speedometer. $[5,6,13,15,17$.

Airship Manometer.-See Manometer. $[13,15$.

Air Thermometer.-See Thermometer. $[13,19,21$.

Air Tube.-See Draught Gauge. $[4,16,17$.

Aitken's Dust Counter.-See Dust Counter.

Alarm Thermometer.-See Thermometer. $[4,6,13$ 16, 17, 24, 15.] Albumenometer.-Any instrument for determining the parts per 1,000 of albumen in urine. $[13,21$.

Albumenometer, Aufrecht's.-

Albumenometer, Esbach's. - [21.]

Albuminimeter.-See Albumenometer. 
Alcoholometer.-A hydrometer (q.v.) graduated to indicate the - alcoholic strength of spirits. $[5,13,15,17,21$.

Aldis Spherometer.-See Spherometer. [1.]

Alembic.-An old from of retort used for distillation.

Aleurometer.-An instrument to measure the elasticity of the gluten of flour.

Alidade.-A rule with telescope or sights at its ends for use on a Surveyor's Plane Table to give the direction of any object from a given point. $[2,6,13,15,17,18,20,24,25$, 27, 28.]

Alidade, Reeves's Distance-Finder.-See Distance-Finder. [28.]

Alignment Tester.-An instrument for testing the exact alignment of machine-tool beds, etc. [4.]

Alkalimeter.-(I) An instrument to ascertain the strength of alkalies or the quantity of alkali in a mixture. (2) A dropping-bottle for delivery of small quantities of re-agent, whether chemical or bacteriological. $[13,17,21$.

Alkalimeter, Schuster's. -

Altazimuth.-An instrument for measuring altitudes and azimuths. Generally a telescope provided with altitude and azimuth movements. $[3,6,9,13,15,17,18,20,21,25,26$, 27.]

Alti-hyphydroscope.-A submarine periscope (q.v.) modified so as to give views not only of the sea surface, but of elevated objects. [26.]

Altimeter.-An instrument for taking altitudes, as a quadrant sextant, theodolite, etc. Also used to describe an aneroid barometer, which indicates heights. $[4,13,15,16,17,20$, $21,25,27$.

Altiscope.-An arrangement of lenses and mirrors or prisms which enables a person to observe an object in spite of intervening objects. See also Periscope. [16.]

Altitude Recorder. - A form of barograph (q.v.) for recording the varying and maximum altitude attained.

Amblyoscope.-An instrument for testing muscular insufficiencies of the eyes in strabismus. [2.]

Ambulator.-An instrument used by Surveyors for measuring linear distances over the ground. It consists of an accurately

t turned wheel with handle. Attached to the axis is a box containing gearing and dial by means of which the distance over which the wheel is pushed is registered. $[16,17,21$.

Amici Prism.-See Prism. [2, 3, 20, 26.]

Ammeter.-A galvanometer (q.v.) graduated for the measurement of electric currents in terms of amperes. See also ThermoAmmeter.

Ammeter, Recording.-A form of ammeter in which the current is automatically recorded.

Ammonia Gauge.-A form of pressure gauge made of steel used in the measurement of the vapour pressure of ammonia. $[5,6$. 
Ammoniameter.-A hydrometer graduated to indicate the strengths of ammonia solutions. [15.]

Ampere Meter.-See Ammeter.

Amsler's Integrator.-See Integrator. [21.]

Amsler's Planimeter.-See Planimeter.

Anærobic Apparatus.-For obtaining cultures of bacteria which do not grow in the presence of oxygen. [26.]

Anærobic Apparatus.-An apparatus for obtaining plate cultures of anærobic bacteria. [26.]

Anærobic Apparatus, McGowan's.-

Anærobic Apparatus, McLeod's.-

Anallatic Telescope.-A surveying telescope fitted with an additional lens in the focal plane of the object-glass, in order to avoid the necessity of adding a constant for tacheometrical measurements. $[3,17,18,20,21,27$.

Anastigmat.-A lens corrected for astigmatism. $[1,3,8,18,20$, 23,26 .]

Anastigmatic Objective.-An object-glass (q.v.) corrected for astigmatism. $[1,3,8,20,25$.

Anderson Slide-Rule.-See Slide-Rule. $[13,15,20$.

Anemo Biagraph.-See Anemograph. $[15,17,20,21$.

Anemogram.-The diagram of a recording anemometer.

Anemograph.-A recording anemometer or wind-gauge. $17,20,21$.]

Anemometer.-An instrument for measuring the force and velocity of the wind, or of currents of air or other gases. There are two types: (I) Cup (or Robinson) Anemometer, consisting of four hemispherical cups attached to the ends of a light metal cross which rotates under the force of the wind, the rate of revolution being registered on a dial, counter or chart. (2) Pressure Tube (Dines's) Anemometer, consisting essentially of a Pilot tube (q.v.) head connected to a manometer, the wind exerting a pressure on one limb and a suction on the other limb and the combined effect being recorded on a chart or otherwise registered. $[2,5,13$, $15,16,17,20,21,24,25,26,27$.]

Anemometer, Fletcher's.-For measuring the speed of flue gases $[13,15,17,21$.

Anemometer, Inclined Pattern.-A form of pressure gauge for measuring small pressures. A Pilot head is connected to a $\mathrm{U}$ tube which can be inclined at any angle so as to vary the sensibility. $[6,13,16,17,20,21,24,25$. $]$

Anemometer, Lea Biram.-A special form of Biram anemometer with one dial and one pointer. $[13,21$.

Anemometer Pressure Plate.-For indicating the pressure of wind acting on the surface of a plate against a spring and suspended to work over a vertical quadrant. $[13,15,17,21$.

Anemoscope.-An instrument which indicates the direction of the wind. $[13,15,17,21$. 
Averoid.--See Barometer. $[2,3,5,6,13,15,16,17,20,21,24$, $25,26,27,28$.]

Aneroidograph.-A self-recording aneroid barometer.

Anglemeter.-An instrument used by geologists to measure the dip of strata. [17.]

Angle Mirror.-See Optical Square. $[2,11,13,15,17,21,24$, $25,27$.

Angle-of-Sight Instrument.-An instrument for measuring the angle with the horizon which an object subtends at the eye. It consists of a spirit-level and an adjustable sighting apparatus. $[2,3,6,13,15,18,20,25,26,27$.

Angleometer.-An instrument for measuring external angles. $[13,15,17$.

Angle Sextant.-A special form of sextant used on ships for quickly measuring horizontal or shore angles. $[6,13,15$, $16,17,25,27$.

Angstrom's Compensation Pyrheliometer.-See Pyrheliometer.

Anorthoscope.-An optical toy for producing pictures by means of two revolving discs.

Anthrocometer.-An instrument for measuring the carbonic acid in a mixture.

Anthropometric Apparatus.-Instruments designed for testing and measuring the chief physical and some mental characteristics of the human subject.

Antimeter.-A modification of the quadrant for measuring small angles.

Apertometer.-An optical arrangement for measuring the numerical and angular aperture of a lens, especially of a microscope objective. $[2,3,20,26$. $]$

Aphengoscope.-A modification of the magic lantern, for exhibiting opaque objects. $[2,3,17,20,26$. $]$

Aplanatic Lens.-See Lens. $[1,2,3,8,9,10,17,20,21,22,23$, 26,27 .]

Aplanatic Magniffer.-See Magnifier. $[1,2,3,9,10,15,17,20$, $21,22,25,26,27$.

Apochromatic Condenser.-See Condenser. [2, 3, 20, 22, 26.]

Apochromatic Object-Glass.-See Object-Glass. $[2,3,8,20,22$, 26.]

Apomecometer.-An instrument for measuring the heights of objects at a distance, e.g., trees, buildings, etc. $[15,21$.

Apophorometer.-An instrument enabling sublimates obtained from substances at high temperatures to be collected in their entirety and weighed. [4.]

Architects' Scales.-Scales made of ivory, boxwood, or celluloid, and graduated for use by architects for drawing and designing. $[2,5,6,15,16,17,20,21,24,25,27$.

Arcograph. - An instrument for describing an arc of a circle without the use of a central point; a cyclograph or curvo. graph. [27.] 
Areograph.-An instrument for drawing a circular arc without the use of a central point. [2\%.]

Argentometer. - A hydrometer for measuring the density of silver solutions. $[6,17,21$. $]$

Arithmometer.-A comprehensive name for a calculating machine. $[17,20,21$.

Armillary Sphere.-An ancient astronomical apparatus composed of rings to represent the circles of the celestial sphere.

Armillary Sphere Sun-Dial.-A form of skeleton sphere in which the shadow of the central axis or pole falls on the divided equatorial circle and indicates the time. [15.]

Armstrong Scale.-A drawing scale, containing a set of eight scales, used chiefly by engineers.

Arrows for Land Chain.-Strong wire pins for use with the land or surveying chain. $[2,5,6,13,15,16,17,20,21,24,25,27$.]

Arsenic Apparatus.-Used in the preparation and testing of arsenic.

Artificial Horizon.-An instrument used to give the true horizontal level and to determine by means of a sextant the true altitude of a heavenly body. It may consist of (I) a bath of mercury in a suitable vessel ; (2) a piece of silvered or black glass suitably mounted. $[2,5,6,13,15,16,17$, $20,21,24,25$.]

Artificial Horizon, George's.-A portable form of mercurial artificial horizon for sea and exploring work. $[6,13,15,17$, $21,24,27$.

Artiflcial Horizon, Paget.-An improved form of bubble horizon for attachment to a sextant. [13, 15.]

Ashton's Compass Rule.-See Compass Rule. [13, 15.]

Aspirator.-An apparatus for passing air or gases through or over certain liquids or solids.

Aspirometer.-An aspirator graduated so as to measure the volume of air or other gases aspirated.

Assay Apparatus.-Equipment for analysis of metallic ores, etc. Assmann's Psychrometer.-See Psychrometer. $[6,17,21$.

Astatic Galvanometer.-See Galvanometer. $[4,16,19$.

Astigmatic Test Chart.-A diagram with lines drawn in various directions for testing astigmatism of the eyesight. $[2,8$, $20,26$.

Astrodicticum.-An astronomical instrument by means of which many persons are able to view the same star at the same time.

Astrolabe.-The ancient form of instrument for taking the altitude of a star or heavenly body. It is now superseded by the quadrant or sextant.

Astrometer.-An instrument invented by Sir John Herschel for measuring the apparent magnitudes of the stars.

Astrometeoroscope.-An apparatus for demonstrating by means of the optical lantern the effects of persistence of vision.

Astronomical Clock. 
Astronomical Telescope.-See Telescope.

Astronomical Transit.-See Transit.

Astropatrotometer.-An instrument to measure the brightness of stars by comparing them with a standard artificial star.

Astroscope.-An old astronomical instrument formed of two cones on the surfaces of which the constellations were delineated. [18.]

Atmidometer.-An instrument for measuring the evaporation of water, ice, and snow. $[17,21$.

Atmolyzer.-An instrument for illustrating the separation of gases.

Atmometer.-See Evaporometer. [17, 18.]

Atmospheric Slide-Rule.-See Slide-Rule. $(13,15,2 \%$.]

Atomizer.-An instrument for reducing a liquid to the form of spray.

Atwood's Machine.-An apparatus designed to demonstrate the relations of time and space in the motion of a falling body, used also to determine the value of the acceleration due to gravity. $[18,19$.

Audiometer.-An instrument by which the power of hearing can be gauged or recorded on a scale.

Audiphone.-An instrument, placed against the teeth, which conveys sound to the auditory nerve.

Auriscope.-An instrument for examining, by means of an illuminating device, the condition of the ear.

Aurora Tube.-A tube of uranium glass through which discharges of an induction coil are transmitted to produce the optical effect of aurora. [21.]

Ausculator.-See Stethoscope.

Autoclave.-A vessel under steam pressure, for sterilising and other purposes; with a gauge for recording atmospheric pressure and temperature. $[2,26$.

Antoclave, Soxhlet's.--An autoclave used in the determination of starch in grains and the diastatic power of malt.

Auto-Collimator.-A telescope with a means of reflecting light through the instrument in the direction of the line of sight. $[1,3,8,17,26,27$. $]$

Auto-Laryngoscope.-An instrument by which one may inspect one's own larynx. [2.]

Automatic Machines.-A term generally applied to machines which, when once set in action and provided with necessary motive power, continue to work without further human intervention.

Auto-Ophthalmoscope.-An ophthalmoscope (q.v.) by which one may inspect one's own eyes.

Auxanometer.-A laboratory instrument to measure the rate of growth of plants, usually fitted with clock-driven drum to provide a record.

Auxanometer.-Any instrument to measure the growth of plants. 
Auxanometer Klinostat.-A similar instrument to the above, but arranged to take the plant in a vertical or horizontal position, so as to determine the effect of gravity on the plant's growth.

Auxograph.-An instrument for indicating the growth of a plant. Averaging Instrument, Goodman's.-An instrument for finding the averages in indicator diagrams. [15.]

Aviation Compass.-See Compass. $[9,13,15,16,17,20,21,27$. Aviation Revolution Indicator.-See Revolution Indicator. [6, $15,17$.

Axometer.-An instrument to determine the required height of the bridge of a pair of spectacles.

Ayrton-Mather Galvanometer.-See Galvanometer. $[4,16,19$. Azimuth Compass.-See Compass. $[13,15,16,17,20,21,25,27$ : 28.7

Azimuth Dial.-See Dial. [13, 15, 16, 17, 20, 21, 24, 27, 28.]

Azimuth Mirror.-See Mirror. $[13,15,16,17,28$.

Azotometer.-An instrument for measuring or determining the proportion of nitrogen in air or in a mixture of gases.

Back Staff.-An instrument formerly used at sea for taking the sun's altitude, so called because the back of the observer was turned towards the sun when he made the observation.

Bacteriological Incubator.-An apparatus, heated by gas, oil or electricity, for promoting the growth of bacteria. [2, 3, 26.]

Bacteriological Steriliser.-A sterilising apparatus for bacteriological work.

Bacterioscope.-An instrument for the microscopical examination of bacteria. [2.]

Baines's Slide-Rule.-See Slide-Rule. [15.]

Bake-oven Thermometers.-See Thermometer.

Baker's Temperating Thermometer.-See Thermometer.

Balance.-An instrument for determining equality or difference of weight. $[2,4,13,17,20$.

Balance, Actinic.-See Bolometer.

Balance, Aerodynamic.-An instrument for the investigation of the stability of aeroplanes by means of experiments on models. The model aeroplane is suitably fixed to the balance, which projects into a wind channel through which a stream of air at the required velocity can be driven. The forces acting on the model are counterbalanced by the adjustment of weights on the arms of the instrument.

Balance, Chemical.-A sensitive balance consisting essentially of a horizontal beam supported on a knife-edge, either of steel or agate, on the top of a pillar. From the ends of the beam pans are suspended, also from knife-edges. $[2,5,17,20$.

Balance, Electric.-An instrument for measuring electric currents by balancing electro-magnetic forces between conductors against gravity. 
Balance Electrometer.-See Electrometer. [16.]

Balance, Hydrostatic.-A balance for weighing substances in water to obtain their specific gravity.

Balance, Joly's Specific Gravity.-A spring balance; used for the determination of specific gravities, in which the substance to be weighed is suspended from a vertical metal spiral spring.

Balance, Physical.-Similar in type to the Chemical Balance, but generally less sensitive and designed to carry heavier loads.

Balance, Spring.-A form of balance in which the weight of the body to be determined is measured by the extension or compression of an elastic spring.

Balance, Thermic.-See Bolometer.

Balance Thermometer.-See Thermometer. $[13,20,21$.

Ballistic-Galvanometer.-See Galvanometer. $[4,16,19$.

Ballistic-Pendulum.-See Pendulum. [19.]

Banana Thermometer.-See Thermometer.

Barmacrometer.-An instrument for determining the height and weight of a newborn infant.

Bar-Magnet.-A steel bar permanently magnetised. $[2,10,13$, $15,16,19,21,24,27,28$.

Barograph.-A form of aneroid barometer (q.v.) provided with a clockwork-driven drum, pen and chart for recording automatically, in the form of a curve, variations of atmospheric pressure. $[2,3,4,5,6,9,10,13,15,16,17,20,21,24,25$, $26,27,28$.

Barometer.-An instrument for determining the weight or pressure of the atmosphere and, indirectly, for measuring heights (e.g. of mountains, etc.) above the earth's surface. Made in two principal forms, the Aneroid and Mercury Barometers. $[2,3,5,6,9,10,13,15,16,17,20,21,24,25$, $26,27,28$.]

Barometer, Aneroid.-A form of barometer without liquid. Its action depends on the effect of the varying pressure of the atmosphere on the elastic sides of a metal box, from which the air has been exhausted. See also Barograph. $[2,3,5$, $6,13,15,16,17,20,21,24,25,26,26,27,28$.

Barometer, Board of Trade Pattern.-A mercurial barometer of the type specified by the Board of Trade. [15.]

Barometer, Boylean Mariotte.-A portable mercury barometer in which the atmospheric pressure is determined by a uniform volume of air being admitted to the cistern and compressed by the advance of the mercury to a fixed point. The total length of the instrument is under 15 in. See also Sympiesometer. $[13,27,28$.

Barometer, Collie's.-A portable mercury barometer provided with a flexible rubber tube in place of the usual glass tube.

Barometer, Dial or Wheel.-A mercury barometer in which the movement of the mercury is measured by means of a float 
and counterpoise fixed to a pointer travelling over a circular dial.

Barometer, Dines's Self-Recording.-A mercury barometer giving records on a chart. $[2,13,17,20,21,26$.

Barometer, Fitzroy.-A mercury barometer in a wooden frame, usually carved.

Barometer, Fortin.-A mercury barometer. The mercury in the cistern is raised to a fixed point at each observation before the readings are taken. It is safely portable as there is a flexible cistern which allows of the tube being completely filled with mercury. $[2,5,6,13,17,20,24,21,27$.

Barometer, Gay-Lussac. - A siphon form of mercury barometer. Barometer, Glycerine.-A barometer in which the liquid used is pure glycerine.

Barometer, Kew.-A mercury barometer. There is no flexible cistern and the scale is contracted to allow for the capacity of the cistern. This pattern cannot be made "portable" in the sense in which the Fortin can. $[5,13,17,21,27$.

Barometer, King's.-A self-recording mercury barometer in which the atmospheric pressure is determined by weighing the column of mercury, instead of by measuring its length.

Barometer, Marine.-A form of mercury barometer for use on board ship, in which the tube is constricted so as to damp the motion of the mercury and prevent sudden oscillations. The frame is suspended in gimbals and attached by an arm to a vertical fixture of the ship. $[5,6,13,15,16,17,21,26$, 28.]

Barometer, Mercury. - Consists of a column of mercury enclosed in a vertical glass tube deprived of air, the lower end of which dips into a cistern, also containing mercury. The pressure of the atmosphere on the mercury in the cistern supports the column of mercury in the tube, the height varying according to the pressure. $[2,13,17,20,21,26$.

Barometer, Water.-A barometer in which the variations of atmospheric pressure are measured by the varying height of a column of water. $[13,17$.

Barometrograph. - See Barograph. [27.]

Baroscope.-An instrument designed to show that bodies in air lose as much of their weight as that of the air which they displace. [21.]

Barry Proudfoot Machine Protractor.-See Protractor.

Baseline Apparatus.-An apparatus for laying off a standard baseline for trigonometrical survey work. $[6,21,25,27$.

Bathometer.-An instrument for measuring the depth of the sea, especially for taking soundings without a measured sounding line. $[13,15,16,17,28$.

Batoreometer.-An instrument for measuring minute variations of thickness. The contact of a micrometer screw with the object to be measured is indicated by the passage of an electric current. $[4,19$. 
Battery, Electric.-A group of electrical elements (e.g. Leyden jars or chemical cells) arranged in series or in parallel, so as to yield an electric current. $[17,26$.

Battery, Gravity.-A battery in which the different liquids range themselves at different heights by virtue of their different specitic gravities.

Battery Hydrometer.-See Hydrometer. $[5,6,13,15,17,21$. Beale Neutral Tint Reflector.-See Reflector. [2, 3, 17, 20, 22, 26.] Beale's Deviascope.-See Deviascope. [15.]

Beam Compass. - An instrument consisting of a wooden or brass beam having sliding sockets carrying steel or pencil points. Used for describing large circles the radii of which are beyond the extent of the common compasses, and also for transferring lengths to be measured. $[2,5,6,13,15,16,17$, $19,20.21,24,25,26,27$.]

Beam Compass.-A simple form of triangular compasses for copying large plans. $[2,13,15,17,20,21,26,27$.

Beam Compass, La Trobe.-A light form of beam compass, consisting of two runners attached by a flexible strap which, if compressed slightly, instantly releases them. $[13,21$.

Beam Compass, Roller.-A beam compass with roller adjustment. $[2,6,13,15,20,21,24,26,27$.

Beck-Thorp Pocket Diffraction Spectroscope.-See Spectroscope.

Beghin Slide-Rule.-See Slide-Rule. [15.]

Bell's Naval Station Keeper. - See Naval Station Keeper. $[13,15$, $17,20$.

Bench, Lens-Testing.-An apparatus for measuring the aberrations of lenses. $[2,3,10,17,21,26,27$.

Bench, Optical. - An apparatus for making optical experiments and tests. $[2,3,4,10,17,19,21,26,27$.

Bench, Photometric.-A bench which carries the apparatus for measuring the intensity of a source of light by comparison with a standard. $[3,10,27$.

Benson's Comb Nephoscope.-See Nephoscope, Benson's Comb. $[15,17$.

Besidometer.-An instrument which indicates the proper distance of spectacles between the hinges; that is, the breadth of the forehead.

Bevel Protractor.-A form of flat bevelled protractor for setting off angles. $[5,6,15,16,17,20,21,24,25,27$.

Bifilar Micrometer.-See Micrometer. $[2,3,11,17,20,22,25,26$.

Bilge-Water Gauge.-A gauge for showing the depth of bilgewater in the hold of a ship. $[13,15$.

Bi-Meter CO Recorder.-See CO Recorder. [4.]

Binnacle.-The case box or stand by which the compass on board ship is protected. $[13,15,16,17,28$.

Binocular.-An instrument (e.g., Microscope, Telescope or Magnifier) having two tubes, each furnished with lenses, for the use of both eyes at once. The term is also used as a 
synonym for a Field Glass (q.v.). $[2,3,5,9,10,13,15,16$, $17,18,20,21,22,24,25,26,27,28$.]

Binocular, Galilean.-A binocular constructed on the same principles as the Galilean Telescope (q.v.).

Binocular Magnifier.-See Magnifying Glass. $[2,3,10,13,15$, $20,26,27$.

Binocular Microscope.-See Microscope. $[2,3,5,9,15,17,20$, $21,22,27$.

Binocular Telescope.-See Telescope. $[2,3,5,9,15,17,20,21$, $22,27$.

Bioscope.-See Cinematograph. $[3,20$.

Biram Air Meter or Anemometer.-A form of anemometer (q.v.) with revolving vanes for registering the rate of air currents in mines, etc. $[2,5,6,10,13,15,16,17,21,24,27$.

Birt's Buoy \& Nipper. - An apparatus or device used on a ship for obtaining a vertical or plumb sounding. [15.]

Bisecting Compasses.-See Bisecting Divider. $[6,13,15,17,21$, 24,27 .]

Bisecting Divider.-See Divider. $[2,6,13,15,17,21,24,27$.

Blackburn's Pendulum.-See Pendulum.

Blanchimeter.-An instrument for measuring the bleaching power of chloride of lime and potash.

Blast-Meter.-An anemometer or wind-gauge as applied to the nozzle of a blowing engine, etc. [17.]

Blast Recorder.-An instrument for recording on a revolving drum the duration, pressure and time of a blast. $[5,6$.

Blind Scale Thermometer.-See Thermometer. $[4,5,6,13,15$, $16,17,20,21$.]

Blisch Horizon Corrector Prism.-An instrument for attaching to any sextant, and giving the correction for dip and refraction. [15.]

Boiling Point Apparatus.-An instrument, called a hypsometer (q.v.), used for determining altitudes by observation of the boiling points of water. $[2,5,6,13,15,17,21,24,25,27$.

Bolometer.-An instrument for measuring minute quantities of radiant heat, especially in different parts of the spectrum; called also Actinic Balance and Thermic Balance. $[4,19$.

Bone and Wheeler's Gas Analysis Apparatus.-For gas analysis purposes.

Boning-Rods.-Stout T-squares used with mechanic's levels in surveying work. $[5,6,13,15,16,21,24,25,27$.

Borda Pendulum. - See Pendulum.

Bordering Pen.-A special form of pen for drawing in border lines on plans and maps. $[5,6,13,15,17,20,21,25,27$.

Bo's'un Reel. -A simple form of sounding winch. $[13,15,28$. Boucher's Calculating Circle.-See Slide-Rule. $[5,13,15,17,21$, 24,27 .]

Bourdon's Pressure Gauge.-See Pressure Gauge. $[5,13,15,16$, $17,21,27,28$.

Bow Calliper.-See Calliper. $[6,15,20,24,26,27$. 
Bow Compass.-Drawing compasses (q.v.) for describing small curves or circles. $[2,5,6,9,13,15,17,20,21,24,25,26,27$. Bow Pen.-A drawing instrument for describing circles in ink. $[2,6,9,13,15,17,20,21,24,25,26,27$.

Bow Pencil.-A drawing instrument for describing circles in pencil. $[2,6,9,13,15,17,20,21,24,25,26,27$.

Box Photometer. -See Photometer. $[2,3$.

Box Sextant.-See Sextant. $[2,3,5,6,9,10,13,15,16,17,20,21$, $24,25,26,27,28$.]

Boxwood Compasses.-For drawing circles and curves with chalk on the blackboard for lecture purposes. $[6,13,15$, $20,21,27$.

Boys's Calorimeter.-See Calorimeter. [19.]

Boys's Radio-Micrometer.-See Radio-Micrometer. [4.]

Brearley Curve Tracer.-See Curve Tracer. [4.]

Broca Galvanometer.-See Galvanometer. $[4,19$.

Brook's Curves.-Flexible steel bands adjustable to any form of curve for draughtsmen's use. $[2,5,13,15,21,24,25,27$.

Brooke's Sounding Apparatus.-See Sounding Apparatus. [13, 15.]

Browning's Pocket Spectroscope.-See Spectroscope. $[2,10,17$, 20.]

Browning's Spectroscope.-See Spectroscope. [17, 20.]

Bryan's Oscillating Table.-See Oscillating Table. [19.]

Bullet Compasses.-See Compasses.

Bull's-Eye Condenser.-See Condenser. $[2,3,8,9,10,17,20$, $21,22,26$.]

Bunsen Burner.-A gas jet fitted with an adjustable air admission so that gas and air are mixed in such proportions that they burn with a non-luminous flame of high temperature. Used in incandescent gas burners. [2. 10.]

Bunsen's Photometer.-See Photometer. [2, 10.]

Burel Level.-See Level.

Burette.-An apparatus for delivering measured quantities of liquid or gas received or discharged. It consists essentially of graduated glass tube and stop-cock. $[2,13,17,21$.

Burgess's Colorimeter.-See Colorimeter.

Burner.-See Bunsen Burner and Méker Burner. [2, 10.]

Burnet Bearing Clamping Compass.-See Compass. [15, 28.]

Burrough's Adding Machine.-See Adding Machine. [20.]

Butyrometer.-An instrument for determining the amount of fatty matter or butter contained in milk. $[2,21,26$.

Butyro-Refractometer.-See Refractometer.

Cadran.-An instrument with a graduated disc by means of which angles of gems are measured in the process of cutting and polishing.

Calcimeter.-An instrument for making volumetric analyses of bone dust, meerschaum, and other substances containing lime. 
Calcimeter, Clarke's.-For testing cement, slurry, limestone, etc. Calculating Instrument, Thacker's. - A calculating machine consisting of a cylinder with divided scales, working in an open framework with triangular bars. $[13,15,27$.

Calculating Machine.-A machine for calculating by mechanical means. $[13,17,20,21,27$.

Calculating Rule.-A slide-rule (q.v.). $[5,9,13,15,16,17,20$, $21,24,27$.

Calculator, Fearnley's Universal.-A calculating disc having a long scale in spiral form.

Caleidophone.-See Kaleidiphone.

Caleidoscope.-See Kaleidiscope.

Callendar Pyrometer. - See Pyrometer. $[13,20,21$.

Callendar Recorder.-See Recorder. [4, 21.]

Calligraph.-A writing machine. [20.]

Calliper Square.-A draughtsman's or mechanic's square, having a graduated bar and adjustable jaw or jaws. $[15,20,27$.

Callipers.-Instruments for measuring the external or internal diameter of a body. Used by the turner in lathe work. See also Micrometer Calliper, Micrometer Dial Calliper, and Micrometer Screw Contact Calliper. $[2,5,13,15,19,20,25$.

Callipers, Bow.-Used for measuring the external diameters of large objects, such as round timber. $[6,15,20,24,26,27$.

Callipers, Gunner's.-Callipers for calibrating shot, shell, guns, etc. $[1,27$.

Callipers, Hull.-Callipers for taking the thickness of square timber. [15.]

Callipers, Outside.-Callipers for measuring the external diameter of cylindrical pieces of material. $[17,20,21,25$.

Callipers, Vernier.-Callipers with vernier reading. [25.]

Calorescope.-An apparatus for producing heat for demonstration purposes.

Calorigraph.-A recording calorimeter (q.v.).

Calorimeter.-An apparatus for measuring the quantities of heat received from or by bodies or developed or absorbed by some mechanical or chemical process, such as chemical combination, friction, combustion, etc. Used also in the determination of the specific heats and calorific values of substances. In its simplest form it consists of a thin vessel, usually cylindrical, of brass or copper. There are various modifications depending upon the materials (solids, liquids or gases), the specific heats or calorific values of which are to be determined. $[2,4,13,15,17,19,21,26$. $]$

Calorimeter, Gas, Boys's.-A calorimeter for determining the calorific value of combustible gases, depending in principle on a small stream of water abstracting the heat from a slowly-travelling stream of gas. [19.]

Calorimeter, Fischer's.-A silver calorimeter for determining heat of combustion. 
Calorimeter, Ice, Bunsen's.-A glass calorimeter in which the quantity of heat given out by a body is measured by the determination of the amount of ice melted.

Calorimeter, Fuel.-Any calorimeter for determination of the calorific value of fuels. $[4,17,21$. $]$

Calorimeter. Lewis-Thomson.-A calorimeter for determining the heating power of coal and indicating the number of parts of water a given quantity of coal is capable of boiling. $[15,17$.

Calorimeter, Mahler's Bomb.-A steel shell or bomb calorimeter, employing oxygen for combustion, used in the determination of the heat of combustion of solids, liquids and gases.

Calorimeter, Rowland Wild's.-A calorimeter, employing sodium peroxide for combustion, for determining the calorific value of coal.

Calorimeter, Rosenhain's.-An improved form of Thomson fuel calorimeter.

Calorimeter, Sarco.-A calorimeter on the Mahler's Bomb principle for the determination of the calorific values of coal, coke, peat, liquid fuels, oils, etc., and producer gas. $[13,15$, 17.].

Calorimeter, Simmance-Abady.-English standard gas calorimeter for determining the calorific values of gas, oils, spirits, etc. $[13,15,1 \%$.

Calorimotor.-A voltaic battery having large plates and producing powerful heating effects.

Cambridge Extensometer.-See Extensometer. [4.]

Cambridge Flow Recorder.-See Flow Recorder. [4.]

Cambridge Measuring Microscope.-See Measuring Microscope. [4.]

Cambridge Optical Pyrometer.-See Pyrometer. [4, 21.]

Camera, Photographic.-An apparatus having a chamber, usually a box with lenses at one end and a sensitised photographic plate or film opposite for taking photographs. $[3,8,9,15$, $16,17,20,21,22,26$.]

Camera-Lucida.-An instrument which, by means of a prism or mirror, causes an apparent image of an external object to appear as if projected upon a surface, as of paper or canvas, so that the outlines may be conveniently sketched. It is frequently used with the microscope. $[2,3,15,17,20$, $21,22,26$.]

Camera-Obscura.-An apparatus in which the images of external objects formed by a convex lens and a prism or concave mirror are thrown on a paper or other white surface in the focus, within a darkened chamber or box, so that they may be sketched or observed. $[3,17,20,26$. $]$

Campbell Stokes's Standard Sunshine-Recorder.-See SunshineRecorder. $[3,5,6,17,20,21,25,26,27$.

Camptometer.-A form of cross staff head for laying out camps. $[13,[21]$. 
Campylometer.-A pocket instrument capable of giving at one reading the metric length of any line, straight or curved, on a map or plan.

Capillary Electrometer.-See Electrometer.

Carbolimeter.-An instrument for the estimation of phenol (carbolic acid).

Carbolimeter, Muter's.-

Carbonate of Lime Apparatus, Hall and Russell's.-For the determination of small quantities of carbonates.

Carbonometer.-An instrument for detecting the presence of an excess of carbonic acid by its action on lime water.

Carburometer.-An instrument for determining the composition of gases contained in carbonic oxide, hydrogen, etc.

Cardiograph.-An electrical recording instrument which, when placed in contact with the human chest, will register graphically the comparative duration and intensity of the heart's action.-See also Electrocardiograph. [21.]

Cardioid Condenser. - See Condenser. [2,22, 26.]

Cardisygmograph. - A combination of the cardiagraph and the sygmograph (q.v.). [21.]

Carpenter's Gauge.-A gauging tool used by carpenters for marking off woodwork.

Carré's Freezing Apparatus.-See Freezing Apparatus. [20.]

Cascade, Gassiot's.-An electric apparatus for use with an air pump to illustrate electrical phenomena.

Cassegrain Telescope.-See Telescope. $[3,11,13,18$.

Cassela Petrol Tank Gauge.-For indicating the amount of petrol in the tank. $[6,21$.

Catadioptric Light.-A system of illumination in which reflection and refraction are both employed (in lighthouse work). [7.]

Catadioptrical Telescope.-See Telescope.

Cathetometer.-A horizontal telescope moving on a graduated vertical support for measuring, at a distance, differences of vertical heights. $[2,3,4,6,13,15,17,18,19,21,25,26,27$.

Catopter.-A reflecting optical instrument; a mirror.

Catoptric Cistula.-A box with several sides, lined with lookingglasses so as to multiply images of any object placed in the box.

Catoptric Dial.-A dial in which the indications of the hour are read by reflection in a mirror.

Catoptric Light.-A mirror, or series of concave mirrors, preferably parabolic, by which the rays from one or more lamps are reflected in a parallel beam so as to render the light visible at a great distance. [7.]

Catoptric Telescope. - See Telescope.

Cavalry Sketching-Board.-A military sketching-board permitting sketches to be made on horseback. $[2,15,17,20$, $21,24,27$.

Cecograph. - A French writing machine for the blind; a chiragon. Celestial Globe.-See Globe. $[2,13,15,20,27$. 
Cement Apparatus.-For determining the soundness of cement in a few hours.

Cement Gauger (Faija's)._An apparatus for gauging 2 to $4 \mathrm{lbs}$. of cement. The cement is reduced to the proper consistency for forming into briquettes to be tested.

Cement Hopper (Faija's).-For determining the weight per bushel of different cements for comparison.

Cement Needle Apparatus. - For ascertaining the time of setting of cemert. $[17,21$.

Cement-Tester.-An apparatus to test the cohesion of cement as a homogeneous hard body. $[2,17,21$.

Cement-Testing Machine.-British standard pattern. An apparatus for determining, by the application of weights, the breaking strain of prepared briquettes of cement. $[2,1 \%]$

Cement-Testing Machine.-Salter's improved pattern. An apparatus for determining, by the application of weights, the breaking strain of prepared briquettes of cement. [17.]

Centrifugal Force Machine (Robinson's). - An apparatus for the quantitative measurement of centrifugal force. $[2,19$.

Centrifugal Machine.-See Centrifuge. $[2,3,10,17,22,26$.

Centrifuge. - A centrifugal machine for sedimenting fluids (e.g., blood, urine, sputum, milk, etc.) by the rapid revolution of vessels containing them, for purposes of analysis. $[2,3$, $10,17,22,26$.]

Centrolinead.-An instrument for drawing lines in perspective. $[2,5,15,17,21,24,27$.

Cephalometer.-An instrument for measuring the size of the fetal head during parturition.

Ceraunoscope.-An instrument employed in the ancient mysteries to imitate thunder and lightning.

Chain-Inclinometer.-A form of level in which the inclination of the surveyor's chain is indicated on a scale by the pointer on the end of the level. $\quad[15,20,21,27$.

Chains, Land.-Surveyiñ chains for lineal measurements of land. Usually of roo links, equal to $66 \mathrm{ft}$. $[2,5,6,13,15$, $16,20,21,24,25,27$.]

Chain Scales and Offsets. - For the use of draughtsmen in map measurements. $[2,5,6,13,15,21,24,25,26,27$.

Chapman Hunter Pitchometer.-See Pitchometer.

Charm Compass.-See Compass. $[2,3,5,9,13,16,17,20,21,27$.]

Chart.-Derived from a Greek word signifying a leaf of paper. Applied to any diagram which gives a graphic representation of certain facts, such as barometric, thermometric, and wind charts. It is more generally understood to signify the chart as used by mariners; gives the representation of a portion of the earth's surface projected on a plane. This may be on the globular, mercator, plane, or gnomonic projection. $[13,15,16$.

Chart Dividers.-An instrument for taking measurements on charts. $[5,9,13,15,16,17,20,21,27,28$. 
Chart Frame.-A strongly-made frame, having a transparent top with a pencilling surface in which the chart can be placed and used on the deck or bridge of the ship. $[13,15,16,20$, 28.]

Chartholder.-A device for holding charts stretched out and flat on the chart-table at sea. [28.]

Chart Magniffer.-See Magniffer. $[2,13,15,16,20,21,27,28$.]

Chartometer.-An instrument for measuring distances on charts and maps. $[13,15,21,27$.

Chart Protractor.-See Protractor. $[13,15,16,21,28$. $]$

Chart Table.-A frame or table with a transparent top in which the chart can be used on a ship's bridge. See Chart Frame. $[13,15,16,28$.

Chart Weights.-Lead weights, generally cased in leather, for holding down a chart. $[2,13,15,17,21,27,28$.

Chattock Tilting Micromanometer.-See Micromanometer. [4.]

Cheilvangroscope.-An apparatus to enable the circulation of the blood to be examined.

Chemical Balance.-See Balance. $[2,5,17,20$. $]$

Chemical Thermometer.-See Thermometer. $[2,5,6,15,16,17$, $20,21,25$.]

Chemists' Slide-Rule.-See Slide-Rule. [13, 24.]

Chiragon.-See Cecograph.

Chlorometer.-An instrument to test the decolourising or bleaching powers of samples of chloride of lime. [25.]

Chondrometer.-A steelyard or balance for weighing grain. [5, 17, 21.]

Chorograph.-An instrument for constructing triangles in marine surveying, etc. [15.]

Chromascope.-An instrument for showing the optical effects of combining colours. [26.]

Chromatometer.-A scale for measuring the degrees of colour.

Chromatoscope.-A reflecting telescope, part of which is made to rotate eccentrically so as to produce a ring like the image of a star, instead of a point. Used in studying the scintillations of the stars.

Chromatrope.-An instrument for exhibiting certain chromatic effects of light (depending upon the persistence of vision and mixture of colours) by means of rapidly rotating discs variously coloured. $[20,26$. $]$

Chromometer, Wilson's.-An instrument for determining the colour of petroleum.

Chromoskop (Ives's). - An instrument for viewing simultaneously positives in three colours, producing a single positive in natural colours.

Chronograph.-A time-indicator. Astronomical intervals are noted by pressing a key, which makes one dot or puncture on a travelling strip of paper at the commencement and another at the end of the observation. The term is also used to designate a form of stop-watch for measuring with 
precision intervals of time, usually up to 30 minutes. See also Electro-Chronograph. $[4,11,13,15,16,17,21,24,25$, $26,27$.

Chronometer.-A specially accurate timepiece for use in nautical and astronomical observations. $[13,15,16,17,20,21,24$, $25,27,28$.]

Chronopher.-An instrument for signalling by electricity the correct time to distant places.

Chronoscope.-An instrument for measuring minute intervals of time, used in determining the velocity of projectiles, the duration of short-lived luminous phenomena, etc. $[17,27$, 28.]

Chronothermometer.-Consists of a circular thermometer with a watch movement in the centre, with a hand which revolves over the thermometer scale at the rate of $20^{\circ} \mathrm{Fah}$. in $1_{5}$ minutes. Used for testing petroleum by measuring the heating power of a flame. $[13,15$.

Chyometer.-An instrument for measuring liquids. It consists of a piston moving in a tube in which is contained the liquid - the quantity expelled being indicated by graduations upon the piston rod.

Cinematograph.-An apparatus for rapidly projecting on a screen a series of consecutive instantaneous photographs, in such a manner as to give the impression of a moving object. $[2,3,8,20$.

Circuit-Breakers.-See Mine-Explosion Apparatus. [4.]

Circular Micrometer.-An annular form of the micrometer, first suggested by Boscovitch in $174^{\circ}$, and afterwards revived by Olbers in 1798 . $[8,11$.

Circumferentor.-A surveying instrument for measuring horizontal and sometimes vertical angles. $[2,13,15,17,18,20$, $21,24,25,26,27$.

Cistula.-See Catoptric Cistula.

Claude Lorraine Glass.-A black glass convex mirror, used for sketching, to give a monochromatic view of scenery. $[2,3$, 17.]

Clepsydra.-A kind of water-clock or an hour-glass serving to measure time by the fall of a certain quantity of water or other substance, commonly out of one vessel into another.

Clift Air-Speed Indicator.-A speed instrument for aeroplanes.

Clift Petrol-Tank Gauge.-See Petrol-Tank Gauge.

Climatometer.-An instrument for indicating the fluctuations of temperature with special reference to its perception by the human body. [13.]

Climb Meter.-An instrument to indicate and measure the rate of the rising of an aeroplane. $[15,17,21$.

Clinical Thermometer.-See Thermometer. $[2,5,6,9,13,15$, $16,17,20,21,24,25,26,27,28$.]

Clinograph. - An adjustable set-square, useful when a number of lines are required at an angle to the base line other than 
the angles found on an ordinary set-square. $[2,5,13,15$, $17,21,24,27$.]

Clinometer.-Any instrument for measuring angles of inclination by reference to a plumb line, spirit level, or other means of obtaining a true vertical or horizontal line. See also Level. $[2,3,5,6,10,13,15,16,17,18,20,21,24,25,26$, 27.]

Clinometer, Abney's.-A form of reflecting level, for the measurement of angles of inclination, in which the level is placed above the sighting tube upon an axis which forms the centre of a divided arc. $[2,5,9,10,13,15,17,18,20,24,25,26$, 27.]

Clinometer, Admiralty.-A clinometer for indicating the heel of the ship. $[1,3,13,15,16,17,18,21,23,28$. $]$

Clinometer Compass.-An instrument consisting of a clinometer sight attached to a light compass.

Clinometer, De Lisle Reflecting.-A modified form of Burel level (q.v.), with which inclines upwards or downwards can be measured. $[2,6,13,17,21,24,25,27$.

Clinometer, Evelyn Bubble.-A bubble form of clinometer for indicating the heel of a ship.

Clinometer, Lateral.-To indicate the lateral heel or dip of an aeroplane, etc. $[13,16,17,21$.

Clinometer, Longitudinal.--To indicate the inclination or dip of an aeroplane, etc., fore and aft. $[13,15,16,17,21,27$.

Clinometer, Mallock's.-An instrument for measuring the rolling angle of a ship.

Clinometer Rule.-A clinometer in the form of a stout $\mathbf{I} 2$ in., one fold, boxwood rule, used by civil engineers. [15.]

Clinometer, Watkin.-A pendulum clinometer in a round case carrying a light rim graduated on the interior and having the reading magnified in a concave reflector. Used in surveying. $[13,21,25,26,27$.

Cloth Oil-Tester, Mackey's.-An apparatus for testing the liability of oils in cloth mills to develope heat spontaneously. $[5,13$.

Cloth Counting Glasses.-See Linen Provers. $[2,5,13,15,17,20$, $22,24,25,26$.]

Cloud Mirror.-A flat circular black glass reflector marked with the points of the compass, fixed on levelling screws, used for charting the position of clouds. $[13,15,17,21$. $]$

Coal Calorimeter. - See Calorimeter. $[4,15,17$.

Coal Dust Manometer.-See Manometer. [4.]

Coal Pastille Press.-For making coal pastilles for testing in calorimeters. [4.]

Coal Tar Still Thermometer.-See Thermometer. $\quad[5,6,15,16,17$, 21.]

Coastguard Telescope.-See Telescope. $[2,3,5,8,9,13,15,16$, $17,18,20,23,24,25,26,27$.] 
Cobalt-Hygrometer.-A hygrometer made by dipping unsized paper into a solution of cobaltous chloride, sodium chloride, and a little gum arabic. It is slightly hygroscopic. [13.]

Cobweb Micrometer.-See Micrometer. $[2,3,17,21,22,26,27$.

Coddington Lens.-See Lens. $[2,3,8,9,13,15,17,20,21,22$, $21,26,27$.]

Coddington Magnifier.-See Magnifying Glass. $[2,3,5,9,13$, $15,17,20,21,22,24,25,26,27$.]

Cœlostat.-A mirror made to move automatically to direct a beam of light from a star in a constant direction. $[11,14$.

Coffin Averaging Planimeter.-See Planimeter. $[10,13,15,16$, $21,24,28$.

Coleman Archbutt's Viscometer.-See Viscometer. [13.]

Colliascope.-A model for teaching the practice of the rule of the road at sea. $[13,15$.

Colliery Barometer.-A mercurial barometer with a special scale for use in coal mines. See Barometer. $[5,6,13,16,17$, $21,24,27$.

Collimator.-A telescope arranged to transmit a parallel beam of light and used to determine errors of collimation. $[1,2$, $3,8,9,13,17,18,20,21,22,24,25,26,27$.]

Collimator, Floating.-A form of artificial horizon.

Colliograph.-A complete set of small models of the various types of vessels and craft, together with a plan board and scale and other details, as used in the Admiralty Court. [15.]

Colorimeter.-An instrument for measuring depth of colour, especially of a liquid, by comparison with a standard. See also Tintometer. $[17,21$.

Colorimeter, Stammer's. - A colorimeter for use with mineral oils.

Colorimeter, Stokes's.-See Colorimeter. [21.]

Colorimeter, Walpole's.-An instrument for the titration of coloured fluids.

Colour Perception Apparatus.-An instrument for testing the colour perception of the eye.

Colour Perception Lamp.-A special form of lamp devised by Dr. Edridge Green for the detection of colour-blindness. [2.]

Colour Screen.-See Filter.

Colour Test (Edridge-Green).-A test for the detection of colourblindness. $[2,9$.

Combustion Recorder.-An apparatus for analysing boiler-flue gas and recording the percentage on a chait. $[8,17$.

Comet-Finder.-A telescope of low power, having a large field of view, used for finding comets. $[2,3,11,17,27$.

Communicator.-(I) An instrumental device for transmitting to a secondary dial or register the reading of a primary instrument. It may be electrical or mechanical. (2) An electrical or mechanical device for communicating orders on an aeroplane, motor-car, etc. 
Communicator, Electrical.-An electrical type of communicator. Communicator, Mechanical.-A mechanical type of communicator.

Commutator.-An instrument which periodically interrupts an electric current. Also a key enabling the direction of an electric current in a circuit to be readily reversed. [16, 19.]

Comparator.-An instrument for accurately measuring lengths or checking scales by comparison with a standard scale. $[3,4,21$. $]$

Comparator, Co-ordinate.-An apparatus for the analysis of physiological and other records, by measurements made with a micrometer microscope. Particularly suitable for measuring photographic records on either plates or paper. [4.]

Compass.-An instrument for indicating directions upon the earth's surface by means of a magnetic bar or needle turning freely upon a pivot, and pointing in a northerly and southerly direction. The needle may move over a fixed dial or have the dial attached to, and moving with, it. $[2,5,6,9,13,15,16,17,18,20,21,24,25,27,28$. $]$

Compass, Aviation.-A form of compass designed for use on aeroplanes. $[9,13,15,16,17,20,21,27$.

Compass, Azimuth. - A compass with a card divided into degrees and having vertical sights. $[13,15,16,17,20,21,25,27$, 28.]

Compass, Burnet Bearing Clamping.-A liquid azimuth compass, for use in boats and small yachts, having a device for clamping the card the moment the bearing is observed. $[15,28$.

Compass, Charm.-A small, magnetic compass, mounted in various designs, in gold or silver, for attachment to the watch chain. $[2,3,5,9,13,15,16,17,20,21,27$.

Compass, Creagh-Osborne.-A liquid compass designed for military, naval and aeronautical uses. $[13,15,16,20,26$, 27.]

Compass, Jumper Stay.-A compass suspended from the jumper stay of a ship, with an arrangement for locking the card and then lowering it to the deck. The compass being suspended at a height above the vessel's deck, is not affected by the magnetism of the ship. $[13,28$.

Compass, Kelvin.-A short needle, light card form of compass.

Compass, Lifeboat Pattern.-A boat compass for use on lifeboats, usually to B.O.T. specification. $[13,15,16,28$.

Compass, Liquid.-A compass having the card floating in liquid so as to damp the oscillations. $[13,15,16,28$.

Compass, Marching. - A pocket magnetic compass having a movable indicator which can be set to the angle between the North and South magnetic meridian and the marching direction. $[2,5,6,10,13,15,16,17,20,21,24,25,26,27$.

Compass, Overhead Pattern.-A ship's compass arranged for observation from below the card. $[13,15,16,28$. 
Compass, Paget.-A form of compass invented by George Augustus Paget, the main features being a light card with short needles. [15.]

Compass, Prismatic.-A compass provided with a prism for viewing the compass card and a distant object at the same time. $[2,5,9,10,13,15,16,17,18,20,21,24,25,26,27$. $]$

Compass, Projector Pattern.-A ship's compass arranged for projecting an image of the card to a convenient place, and usually producing a magnified image.

Compass, Spirit.-A liquid compass (q.v.) in which the liquid is a dense spirit. $[13,15,16,28$. $]$

Compass, Vertical Card.-A ship's compass fitted with prism or mirrors so arranged as to produce an image of the compass card in a vertical plane. The prism, or mirrors, are sometimes designed to produce a magnified image. $[13,15,21$.

Compass-Card.-The card of a compass on which the cardinal points are indicated and degrees marked. It is usually attached to the needle and is read with reference to an index mark, called the lubber line. $[13,15,16,17,21,24$, 27,28 .]

Compass-Card, Coronet.-A special form of light, short needle compass-card, showing the divisions in a semi-vertical position. [28.]

Compass-Needle.-The magnetised or polarised bar which, when freely suspended or attached to a disc having a central cap working on a pivot, assumes a magnetic North and South position. $[9,13,15,16,17,18,19,21,24,25,27,28$.

Compasses.-A drawing instrument consisting essentially of two limbs, rotating on the same axis, one terminating in a point and the other in a pen or pencil, and used for describing circles and arcs. $[2,5,6,9,13,15,16,17,20$, $21,24,25,26,27,28$.]

Compasses, Bullet.-Compasses with a bullet at the end of one leg to set in a hole. $[15,21$.

Compasses, Club. - Of the same type as Bullet Compasses.

Compasses, Cone.- Of the same type as Bullet Compasses.

Compasses, Elliptic.-Compasses with attachment for drawing ellipses. $[2,6,13,15,17,20,21,27$.

Compasses, Pillar.-Folding pocket compasses with a detachable bow and pencil. $[2,5,6,13,15,16,17,21,24,27$.

Compasses, Proportional.-Compasses used in the enlargement or reduction of plans. The instrument has two pairs of points working on an adjustable centre, the distance between one pair of points is always in the same proportion to that between the other pair. $[2,5,6,13,15,16,17,20,21,24$, $25,26,27$. 
Compasses, Triangular.-Drawing compasses or dividers with three legs, enabling three known positions to be accurately and quickly marked off. $[2,5,13,15,16,17,20,21,24$, $26,27,28$.]

Compasses, Vertical Drawing. $[15,21$.

Compensating Eyepiece.-See Eyepiece. [1, 2, 3, 20, 22, 26.]

Compensator.-A piece of soft iron or magnet to neutralise the effect of the iron of a ship upon the compass needle. [15, $16,28$.

Compression Extensometer.-See Extensometer. [4.]

Compressor.-A microscope fitting for holding live objects with a gentle pressure. $[2,3,20,26$. $]$

Compound Pendulum.-See Pendulum.

Computer.-A transparent sheet ruled with squares for computing areas on plans drawn to scale. $[13,15,21,24,27$.

Computing Scale. A rule with sliding index frame for computing areas on maps. $[15,21,24,25,27$.]

Concave Lens.-See Lens. $[1,2,3,8,9,10,11,13,15,17,20,26$. $]$

Concave Mirror.-See Mirror. $[1,2,3,8,10,11,13,15,17,20,26$.

Concave Plane.-A compass plane for smoothing curved surfaces.

Concentric Eyepiece.-See Eyepiece. [2, 3, 10, 22, 27.]

Conchometer.-An instrument for measuring biological shells, and the angle of their spire.

Condenser.-(I) An optical system of lenses for converging light to a point. (2) Two electrical conductors, usually of thin plates or sheets of metal, with a larger plate of non-conducting material between them, e.g., a Leyden jar. $[1,2$, $3,8,9,10,11,14,17,20,22,26$.]

Condenser, Abbe.-A non-achromatic and non-aplanatic system of lenses used to concentrate a wide-angled cone of light upon an object viewed by the miscroscope. $[2,3,9,17$, $20,22,26$.]

Condenser, Achromatic.-A system of lenses corrected for chromatic aberration used for illuminating, with a wide angle, transparent objects when viewed with the microscope. $[2,3,11,20,22,26$. $]$

Condenser, Apochromatic.-An optical condenser in which the lenses are corrected for the secondary spectrum. $[2,3,20$, 22,26 .]

Condenser, Bull's Eye.-A convex lens used for converging or rendering parallel a beam of light. $[2,3,8,9,10,17,20$, $21,22,26$.]

Condenser, Cardioid.-A dark ground illumination employing cardioid reflectors. $[2,22,26$. $]$

Condenser, Paraboloid.-A reflecting glass paraboloid for microscopic dark ground illumination in the observation of living bacteria. $[2,3,20,22$.

Condenser Thermometer.-See Thermometer. $[5,6,13,15,17$, 20, 21.] 
Conductometer.-An instrument for illustrating the comparative power of different substances for conducting heat, electricity, etc.

Confectioners' Thermometer.-See Thermometer. $[5,6,13,15$, 16, 17, 20,21.]

Constant Deviation Prism.-See Prism. [3, 10, 13, 14.]

Constant Temperature Apparatus.-Any apparatus for maintaining a constant temperature in an enclosed space. See Thermostat.

Contact Makers.-See Mine-Explosions Apparatus. Operated by the explosion and connected with the sampling bottles so as to determine the instant at which the sample of gas should be taken. [4.]

Co-ordinate Comparator.-See Comparator. [4.]

Co-ordinatograph.-An instrument for plotting points by their rectangular co-ordinates.

Copper Case Thermometers.-See Thermometer. $[13,15,16,17$, $20,21,27,28$.]

Copying Glass.-An arrangement of glass plate and reflecting mirror beneath; used in tracing drawings and plans. [20, 24,27 .]

Cordite Apparatus.-An apparatus for estimating the volatile matter in gun-cotton.

$\mathrm{CO}_{2}$ Recorder.-An instrument for determining and recording the percentage of carbon dioxide in the gases emitted by a chimney, etc. $[4,13,17$.

$\mathrm{CO}_{2}$ Recorder, Bi-Meter.-A type of $\mathrm{CO}_{2}$ recorder in which the flue gases are measured in gas meters before and after the absorption of the $\mathrm{CO}_{2}$ by lime or similar agent, the two meters being connected by a differential gearing to the mechanism driving the recording pen. [4.]

Corner Cube Prism.-A prism having three triangular surfaces at right angles to each other and one surface at equal inclination to the other three. It has the property of reflecting light incident at any angle on the large surface back along the line of incidence. $[3,6,10,13,14$. $]$

Corner Curve.-A drawing curve used by draughtsmen. $[2,15$, $20,21,24,25,27$.]

Coronet Compass-Card.-See Compass-Card. $[13,15,16,28$.

Corundum.-A hard crystal used for the pivots and caps of magnetic compasses, etc. $[8,16$. $]$

Cosmolabe. - An instrument resembling the astrolabe (q.v.), formerly used for measuring the angles between heavenly bodies.

Cosmosphere.-An apparatus for showing the position of the earth at any given time, with reference to that of the fixed stars. A hollow glass globe, upon which are depicted constellations; terrestrial sphere inside. [13.] 
Counter, Engine.-An instrument for counting the number of revolutions or strokes of an engine or machine. $[5,13,15$, $16,17,21,28$.

Course-Corrector.-An instrument of the Pelorus (q.v.) type for determining compass deviations. $[13,15,16,28$.

Course-Indicator.-A combination of straight-edge and protractor for use with sea charts. [15.]

Course-Setter.-Capt. Aamundsen's patent. An instrument designed for rapidly and accurately correcting courses, bearings, azimuths, etc.

Crack Micrometer.-See Micrometer. [4.]

Craniometer.-An instrument for measuring skulls and bones. $[2,21$. $]$

Creagh-Osborne Compass.-See Compass. $[13,15,16,20,26,27$. Creagh-Osborne Protractor.-See Protractor. $[13,15,20,26,27$. Cremometer, Chevalier's.-A graduated jar for the measurement of cream.

Crookes's Tube.-A vacuum tube of glass fitted wth electrodes for the discharge of electric current.

Crosby Indicator.-See Indicator. $[13,15,16,17$.

Cross-Head.-A brass octagon with sights on each face, used by surveyors for setting out angles. $[2,3,13,15,17,20$, $21,24,25,26,27$.]

Cross-Staff.-An ancient instrument consisting of a wooden bar with a divided scale, with a wooden cross-bar fitted to and moveable along the other, by means of which the navigator could measure the angle of altitude of the sun above the horizon. See also Fore-Staff.

Cryophorus.-An instrument used to illustrate the freezing of water by its own evaporation. [21.]

C.S.I. Air-speed Indicator.-A speed instrument for aeroplanes. See Speedometer. [21.]

Cup Anemometer.-See Anemometer. $[15,17,20,21,24,25$. Cupel-Pyrometer.-See Pyrometer. [4.]

Current-Meter.-An instrument for measuring the velocity of currents of water, consisting of a screw geared to a divided dial, or other measuring device. $[2,6,13,15,17,21,24$, $25,27.7$

Current-Regulator.-An electrical device for regulating the intensity of the current allowed to pass a given point. [16.]

Current-Slide.-A slide placed upon the stage of the microscope in which a current of fluid can be made to pass across the field of the microscope. $[3,13,26$.

Curvature of Spherical Surfaces Apparatus.-For determining the curvature of spherical surfaces. Designed by Dr. Searle, Mr. Aldis, and Mr. Dobson. $[1,3,19$.

Curve Pen.-A pen used by draughtsmen in the drawing of curves. $[2,5,6,9,13,15,17,20,21,24,27$. 
Curve-Tracer, Brearley.-A semi-automatic apparatus for the recording of curves in any experiment in which the deflections of a galvanometer vary with time. Originally designed for obtaining recalescence curves on an open scale with rectangular co-ordinates. [4.]

Curves, Elliptic.-Curves cut from a turned cone, used for drawing ellipses. $[2,6,13,15,20,21,24,27$.

Curves, Mathematical.-Pieces of wood, celluloid, etc., cut in the forms of various curves for the use of draughtsmen. $[2,5,6,9,13,15,17,20,21,24,25,26,27$.

Curvograph.-See Arcograph.

Cust's Station Pointer.-See Radiograph. $[13,15,21,25$.

Cutting Compass.-Drawing compasses, one of the legs of which is a cutter to cut washers, wads, and circular discs of paper, etc. $[13,21$.

Cyanometer.-An instrument for measuring degrees of blueness. Cyclograph.-See Arcograph.

Cyclograph, Hooke's. - An instrument invented by Dr. Hooke for producing arcs of high radii by oblique rolling contact.

Cycloidograph.-An instrument for the practical drawing of cycloids. [21.]

Cycloids.-An instrument for describing cycloidal curves. [2\%.] Cyclonometer.-An instrument for estimating the approximate direction and speed of approaching cyclones. [15.]

Cycloscope.-A machine for measuring at any moment the velocity of rotation.

Cymograph.-An instrument for taking full-size profile drawings from mouldings in brass. [21.]

Cystoscope.-A small microscope or periscope with an illuminant, for inserting in various orifices of the human body for examination of disease. $[1,3,13,22,26$.

Dairy Acidimeter.-See Acidimeter. $[8,13,17,21$.

Daniell's Hygrometer.-See Hygrometer.

Dasymeter.-An instrument for testing the density of gases. It consists of a thin glass globe, which is weighed in the gas or gases under observation, and then in an atmosphere of known density. [21.]

Davenport Air-Speed Indicator.-A speed instrument for aeroplanes.

Davis Biram Anemometer.-An improved form of the Biram anemometer.

Davis-Blih-Hedley Dial.-See Dial. [20, 21, 25.]

Davis-Lee-Bottomley Slide-Rule.-See Slide-Rule.

Davis-Lyall Air Speed Indicator.-See Miner's Dial. [21.]

Davis-Martin Wireless Slide-Rule.-See Slide-Rule. [21.]

Davis Self-Registering Water-Gauge and Clock.-An instrument for registering on a chart the water-gauge fluctuations in a coal mine. $[13,21$.

Davis.Shutter.-See Shutter. $[2,3,21,22,26$. 
Davis-Stokes Field Gunnery Slide-Rule.-See Slide-Rule. [21.]

Day and Night Telescope.-See Telescope. $[3,5,8,9,10,13,15$, $16,17,20,26,27,28$.]

Dead-beat Centre-Seconds Clock.-A clock with electric contacts and sounder to facilitate counting the number of seconds when timing experiments. $[10,13,17,19$.

Debuscope. - A modification of the kaleidoscope invented by M. Debus.

Declination Compass.-An instrument by which the magnetic declination of any place may be measured when its astronomical meridian is known.-See also Compass. $[13,15,16$, $17,20,21,25,27$.

Declinometer.-See Declination Compass. $[13,17,21,25,27$.

Deep-Sea Thermometer.-See Thermometer. $[6,13,15,17,20,21$. $]$

Deflagrator.-An instrument for producing intense heat. It was generally a form of the voltaic battery.

Deflectometer.-Askenasy's apparatus for measuring the deflection of a bridge under a passing load. [21.]

Deflector.-An instrument in use on board ship for comparing the magnetic directive force on different courses. $[13,15,16$.

Deflector, Kelvin.-An instrument used in correcting or adjusting the magnetic compass on vessels when bearings of landmarks or heavenly bodies are not available. The instrument, which was designed by Lord Kelvin, gives a measure of the directive force on the compass when the ship is on various courses. It consists of a magnet of adjustable magnetic moment, fitted for application to the compass bowl and to revolve about the compass centre, the magnetic moment of the deflector magnet being indicated empirically on the scale. [16.]

Delezenne's Circle.-An apparatus for showing induced currents produced by rotation of a coil in the earth's magnetic field.

Delineator.-A perambulator or geodetical instrument on wheels with registering devices for recording distances between points on the earth's surface. $[13,27$.

Delineator, Lenthall's. - An instrument for solving many problems in dead reckoning in navigation, without the use of books or tables. [13.]

De Lisle Reflecting Clinometer.-See Clinometer. $[2,6,13,15,17$, $21,24,25,27$.

Demi-Circle.-An instrument for measuring and indicating angles. It resembles a protractor. $[13,16,20,21$.

Dendrometer.-An instrument for determining the height and diameter of trees, $[15,17,21$.

Densimeter. - An apparatus for ascertaining the specific gravity of a liquid. $[4.13,15,17,21$.

Densimeter, Recording.-An instrument giving a continuous record of the density of a liquid, and thereby the varying strength of acid or alkaline solutions in chemical processes, etc. $[4,13,21$. $]$ 
Dentiphone.-An instrument which, placed against the teeth, conveys the sound to the auditory nerve.

Depth Gauge.-Any form of instrument for the measurement of the depths indicated by sounding tubes in sea soundings. $[13,15,16,21,28$. $]$

Depth Recorder.-A pneumatic instrument for the measuring and recording of vertical depths in sea soundings. $[13,15,16,28$.]

Dermopathic Instrument.-An acicular instrument used to introduce a vesicatory beneath the skin.

Detector Galvanometer.-See Galvanometer. $[10,16$.

Deviaplane.-Enright's patent. An apparatus by which the effect of sub-permanent magnetism and of magnetism induced in iron beams and pillars can be indicated. [13.]

Deviascope.-A large model used at Board of Trade examination rooms and in navigation schools for illustrating and teaching the deviation of the compass in iron ships. $[13,15$.

Deville's Theodolite. -See Theodolite. $[13,20,21,25,2 \%$.]

Dewar Flask.-A flask for keeping cold or hot liquids or solids for long periods of time. It consists of a double-walled glass vessel, the space between the two walls being exhausted of air and the inner surface of the vacuum space being silvered.

Diagometer.-An electroscope, in which a dry pile is employed to measure the amount of electricity transmitted by various bodies, or to determine their conducting powers.

Diagonal Eyepiece.-See Eyepiece. $[2,3,6,9,10,11,13,15,17$, $18,20,24,25$.]

Diagonal Scale.-A mathematical scale, consisting of a set of parallel lines drawn on a ruler, with other lines crossing them at equal angles and at equal distances from each other. $[2,5,6,15,16,17,20,21,24,25,27$.

Diagraph.-A drawing instrument combining protractor and scale. $[13,15,20,2 \%$.]

Dial.-Generally the scale or recording part of many instruments, more particularly a sun-dial $(q . v$.$) . [9,13,15,16,17$, $18,20,21,24,25,27$.]

Dial, Azimuth.-A dial whose style is at right angles to the horizon. $[13,15,16,17,20,21,24,27,28$. $]$

Dial, Hadley.-An old form of Surveyor's dial. [13, 18, 21, 27.]

Dial, Mining.-A special form of magnetic compass, with sights, used in underground surveying. $[2,5,6,13,15,16,17,18$, $20,21,24,25,26,27$.]

Dial, Refracting.-A dial in which the reading of the hour is viewed through some transparent, refracting fluid. [13.]

Dial Sight.-An instrument with a divided circle for reading azimuth angles; usually supplied as a panoramic periscope used for indirect firing with artillery. $[3,9,11,13,15,16$, $18,20,21,27$.

Dial"Thermometer.-See Thermometer.

Dialling-Globe.-An instrument for drawing all sorts of sun. dials. 
Dlamond-Gauge.-A gauge employed by jewellers in estimating the sizes of small diamonds.

Diaphanometer.-(I) An instrument for measuring the transparency of the air. (2) For determining the degree of turbidity and depth of colour of solutions.

Diaphanoscope.-An instrument for the investigation of grass seeds, barley and wheat for farinaceousness and hardness.

Diaphanoscope.-A dark box for exhibiting transparent pictures, with or without a lens.

Diaphonometer.-An instrument used in testing spirits by determining their transparency.

Diaphote.-An instrument designed for transmitting pictures by telegraph.

Diaphragm.-(I) A plate with an opening, placed in an instrument to exclude light or heat. Lines or webs may be placed across the opening for the determination of definite positions. (2) A thin septum for separating two spaces or bodies. See also Iris-Diaphragm. $[3,8,17,20,26$.

Diaphragm-Plate.-See Diaphragm. [20.]

Diathermometer.-An instrument for examining the thermal resistance or the heat-conducting power of objects.

Diatom-Prism.-See Prism. $[2,3$.

Dibdin's Hand Photometer.-See Photometer.

Dichroioscope.-An instrument to exhibit the two complementary colours of polarised light. The quality called the dichroism of crystals consists in transmitting different colours when viewed in different directions. Used for testing precious stones. $[2,3,14,17,20,21,22,26$.

Dietherescope.-An instrument for geodesy and the teaching of optics.

Differential Draught-Gauge.-See Draught-Gauge. $[6,16,17$.

Differential Manometer.-See Manometer. [6, 17.]

Differential Thermometer.-See Thermometer. $[13,15,16,17$, $20,21,25$.]

Diffraction Grating.-A series of fine parallel lines ruled with great regularity on glass or metal for producing a spectrum by the interference of light. See also Lummer-Gehrcke Parallel Plate. $[2,3,10,14,20,26$.

Diffraction Grating, Thorp.-A cast in celluloid of a ruled diffraction grating $(q . v.) . \quad[3,17$.

Diffusionometer.-An instrument to ascertain the rate at which diffusion of gases takes place.

Diffusion Tube.-An instrument for determining the rate of diffusion of different gases. It consists of a graduated tube closed at one end by plaster of Paris, a substance which, when moderately dry, possesses the required porosity.

Dilatometer.-An instrument for measuring the dilation or expansion of a substance, especially of a fluid. [25.]

Dines's Anemometer.-Sec Anemometer. $[15,17,21,25$.

Dines's Meteorograph.-See Meteorograph. $[6,13,15,17,20,21$. 
Dines's Self-Recording Mercurial Barometer.-See Barometer. $[2,13,15,17,20,21,26$.

Diopter. - An old form of theodolite (q.o.). [27.]

Dioptric Light.-A plan of lighting used in lighthouses in which the optical system is one of refraction instead of reflection. [7.]

Dioptric Micrometer.-See. Micrometer. [25.]

Dioptric Telescope.-See Telescope. $[1,3,11,13,17,20$.

Dip Circle.-An instrument for determining the magnetic dip at any spot on the earth's surface. $[2,4,6,13,15,17,19$, $21,25,27$.]

Dip Circle, Fox.- $[2,17$.

Dip Compass.-A magnetic needle suspended between centres so as to move readily in a vertical plane. $[2,6,13,15,16$, $17,21,24,25,27$.]

Dip Inductor.-An instrument for determining the direction of a magnetic field, depending on the principle that when a coil of wire is rotated in the field using a suitable commutator the resulting E.M.F. only vanishes when the axis of rotation is parallel to the direction of the magnetic field. [4.]

Dip Needle.-A magnetic needle, suspended at its centre of gravity and moving in a vertical plane so as to indicate on a graduated circle the magnetic dip or inclination. $[2,6$, $13,15,16,17,18,21,24,27,28$.]

Dip Sector.-An astronomical reflecting instrument. [27.]

Dipleidoscope.-An instrument for determining the apparent time of noon. It consists of two mirrors and a plane glass disposed in the form of a prism, so that by the reflection of the sun's rays from their surfaces, two images are presented to the eye, moving in opposite directions and coinciding at the instant when the sun's centre is on the meridian. $[2,26$. $]$

Dipping Refractometer.-See Refractometer. [14, 26.]

Director.-A form of military theodolite $(q . v$.$) for directing$ gunfire. $[3,8,13,18,20,21,24,27$.

Direct-Vision Liquid Prism.-See Prism. $[2,3,14,20,26$. $]$

Direct-Vision Spectroscope.-See Spectroscope.

Discharging Rod.-An instrument to discharge a charged electrical jar or battery. It has a glass handle and a pair of hinged rods with balls on the ends, which are brought into connection respectively with the two surfaces or poles of the jar or battery. [26.]

Dissecting Microscope.-A microscope with rack adjustment for focus, spring clips to hold the object-slide, movable arm for carrying the lenses, usually of low magnification, for examining anatomical and botanical objects. $[2,3,5,9$, $17,20,21,22,26$.]

Distance-Finder.-A rangefinder. $[3,13,15,17,20,21,27,28$.]

Distance-Finder, Alidade (Reeves's). - A form of alidade provided with two small telescopes which can be attached to the ends of the rule and used for range-finding. [28.] 
Distance-Finder, Smith's.-An instrument for calculating the - offshore distance at sea. [15.]

Distance-Finder, Stewart's. - An optical instrument, consisting of a moveable prism plate, a small sighting telescope, and a xylonite diagram plate; used for ascertaining the distance

of an object and for keeping a ship on station with another. $[8,13.15$.

Distance-Meter.-A rangefinder or telemeter. $[2,13,15,17,20$, $21,27$.

Distance-Recorder, Forbes's.-A form of ship log.

Dittmar's Gas Analysis Apparatus.-See Gas Analysis Apparatus. [17.]

Divider.-An instrument for dividing lines, describing circles, etc. A form of compass. $[2,5,6,9,13,15,16,17,20,21$, $24,26,27,28$.]

Divider, Hair.-A pair of dividers, one of the legs of which is provided with a set-screw and spring, admitting of a very fine adjustment between the two points. $[2,15,17,21,24$.]

Dividing Engine.-A machine for accurately dividing the linear or circular scales of surveying, astronomical and other instruments. $[4,6,10,13,17,18,19,21,27$.

Dividing Machine.-See Dividing Engine. $[4,10,13,15,17,18$, $19,21,24,27$.]

Dolezalek Quadrant Electrometer.-See Electrometer. [4, 19.]

Dosimeter.-A drop meter for measuring a certain number of drops.

Dotting Pen.-A drawing pen having a toothed wheel inserted between the nibs for producing a dotted or spaced line, for the use of draughtsmen. $[2,5,13,15,17,20,21,24,26,27$.]

Double-Coil Galvanometer.-See Galvanometer, Thomson. [4, 16.]

Double-Image Prism.-See Prism. [2, 3, 13, 20, 22.]

Double Sextant.-See Sextant. $[2,10,13,15,20,21,26,27,28$. Doublet Magniffer.-A magnifying glass $(q . v$.$) composed of$ two lenses, sometimes cemented together and sometimes separated. $[1,2,3,10,17,20,21,22,26$. $]$.

Dough-Testing Thermometers.-See Thermometer. $[5,6,13,15$, 20$.

Draught-Gauge.-A manometric or other pressure gauge for the measurement of pressures slightly above or below atmospheric, as chimney draught, etc. See also Manometer and Pitot Tube. $[4,5,16,17$.]

Draught-Gauge, Differential.-An instrument for measuring the varying draught in steam boilers, coke oven plants, etc. $[6,16,17$.

Drawing-Board.-A rectangular board of pine wood, specially framed to prevent warping, and having a true surface and edges for the use of draughtsmen. $[2,5,6,13,15,17,20$, $21,24,26,27$.]

Drawing-Eyepiece.-See Eyepiece. [2, 3, 10, 17, 20, 22, 26.] 
Drawing Pens.-For the use of draughtsmen. $[2,5,6,9,13,15$, $17,20,21,24,25,26,27$.]

Drawing Pins.-For the use of draughtsmen. $[2,5,6,9,13,15$, $17,20,21,24,25,26,27$.

Drawing Scales.-Mathematically divided scales for the use of draughtsmen. $[2,5,6,9,13,15,17,20,21,24,25,26,27$.

Drawing Table.-A mounted drawing board and stand for the use of draughtsmen. $[2,5,6,9,13,15,17,20,21,24,25$, 27.]

Dredge-Steward Omni-Telemeter.-A form of portable telemeter (q.v.) invented by the late Mr. W. Dredge. [13.]

Drop Arrow.-A special form of chain arrow for surveying on hilly ground. $[2,6,13,15,16,17,21,24,27$.

Drop Shutter. -See Shutter. $[3,20,26$.

Drosometer.-An instrument for measuring the quantity of dew on the surface of a body in the open air. [13.]

Dry Gauge.-A gas pressure gauge which contains no liquid. [4. 17.]

Ductilemeter.-An instrument for accurately determining the ductility of metals.

Duddell Thermogalvanometer.-See Thermogalvanometer.

Duddell Thermo-Ammeter.-See Thermo-Ammeter. [4.]

Duddell Oscillograph.-See Oscillograph. [4.]

Dumb Plate or Dial.-See Pelorus. $[13,15,16$.

Dumpy Level.-See Level. $[2,5,9,10,13,15,16,17,20,21,24$, $25,26,27$.

Dunbar-Scott Auxiliary Top and Side Telescope.-An attachment to the theodolite for plumbing or transferring bearings down vertical or inclined shafts, or for taking any steep sights which cannot be read by the main telescope. $[2,5,6$, $9,10,13,15,16,17,20,21,24,25,26,27$.]

Duplex Gauge.-See Gauge.

Duplex Standard Test-Gauge.-See Test-Gauge. $[5,13,15,17,28$.

Dust-Counter, Aitken's.-An instrument for determining the amount of dust in any atmosphere. It operates by the dust particles acting as nuclei for condensation.

Dynactinometer.-An instrument for measuring the intensity of the photogenic (light-producing) rays and computing the power of object-glasses.

Dynameter.-An instrument for determining the magnifying power of telescopes. It usually consists of a micrometer applied to the eye end of a telescope for measuring accurately the diameter of the emergent pencil of light. $[2,3$, $17,21,25,26$.]

Dynamograph. - A recording dynamometer.

Dynamometer.-An apparatus for the measurement of force, especially muscular effort of men or animals, or the force exerted by a motor, or that required to operate machinery. 
Dynamometer Car Equipment.-A special set of instruments designed and arranged for use in the dynamometer car to record the various quantities required in testing speed and work on a railway train whilst in motion. [4.]

Dynamometer, Thrust and Torque. - A dynamometer for measuring the thrust and torque of shafts of aeroplane propellers. $[4,16$.

Ear-Trumpet.-An instrument designed for the collection and conduction of sound-waves; for the use of the deaf.

Ebuliscope.-An instrument for observing the boiling point of liquids, especially for determining the alcoholic strength of a mixture by the temperature at which it boils.

Eccentrolineads.- An instrument for drawing eccentric lines, arms of wheels, etc. $[6,21,27$.

Echelon Grating.-A grating for the production of spectra, composed of a flight of steps of plane-parallel glass plates of equal thickness placed in echelon. $[10,14,26$.

Echometer.-A graduated scale for measuring the duration of sounds and determining their different values and the relation of their intcrvals.

Echoscope.-An instrument for intensifying sounds produced by percussion of the thorax.

Eclipsareon.--An old instrument for showing the phenomena of eclipses ; as to their time, quantity, duration, progress. [20.]

Economiser Thermometer.-See Thermometer. $[5,6,13,16,21$. Edgeworth's Stadiometer.-See Stadiometer. [13.]

Edney's Air-Pressure Gauge.-See Gauge. [5.]

Ehrlich Eyepiece.-See Eyepiece. [2, 3, 22, 26.]

Eidograph.-An instrument for copying drawings on the same or different scales; a form of pantograph (q.v.). $[2,5,13$, $15,17,20,21,21,25,27$.

Eidoscope.-An instrument on the principle of the kaleidoscope which produces an infinite variety of geometrical figures by the independent revolution of two perforated metallic discs on their axes. [13.]

Eight-Bell Clock.-A timepiece with a special striking arrangement, which, instead of striking the hour from I to I2, strikes on a gong or bell, to indicate the time according to the ship's watches as kept at sea, striking consecutively from $I$ to 8 in every 4 hours. Some are also made to strike from $I$ to 8 , then $I$ to 4 , twice over consecutively, to indicate the dog watches, and $I$ to 8 again. $[13,15,16,17,28$.

Eikonometer (Wright's).-An optical apparatus for determining the magnifying power of a microscope or for the measurement of microscopic objects. The image is brought to a focus on a micrometer scale which is examined by a magnifier. [3, $22,26$.

Einthoven String Galvanometer,-See Galvanometęr. 
Elacometer.-An apparatus for determining the amount of oil contained in any substance, or for ascertaining the degree of purity of oil.

Elatrometer.-An instrument for measuring the degree of rarefaction of air contained in the receiver of an air-pump.

Electric Alarm.-A form of electric bell or other sounder sometimes used in connection with a thermostat, for giving an alarm when the temperature rises to a point at which the instrument recording the temperature completes the circuit. $[4,6,16,21$.

Electric Balance.-An instrument used for determining the value of electrical balance by employing the force between neighbouring coils through which the current flows. $[16,19$.

Electric Battery.-A series of voltaic cells or of Leyden jars connected in series or in parallel to yield an electric current.

Electric Clock.-A dial with hands and gong-train impelled by recurrent impulses from an electromagnet. $[10,16,17$.

Electric Furnace, Lessing's. - An electric furnace for the determination of the coking properties of coal.

Electric Signal Timing Clock.-Designed to give an automatic electric bell signal for timing observations in laboratory and other work. $[10,18$.

Flectric Slide-Rule.-A special form for electric calculations. [15.] Electric Thermostat.-See Thermostat. $[4,13$.

Electrical Distance-Pyrometer.-See Pyrometer. $[6,13,16$.

Electrical Distance Thermometer.-See Thermometer. $[4,6,13$, 16.]

Flectrical Locomotive Pyrometer.-See Pyrometer. $[4,13,16$.

Electro-Calorimeter.-See Calorimeter. [19.]

Electro-Cardiograph.-An instrument used in the study of heart affections, enabling the records to be obtained of the minute electric currents produced by the action of the heart, by means of a string galvanometer (q.v.) and photographic recording apparatus. [21.]

Electro-Chronograph.-An instrument for recording time and events in the instant and order of their occurrence, as in the notation of transits in observatories. $[4,13,15,16,17$, $21,24,25,27,28$.]

Electroergometer.-An instrument for measuring the work done in an electric circuit or part thereof.

Electro-Magnet.-See Magnet.

Electrometer.-An instrument for measuring differences of electrical potential. $[4,16,19$.

Electrometer, Balance.-An electrometer in which the electrostatic attraction between two plates is measured by means of a simple balance arm. [16.]

Electrometer, Capillary, Lippmann's.-An electrometer in which electric potential differences are measured by variations in the surface tension of a liquid, usually mercury, contained in a capillary tube. 
Electrometer, Dolezalek Quadrant.-An electrometer in which a light needle or vane, usually of aluminium, is suspended, when in use, in the geometrical centre of quadrant shaped metal plates. Opposite pairs of quadrants are connected and charged to the same potential, and the deflections of the " needle" are observed by means of a reflecting mirror. $[4,19$.

Electrometer, Laby String.-An electrometer in which the moving system is a silvered glass or quartz fibre, stretched lightly between and parallel to two metal plates charged to different potentials. [4.]

Electrometer, Thomson's Quadrant.-A quadrant electrometer of similar type to the Dolezalek electrometer (q.v.). [16, 21.]

Electrometer, Universal Portable.-A type of gold-leaf electrometer designed by Mr. C. T. R. Wilson, in which the goldleaf hangs within an inner case which is maintained at a suitable potential by means of a quartz Leyden jar. The instrument will measure very small as well as higher potentials. [4.]

Electrometer, Wilson-Kaye.-A sensitive electrometer in which a gold leaf is attracted towards a charged plate, and the resulting deflection of the leaf, which is observed by means of a microscope, gives a measure of the potential to which the leaf has been charged. [4.]

Electropeter.-An instrument used to change the direction of electric currents; a commutator.

Electrophone.-An instrument for producing sound by electric currents of high tension. By means of twin receivers placed to the ears operatic performances, etc., at a distance may be heard.

Electrophorus.-An instrument for exciting electricity and repeating the charge indefinitely by induction. It consists of a flat cake of resin, shellac, or ebonite upon which is placed an insulated plate of metal. [19.]

Electrophotometer.-An instrument for measuring the intensity of light by means of electricity. See also Photometer.

Electropyrometer.-An instrument for measuring high temperatures by means of electrical effects such as change of resistance or thermoelectric effects. See Pyrometer. [1.]

Flectroscope. - An instrument for demonstrating the sign and to some extent the magnitude of an electric charge. [13, $19,26$.

Flectro Slide-Rule.-See Slide-Rule. [15.]

Elliott Air-Speed Indicator.-A speed instrument for aeroplanes. Ellipse.-A device for drawing the figure of an ellipse. [15, 17, $20,27$.

Ellipsograph.-An instrument for drawing ellipses. $[6,20,21$.

Elliptic Compasses.-See Compasses. $[2,6,13,17,20,21,27$.

Flliptic Curves.-See Curves. [2, 6, 13, 15, 20, 21, 24, 27.]

Elliptograph.-See EHlipsograph. [21.] 
Endless Tangent Screw.-See Screw.

Endoscope.-An instrument for examining the interior of the rectum.

Endosmometer.-An instrument to measure the rapidity of the passage of a less dense fluid through a membrane or porous septum which separates it from a denser fluid.

Engine Counter.-See Counter. $[5,13,15,16,17,21,28$.]

Engine Indicator.-See Indicator.

Engine Power Computer, Pickworth's.-A special slide-rule, devised by Mr. Pickworth, for calculating the power, dimensions, and mechanical efficiency of an engine. [15, 21, 24.]

Engine Telegraph.-A mechanical instrument used on all steamships for transmitting and acknowledging the receipt of orders from the bridge to the engine room.

Engineer's Scales.-Graduated scales for the use of engineering draughtsmen. $[5,13,15,17,20,21,24,25,26,27,28$.

Engiscope.-A reflecting microscope in which the image is viewed at a side aperture in the tube in a manner similar to the Newtonian telescope.

Engler's Viscometer.-See Viscometer.

Enormatrope.-An optical toy: a card on which confused or imperfect figures are drawn, but which form to the eye regular figures when the card is rapidly rotated. See Thaumatrope.

Epidiascope or Episcope.-A universal microscopic projection apparatus for illustrating lectures and for illuminating and projecting the image of opaque objects upon a screen. $[2$, $3,20$.

Equatorial Telescope.-See Telescope. $[2,3,6,8,9,11,13,15$, $17,18,20,21,25,26,27$.]

Erecting Eyepiece.-See Eyepiece. $[1,2,3,8,9,10,11,13$, $15,16,17,18,20,21,22,23,24,27$.]

Erecting Prism.-See Prism.

Erector.-An attachment to a microscope, telescope, or other optical instrument, for making the image erect, instead of inverted. $[2,3,8,9,10,11,17,18,20,21,22,26,27$.

Ergograph.-A physiological, experimental apparatus for studying the process of tatigue in the living subject.

Erinometer.-An instrument for measuring the diameter of minute particles of fibres from the size of the coloured rings produced by the diffraction of the light in which the objects are viewed.

Esthermoscope.-An instrument to express the climatic influences

which tend to affect the normal temperature of the body.

Esthesiometer.-An instrument to ascertain the tactile sensibility of the human body.

Etalon Grating. $-A^{5}$ pair of parallel glass plates set with an interval between them to produce by the interference of light a great dispersion. A form of spectrum grating. $[10,14$. 
Endiometer.-A graduated glass tube, fitted with platinum electrodes, used in analysis of explosive gas mixtures.

Evaporimeter or Evaporometer.-An instrument for ascertaining the quantity of a liquid evaporated in a given time. An atmometer. $[6,13,17,18$.. $]$

Evaporimeter, Piche's. - Consists of a graduated glass tube which is filled with the liquid and closed by a piece of filter or blotting paper.

Evaporimeter, Pickering's.-Consists of a copper reservoir and a linen evaporating surface $50 \mathrm{sq} . \mathrm{cm}$. in area. The volume of liquid evaporated is measured by a graduated glass tube.

Evelyn Bubble Clinometer.-See Clinometer. [13, 15.]

Everest Theodolite.-See Theodolite. $[2,13,20,21,25,26,27$. Evershed Spectroscope.-See Spectroscope. [2, 14, 26.]

Ewing Compression Extensometer.-See Extensometer.

Ewing Extensometer.-See Extensometer. [4.]

Ewing's Apparatus.-An apparatus for experiments on the bending of bars and for cantilever experiments. [19.]

Extension-Measuring Apparatus.-An instrument for measuring minute extensions, deflections, and compressions by means of a multiplying optical apparatus. See also Extensometer. [19.]

Extensometer.-An instrument for measuring the extension of a body; especially for measuring the elongation of bars of iron, steel, or other metal or material subjected to a tensile force. $[3,4,8,19$.

Extensometer, Cambridge.-An extensometer in which the extension of the test piece is measured by a micrometer screw and a modified form of contact measurement. [4.]"

Extensometer, Dr. Morrow's Mirror.-An extensometer in which the extension is measured by the deflection of a beam of light reflected from a mirror connected to two parts of the test piece. $[3,20$.

Extensometer, Ewing.-An extensometer, designed by Sir J. A. Ewing, in which the extension of the test piece is measured by means of a microscope with an eyepiece micrometer. [4.]

Extensometer, Ewing Compression.-An instrument for measuring the elastic compression of short blocks; constructed on similar principles to the Ewing Extensometer. [4.]

Eyeglass.-Any form of lens for aiding and correcting vision, such as spectacles, a monocle, a pince-nez. $[2,3,9,13,14$, 17, 21.]

Eyeglasses, Frameless.-A single or double eyeglass made without a rim or frame. $[2,9,15,17,20,21$.

Eyepiece.-An eyepiece is the lens or combination of lenses, next the observer's eye, used in microscopes or telescopes, etc., to examine the image formed at the focus" of the object-glass. $[1,2,3,8,9,10,11,13,15,16,17,18,19,20,21,22,23,24$. $25,26,27$. 
Eyepiece, Diagonal.-(I) An eyepiece fitted with a prism to enable the observer to view, at right angles to the axis of the optical instrument, the object. (2) An eyepiece in which a very small portion of the sun's light is reflected from the first surface of a wedge-shaped prism, the rest being transmitted. $[2,3,6,9,10,11,13,15,17,18,20,21$, $24,25,26,27$.]

Eyepiece, Ehrlich.-A microscope eyepiece with a variable diaphragm, for estimating the number of red and white corpuscles in the blood. $[2,3,22,26$.]

Eyepiece, Erecting.-The form of eyepiece used in telescopes and microscopes for giving an upright image of the object observed. $[1,2,3,8,9,10,11,13,15,16,17,18.21,22,23$, $24,27$.

Eyepiece, Huyghenian.-A negative eyepiece, designed by Huyghens, for a microscope or telescope. It consists of two plano-convex lenses separated by a considerable space, with both curves turned away from the eye and towards the incidental light. The focal lengths of the field and eye lenses are in the ratio $3: 1$, while the distance between them is numerically equal to twice the focal length of the eyelens. $[2,3,17,18,20,21,22,23,26,27$. $]$

Eyepiece Indicator.-A pointer mounted in a microscope eyepiece. $[2,3,20,22,26$. $]$

Eyepiece, Kellner.-An eyepiece giving a very wide field of view. It consists of a cemented pair of achromatic lenses and a double convex lens. The field and eye lenses are of equal focal lengths, and are separated by a distance numerically equal to the focal length of either. $[2,3,10,20,22,23$, 26,27 .]

Eyepiece Lenses.- Simple or compound lenses used at the eye end of telescopes, etc. $[1,2,3,6,8,9,10,11,12,14,15$, $17,18,20,21,22,23,24,25,26,27$.]

Eyepiece Micrometer.-A graduated scale usually placed in the focus of the eyelens of an eyepiece. The graduated scale is often replaced by one or more cobwebs or lines moved by a micrometer screw. $[2,3,10,11,14,18,19,20,21,22,25$, 26,27 .]

Eyepiece, Monocentric- -A concentric eyepiece. $[2,3$.

Eyepiece, Negative.-An eyepiece incapable of giving a positive image, i.e., the image due to the objective is formed on the negative side of the field lens. $[1,2,3,8,10,11,17,20,21$, $23,25,26,27$.]

Eyepiece, Pancratic.-An erecting eyepiece of which the power can be varied by altering the position of the lenses.

Eyepiece, Positive.-An eyepiece giving a positive image.

Eyepiece, Ramsden.-A positive eyepiece, designed by Ramsden, consisting of two plano-convex lenses of the same kind of glass; but with their curved faces turned towards each other. The two lenses are of equal focal lengths and separated by 
a distance equal to two-thirds of the numerical value of the focal length of either. $[2,3,8,10,11,13,17,18,19,20,21$, $22,23,24,25,26,27$.

Eye-Protectors.-A special form of spectacles with coloured or tinted glasses for protecting the eyes from glare, dust, etc. See Goggles. $[2,9,13,15,18,20,21,26,28$.

Eyeshade.-A hood or shield on an eyepiece to cut off light from the employed or unemployed eye. $[2,3,8,18,20,21$, $22,26$.

Eye-Speculum.-A curved reflector with a small central aperture used by ophthalmic surgeons for concentrating light on to the eye. [20.]

Fabry and Perot Interferometer.-See Interferometer.

Facila Set-Squares.-For the use of draughtsmen. $[6,13,15$, $20,21,24,27$.

Faciometer.-An instrument designed to measure the face for spectacle-fitting. [20.]

Fahrenheit's Hydrometer.-See Hydrometer.

Fairy Sinker.-See Sinker. $[13,28$.

Faraday Prism.-See Prism. [13.]

Farmar's Profit-Calculating Rule.-A special form of slide-rule (q.v.). $\quad[5,13,15$.

Fearnley's Universal Calculator.-See Calculator.

Feed-Water Thermometer.-See Thermometer. $[5,13,15,16$, $20,21,28$.]

Féry Radiation Pyrometer.-See Pyrometer. $[4,13,21$.

Féry Spiral Pyrometer.-See Pyrometer. [4, 13, 21.]

Field and Cust Tide Recorder.-See Tide Recorder. $[4,13,21$.

Field Glass.-A binocular telescope in compact form for hand use and having somewhat higher powers than an opera-glass. See also Binocular. $[2,3,5,9,10,13,15,16,17,18,20,21$, $24,25,26,27,28$.]

Field-Plotter. $=$ An instrument used for mechanically solving triangles in gunnery. $[13,18,20,23,27$.

Fighting Map Board.-A transparent celluloid sector and $50^{\circ}$ arc, with a range-scale, a board of 6-ply wood with two brass arms, and a waterproof case. [20.]

Filar Micrometer.-See Micrometer. $[2,3,17,18,20,22,27$.

Filter (Light).-A coloured plate or layer of fluid for filtering light by allowing only light of definite wave-length to pass. $[2,20$.

Finder.-As applied to the telescope, a small low-power telescope fitted to the side of the large one for finding the object. As applied to the microscope, a means for registering the position of an object on the slide so that it can readily be found again. Also an auxiliary optical apparatus fitted to a photographic camera to enable the object to be viewed (Viewfinder). $[2,3,8,9,13,17,18,20,21,27$. 
Finder, Wright's. - A finder consisting of a square of $25 \mathrm{~mm}$. divided into $25 \mathrm{~mm}$. engraved on the stage of a microscope. $[2,10,22,26$.

Fire-Damp Photometer.-See Photometer.

Flame Manometer. - See Manometer.

Flank Observation Computer, Notcutt.-An instrument designed to determine the necessary corrections when ranging from a flank. [15.]

Flash Point Apparatus.-An apparatus for testing the flashing point (i.e., the temperature of ignition) of oils by bringing a flame into momentary contact with the vapour. There are many forms. $[13,15,17,21$.

Flash Point Apparatus, Abel's.-For petroleum mixtures. [13, $15,17,21$.]

Flash Point Apparatus, Abel-Pensky.-The same apparatus as Abel's, with addition of clockwork to open the cover and depress the test flame. $[13,15,17$.

Flash Point Apparatus, Gray's.-For heavy mineral oils. [13, 15, 17.]

Flash Point Apparatus, Pensky-Marten's.-For the testing of heavy oils. $[13,15,17$.

Flash Test.-See Flash Point Apparatus. $[13,15,17,21$.

Fletcher's Anemometer.-See Anemometer. $[13,15,17,21$.

Fletcher's Inclined Plane and Trolley Apparatus.-An apparatus for demonstrating the laws of acceleration and impact. [19.]

Fletcher's Thermo-Hydrometer.-See Thermo-Hydrometer. [13, $15,21$.

Flicker Photometer.-See Photometer.

Flinder's Bar.-A soft iron bar which is fixed generally on the forward side of the ship's compass to compensate the error caused by the induced magnetism in the vertical iron on the ship. $[13,15,16,17,28$.

Floating Collimator or Intersector.-See Collimator.

Floating Photographic Telescope.-See Telescope. [13, 15.]

Flour Hopper Thermometer. - See Thermometer. $[5,6,13,15$, 17, 21.]

Flow Recorder.-An instrument for recording the volume of gas or air passing through a pipe. [4.]

Flow Recorder, Cambridge.-

Flue Gas Thermometer.-See Thermometer. $[5,13,15,16,17,21$. Fluid Compass.-See Compass.

Fluid Level Indicator.-For indicating the fluid or liquid level in oil and spirit tanks of aeroplanes, etc. $[2,13$ 15.]

Fluidimeter, Phillip's.

Fluid-Lens,-See Lens.

Fluid-Meter.-See Meter. [4.]

Fluxmeter.-An instrument for the exploration and, in conjunction with a galvanometer, estimation of the strength of magnetic fields. [4,19.] 
Fluxmeter, Grassot.-A form of suspended coil galvanometer (q.v.) specially designed for the investigation of magnetic fields. [4.]

Flying Sounder.-See Sounder. $[13,15,16,17,28$.

Focometer.-An instrument for measuring the focal length of a lens. $[2,3,10,13,15,17,18,22,26,27$.

Focostat Lens.-See Lens. $[3,20,26$.

Focussing Glass.-A magnifying lens on a mount suitable for placing on the screen of a camera for determining the exact focus. $[1,2,3,8,10,17,18,20,22,23,26$. $]$

Fog-Horn.-A horn or trumpet, either blown by the mouth or by steam or other mechanical means, for use at sea in fog weather. $[13,15,16,17,28$.

Folder.-A form of eyeglasses in which the lenses fold together for the pocket, and grasp the nose by a spring bow or stiff joint when in use. $[2,9,13,15,17,20,21,26$. $]$

Footner's Railway Gauge.-See Gauge. $[15,21,27$.

Footner's Railway Gauge and Clinometer.-See Gauge. [21, 27.] Forbes's Distance Recorder.-See Distance Recorder.

Forceps.-A two-bladed metal instrument of the nature of pliers or pincers used for seizing and holding small objects firmly. $[3,17,20,21,26$. $]$

Fore-Staffi.-An instrument formerly used at sea for taking the altitudes of the heavenly bodies.

Fortin Barometer.-See Barometer. $[2,5,6,13,15,17,20,21$, $24,27$.

Foucault Prism.-See Prism.

Fox Dip-Circle.-See Dip-Circle. $[2,17$.

Frameless Eyeglasses.-See Eyeglasses. [2, 9, 15, 17, 20, 21.]

Franklin Spectacles. - See Spectacles. $[2,9,15,20,21$.

Freeboard Hydrometer. - See Hydrometer.

Freezing Apparatus, Carré's. - A vessel containing sulphuric acid, connected at one end to the flask containing the water to be frozen and at the other end to an air-pump. The water vapour formed under the reduced pressure is absorbed by the acid and the temperature falls to freezing point owing to the continued evaporation. [20.]

French Curves.-See Curves, Mathematical. [2, 5, 13, 15, 17, 21, $24,25,26,27$.]

Frequency Meter.-An instrument for measuring the frequency - of vibration or the frequency of an alternating current (1) electrical circuit.

Fresnel Lamp or Lantern.-See Lantern. [26.]

Fresnel Lens.-See Lens. [3, 26.]

Fresnel's Mirror.-See Mirror. [3.]

Fresnel Prism.-See Prism. [3, 14, 26.]

Fry Micromanometer.-See Micromanometer. [4.]

Fuel Calorimeter.-See Calorimeter. [4, 17, 21.]

Fulgurata.-A spectro-electric tube in which the decomposition liquid by the passage of an electric spark is observed. 
Fuller's Calculating Slide-Scale.-See Slide-Rule. $[2,13,15,20$, $21,24,25,26,27$.

Galactometer.-An instrument for ascertaining the quality of milk by its specific gravity; a lactometer $(q . v.) . \quad[5,13$.

Galact's Densimeter. - A galactometer (q.v.).

Galilean Binocular.-See Binocular. [15.]

Galilean Telescope.-See Telescope.

Gallows Square.-A drawing or setting out square for ship architecture. $[15,21$.

Galton's Whistle.-An acoustical instrument for testing the limits of human audibility. It consists of a fine bore brass tube with adjustable screw piston, and air bellows.

Galvanic Battery.-A number of connected galvanic cells. (See Battery.)

Galvanometer.-An instrument for measuring electric currents, usually by the deflection of a magnetic needle in the magnetic field created by an electric current, or by the deflection of a moving coil, carrying the current, in the field of a fixed magnet. There are thus two main types, the moving magnet and the moving coil galvanometer. $[4,10,13,19,16$.

Galvanometer, Astatic.-A moving magnet galvanometer in which the sensibility is increased by employing an astatic needle, i.e., a combination of two magnetised needles with their poles turned opposite ways. $[4,16,19$.

Galvanometer, Ballistic.-A moving magnet galvanometer in which the needle and its attachments have a large moment of inertia. Used to measure the total quantity of electricity that passes in currents of short duration. $[4,16,19$.

Galvanometer, Broca.-A moving magnet galvanometer in which the magnet system consists of two steel wires placed vertically and each so magnetised that its two ends are of like polarity, with a consequent pole in the middle. $[4,19$.

Galvanometer, D'Arsonval.-A moving coil galvanometer. The magnetic field is produced by a number of horse-shoe magnets laid one above the other, their feet being so shaped as to leave a vertical cylindrical hollow.

Galvanometer, Differential.-A galvanometer with two equal coils nearly coinciding with one another, each connected to its own pair of binding screws. Used to measure the difference of two currents.

Galvanometer, Double Coil.-An astatic galvanometer invented by Lord Kelvin. $[4,16$.

Galvanometer, Einthoven String.-A very sensitive moving coil galvanometer in which the coil is reduced to a single very fine fibre or "string" passing between the poles of a powerful electromagnet. [4.]

Galvanometer Lamp and Scale.-The lamp and scale used with the mirror or other galvanometer $\left(q . v_{0}\right)$ in which the 
deflections are measured by the movements over the scale of the beam of light reflected from the galvanometer mirror. $[4,16,19$.

Galvanometer Lenses.-Lenses used with reflecting instruments, such as mirror galvanometers, to aid in obtaining a beam of reflected light, by which the deflections may be observed. $[1,3,4,10,16,19$.

Galvanometer, Mirror.-A sensitive galvanometer in which the current deflects a mirror attached to the moving magnet or coil, measurement being made by observing the movement of a beam of light (reflected from the mirror) over a graduated scale. $[4,16,19$.

Galvanometer Mirrors. - Small light mirrors which can be attached to the suspensions of galvanometers or similar instruments in order to give a beam of reflected light which will move as the instrument is deflected, and so magnify the deflections for convenience of observation. $[3,4,10$, $12,16,19,21,23$.]

Galvanometer, Paschen.-An improved form of Thomson Galvanometer of extremely high sensitivity. The moving system consists of two groups, each composed of 13 very light magnets, arranged alternately on opposite sides of a fine glass stem.

Galvanometer, Pivoted Moving Coil.-An instrument for use under rough conditions, or where a portable instrument is required. The moving coil, instead of being suspended in the magnetic field, is supported on jewelled pivots. The deflections are generally read by means of a pointer swinging over a scale instead of by a mirror. $[4,10,16,19$.

Galvanometer, Recording.-A galvanometer provided with a recording arrangement so that the results are given on a chart. $[4,16$. $]$

Galvanometer, Sine.-A galvanometer in which the strength of the current is measured by the sine of the angle through which the coil has to be turned to be parallel to the deflected needle. [19.]

Galvanometer, Tangent.-A galvanometer in which the strength of the current is measured by the tangent of the angle of deflection of the magnet. $[19,20,24$.

Galvanometer, Thomson.-A moving magnet galvanometer in which the moving system is formed of two groups, each consisting of four small magnets. $[4,16,19,21$.

Galvanometer, Thread Recorder.-A recording galvanometer of the moving coil type in which a pointer attached to the moving coil is automatically depressed at regular intervals on to an inked thread which passes across the surface of a revolving drum carrying a chart. The depression of the pointer presses the inked thread against the chart and so gives a record of the galvanometer deflection at the moment in the form of a dot. [4.] 
Galvanometer Telescope and Scale.-A device for observing deflections of mirror galvanometers or similar instruments. The apparatus is arranged so that the image of the scale formed by reflection in the galvanometer mirror can be seen through the telescope, and the magnitude of the deflection is deduced from the change in the reading of the scale which corresponds to the cross-line of the telescope. $[1,3,4,10,16,19$.

Galvanoscope.-An instrument for detecting the presence of electrical currents, especially such as are of feeble intensity. [16.]

Galvanothermometer.-An instrument for measuring the beating effect of a galvanic current.

Gas Analysis Apparatus.-Apparatus for the chemical analysis of gas and gaseous mixtures. The gases are passed through various vessels and absorbed by suitable agents or exploded by an electric spark. Many forms are made to suit individual processes and requirements. [13.]

Gas Analysis Apparatus. - [17.]

Gas Gauge.-See Gauge. $[4,5,6,13,15,17,21,26$. $]$

Gas-Leak Indicator. - See Indicator. $[4,5,17,21$.

Gasophaner.-An indicator of the presence of poisonous gases. [21.]

Gas Pressure Meter.-See Meter.

Gas Purity Meter.-See Meter. [4.]

Gas Regulator, Reichert's. - A mercury gas regulator for regulating the temperature of ovens, incubators, etc. $[2,4$.

Gas Works' Thermometer.-See Thermometer. $[4,5,13,15,16,17$, 21.]

Gasoscope.-An apparatus for detecting the presence of any dangerous gas from a gas leak in a coal mine or dwellinghouse.

Gassiot's Cascade.-See Cascade.

Gauge, Bourdon Pressure or Vacuum.-An instrument invented by M. Bourdon of Paris, consisting of an elastic flattened tube of metal bent to a circular form and communicating with the steam, air or other fluid under test. An increase of pressure tends to straighten the tube, a decrease to make it curve. One end of the Bourdon tube is fixed and the other free to move. The movement is communicated to a pointer which indicates, on a dial or on a chart, the amount of pressure or vacuum. $\quad[4,5,6,13,15,16,17,20,21,24,25$, $26,27,28$.]

Gauge, Bourdon Pressure, Duplex.-A similar instrument to the above, but provided with two Bourdon tubes and two pointers so that two readings are obtained. The mean of the two readings gives a more accurate figure than one reading alone, and the instrument can thus be used as a standard. [15.]

Gauge, Depth.-An instrument for determining the depth of water by means of the pressure it exerts. Sometimes called a Hydro-Barometer (g.v.). See also Tide-Gauge. [15.] 
Gauge, Draught.-For measurement of pressure slightly above or below that of the atmosphere, as chimney draughts, etc. Usually consists of a U-tube containing water, mercury or other liquid, provided with a suitable scale. [15.]

Gauge, Dry.-A gas-pressure gauge which contains no liquid.

Gauge, Edney's Air-Pressure.-A self-recording air or draught gauge.

Gauge, Footner's Railway.-A gauge used by railway engineers for indicating the banking of the outer rail on a curve. [15, $21,27$.

Gauge, Gas.-For testing the pressure in gas supply pipes. [4. $5,6,13,17,21,26$.]

Gauge, Hole.-A taper tool or instrument with graduated scale for determining the size of holes. See also Petrol-Tank Gauge, Pit-Water Gauge, Steam-Gauge.

Gauge, Hydraulic.-For high pressure such as those produced by hydraulic pumps. $[5,17$.

Gauge, Vacuum.-An instrument for indicating the difference between the external atmospheric pressure and the pressure inside a partially exhausted vessel. May be constructed on the Bourdon principle (see above) or may depend on the use of aneroid boxes, diaphragms, etc. $[5,13,15,16,17,21,28$.

Gauge-Glass Protectors.-An attachment for the prevention of injury to the attendant in case of breakage of the gaugeglass. [15.]

Gay-Lussac Alcoholometer.-See Alcoholometer.

Gay-Lussac Barometer.-See Barometer.

Gay-Lussac Densimeter.-See Densimeter.

Geissler's Tube.-A glass tube provided with platinum electrodes and containing some gas under very low tension, which becomes luminous when an electric discharge is passed through it. $[26$.

Geocyclic Machine.-A machine for demonstrating the simple processes by which day and night, and the seasons, are produced.

Geodescope.-A combined celestial and terrestrial globe.

Geometric Pen.-An instrument for drawing geometric curves, in which the movements of a pen or pencil, attached to a revolving arm of adjustable length, may be indefinitely varied by changing the toothed wheels which give motion to the arm. $[13,17,21,25,26$.

Geometric Square.-A portable instrument in the form of a square frame for ascertaining distances and heights by measuring angles. $[13,21$. $]$

George's Artificial Horizon.-See Artificial Horizon. $[6,13,15$, $17,21,24,27$.]

Geoscope.-See Orrery.

Geothermometer.-An instrument for measuring the temperature of the earth at different depths, as in mines and wells. [21.] 
Gimbal (Gimbol).-A form of universal joint for securing free motion in suspension, or for suspending anything, as a lamp, a compass, a chronometer, etc., so that it may always retain a certain position or be in equilibrium. $[13,15,16,28$.

Girthing Strap.-A strap used for measuring the girth or dimensions of timber. $[17,21,24,27$.

Girt Tape.-A broad strong tape for measuring the perimeter or girth of timber. $[5,21,24,27$.

Glass.-See Optical Glass.

Glass Hydrometer Jars.-Glass jars used in oil-testing and for other purposes. $[5,13,15,17,21,28$.

Glaucometer.-See Gleucometer.

Gleucometer.-An instrument for measuring the sp. gr. and ascertaining the quantity of sugar contained in must (the expressed juice of the grape or other fruit before fermentation). $[13,21$.

Globulimeter.-An instrument for measuring the number of red corpuscles in the blood. The method depends on the differences of tint obtained by mixing a sample of blood with sodium carbonate solution. [21.]

Glue Viscometer.-See Viscometer. [21.]

Glycerine Barometer.-See Barometer.

Glyphoscope.-A stereoscopic hand camera invented by Jules Richard.

Gnomon.-The index or style of a sundial. Formerly a style or column erected perpendicularly to the horizon, used in astronomical observations by observing the length of its shadow.

Goggle.-A special form of spectacles for preserving the eyes from wind, dust, and exposure to strong light. $[2,9,13,15$, $17,18,20,21,26,27,28.7$

Goniometer.-An instrument for measuring angles and especially those of crystals : the reflecting goniometer and the double image goniometer. $[1,2,3,13,14,17,19,20,21,22,25,26$. $]$

Goodman's Averaging Instrument.-See Averaging Instrument. [15.]

Goodman's Planimeter.-See Planimeter.

Gradient Indicator.-See Indicator. $[6,15,16,1 \%$.

Gradient Telemeter Level.-See Level. $[13,17,18,21,24,25$, 27.]

Gradienter Screw.-A micrometer screw (q.v.) fitted to a tangent arm which can be clamped to the trunnion of a telescope or theodolite. $[6,18,24,25,27$.

Gradimeter.-A special form of surveying level (q.v.). [18, 25.]

Gradiometer.-An instrument which, while performing all the duties of a first-class level, is designed also for taking vertical inclines at small fixed angles; for railways, drainage works, etc. $[13,17,18,21,25$. $]$

Gradioplane.-An instrument specially designed for very accurate underground surveying. $[13,21$. 
Graduated Glassware.-The unit of capacity is the cubic centimetre volume of one gram of water weighed in vacuo at $4^{\circ}$ C. Volume marked corresponds to air and water temperature of $15^{\circ} \mathrm{C}$. Barometer pressure, $760 \mathrm{~mm}$. [17, 21.]

Graduating Machine.-See Dividing Engine.

Graduator.-An instrument for dividing any line, straight or curved, into equal parts. [10.]

Granometer.-An instrument for quickly counting seeds of corn, etc.

Granta Compression Instrument.-See Extensometer. [19.]

Granta Extensometer.-See Extensometer. [8, 19.]

Graphometer.-A surveying instrument for taking angles. Called also a demi-circle. $[13,17,21$.

Graphoscope.-An optical instrument for magnifying engravings, photographs, etc., usually having one large lens and two smaller ones. $[17,20,26$.

Graphostereoscope.-A combined graphoscope and stereoscope for viewing stereoscopic slides. [20,26.]

Grassot Fluxmeter.-See Fluxmeter. [4.]

Graticule.-A cross-line or scale engraved on glass (or, sometimes, webs or platinum points), placed in the focal plane of the eyepiece of an instrument for sighting or measuring $[1,2,3,9,10,13,14,15,16,17,18,20,22,24,25,26,27$.

Grating.-See Diffraction Grating. Also Echelon and Etalon Grating. $[10,14$.

Gravette Level. - See Level. [13.]

Gravette Rule.-See Slide-Rule. [21, 24.]

Gravimeter.-An instrument for ascertaining the specific gravity of bodies. See also Hydrometer. $[13,15,17,21$.

Gravitometer.-An instrument for indicating and recording the specific gravity of gas.

Gravity Battery.-See Battery.

Gravity Bottle.-See Specific Gravity Bottle. [21.]

Gravity Indicator.-See Indicator.

Gray's Flash-Point Apparatus.-See Flash-Point Apparatus. [13, 15,17 .]

Great Circle Instrument.-An instrument for giving the Great Circle course and distance between any two places on the earth's surface. $[15,27$.

Gregorian Telescope.-See Telescope.

Greenough's Binocular Microscope.-See Microscope. $[2,3,13$, 26.]

Grisoumeter.-A fire-damp detector invented by Mr. Coquillon. Growing-Cell.-A form of trough for use in the miscroscope in which minute living organisms can be kept alive for long periods and examined continuously. [2.]

Grubb Miner's Dial.-See Dial. · $[13,21,27$.

Gum-melting Thermometer. - See Thermometer. $[5,21$. 
Gun Pit Register.-An arrangement designed for keeping the necessary records of field artillery battery in a gun pit.

Gunner's Callipers.-See Callipers. [1,27.]

Gunner's Level.-See Gunner's Perpendicular.

Gunner's Perpendicular.-An instrument for determining the true line of sight of a gun.

Gunner's Quadrant.-See Quadrant.

Gunter's Chain.-A measuring chain (q.v.) used in surveying, $66 \mathrm{ft}$. or 4 rods long, divided into Ioo links. $[5,13,15,16$, $17,20,21,24,25,27$.

Gunter's Quadrant.-See Quadrant.

Gunter's Scale.-A wooden scale. $2 \mathrm{ft}$. long, on one side of which are marked scales in equal parts of chords, rhombs, etc., and on the other side, scales of logarithms of these various parts, by means of which many problems in surveying and navigation may be solved mechanically, by means of dividers alone. $[13,15,17,18,20,21,27$.

Gyroscope.-A rotating wheel with a free suspension mounted in a ring or rings, for demonstrating the dynamics of rotating bodies, the composition of rotation, etc. See Gyroscope Compass. $[13,17,19,26$.

Gyroscope Compass.-An important application of the gyroscope by means of which the true course of a ship is indicated. The instrument is not affected by the magnetic force of the ship. It consists of a heavy disc, mounted with a free suspension and driven at a high speed by electrical power. The centrifugal force of the earth causes this disc to revolve in or coincide with the circle of latitude the ship is on. A dial, which is mechanically connected with the discs, has the points and diagram of the mariner's compass marked on its face and from it is indicated the true course the ship is on. Secondary dials are electrically connected to indicate at other stations on the ship. It is used principally on warships and submarines. $[13,15,26$.

Gyrostat.-A modification of the gyroscope. It consists essentially of a fly-wheel mounted inside a rigid case, to which is attached a thin flange of metal for supporting the instru. ment. It is used in studying the dynamics of rotating bodies.

Gypsum Plates.-Thin parallel plates of gypsum (selenite) for retarding the light of a polariscope. $[3,22,26$. $]$

Hadley Dial.-See Dial.

$[13,15,18,21,27$.

Hadley's Quadrant. - See Quadrant. [13, 15.]

Hædromograph.-An instrument for registering the velocity of the blood.

Hæmachrometer.-An apparatus for measuring the amount of hremaglobin in a fluid by comparing it with a solution of known strength and normal colour. 
Hæmacytometer.-An apparatus for determining the number of corpuscles in a given quantity of blood. $[2,20,21,22,26$.

Hæmacytometer, Barker's.-An apparatus for counting and detecting blood corpuscules. [22.]

Hæmacytometer, Thoma's.-A form of hæmacytometer consisting of a counting chamber in combination with an accurately calibrated mixing pipette for diluting the blood in a certain ratio. $[2,22,26$.

Hæmadromometer.-An hæmadrometer.

Hæmatokrit.-Part of a laboratory centrifuge (q.v.), usually rotated at about 10,000 revolutions per minute. $[2,22,26$.

Hæmatometer.-See Hæmacytometer. [26.]

Hæmodynamometer.-An apparatus for measuring arterial and venous blood-pressure. $[21,26$.

Hæmoglobinometer.-An apparatus for the clinical estimation of hæmoglobin in blood. $[2,21,22,26$.

Hæmomanometer.-A form of hæmodynamometer. [26.]

Hæmometer.-A form of hæmoglobinometer.

Hæmoscope.-An instrument for regulating and measuring the thickness of a layer of blood for spectroscopic observations. [26.]

Hair Compass.-See Hair Divider. $[13,15,24,27$.

Hair Divider.-See Divider. $[2,5,13,15,21.24,27$, $]$

Hair Hygrograph. - See Hygrograph. $[2,6,15,1 \%$.]

Hairspring Dividers.-See Hair Divider. $[2,5,13,15,21,24,27$. Hall's Nautical Slide-Rule.-See Slide-Rule. [15.]

Halometer.-An instrument for measuring the forms and angles of salts and crystals; a goniometer (q.v.).

Haloscope.-An instrument for exhibiting phenomena cornected with halos, parahelia, etc.

Hand Frame. - A form of eyeglass which can be held in the hand. $[2,9,15,20$.

Hand Testing Thermometer.-See Thermometer. $[5,6,13,15,16$, 17, 21.]

Hanging Clinometer.-See Clinometer. $[6,10,15,17,21,24,25$ 27.]

Hanging Compass.-A form of compass very generally used in underground surveying. See Compass. [2. 13, 15, 16, 17, $21,27$.

Hanging Dial.-A modification of the hanging compass for use in mining. $[2,6,13,15,17,21,24,27$.

Hard Porcelain Ware.-British make for laboratory work. [17.]

Harding's Engine Counter.-An improved form of engine revolution counter. See Counter. $[5,13,15,17,28$. $]$

Harmonic Analyser.-An integrating machine for producing mechanically the harmonic constituents of meteorological, tidal, and other curves, to obviate calculations.

Harmonograph.-An instrument by which Lissajou's and Mildi's figures may be drawn on paper by a pen. $[19,26$. 
Harmonometer.-An instrument for measuring the harmonic relations of sound.

Harvey's Apparatus.-For the extraction of gases dissolved in water. See also Absorption Apparatus.

Hastings' Triple Aplanat Magnifier.-An improved and perfect form of triple aplanatic magnifier, based on formulæ by Prof. C. S. Hastings. See also Magnifier. $[13,22$.

Heath's Valvograph.-See Valvograph. $[13,21$.

Hedley Dial.-A form of mine-surveying dial. See Dial. [17, 21, 24,27 .]

Heeling Error Instrument.-A specially designed dipping needle $(q . v$.) controlled by an adjustable weight so that values of the vertical component of the earth's magnetism may be compared. Used in correcting the heeling error in ship's compasses. $[13,15,16$.

Helicograph.-An instrument for drawing helices or spiral lines on a plane. $[13,17$.

Helio-Chronometer.-A form of sundial which shows true clock time by simple direct observation, without reference to equation tables. $[2,5,15,17,20,21$. $]$

Heliograph.-(I) An instrument for obtaining photographs of the sun. (2) An apparatus for telegraphing by means of the sun's rays. See also Photo-Heliograph. $[2,8,13,15,18$, $20,21,24,25,26,27$.]

Heliometer.-An instrument, devised originally for measuring the diameter of the sun, now employed for delicate measurements of the distance and relative direction of two stars too far apart to be easily measured in the field of view of an ordinary telescope. [11.]

Helioscope.-A kind of telescope particularly adapted by means of blackened or smoked glasses, which only partially reflect the light, for viewing the sun. [26.]

Heliostat.-(I) An instrument consisting of an adjustable mirror or reflector worked in connection with a combination of telescopes, used in trigonometrical surveys; with it, triangles with sides over Ioo miles in length can be measured. (2) A mirror moved by clockwork by which a sunbeam is directed continuously to one spot. $[2,3,11$, $13,14,18,20,21,25,26,27$.

Heliotrope.-(I) An astronomical instrument for showing when the sun arrives at its farthest point north or south of the equator as seen at that place. (2) A photographic instrument used to illuminate negatives in the solar camera in making enlarged pictures. (3) A plain flash signalling instrument. $[18,21,27$.

Hemadynamometer.-An instrument by which the pressure of the blood in the arteries or veins is measured by the height to which it raises a column of mercury. See Hæmodynamometer. $[21,26$. 
Hematachimeter.-A form of apparatus for measuring the velocity of the blood.

Hemorheumoscope.-An instrument for observing the flow of blood in a vein.

Herschellian Telescope.-See Telescope.

Hicks's Ballistic Pendulum. - See Pendulum.

Hicks's Level.-See Level. $[13,21,26,28$.

Hicks's Marine Clinometer.-For indicating the heel of the ship.

H.M. Gange. $[13,15,16,21,28$.

Hobson's Pyrometer.-See Pyrometer.

Hodometer.-See Odometer.

Hoffman Head.-A special form of tripod head for surveying instruments.

Hole Gauge.-See Gauge.

Holometer.-An instrument for making all kinds of angular measurements. See Pantometer.

Holophote.-A lamp with lenses or reflectors to collect the rays of light and throw them in a given direction.

Hooke's Cyclograph.-See Cyclograph.

Horizon Glass.- The silvered mirror or speculum attached to the frame of a quadrant or sextant, the upper half of which is left clear, enabling the horizon to be seen directly through it. The image of the sun or star is seen by reflection from the index mirror of the sextant in the lower or silvered part. The clear or upper half of the horizon is sometimes removed when the sextant is only to be used for shore angle work. $[3,6,13,15,16,17,18,24,26$. $]$

Horizontal Dial.-A dial having its plane set parallel to the horizon and fitted with a gnomon or sight which can be revolved for observing horizontal angles. $[13,15,16,25,28$.

Horn Centre.-Used in the drawing office; to save drawings from being marked by the points of the compasses. $[2,5,6$, $13,15,17,21,24,26,27$.]

Horologe.-A sundial or mechanical contrivance for showing the time. $[20,27$.

Horometer.-An instrument for measuring time, as a clepsydra, clock, dial, or watch.

Horoscope.-An optical instrument for observing the time as indicated by the position of the stars and planets.

Horse-Power Computing Scale, Hudson's.-A simple rule of the sliding class for calculating at a glance the horse-powier from the proportions of a steam-engine. $[5,15,21,24$.

Hoskold's Transit Theodolite.-See Theodolite. $[13,25,27$.

Hourglass.-An instrument for measuring time, especially the interval of an hour. It consists of a glass vessel having two compartments, from the uppermost of which a quantity of sand, water, or mercury occupies an hour in running through a small aperture in the lower. See also Log-glass. $[2,6,13,15,16,17,21,28$. 
Houston's Apparatus.-For the bacteriological examination of milk. [13.]

Hudson's Horse-Power Computing Scale.-See Horse-Power Computing Scale. $[5,15,21,24$. $]$

Hull Calliper.-See Calliper. [15.]

Huyghenian Eyepiece.-See Eyepiece. $[2,3,17,18,20,21,22$, $23,26,27$.]

H.S. Range-Finder.-See Range-Finder. $[5,20$.

Hyalograph.-An instrument for tracing a design on a transparent surface.

Hydraulic Gauge.-See Gauge. $[5,15,17$.

Hydro-Barometer.-An instrument for determining the depth of the ocean by its pressure, generally called depth gauge (q.v.). $[6,13,15,17$.

Hydrodynamometer.-An instrument to measure the velocity of a liquid current by the force of its impact.

Hydrogen Purity Meter, Shakespear.-An instrument for determining the purity of hydrogen. It is calibrated directly in percentages of hydrogen, readings being given by the deflections of a pointer.

Hydrograph.-An instrument used in making Mercator or sea charts for giving the varying scale of latitude. $[15,17$.

Hydrometer.-An instrument for determining the specific gravity of liquids. Attributed to Archimedes, but not much used until it was reinvented by Robert Boyle. It usually takes the form of a narrow sealed instrument of cylindrical section and consists of three parts-the counterpoise at the bottom ; the bulb containing air; and the stem with the scale, at the top. Made of glass or gilt brass. In the latter case the hydrometer is usually provided with weights, which are slipped over the stem and alter the buoyancy of the instrument so as to adapt it to liquids of various specific gravities. See also Alcoholometer, Ammoniameter, Saccharometer. $[5,6,9,13,15,16,17,21,24,26,28$. $]$

Hydrometer, Accumulator or Battery.-A hydrometer for taking the specific gravity of liquids in an accumulator. Usually made with flat bulb so that the hydrometer can float between the plates, but sometimes consists of a small hydrometer contained in a glass pipette, into which the acid can be sucked by means of a rubber bulb. Usual range, 1, 1001,250. $[5,6,13,15,17,21$.

Hydrometer, Alcoholometer, Gay-Lussac's.-For testing alcoholic solutions. Scale shows percentage per volume, $0^{\circ}-100^{\circ}$ per cent.

Hydrometer, Ammoniameter.-For testing ammonia solutions ; scale, $0^{\circ}-40^{\circ}$. (To convert to s.g., multiply by 3 and deduct from $I, 000$.)

Hydrometer, Barktrometer.-For tanning liquor. Scale, $0^{\circ}-80^{\circ}$. [15.] 
Hydrometer, Beaumé.-Two kinds in use : heavy Beaume, for liquids heavier than water; and light Beaumé, for liquids lighter than water. In the former, $0^{\circ}$ corresponds to water, $66^{\circ}$ to a specific gravity of $\mathbf{I} \cdot \mathbf{8 4 2}^{2}$. In the latter, $0^{\circ}$ is equivalent to a ro per cent. solution of common salt, and $60^{\circ}$ to a specific gravity of $0 \cdot 745$. [15.]

Hydrometer, Fahrenheit's.-A glass hydrometer similar to Nicholson's. [15.]

Hydrometer, Freeboard.-A hydrometer used on board ship for correcting the draught of vessels loading in fresh or brackish water. [15.]

Hydrometer, Lactometer.-For milk. $[5,13,15,17,21,26$.

Hydrometer, Nicholson's.-Made of japanned tin or brass for taking the s.g. of solids, or of glass for liquids. In the former case the solid is placed on the upper pan of the hydrometer and weights are added till the hydrometer sinks to the zero mark. In the latter the glass hydrometer is placed in the liquid under test with a suitable counterpoise attached at the bottom. $[15,17,21$.

Hydrometer, Oil (Oleometer).- - For vegetable and sperm oils. Scale, $50^{\circ}-0^{\circ}(=870$ to 970$)$. [15.]

Hydrometer for Rubber Latex.-Scale, $970^{\circ}-1,000^{\circ}$.

Hydrometer, Saccharometer.-For determining the specific gravity of sugar solutions. $[5,6,13,17,20,21,25,26$.

Hydrometer, Sikes's.-For determining strengths of alcoholic liquor in glass or brass. Used with tables which convert the hydrometer readings into percentage of proof.

Hydrometer, Twaddell.-For liquids heavier than water. In 6 numbers, embracing the range $0^{\circ}-170^{\circ} \mathrm{T}$. (To convert $\mathrm{T}$. to specific gravity, multiply by 5 and add $\mathrm{I}, 000$.) $[5,13$, $15,17,21,28$.

Hydrometrograph.-An instrument for determining and recording the quantity of water discharged from a pipe, orifice, etc., in a given time.

Hydrophore.-An instrument for obtaining specimens of water from any desired depth, as in a river, lake, or ocean.

Hydrophone.-An instrument for detecting sounds through the medium of water.

Hydropyrometer.-A pyrometer (q.v.) in which the temperature is ascertained by exposing to the action of the heat which is measured a definite weight of some metal, as platinum, steel, copper, etc.; then quenching the same in a known weight of water and noting the rise in temperature of the latter. [5.]

Hydroscope.-An instrument designed to mark the presence of water, especially in air; also a kind of water-clock used by the ancients for measuring time, the water trickling from an orifice at the end of a graduated tube.

Hydrostatic Balance.-See Balance.

Hydro Volume Meter.-See Meter.

Hyetograph.-See Rain-Gauge 
Hygrodeilk-An improved form of hygrometer (q.v.) with a radial diagram and pointer from which the dewpoint is determined. $[4,15,16,17,21$.

Hygrograph.-An instrument for recording automatically the variations of the humidity of the atmosphere. $[6,15,16,17$, $21,27$.

Hygrograph, Hair.-A recording hygrograph depending on the action of moisture upon a hair. $[2,6,15,17$.

Hygrometer.-An instrument generally for measuring the state of humidity of the air. $[5,6,9,13,15,16,17,19,20,21$, $24,25,26,27,28$.]

Hygrometer, Daniell.-A hygrometer in which the humidity of the air is determined by noting the temperature at which dew is deposited. It consists essentially of two thermometers, one immersed in a volatile liquid which, by evaporation, lowers the temperature to the dewpoint ; the other, affixed to the stand, records the temperature of the uncooled air.

Hygrometer, for use in Cotton Factories.-A form of Mason's wet and dry bulb hygrometer (q.v.). [15.]

Hygrometer, Horticultural.-A wet and dry bulb hygrometer with a special cylindrical scale revolving between the thermometers, for ascertaining the likelihood of frost during the night.

Hygrometer, Mason's.-Consists essentially of two thermometers, suitably mounted, the bulb of one being kept wet, the other dry. The evaporation of the moisture round the wet bulb lowers the temperature, and the degree of humidity of the air is determined, by the help of tables, from the difference of the readings of the two thermometers. [15.]

Hygrometer, Regnault's. -A dewpoint hygrometer in which one thermometer, immersed in ether, registers the dewpoint, the ether being rapidly evaporated by a current of air. The dew is deposited on a band of silver foil round the bottom of the jar containing the wet bulb thermometer.

Hygrometer, Self-Recording.-A hygrometer fitted with a revolving drum and chart on which the variations of the two thermometers can be continuously recorded.

Hygrometer, Ventilating, Simmance and Abady's.-A wet and dry bulb hygrometer in which the two thermometer bulbs are placed in the draught of air created by a ventilating fan. See also Pagoscope.

Hygrometric Balance.-An instrument for indicating the relative density of the air and consequent changes of rain or dry weather, made in the form of a balance. [21.]

Hygrophant.-A hygrometer for ascertaining quickly the percentage of moisture in the atmosphere, without reference to tables. 
Hygroscope.-An instrument for indicating the degree of moisture in the atmosphere. See also Polymeter. $[2,15,16,17,21$, $25,26,27$.

Hyman's Range-Finder.-See Range-Finder.

Hyperbolic Curves.-Geometrical curves for the use of draughtsmen. $[15,24$.

Hyphydroscope.-A periscope as used in submarines. See also Alti-hyphydroscope. [26.]

Hypsometer.-An instrument for determining altitudes by observing the boiling point of water, the boiling point being lowered consequent on the reduction of atmospheric pressure at higher altitudes. $[5,6,13,15,17,18,21,24,25,27$.

Hysterisimeter.-An instrument for determining or measuring the effect of strain in materials.

Ice Calorimeter.-See Calorimeter.

Ichnograph. - A term used to designate a ground plan.

Iluminator, Parabolic.-A parabolic mirror for illuminating opaque objects with the microscope. $[2,3,10,20,21,22$, 26.]

Iluminator, Vertical.-A reflector used above the object-glass of a microscope for illuminating opaque objects with high powers. $[2,3,10,20,21,22,26$.

Immisch Thermometer.-See Thermometer. $[20,21,26$.

Impact Testing Machine.-For testing materials to fracture by the force of impact. In some machines fracture is caused by a single heavy blow, in others by a series of lighter blows. $[4,16,24$.

Inclinometer.-An apparatus to determine the inclination of the earth's magnetic force to the plane of the horizon. Called also inclination compass-dip circle. $[15,16,17,21$, 27.]

Incubator Thermometer.-See Thermometer. $[2,5,15,17,21,26$.

Index.-(I) In astronomy, a brass rule accompanying the planetable, furnished with perpendicular sight-vanes at each extremity. (2) The line or arrow from which the reading of a divided scale is made. $[15,27$.

Index Gauge.-An instrument having jaws whose distance apart is indicated by a pointer and dial or other means.

Index Glass.-The silvered mirror or speculum fixed to the index bar of a sextant, the movement of which enables any object up to a certain angle to be reflected into the horizon mirror, and thence to the eye of the observer. $[2,10,13,15,16,17$.

Index Thermometer.-See Thermometer. $[4,15,16,21,25$.

Indicator.-A finger working in the field of a microscope to point out a special object within the field of view. $[2,5,20$.

Indicator, Aeroplane Speed.-An instrument for indicating the speed of revolution of an aeroplane engine.

Indicator, Crosby.-An improved form of engine indicator $(q . v$.$) . [13,15,16,17$. 
Indicator, Engine.-An instrument for measuring the horsepower of a steam or internal combustion engine. It consists of a cylinder having a piston attached to a coiled spring. A pencil is attached to the piston rod and describes a diagram upon a card or paper fixed on a cylindrical drum which vibrates horizontally with each stroke of the engine. The diagram indicates the varying steam pressure during the stroke. $[13,15,16,24$.

Indicator, Gas Leak.-An instrument for locating coal gas leaks and detecting the presence of sewer gas, after-damp, etc. $[4,5,17,21$.

Indicator, Gradient.-An instrument for indicating the up or down gradient of an aeroplane or motor-car. $[6,15,16,17$.

Indicator, Gravity.-An instrument used for the experimental verification of the laws of falling bodies. The falling body generally consists of a blackened glass plate, on which a style attached to a vibrating tuning fork, whose frequency is known, marks a wave curve, from which the time of falling through a known distance can be deduced.

Indicator, Tabor.-A form of engine indicator for testing high speed engines, etc.

Indicator Telegraph.-An electric telegraph in which the signals are given by the deflections of a magnetic needle. [15.]

Indigometer.-An instrument for ascertaining the strength of an indigo solution, as in volumetric analysis.

Indiscope.- $\mathrm{A}$ form of ophthalmoscope (q.v.).

Induction Balance.-An instrument for the eradication of induction currents in telegraph lines. [4.]

Induction Coil.-An apparatus for producing induced electrical currents of great intensity. The essential features are: a central core of soft iron, surrounded first by a coil of thick insulated wire, called the "primary," and then by a longer coil of very thin insulated wire, called the " secondary"; a condenser consisting of alternate layers of tin foil and paraffin wax coated paper, and a means of interrupting the current in the " primary," thus creating induced currents in the "secondary." [4.]

Inductiphone.-A sounding instrument in which vibrations transmitted by the primary are reproduced by a plate and membrane. [4.]

Inductometer.-An instrument or apparatus for ascertaining the force of electrical induction or for comparing the specific inductive capacities of various substances. [4.]

Inflammable Gas or Vapour Detector, Redwood.-An instrument for detecting and accurately measuring small percentages of inflammable gases or vapours. $[13,15$.

Ingram and Stopfer's Oil-Tester.-For lubricating oils.

Inside Calliper.-An instrument for the measurement of the diameter of holes in metalwork, etc., generally reading by vernier to $\mathrm{I}-\mathrm{I}, 000$ in. See Callipers. $[20,25$. 
Integrator.-An instrument giving area and moment upon any diagram, but not the moment of inertia. $[13,15,17,21,24$, 27,28 .]

Interference Apparatus.-An apparatus for studying the interference of vibration, generally applied to Koenig's tuningforks and revolving mirrors for studying sound. [26.]

Interferometer, Michelson's.-An instrument for making very accurate measurements of small distances in terms of the wave-length of light. It consists essentially of four plates of glass so arranged as to be equivalent to two parallel reflecting surfaces, the distance between which can be varied. A beam of light is split up into two components which are recombined after one of them has travelled a small number of wave-lengths further than the other, thus producing interference fringes. $[3,14,25,26$.

Interferometer, Fabry and Perot.-A form of interferometer (q.v.) based on the principle of multiple reflections, by which the width of the bright bands is made many times smaller than the width of the dark bands. It consists essentially of two plates of plane-parallel glass, one stationary, the other movable, the opposed surfaces of the glass plates being half-silvered.

Interferometer, Hilger.-An interferometer for testing the accuracy of optical glasswork. [14.]

Interferometer, Lummer and Gehrcke.-An interferometer, resembling in principle the echelon spectroscope, for obtaining narrow interference fringes under conditions of large retardation of path.

Invar Measuring Tape.-A measuring tape made of the metallic alloy known as Invar which has no perceptible expansion when heated. $[6,13,21,24,27$.

Inward's Parabolagraph.-See Parabolagraph.

Iriscope.-An instrument for exhibiting the prismatic colours of light.

Iris-Diaphragm. - A contractile diaphragm, simulating the action of the iris of the eye, to regulate the size of the aperture in an instrument through which light passes. $[1,2,3,8,17$, $20,23,26,27$.]

Isogon.-An instrument for making a bevel square. By it an angle may be set at once by the degrees and the same angle may be reversed. [15.]

Isograph.-An adjustable set-square, accessory to the tee-square, used principally for drawing slopes of roofs, spires, cones, etc. $[2,13,15,21,24,27$.

Isometrical Protractor.-See Protractor. [27.]

Jacob's Staff.-A pole with iron shoe used as a stand for a prismatic compass, box sextant, or clinometer. $[2,13,15$, $17,21,24,25,27$.

Jakin Slide-Rule.-See Slide-Rule. $[13,15$. 
Jam-Boiling Thermometer.-See Thermometer. $[5,6,13,15$, $16,17,21,26$.]

James Submarine Sentry.-See Submarine Sentry. $\quad[13,15,17,28$. Jamin Refractometer. - See Refractometer.

Jaurus Marine Recorder. -

Joint Pliers.-A pair of pliers adapted for securing the joints of compasses and similar instruments. $[6,15$.

Jointed Microscope. - See Microscope. $[2,13,21,26$.

Joly's Balance.-See Balance.

Joist Scale.-This scale is a combined, direct, and a bisecting scale for setting out, opening, etc., from their centres. It is used to mark off joists or rafters in brickwork. $[15,21,24$.

Jordan Barometer.-A glycerine barometer (q.v.).

Jumper Stay Compass. - See Compass. $[13,28$.

Kaleidophone.-An instrument consisting of a reflecting knob at the end of a vibrating rod or thin plate, for making visible, in the motion of a point of light reflected from the knob, the paths or curves corresponding with the musical notes produced by the vibrations.

Kaleidoscope.-An instrument which contains loose fragments of coloured glass, etc., and reflecting surfaces so arranged that changes of position exhibit its contents in an endless variety of beautiful colours and symmetrical forms. See also Polygonoscope. $[2,20,26$.

Kater's Reversible Compound Pendulum.-See Pendulum.

Kathetometer. - See Cathetometer. $[2,3,4,13,25$.

Kellner Eyepiece. - See Eyepiece. $[2,3,10,20,22,23,26,27$.

Kelvin Deflector.-See Deflector. [16.]

Kelvin Dip Needle.-A special form of dip-needle (q.v.). [16.]

Keratometer.-An optical instrument for measuring by reflection the curvature of the cornea of the eye in all meridians. [ 2 , $3,13,21,26$.]

Keratometer, Sutcliffe Self-Recording.-An improved form of direct reading keratometer, in which the astigmatic error of the cornea is given in dioptries. $[1 \%, 21,26$.

Keratoscope.-An instrument for the examination of the eye in cases of cataract. [26.]

Kerotome.-A surgical instrument for dividing the cornea in operations for cataract. $[6,26$.

Kew Magnetometer. See Magnetometer. [15.]

Kew Pattern Barometer.-See Barometer. $[5,13,15,17,21,27$.

Kinematograph.-See Cinematograph. $[3,8$.

Kinescope (Kinetoscope). - An instrument for producing curves by the combinations of circular movements.

Kinetic Energy Apparatus.-As designed by Mr. A. P. McMullen, R.N. College, Dartmouth.

Kite Balloon Winch-Indicator.-To indicate the speed in feet per minute at which the cable is wound out and in; also the total length of cable out. 
Klinometer.-See Clinometer.

Elinostat.-An instrument for determining the influence of gravitation on the growth of plants.

Koniscope.- A hand instrument consisting of an air-pump and observation tube for testing the comparative amount of dust in the atmosphere.

Kymograph. - A rotating drum, upon the surface of which records of the occurrence of phenomena under observation may be traced by means of suitable apparatus fitted with writing points. [4.]

Kymoscope.-An instrument for demonstrating wave-motion in acoustical experiments.

Laboratory Dividing Engine.-A simple dividing engine for physical, chemical, and engineering laboratories. See Dividing Engine. $[6,10,13,19,21$. $]$

Laboratory Fittings.-British make. [2.]

Laboratory Glassware.-British make. [2.]

Laboratory Governors.-For governing the flow of gases.

Laboratory Meters. - For accurate measurement of gas and air.

Laby String Electrometer.-See Electrometer. [4.]

Lactobutyrometer.-An apparatus for ascertaining the quantity of buttery matter in a particular sample of milk. $[13,21$, 26.]

Lacto-Densimeter.-A form of hydrometer (q.v.) specially graduated for finding the density of milk and thus discovering whether it has been mixed with water, or some of the cream removed. $[13,21,26$. $]$

Lactometer. - An instrument for estimating the purity or richness of milk : as a measuring glass, specific gravity bulb, or other apparatus; called also a galactometer. See also Hydrometer. $[5,13,15,17,21,26$. $]$

Lactoscope.-An instrument for estimating the amount of cream contained in milk by ascertaining its relative opacity. [21.]

Lamp-Rotator, Paterson's.-An instrument designed by Mr. C. C. Paterson for revolving lamps suspended vertically.

Lamp-Spinner, Simmance-Abady.-An instrument for spinning lamps horizontally or at any angle. [13.]

Land Chain.- An iron or steel chain used by surveyors in the measurement of land. The chain in general use is one of Ioo links, equal to $66 \mathrm{ft}$., Io square chains giving the statute acre. A lighter or shorter chain of 50 links is also used. Land chains are also made roo ft. in length and $50 \mathrm{ft}$. [2, $5,13,15,16,17,20,21,24,25,26,27$.]

Land-Marker.-A machine for laying out rows for planting.

Landscape Mirror.-See Claude Lorraine Glass. [3, 26.]

Lantern, Magic.-An optical instrument consisting of a case enclosing a light and having suitable lenses for throwing an enlarged image of a small picture upon a screen. $[2,8$, $17,20,21,26$.] 
Lantern, Fresnel.-An optical projection lantern having its lamp or light surrounded by a hollow cylindrical Fresnel lens (q.v.). [26.]

Laryngoscope.-An instrument consisting of two mirrors for reflecting light upon and examining the larynx. $[2,13,26$.

Laryngostroboscopic Apparatus.-A method for observing the vibration of the vocal chords during the production of sounds. It consists of a laryngoscope, and a means of rapidly interrupting the source of light so that the chord may be observed at any periodic position.

La Trobe Beam Compass. - See Beam Compass. [13, 21.]

Lea Biram Anemometer.-See Anemometer. [13, 21.]

Leach and Lythgoe's Refractometer Scale.-See Refractometer Scale.

Lean's Dial.-An old form of mining dial (q.v.) invented by Mr. J. Lean. $[6,13,17,21,24,25$. $]$

Lean's Miner's Theodolite.-See Theodolite. $[6,13,18,21,25$.

Lecture Galvanometer.-A type of galvanometer (q.v.) with large mirror for projection; adapted to demonstration purposes. $[4,10$.

Leeway Indicator. [15.]

Leffmann Beam Centrifugal Machine.-For milk analysis. See Centrifuge.

Lencoscope.-An instrument for testing the colour perception of the eye or for comparing different lights as to their constituent colours or their relative whiteness.

Lens.-In optics, a portion of a refracting medium bounded by two curved surfaces, or by one plane surface and one curved surface. Usually made of glass or other transparent substance. See also Polyoptrum and Polyscope. $[1,2,3,8,9$, $10,11,12,13,14,15,17,18,20,21,22,23,24,26,27$.

Lens, Achromatic.-A lens corrected for chromatic aberration ; as compared with an apochromatic lens (q.v.) it is corrected for only two colours.

Lens, Aplanatic.-A lens which is free from spherical aberration and satisfies the sine condition. $[1,2,3,8,9,10,17,20$, $21,22,23,26,27$.]

Lens, Apochromatic.-A lens corrected for chromatic aberration for the secondary spectrum.

Lens, Coddington.-A cylindrical lens with a deep groove cut in midway between the ends and acting as a diaphragm giving a good definition and wide field; generally used as a pocket magnifier. $[2,3,8,9,13,15,17,20,21,22,24,26,27$.

Lens, Flnid.-A lens in which a liquid is imprisoned between circular glass discs of the required curvature.

Lens, Focostat.-A lens with slide and universal joint, but attached to a dissecting needle; for biological work. [3, 20,26 .] 
Lens, Fresnel.-A compound lens formed by placing around a central convex lens rings of prisms so shaped as to have all the same focus ; used in lighthouses. $[3,18,26$. $]$

Lens, Photographic.-A lens specially designed for taking photographs. $[1,2,3,8,9,10,17,18,20,22,23,26$. $]$

Lens, Portrait.-A compound photographic lens adapted to portraiture.

Lens, Rapid Rectilinear.-A photographic lens consisting of two symmetrical combinations to avoid distortion. Introduced by J. H. Dallmeyer.

Lens, Stanhope.-A lens with a focus at one of its surfaces. $17,20,26$.]

Lens, Telephoto.-A compound photographic lens giving large pictures at short camera extensions for distant objects.

Lens, Wide Angle.-A photographic lens of short focal length giving a wide angle of view.

Lens Measurer (Geneva).-An instrument for measuring the curvatures of spectacle lenses directly on a graduated dial by the motion of a movable leg between two fixed legs.

Lenticular Glass.-A glass of the form or shape of the seeds of a lentil ; convex. [3.]

Lessing's Electric Furnace.-See Electric Furnace.

Level.-An instrument by which to find a horizontal line or adjust something with reference to a horizontal line, such as surveyor's level, builder's level. $[1,5,6,10,13,15,16$, $17,18,19,20,21,24,25,26,27$.

Level, Abney.- Invented by Sir Wm. Abney. A pocket or hand reflecting level consisting of a spirit level, a divided arc and a sighting tube. A reflector in the sighting tube enables the bubble to be seen at the same time as the object. $[2,5,6,9$, $10,13,15,17,18,20,21,24,25,26,27$.]

Level, Aldis Optical.-A form of sensitive level bubble in which the movement of the bubble is greatly magnified by optical means involving the use of the bubble as a negative lens through which a fixed mark is either viewed or has its image projected.

Level, Builder's.-A simple form of the Surveying Level (q.v.).

Level, Bural.-See Reflecting Level below.

Level, Clinometer.-Consists of a small spirit level mounted on an inclinable frame with a divided arc.

Level, Cushing's. - In this pattern the object-glass and the eyepiece can be reversed, thus giving increased accuracy in reading, as in a Y-Level.

Level, Drainage.-Similar to Builder's.

Level, Dumpy.-A surveying level in which the telescope is fixed. $[2,5,9,10,13,15,16,17,20,21,24,25,26,27$.

Level, Gradient-Telemeter.-A special form of surveying level and gradient indicator and telemeter. With this instrument and a levelling staff distances are measured with considerable accuracy and rapidity. $[13,15,17,18,21,24,25,27$. 
Level, Gravette.-A form of level invented by M. Gravette. [13.] Level, Hicks's.-A hermetically sealed, vertical, circular level. $[13,21,26,28$.

Level, Reflecting. - A simple form using a small mirror. Sometimes called the Bural Level after its inventor, Col. Bural. $[13,17,21,25,27$.

Level, Spirit.-A glass tube almost filled with liquid, but leaving a small bubble to act as an index. The inside of the tube is ground to a definite curvature according to the desired sensitivity. The tube is suitably mounted to indicate level. $[2,3,15,16,17,19,20,21,23,24,25,26,27$.

Level, Stride.-A spirit level mounted on a frame with two legs shaped so as to be placed on the axis of the telescope of a theodolite or similar instrument.

Level, Surveying. - A telescope mounted so that it can be readily placed in a truly horizontal position and used with a levelling staff to obtain small differences of level in surveying. $[2$, $13,15,16,18,20,21,24,25,26,27$.

Level, Water.-An instrument to show the level by means of water in a trough or in upright tubes connected by a pipe. $[21,24,25,27$.

Level, Y.-A form of surveying level in which the telescope is supported on two Ys. It can thus be readily reversed so as to eliminate errors due to the instrument not being set truly level.

Levelling Rod.-See Levelling Staff. $[2,3,15,16,21,24,25,27$.

Levelling Rule.-A measuring rule with an attached spirit level. $[13,15,24,27$.

Levelling Staff.-A staff, generally of telescopic construction, marked with divisions representing vertical heights, use, for surveying purposes. $[2,3,5,13,15,16,17,20,21,24$, $25,26,27$.]

Levelling Stand.-An instrument used in photography to support a glass plate in a horizontal position.

Lewis Thomson Calorimeter.-See Calorimeter. $[15,17$.

Lieberkuhn.-A concave metallic mirror attached to the objectglass end of a microscope to concentrate light down upon an opaque object. $[2,3,17,20,22$.

Life Slide.-A microscopic slide with means provided to enable living objects to be kept alive during observation extending over long periods. $\quad[2,3,17,26$.

Light-Registering Apparatus.-An automatic device invented by Prof. Roscoe to keep a record of the amount of light that falls at any particular spot during small fixed intervals.

Lightning Arrester.-A contrivance used in telegraphy for guarding against the passage of atmospheric electricity through the instruments.

Lightning Conductor.-An appliance for protection of buildings against destruction or damage by lightning. Usually a 
copper rod extending from the top of the building to a large metal plate buried in the ground. [21.]

Lightning Rod.-A metallic rod or band in communication with a lightning conductor.

Lime-Light.- $\AA$ block of lime rendered incandescent by an oxyhydrogen blow-pipe or jet, used particularly as a magiclantern illuminant. $[20,26$.

Lind's Anemometer.-See Anemometer.

Line.-A slender threadlike measuring tape or cord. [24, 27.]

Line, Masonry. - The bricklayer's cord, which is his guide for level and direction.

Linear Micrometer.-A graduated scale placed in the field of a telescope and used to measure distances between objects. $[13,18,21,25,27$.

Linen Prover.-A simple microscope for counting the threads in a given space of linen fabrics. $[2,5,13,15,17,20,21,22$, $24,25,26$.]

Linseed Oil Thermometer.-See Thermometer. $[5,13,15,16,21$. Liquid Compass. - See Compass.

Lissajou's Figures Apparatus.-Apparatus for the analysis of the vibrations of tuning forks. Light is reflected from a small mirror attached to the tuning forks and the images thrown on a suitable screen giving rise to the "Lissajou's Figures." [19.]

Lister's and Babcock's Centrifugal Machine.-For milk analysis. See Centrifuge.

Lister's Inclinometer.-See Inclinometer. [21.]

Lister's Theodolite.-See Theodolite. $[13,21$.

Littrow Spectroscope.-See Spectroscope. [14.]

Litrameter.-An instrument for ascertaining the sp. gr. of liquids.

Live Box.-An apparatus for holding living objects during observation with the microscope. $[2,3,17,20,21,22,26$.

Live Trap.-A special form of life-slide, for use with the microscope.

Livingstone Depth Gange or Sea-Sounding Gauge. [15.]

Loaf-Testing Thermometer.-See Thermometer. $[1,5,13,16$, 17, 21.]

Locomotive Pyrometers.-See Pyrometer. $[4,13,17$.

Log.-An apparatus for measuring the rate of a ship's motion through the water. $[13,15,16,17,21,28$.

Log, Electric.-A $\log (q . v$.$) in which the indications are trans-$ mitted electrically to receiving instruments. [15.]

Log-glass.-A small sandglass used to time the running out of a log line. $\quad[13,15,16,17,21,28$.

Log-line.-A line to which the ship's log is attached. $[13,15$, $16,17,21,28$.

Log-Log Duplex Slide-Rule.-See Slide-Rule. 
Logograph.-An instrument for giving a graphic representation of the motion of the air-waves of speech. It consists of a horn connected with a diaphragm, which, by means of a pen, records its vibrations on a traversing strip of paper.

Logometer. - A scale for measuring chemical equivalents.

Log Ship.-A thin flat piece of board in the form of a quadrant of a circle attached to the log-line. $[13,15,16,21,28$. $]$

Lorgnette.-Eyeglasses of elaborate design, with handle to hold in the hand. $[2,9,15,17,20,21$.

Louchettes.-Opaque spectacles, with perforations in the centre to force the eyes to assume their normal positions.

Lovibond's Tintometer.-See Tintometer. $[3,5,13,17,21,26$.

Lowry's New Pattern Thermostat.-See Thermostat.

Lucernal Microscope.-See Microscope. [26.]

Lucimeter.-An instrument for measuring the intensity of light ; a photometer (q.v.). [13.]

Lumeter (Holophane).-A portable photometer (q.v.). [3.]

Luminous Geh Plate.-A glass plate for producing extended spectra by the interference of light reflected from its surfaces. [14.]

Lummer-Gehrcke Parallel Plate.-A very accurate plane-parallel plate of glass which acts as a diffraction grating (q.v.). [2, $3,10,14,20,26$.]

Lunette.-A species of convexo-concave lens for spectacles. $[17,26$.

Lunge's Nitrometer.-See Nitrometer.

Lux's Gas-Balance.-A delicate instrument for determining the weights of gases.

Lysimeter.-An instrument for measuring the water that percolates through a certain depth of soil.

\section{Macfarlane and Caldwell's Gas Analysis Apparatus.-See Gas Analysis Apparatus. [17.]}

Mackey's Cloth Oil-Tester.-See Cloth Oil-Tester. $[5,13$.

Macrometer.-An instrument for determining the size of distant or inaccessible objects by means of two reflectors on a common sextant.

Maddox Rod.-An instrument used in sight-testing.

Magic Lantern.-See Lantern. [2, 20.]

Magnet.-A body charged with or possessing the property of magnetism, such as the loadstone. Artificial magnets are usually made of bars of steel, magnetised by rubbing them with another magnet, or by coiling a wire in the form of a helix round a core of soft iron or steel and sending an electric current through the wire. In the latter case the magnet is termed an electro-magnet. $[13,15,16,17,19$. $26,28$.

Magnets, Robinson.-Spherical-ended magnets with true poles. [19.] 
Magnetic Balance.-A simple instrument for experiments on magnets. $[16,19$.

Magnetic Battery. - A combination of bar or horse-shoe magnets with the like poles adjacent, so as to act together with great power. $[16,26$. $]$

Magnetic Compass.-See Compass. $[5,13,15,16,20,24,25,27$.

Magnetic Compensator.-A contrivance connected with a ship's compass for compensating or neutralising the effect of the iron of the ship upon the needle. $[15,16,28$.

Magnetic Needle.-A light bar of steel magnetised, and suspended at its centre on a sharp pointed pivot or by a delicate fibre so that it may take up freely the direction of the magnetic meridian. It constitutes the essential part of the magnetic compass. $[13,15,16,17,21,24,27$.

Magnetic Standard (Duddell's Magnetic Standard).--An instrument consisting essentially of a pair of fixed coils, through which an electric current is passed; and a pair of moving coils, which can be rotated in the magnetic field produced by the fixed coils, thus producing an induced electric current. Its principal purpose is the calibration of ballistic galvanometers under conditions identical with those under which they will be used. [4.]

Magnetic Standard (Hibbert's).

Magnetic Telegraph.-A telegraph acting by means of a magnet. Magneto-Electric Machine.-A form of dynamo electric machine in which the magnetic field is maintained by permanent steel magnets. [17.]

Magnetograph.-An instrument for registering, by photography or otherwise, records of the states and variations of any terrestrial magnetic elements. $[4,6,15,17,21$.

Magnetometer.-An instrument for the measurement of magnetic declination and of the horizontal component of the earth's magnetic force. It consists essentially of a magnetic needle or bar, suspended so as to swing freely in a horizontal plane. According to the suspension the magnetometer may be Unifilar or Bifilar, and according to the observations required may be Vibration or Deflecting. $[4,13,15,1 \%]$

Magnetomotor.-A voltaic series of two or more large plates which produce a great quantity of electricity of low intensity, adapted to the exhibition of electromagnetic phenomena. $[13,17$.

Magnifier, Aplanatic.-A magnifying lens corrected for spherical aberration. $[1,2,3,9,10,15,17,20,21,22,25,26,27$.

Magnifier, Binocular.-A combination of two magnifying glasses for stereoscopic observation of small solid objects. $[2,3$, $10,13,15,20,26,27$.

Magnifier, Chart.-A hand magnifying lens for reading the soundings and other marks on a chart. $[2,13,15,16,20$, 21. 27,28 .] 
Magnifler, Coddington.-A magnifying glass composed of a cylindrical lens with a deep groove cut in at an equal distance from either end, acting as a diaphragm, giving good definition and wide field. $[2,3,5,9,13,15,17,20,21,22,24$, $25,26,27$.]

Magnifier, Triple Aplanat.-A magnifier composed of two meniscus lenses of flint glass separated by a double convex lens of crown glass or similar construction. $[1,2,3,12,13$, $15,22,23,26$.

Magnifying Cursor.-A slide-rule cursor with a magnifying lens attached. See also Slide-Rule. $[2.6,13,17,21,24,27$.

Magnifying Glass.-A convex glass or lens having the property of magnifying the image of the object observed. $[2,3,5$, $13,16,17,20,21,22,24,26,27$.

Magnophone.-A microphone (q.v.).

Mahler's Bomb Calorimeter.-See Calorimeter.

Mallock's Clinometer.-See Clinometer.

Mallock's Rolling Instrument.--See Rolling Instrument. $[13,21$.

Maltwood's Finder.-A slide for the microscope, ruled in numbered squares for registering and finding microscope objects. $[2,3,10,20,22,26$.

Mangin Mirror.-See Mirror.

Mancuvring Boards.-An instrument for the rapid graphical solution of plane and spherical trigonometrical problems.

Manometer.-An instrument for measuring the tension or elastic force of gases, steam, etc. ; constructed usually on the principle of allowing the gas to exert its elastic force in raising a column of mercury in an open tube, or in compressing a portion of air or other gas in a closed tube with mercury or other liquid intervening, or in bending a metallic tube or spring so as to set in motion an index. A pressure gauge. See also Gauge. $[5,6,13,15,16,17,18,21$.

Manometer, Air.-A sensitive form of pressure gauge to indicate the pressure of the gas in the balloon of an airship. $[4,13$, $15,16,17$.

Manometer, Coal Dust.-A manometer for recording the pressure developed during an explosion of coal gas. [4.]

Manometer, Differential.-A manometer for indicating differences of gaseous pressures, used in the measurement of the pressure of furnace gas, etc. $[6,1 \%$. $]$

Manometer, Flame.-An instrument for obtaining graphic representations of the sounds of the human voice.

Manoscope.-Strictly an instrument to indicate, but not to measure, variations of gaseous pressure. Loosely used, the term is the same as manometer (q.v.).

Map Measurer.-An instrument with a little wheel of known circumference which is made to roll along a line and indicate its length, the number of revolutions being counted. $[2,5$, $6,13,15,17,20,21,24,25,26,27$.] 
Marching Compass.-See Compass. $[2,5,6,10,13,15,16,17$, $20,21,24,25,26,27$.]

Marconi Telegraph. - The term usually applied to the wireless telegraph apparatus named after its principal inventor.

Mareograph.-A registering tide-gauge. $[15,17,21$.

Marey's Sphygmograph.-See Sphygmograph.

Marine Barometer.-See Barometer. $[5,6,13,15,16,17,21$, $26,28$.

Marine Chronometers.-See Chronometers. $[13,15,16,17,20$, $21,24,28$.]

Mariner's Compass.-A ship's compass (q.v.). $[9,13,15,16,17$, $20,21,28$.]

Mark VI. Compass.-A Service pattern marching compass. $9,13,15,16,20,21,24,25,26,27$.

Mark VII. Compass.-A Service pattern marching compass. [6, $9,13,15,16,20,21,24,25,26,27$.]

Mark VIII. Compass.-A Service pattern marching compass. [6, $9,13,15,16,21,25,26,27$.

Mark IV. Telescope.-A Service pattern signalling telescope (q.v.).

Marking Gauge.-A tool or instrument for rapidly marking set dimensions on woodwork, etc. $[8,15$.

Marquois Scale.-A special scale and triangle used for military drawing. $[2,5,6,13,15,17,20,21,24,25,26,27$.

Mason's Hygrometer. - A form of wet and dry bulb thermometer. $[5,6,9,13,15,16,17,20,21,24,26$. $]$

Mathematical Instruments. - The various instruments used by draughtsmen and engineers for geometrical and mechanical drawing. $[2,6,13,15,17,20,21,24,25,27$.

Maxim Fire-Director and Protractor.-A protractor designed especially for use with the Vickers gun and Mark VII. S.A. ammunition. [20.]

Maximum Registering Aneroid.-For registering the maximum altitude attained. See Barometer. $[2,6,13,15,17,20,21$, $24,26,27$.]

Maximum Thermometer.-See Thermometer. $[2,5,6,13,15$, $16,17,20,21,24,25,26,27$.]

Maxwell's Vibrating Needle.-An apparatus for finding the modulus of torsion of a wire by observing the times of swing of tubes of different moments of inertia which are suspended from the wire under test. $[4,19$.

McInnes Indicator.-Improved form of engine indicator (q.v.). $[13,15,16,17,28$.

Meanometer.-A boxwood scale divided with the various indicator scales, and having a sliding index for ascertaining the mean pressure of steam from an indicator diagram. $[13,15,28$.

Measuring Microscope.-A special form of microscope for workshop use for the accurate measurement of small distances, e.g., by the use of an eyepiece micrometer or of a micrometer screw by means of which the microscope can be traversed. $[2,3,4,6,10,14,19,21,22,25,26$. $]$ 
Meatoscope.-A speculum for examining a natural passage such as the urethra.

Mechanical Equivalent of Heat Apparatus.-As designed by Dr. G. F. C. Searle, F.R.S. $[4,19$.

Mechanical Finger.-A device for selecting microscopical specimens from a mass of material and placing it upon a slide for mounting. $[2,26$.

Mechanical Locomotive Pyrometer.-See Pyrometer, Locomotive. [16.]

Mechanical Stage.-An appliance for attaching to the stage of a microscope for moving a specimen vertically and horizontally. $[2,3,8,17,21,22,26$. $]$

Megalethoscope.-An optical apparatus in which pictures are viewed through a large lens with stereoptical effects. It is often combined with a stereoscope.

Megalograph.-A form of camera lucida (q.v.).

Megameter.-An instrument for determining longitude by observation of the stars.

Megaphone.-A device for increasing the sound and carrying power of the voice. It consists of a conical funnel with a suitable mouthpiece. It can also be used to increase the power of hearing. $[13,15,16,17,26,28$. $]$

Megascope.-A modification of the magic lantern, used especially for throwing a magnified image of an opaque object on a screen, solar or artificial light being used. $[2,17,26$.

Méker Burner.-A special form of Bunsen burner providing for complete combustion of the mixture of gas and air and giving a mass of flame at practically the same temperature throughout. The coolest portion of the flame is hotter than the hottest portion of the ordinary Bunsen flame.

Mekometer.-A two-man rangefinder used in the infantry, consisting of two angle measuring instruments connected by a long wire and operated by two observers. $[6,13,17$, $18,20.21,25,26,27$.

Melanoscope.-An instrument containing a combination of coloured glasses such that they transmit only red light, so that objects of other colours, as green leaves, appear black when seen through it. It is used for viewing coloured flames to detect the presence of potassium, etc., by the red light which they emit.

Melodiagraph.-A contrivance to record the notes of tunes played upon an instrument.

Melville Stadia.-An improved form of levelling staff (q.v.) for facilitating the reading of a staff in hot climates.

Mercurial Plumb Bob.-A special form of plummet made of hollow steel filled with mercury. $[13,15,17,21,24,27$.

Mercury Micro-Lamp.-An electric light formed by passing a current through mercury vapour and thus producing light of a few definite colours, used for the illumination of microscopic specimens. $[2,3$. 
Meridian Circle.-A transit instrument with a graduated circle securely fastened at right angles to the horizontal axis, and turning with it. $[10,21,24,25,27$.

Meridian Instrument.-Any astronomical instrument having a telescope that revolves in a meridian plane. $[10,18,21,24$, $25,27.7$

Meridian of a Globe, or Brass Meridian.-A graduated circular ring of brass, in which the artificial globe is suspended and revolves. $[13,15$.

Metal Bending Tester, Sankey's.-A workshop instrument for testing steel and other metals by observing the energy required to break a small test piece by repeated bending.

Meteorograph, Dines's.-An instrument used in investigations of the upper atmosphere. Made in two forms: (A) Consisting of a barograph (q.v.) and thermograph (q.v.) marking on very small, silvered copper plates which are subsequently examined under the microscope ; this form is attached to a small balloon. And (B) Consisting of a barograph, thermograph, hygrograph, and wind-velocity recorder, the four records being made on a circular paper chart; this form is attached to a kite. $[6,13,17,21$. $]$

Meteorometer.-An apparatus for receiving at a local station, transmitting to a central station by telegraph, and there recording the direction and velocity of the wind, condition of the barometer and thermometer, and amount of rainfall. [17.]

Meteoroscope.-An instrument used for taking angles and making measurements of the heavenly bodies.

Meteor Wind Corrector.-A celluloid instrument designed by Major Hatfield for i8-pdr. gun. [15.]

Meter.-An instrument for measuring, and frequently for recording automatically, the quantity measured, e.g., gas meter, water meter, electricity meter, etc. $[16,17,20$.

Meter, Fluid.-An instrument for measuring the quantity of fluid passing a selected point. [4.]

Meter, Gas Pressure.-An instrument for measuring the gas. pressure in gasworks, etc. [17.]

Meter, Gas Purity.-An instrument for the determination of the purity of gas. [4.]

Meter, Hydro-volume.-An instrument for measuring the consumption of furnace gas and air.

Metric Scales.-Measuring scales divided according to the metric system for the use of draughtsmen. $[2,5,6,13,15,17,21$, $24,25,26,27$.]

Metrochrome.-An instrument for measuring colours.

Metrograph.-An instrument attached to a locomotive for recording its speed and the number and duration of its stops.

Metroscope.-An instrument for measuring inaccessible heights and distances and for levelling. 
Mica Wave-Plate.-A thin sheet of mica for measuring the retardation of polarised light. $[2,3,22,26$.

Michelsen's Actinometer.-See Actinometer. $[17,20,21,26$. Michelson's Interferometer.-A special form of interferometer (q.v.).

Michelson's Pyrheliometer.-See Pyrheliometer.

Micro-Electroscope.-A form of electroscope by Mr. C. T. R. Wilson, in which a strip of gold leaf hangs beside a prolongation of a wire, to which it is attached at its upper end. When the electroscope is charged the wire repels the gold leaf, the deflection of which is measured either by a microscope with micrometer eyepiece, or against the reflected image of a millimetre scale. $[4,19$.

Micrograph.-A pantograph (q.v.) for executing extremely minute writing and engraving.

Micromanometer.-A sensitive manometer (q.v.) for measuring very small differences of pressure. $[4,13,17$.

Micromanometer, Chattock Tilting.-A manometer in the form of a modified V-tube water gauge. The principle of the gauge is that of a V-tube in which the difference of the pressures on the surfaces of the water in the two limbs of the tube is measured by tilting the gauge through a very small angle so that there is no displacement of the water along the tube. [4.]

Micromanometer, Fry's.-An instrument in which the two pressures whose difference is to be measured are applied to the two sides of a stretched circular membrane. The resulting displacement of the centre of the membrane twists a suspended mirror, and the deflection of a spot of light reflected from this mirror indicates the pressure difference. [4.]

Micromanometer, Threlfall's.-An instrument consisting essentially of a V-tube containing oil or water, the two limbs of which are formed by air-tight vessels. The difference in pressure between the two limbs is determined by means of a micrometer screw adjusted until its tip just touches the surface of the liquid in one of the limbs, the micrometer head being graduated to give readings of pressure difference directly. $[4,21$.

Micrometer.-(I) An instrument used with a telescope or microscope to measure small distances or the apparent diameters of objects which subtend very small angles. (2) A mechanical device for measuring small lengths in engineering and other work. $[2,3,9,13,14,17,18,20,21,22,21,25,26,27$.

Micrometer Balance.-A balance for ascertaining minute differences in weight.

[26.]

Micrometer, Bifilar. - A micrometer with two threads, one of which at least is movable. $[2,3,11,1 \%, 20,22,25,26$.

Micrometer, Calliper.-A calliper with a micrometer screw for measuring dimensions with great accuracy. See also Calliper. $I[2,5,19,25$. $]$ 
Micrometer Circular Ring.-A metallic ring fixed in the focus of the object-glass of a telescope and used to determine differences of ascension and declination between stars.

Micrometer, Cobweb. - A micrometer in which cobweb threads are used. Usually consists of a viewing eyepiece, cobwebs mounted on a slide, and a micrometer screw with divided scale. $[2,3,17,21,22,26,27$.

Micrometer, Crack.-A micrometer for detecting and measuring the relative movements of the two sides of a crack or fissure in a building and so ascertaining how the crack is developing. [4.]

Micrometer Dial Calliper.-A calliper with micrometer screw, and dial from which the dimensions are read. See also Calliper.

Micrometer, Dioptric.-A form of double image micrometer, introduced by Ramsden, in which the divided lens is in the eyetube.

Micrometer, Double Image.-A micrometer in which two images of the object are formed in the field of an optical instrument, usually by the two halves of a bisected lens which are movable along their line of sector by a screw, and distances are determined by the number of screw revolutions necessary to bring about optical coincidence. $[3,13,25$.

Micrometer, Double Refraction.-A double image micrometer in which the two images are formed by the double refraction of rock or crystal or Iceland spar. [3, 13, 25.]

Micrometer Eyepiece.-See Eyepiece, Micrometer. $[2,3,10,18$, $19,20,21,27$.

Micrometer, Filar.-Another name for the cobweb micrometer (q.v.). $\quad[2,3,4,17,18,20,22,27$.

Micrometer, Gauge.-See Micrometer Calliper. [19.]

Micrometer, Linear.-A minute and very delicately graduated scale of equal parts. [1\%]

Micrometer Microscope.-A compound microscope combined with a filar micrometer, used chiefly for subdividing the divisions of astronomical and geodetical instruments, and for exact measurements of small distances. $[2,3,17,21,22$, 25,26 .]

Micrometer, Position.-A micrometer applied to the tube of an astronomical telescope for measuring angles of position in the field of view.

Micrometer, Reeves's Tangent.-A tangent micrometer screw for use on theodolites and sextants. [6.]

Micrometer, Raticulated.-A form of micrometer for measuring small celestial distances.

Micrometer Screw.-A screw fitted to optical and mathematical instruments as a means for exact measurement of very small angles or distances. $[2,3,15,17,20,21,22,24,25$, 27.] 
Micrometer Screw Contact Calliper.-A combination of a calliper and a telephone. When the contact is loosely made, a boiling sound is heard, which ceases when a firm contact is made. See also Calliper.

Micronometer.-An instrument for noting minute portions of time.

Microphone.-An instrument for increasing the intensity of low sounds by communicating their vibrations to a more sonorous body which emits a more audible sound. [26.]

Microscope.-An optical instrument consisting of a lens or combination of lenses for making an enlarged image of an object which is too minute to be viewed by the naked eye. $[2,3,5,8,9,13,16,17,20,21,22,26$. $]$

Microscope, Binocular.-A microscope with two eyetubes, fitted with eyepieces, for viewing the object through the objectglass with both eyes at the same time. $[2,3,5,9,15,17$, $20,21,22,27$.]

Microscope, Greenough Binocular.-A combination of two microscopes, each with a set of erecting porro prisms, giving a pronounced stereoscopic effect. $[2,3,13,26$.

Microscope, Jointed.-A pocket microscope in which the handle and lens-holder shut down against the slide on which the object pliers are adjustable. $[2,13,21,26$.

Microscope, Lucernal.-A form of microscope in which the object is illuminated by means of a lamp and its image is thrown upon a plate of glass connected with the instrument or on a screen independent of it. [26.]

Microscope, Reflecting.-A microscope in which the image formed by a small concave speculum may be viewed either by the naked eye or through an eyepiece.

Microscope, Solar.-A microscope in which the sunlight is used as an illuminant. An enlarged image of the object is projected upon a screen in a darkened room or dark box.

Micro Spectroscope.-A spectroscope arranged for attachment to a microscope. See also Spectroscope. $[2,3,14,22,26$.

Micro Tasimeter.-A tasimeter (q.v.) arranged for measuring very small extensions.

Micro-Telescope.-A combination microscope and telescope suitable for botanical work. $[2,13,21,26$.

Microtome.-An apparatus for freezing preparations and cutting sections of same for microscopic examinations. $[2,3,4,17$, $19,20,22,26$.]

Microtome, Becker's Freezing. [20.]

Microtome, Cambridge Freezing. $[4,26$.

Microtome, Cathcart's. [3, 26.]

Microtome, Granta Ball-Bearing.

Microtome, Swift's. $[3,22$.

Microtome, Williams's. [3,22.]

Mileage Recorder.-An instrument for recording distance in miles travelled by a motor-car, etc. [16.] 
Milk Analyser.-See Leffman-Beam Centrifugal Machine; also Lister and Babcock.

Mine Dial.-See Dial. $[5,16,18,21,24,27$.

Mine Explosion Apparatus.-A set of instruments devised for the investigation of explosions in coal mines. It includes circuit-breakers, contact-makers, measuring machine, onetenth of a second time-markers, and sampling bottles. [4.]

Mine Explosion Measuring Machine. - An instrument for measuring the records obtained from the manometers used in mine explosion apparatus, by means of a microscope and micrometer screw.

Mine Shaft Plummet.-A special plummet used in mining work, made in several sizes $-4 \frac{3}{4}$ lbs., 7 lbs., etc. $[21,24,27$.]

Miner's Circumferentor.-A form of mining compass with sights, used by surveyors for taking horizontal bearings. $[2,13$, $15,17,18,20,21,24,25,26,27$.]

Miner's Dial.-See Dial. $[2,5,6,13,15,16,17,18,20,21,24$, $25,26,27$.]

Minim Measures.-A small graduated glass measure. [17, 20.]

Minimum Thermometer.-See Thermometer. $[2,5,6,13,15,17$, $21,24,25,26,28$.]

Minute Glass.-A glass for measuring a minute or minutes by the running of sand. $[2,13,15,16,17,20,21,28$.

Mirror.-Any glass or polished surface that forms images by the reflection of rays of light. $[1,2,3,8,10,11,13,15,17$, $18,20,26$.]

Mirror, Azimuth.-A mirror fitted on the glass cover of a compass bowl for taking bearings.

Mirror, Fresnel's.-Two mirrors fixed at an inclination of nearly $180^{\circ}$ to one another for producing interference images. See also Parabolic Mirror, Optical Mirror. [3.]

Mirror Galvanometer.-See Galvanometer. $[4,16,19$.

Mirror, Mangin.-A mirror in which the silvered surface has a different curvature from that of the outside surface. The curves are so chosen that the aberration of the lens so formed neutralises that of the spherical mirror.

Mirrorscope.-A simple form of projection lantern for opaque objects.

Mitre Square.-A bevel square whose blades are set immovably at an angle of $45^{\circ}$ with each other. $[15,17,24,25,27$.

Moderator.-An optical device consisting of opal coloured glass or ground glass to moderate and diffuse the light passing from a lamp to an object on the stage of the microscope. $[3,22,26$.

Moisture-Testing Apparatus.-For determining the moisture content of whole grain.

Molten Metal Thermometer.-See Thermometer. $[5,6,16,17$.

Monocentric Eyepiece.-See Eyepiece. [2, 3.] 
Monochord.-An instrument consisting of a wood frame fitted with one or more steel wires and movable bridges, and an arrangement for varying the tension of the wires, used for experiments in sound vibrations. See Sonometer.

Monochromatic Bench.-An optical bench for producing monochromatic light. $[2,3,26$.

Monochromatic Lamp.-A lamp fed with a mixture of a solution of common salt and alcohol, or other lamp for producing monochromatic light. [26.]

Monochromator.-A lamp giving illumination from one part of the spectrum; another name for a spectroscope. [14.]

Monocle.-A single eyeglass. $[10,17,20,21,26$.

Mooney's Rhumboscope.-See Rhumboscope. [15.]

Morrow's Mirror Extensometer.-See Extensometer.

Morsaphore.-A special pattern of ship's semaphore combined with a Morse signalling lamp. $[13,15,16$.

Morse Lamp.-A special lamp for signalling by the Morse code. $[13,15,16,26,28$.

Morse Tapper.-A telegraphic key or instrument for producing the dot and dash signals in telegraphy. $[15,16,17,19,28$.

Motor-Car Gauges.-Various gauges made for and used on motorcars for determining speed, gradient, etc. $[13,17$.

Mountain Barometer.-A portable barometer (q.v.) designed for measuring vertical heights above the sea. $[2,5,6,13,15$, $16,17,20,21,24,25,26,27,28$.]

Mountain Rain-Gauge.-See Rain-Gauge. $[6,13,15,17,20,21$, $24,25,26$.]

Mountain Transit Theodolite.-See Theodolite. $[2,6,13,17,21$, $24,25,26,27$.]

Moving Magnet Galvanometer.-See Galvanometer. $[4,10,16,19$.

Multiplex Slide-Rule.-See Slide-Rule. $[13,21,26$.

Multiplicator.-In galvanometers, a flat coil of conducting wire for multiplying the effect of the current upon the needle.

Munro Air-Speed Indicator.-See Speedometer. [15.]

Muralcircle.-A graduated circle on the plane of the meridian attached permanently to a perpendicular wall, used for measuring arcs of the meridian.

Mydriasis Spectacles.-See Spectacles. [26.]

Mydynamometer.-An instrument for measuring the muscular strength of a man or other animals.

Myograph.-An instrument for determining and recording different phases, such as the intensity and velocity of a muscular contraction. See also Pendulum Myograph. [4.]

Myrioscope.-A form of kaleidoscope (q.v.). [20.]

Nachet's Prism.- See Prism. [2, 3, 26.]

Napier's Compasses. - A draughtsman's folding pocket-compasses, to one leg of which is pivoted a plain point and pencilholder and to the other a plain point and pen. See Compasses. $[2,5,6,13,15,17,20,21,24,25,26,27,28$. 
Napier's Rods.-A set of rods contrived by Baron Napier and first described by him in 1617 for the purpose of facilitating the numerical operations in multiplication and division.

Natrometer.-An instrument for estimating the quantity of soda contained in salts of potash and soda. [17.]

Nauropometer.-An instrument for measuring the amount which a ship heels at sea. $[13,15$. $]$

Nautigan.-A calculating instrument for solving nautical problems. [15.]

Naval Protractor. - A special form of protractor for laying down a ship's course. $[13,15,16,17,28$.

Naval Station Keeper, Bell's.-A pocket prism apparatus for keeping station in the navigation of ships. $[13,15,17,20$.

Naval Telescope.-See Telescope. $[1,2,3,5,6,8,9,10,13,15$, $16,17,18,20,21,23,24,25,26,27,28$.]

Navigraph.-A form of sextant (q.v.) for fixing the position of a ship direct on a chart. [15.]

Navisphere.-A star globe for use in navigation. $[13,15$.

Needle Telegraph.-See Telegraph.

Negative Eyepiece.-See Eyepiece. $[1,2,3,8,10,11,17,20,21$, $23,25,26,27$.]

Nephelodometer.-An instrument for reckoning the distances or velocities of clouds. $[15,17$.

Nephoscope.-An instrument for determining the direction and angular velocities of clouds. $[15,17$.

Nephoscope, Benson's Comb. - A direct vision nephoscope consisting of a vertical rod carrying at the top a horizontal rod bearing a number of equidistant vertical spikes.

Nephoscope, Fineman's.-A reflecting nephoscope consisting of a disc of black glass mounted on a tripod with three levelling screws and a vertical pointer which can be raised or lowered by a rack and pinion, and a magnetic compass placed below the glass.

Newton's Disc.-A cardboard disc, about a foot in diameter, its centre and edges covered with black paper like the spokes of a wheel. Arranged around the centre are strips of paper of such dimensions and tints as to constitute five spectra. It is made to rapidly revolve to show the composition of white light.

Newton's Rings. - Rings of colour caused by the interference of light concentrically arranged when a thin lamina of regularly varying thickness of anything transparent is subjected to the action of light.

Newtonian Telescope.-See Telescope. $[2,3,11,26$.

Nobili's Thermopile or Thermo-Electric Battery. - See Thermopile.

Nicholson's Hydrometer for Solids.-See Hydrometer. $[17,21$. Nicholson's Hydrometer for Liquids.-See Hydrometer. [21.]

Nicol Prism.-A rhomb of Iceland spar for transmitting polarised light. It is bisected obliquely at a certain angle, and the two parts again joined with transparent cement, so 
that the ordinary beam of light produced by double refraction is thrown out of the field by total reflection from the internal cemented surface, and a polarised beam of light alone is transmitted. See also Prism. $[2,3,20,22$, 25,26 .]

Night Glass.-A Galilean binocular (q.v.) with large object-glass giving great illumination at night. [15].

Night Surveying Lamp.-A lamp used in mine surveying. $\quad[6,15$, 27.]

Nilometer.-An instrument for measuring the rise of water in the Nile during its periodic flood.

Niloscope.-A Nilometer.

Nitrogen Apparatus.-For the estimation of nitrogen.

Nitrometer.-An apparatus for determining the amount of nitrogen or some of its compounds in any substance subjected to analysis. An azotometer.

Noctograph.-An instrument or register which records the presence of watchmen on their beats.

Nocturnal or Nocturlabrium.-An old form of instrument, chiefly used at sea, to take the altitude or depression of the pole star, for finding the latitude and the hour of the night.

Normatachograph.-An instrument for determining and registering the duration of more or less complex operations of the mind.

Norrenberg's Polariscope.-See Polariscope. [3, 26.]

Nose-piece. - The end of a microscope body to which the objectglass is attached. Double, triple, or quadruple nosepieces carry two, three, or four object-glasses at one time. $[2,3$, $17,20,21,22,26$.]

Notcutt Flank Observation Computer.-See Flank Observation Computer. [15.]

Notcutt Wind-Corrector.-See Wind-Corrector. [15.]

Nut Angles.-Two special drawing slopes, used by mechanical draughtsmen for giving the angle of hexagon nuts. $[6,15$, 21.]

Object-Glass.-The lens or system of lenses placed at the end of a telescope, microscope, etc., which is nearest to the object being examined. $[1,2,3,8,9,10,11,12,13,15,17,18$, $20,21,22,23,24,25,26,27$.]

Object-Finder.-A means of registering the position of a microscope object in a slide so that it may be readily found in future. $[2,3,17,20,26$. $]$

Object-Staff.-A staff the same height as the level, forming a sight to be viewed by its means, used in determining levels.

A levelling staff. $[13,15,17,24,26,27$.

Objective.-In optics the object-glass (q.v.). $[1,3,10,12,15$ $21,26$.

Obtuse Angle Thermometer.-See Thermometer. $[5,13$. 
Octant.-An instrument for measuring angles; it resembles a quadrant or sextant in principle. The eighth part of a circle. $[10,13,15,16,21,28$.

Ocular.-The eyepiece of a telescope, microscope, or other optical instrument. $[1,2,3,9,10,15,20,21,22,26$. $]$

Odograph. - An apparatus for measuring the length and rapidity of a man's stride in walking. $[13,21$.]

Odometer.-An instrument for measuring distances. A wheel used by surveyors which registers the miles and rods traversed. $[13,17,21,26,27$.

Odontograph.-An instrument for marking or laying off the teeth of gear wheels. $[15,21,24$.

Oenometer.-A form of hydrometer (q.v.) adapted to determine the alcoholic strength of wines. $[13,21$.

Officer of Watch Telescope.-See Telescope. [2, 3, 5, 9, 13, 15, 16, $17,20,21,23,24,25,26,27,28$.]

Offset Square Staff.-A rod usually ten links long and divided into ten equal parts. Used in measuring offsets. $[5,6,13$, $15,17,21,26,27$.]

Offisets.-Short scales for laying off the offset distances on a plan. $[2,5,6,13,15,17,21,24,25,26,27$.

Offsetting Staff.-A wooden staff divided into links for measuring distance on either side of the survey line. $[5,6,13,17,21$, $24,26,27$.]

Ogilvie Air-Speed Indicator.-A speed instrument for aeroplanes. See Speedometer, Air-Speed Indicator.

0'Gorman Tautness-Meter.-See Tautness-Meter. $[4,6,21$.

Ohmmeter.-An instrument for the direct measurement of electrical resistance in ohms.

Oil-Boiling Thermometer.-See Thermometer. $[5,13,16,17,21$.

Oil-Fuel Thermometer.-See Thermometer. $[13,15,16,17,21$, 28.]

Oil Hydrometer.-A hydrometer (q.v.) for indicating the specific gravity of oil. $[5,13,15,16,17,21,28$.

Oil Rod.-A dipping rod for measuring the contents of oil vessels. $[6,13,15,28$.

Oil-Tempering Bath Thermometer.-See Thermometer. $[5,6$, $13,15,16,17$.

Oil-Tester, Thurston's Patent.-An instrument for testing lubricating oils. There is also a recording instrument, railroad and steamship pattern. $[13,15$.

Oil Weight, Redwood Standard.-A standard brass weight used in the measurement of the oil in tanks. $[13,15$.

Oleine Tube.-A graduated tube for determining oleine in oils and fats.

Oleometer.-A hydrometer (q.v.) adapted for determining the relative densities of oils. $[5,13,17,21$.

Oleorefractometer, Jean's. - A refractometer (q.v.) for the analysis of butter, fats, oils, glycerine, turpentine, etc. The refractive 
power of the oil or fat under examination is compared with the refractive power of a standard oil. $[13,26$.

Ombrometer.-An apparatus or instrument to measure the depth of rain which falls; a rain-gauge (q.v.). [17.]

Omnigraph.-See Pantograph. [21.]

Omnimeter. - A theodolite (q.v.) with an additional scale for measuring distances. $[2,13,15,21,25,26,27$.

Oncograph.--An instrument for recording the measurements made by the oncometer (q.v.).

Oncometer.-An instrument for measuring the variations in size of the internal organs of the body, as kidney, spleen, etc.

One Handed Dividers.-Improved chart dividers; can be opened and shut with one hand. See Divider. $[5,6,13,15,16,17$, $21,28$.

One-Tenth of a Second Time-Marker.-In mine explosions apparatus (q.v.) used in connection with the recording manometers to determine time-intervals.

Opacities Apparatus.-Designed by Prof. T. B. Wood, Professor of Agriculture, University of Cambridge, more particularly for ascertaining and comparing the baking quality of wheat. Can be used for comparison of the opacity of liquids. [19.]

Opaque Disc Revolver.-An apparatus for holding and rotating a microscopic object so that five sides of a cube can be examined without removal from the microscope. $[2,3,26$.

Opeidoscope.-An instrument consisting of a tube, open at one end, covered with a flexible membrane at the other, which carries a small mirror for exhibiting on the screen vibrating motion caused by sound. [4.]

Opera-Glass.-A small Galilean binocular telescope (q.v.). It has a concave eyeglass and a convex object-glass, so that the image is not inverted and little light is lost. $[2,5,9$, $10,13,15,16,17,20,21,24,26,27,28$.]

Operameter.-An attachment to a machine to indicate the number of rotations of a shaft. $[5,6,13,15,17$.

Ophthalmic Mirrors.-A special form of mirror used for the examination of the eye. $[2,3,10,20,21,26$.

Ophthalmic Spinthariscope.-An instrument to test the sensitiveness of the retina of the eye by reference to a standard light emitted by radium. $[3,26$. $]$

Ophthalmoscope.-An instrument for viewing the interior of the eye, particularly the retina. Light is thrown into the eye by a mirror, usually concave, and the interior is then examined with or without the aid of a lens. $[2,3,17,20$, $21,26$.

Opisometer.-An instrument with a revolving wheel for measuring a curved line on a map. $[2,15,17,20,21,24,25,26,27,28$.

Opsiometer.-An instrument for measuring the limits of distinct vision in different individuals, for determining the focal 
length of lenses suited for remedying imperfect vision, etc. $[2,5,13$.

Opsonic Apparatus.-Used for taking the opsonic index, or power of resistance to disease organisms. [26.]

Opthalmometer.-(I) A surgical instrument of the nature of compasses for measuring the capacity of the chambers of the eye in anatomical experiments. (2) An optical instrument for ascertaining the true distance at which an object shall be viewed for the accommodation of each eye. $[2,3$, 17, 20, 26.]

Optical Bench.-A rigid, graduated bench, usually of steel, on which the holders for lenses, prisms, sources of light, etc., can be suitably mounted in alignment, with freedom of movement along the bench, for making photometric or other optical measurements. $[2,3,4,10,13,17,19,21,26$. $]$ Optical Circle.-A graduated circle used for the measuring of angles in optical experiments. $[1,13,17$.

Optical Glass.- - [\%.]

Optical Mirror, Plane Circular.-An optically worked plane silvered mirror (q.v.). $[1,3,8,10,11,13,15,17,18,19,21$.]

Optical Mirror, Plane Oval.-A plane mirror of oval outline placed within a Newtonian telescope for directing the light from the spherical mirror into the eyepiece in a direction at right angles to the line of incidence. $[1,3,11,13,15,17$, 18,26 .]

Optical Prism.-Accurately worked prisms for use in optical instruments. See Prism. $[3,8,9,10,11,12,13,15,17,18$, $19,20,26,27$.]

Optical Projection Screen.-A screen for use with a magic lantern having a metallic surface giving a diffuse reflection.

Optical Pyrometer.-See Pyrometer. $[4,21,26$. $]$

Optical Square.-A reflecting instrument used by surveyors and others for laying off lines at right angles to each other. $[2$, $11,13,15,17,21,24,25,27$.

Optigraph.-A form of camera used for the purpose of copying landscapes.

Optometer.-An instrument for ascertaining the extent of vision in different individuals for the purpose of choosing proper lenses to correct defects of sight. $[2,17,26$. $]$

Ordnance Survey Scales.-Drawing scales showing the various scales used in the Ordnance Survey. $[2,5,6,13,15,17,20$, $21,24,25,26,27$.]

Orientator.-An instrument used in regulating the ground plan of a church so as to present the chancel to the east. $[13,15$.

Orograph.-An instrument for mapping out undulating or mountainous surfaces.

Orrery.-An apparatus - which illustrates by the revolution of balls moved by wheelwork the relative size, periodic motions, etc., of bodies in the solar system. [26.]

Orsat's Gas Analysis Apparatus.-See Gas Analysis Apparatus. 
Orthoscope.-An instrument designed to show the condition of the superficial portion of the eye.

Orthoscopic Eyepiece.-An eyepiece giving a specially large field of view; a Kellner eyepiece. Apparent field of view, $40^{\circ}$. $[1,2,3,10,20,21,22,23,25,26,27$. $]$

Orthoscopic Lens.-An arrangement of two achromatic compound lenses separated by an interval. $[1,21,23,26,27$.

Oscillating Prism Telescope.-See Telescope.

Oscillating Table, Bryan's.-An instrument for demonstrating the properties of moments of inertia. [19.]

Oscillograms.-Diagrams produced by means of the oscillograph (q.v.). [4.]

Oscillograph.-An instrument for recording the wave form of current and voltage in alternating current circuits. [4.]

Oscillograph, Duddell.-An oscillograph which traces out and records photographically to uniform scales curves connecting current or voltage with time. [4.]

Oscilometer.-An instrument for measuring the angle through which a ship rolls at sea. $[5,13,15,1 \%$. $]$

Osmometer.-An instrument for measuring osmosis in different liquids.

Osteophone.-An instrument for the transmission of auditory vibration through the bones of the head, so as to be appreciated as sounds by persons deaf from causes other than those affecting the nervous apparatus of hearing.

Ostwald's Capillary Electrometer.-See Electrometer.

Ostwald's Water Thermostat.-See Thermostat.

Otacoustic.-An instrument to facilitate or improve the sense of hearing ; an ear-trumpet.

Otheoscope.-An instrument for exhibiting the repulsive action produced by light or heat in an exhausted vessel.

Othoscope.- An instrument for holding water round the eye to enable the interior to be seen.

Otoscope.-An instrument for viewing the interior of the ear.

Outside Callipers.-See Callipers. $[17,20,21,25$.

Oxide Testing Thermometer.- See Thermometer. $[13,15,21$.

Ozometer.-See Ozonometer.

Ozonometer.-An instrument for ascertaining the amount of ozone in the atmosphere. $[6,17,21$.

Ozonoscope.-An apparatus employed to indicate the presence or amount of ozone.

Pacoometer.-See Passometer. $[2,15,21,24,27$.

Pachometer.-An instrument for measuring thickness, as of the glass of a mirror, or of paper ; a pachymeter. [2.]

Pachymeter.-See Pachometer. [2.]

Paget Angle Sextant. - See Sextant. $[15,27$.

Paget Artificial Horizon.-See Artificial Horizon. [15.]

Paget Compass Card.-A compass card (q.v.) with short needles. [15.] 
Paget Deflector.-A special form of compass deflector. [15.]

Paget Dipping Needle.-A special form of dip needle (q.v.). [15,] Paget Star Globe.-See Star Globe. $[13,15$.

Pagoscope. - A form of wet and dry bulb thermometer with diagram to foretell in the early evening whether there will be a frost during the following night. See also Hygrometer. [2, $15,17,20,21,26$.

Paleophone.-A writing telephone.

Palinurus.-A gimballed instrument with time and latitude scales for use on board ship to ascertain the true course without tables or calculations. [15.]

Pancratic Eyepiece.-See Eyepiece.

Panograph, The Simplex.-A device to assist in making a panoramic sketch in correct proportion and perspective. [21.]

Pantagraph.-A pantograph (q.v.). $[2,5,6,13,15,17,20,21$, $24,26,27$.]

Pantascope.-An optical apparatus for viewing pictures through a magnifying glass. [15.]

Pantochrometer.-An instrument which is a combination of the compass, sundial, and universal sundial. [13.]

Pantograph.-An instrument used in copying plans, maps, and other drawings on the same or on a reduced or enlarged scale. It consists of a series of levers pivoted together having a tracing point and a pencil fixed to suitable points on the levers. See also Plagiograph. $[6,10,13,15,17,21$, $24,25,27$.]

Pantometer.-An instrument for measuring angles for the determination of elevations, distances, etc. $[6,13$.

Paper Scales.-Used by draughtsmen. Made of paper in place of wood. Board of Trade official set. $[2,5,15,17,20,21$, $24,26,27$.]

Paper Weighing Balance.-A weighing machine used by papermakers for ascertaining the weight per ream by weighing one sheet.

Parabola (Wenham's).-A glass reflector of paraboloid shape for reflecting oblique light upon a microscopic object from below. $[2,3,20,22$.

Parabolagraph, Inward's.-An instrument founded on that property of the parabola by virtue of which any point on it must be equally distant from a point called the focus and a line called the directrix.

Parabolic Curves.-A set of wood or metal curves for drawing parabolas. $[2,15,20,21,24,25,27$.

Parabolic Iluminator.-See Iluminator. $[2,3,20,22,26$.

Parabolic Mirror.-A mirror, usually concave, the surface of which is generated by the revolution of the arc of a parabola. $[1,3,11,26$.

Paraboloid Condenser.-See Condenser. $[2,3,20,22$. 
Parallactic Instrument.-An instrument invented by Ptolemy for determining the moon's parallax.

Parallel Chart Dividers. - A fine pointed divider (q.v.) for setting off parallel lines and accurately marking a ship's position on the chart. $[2,13,15,16,17$.

Parallel Circular Plates.-Optically worked parallel glass plates. $[10,13,15,20,21$.

Parallel-Compressor.-A means for holding or compressing an object under the microscope. It consists of two frames, each carrying a thin glass, and mechanism for bringing the glasses together while keeping them parallel. $[2,3,20$.]

Parallel Dividers.-For the use of draughtsmen. See Parallel Chart Dividers. $[2,13,15,17$.

Parallel Rule, Rolling.-A single bar fitted with two toothed rollers of equal diameter running on spindles, for the drawing of parallel lines. See also Rolling Instrument. $[2,5,6,13$, $15,16,17,20,21,24,25,26,27,28$.]

Parallel-Ruler. - A draughtsman's instrument for drawing parallel lines. $[2,5,13,15,16,17,20,21,24,25,26,27,28$.

Paralleloscope.-An instrument for using gunsights in a confined situation. $[3,20$.

Paschen Galvanometer.-See Galvanometer. [4.]

Paterson's Lamp-Rotator. - See Lamp-Rotator.

Peake's Patent Control Board.-An electrical device for use with the thermo-electric pyrometer, enabling the scale of an indicator or recorder to commence at any desired temperature, thus allowing of a more open scale over the working range of temperature. [4.]

Pedometer.-An instrument to count the steps by registering the rise and fall of the body. A pace measurer. It is usually in the form of a watch. $[5,6,9,13,15,16,17,20,21,24$, $25,26,27$.]

Peirameter or Pirameter.-An instrument to indicate the amount of resistance offered by the surface of roads.

Pelorus or Dumb Plate.-A dumb compass card (without magnetic needles), or azimuth dial, supported in gimbals and fitted with sight vanes for telling or reading off a bearing. $[13,15,16$.

Pelvimeter.-An instrument to measure the diameter of the pelvis.

Pendant Clinometer.-A hanging clinometer. See Clinometer.

Pendulum, Ballistic, Hicks's.-An instrument for comparing moments and investigating the laws of inelastic impact, consisting of a wooden framework with three cross-pieces screwed to the top, from which are suspended, by strings, two light wooden platforms, carrying weights and with pointers attached, by means of which the distance apart of the platforms may be ascertained upon a divided scale below. [19.] 
Pendulum, Blackburn's.-A pendulum with double suspension, so as to give simultaneously oscillations in two vertical planes at right angles, the bob consisting of a funnel containing fine sand or other material which, as it flows out, traces Lissajou's curves. Used in investigations of simple harmonic motion.

Pendulum, Borda.-A form of simple pendulum (q.v.) used for the determination of " $g$," consisting of knife-edge, heavy ball, wire suspension and bracket support with plate glass surface. The period of the knife-edge without the suspension wire can be adjusted by means of a movable weight.

Pendulum, Compensation, Harrison's.-A compound pendulum consisting of a framework containing rods, alternately brass and iron, so arranged that any rise or fall in temperature is compensated, as the steel rods lengthen downwards while the biass rods lengthen upwards, thus keeping constant the distance between the point of suspension and the centre of gravity of the pendulum.

Pendulum, Compound.-An instrument differing from the Simple Pendulum essentially in the fact that in place of a light string we have a rigid rod, the mass of which is not negligible compared with the mass of the bob. It may be of cylindrical or rectangular bar form, and is usually fitted with knife-edge for suspension.

Pendulum, Cycloidal.-A simple pendulum in which the string near the point of suspension presses, when swinging, on cheeks, so that the bob is made to swing in a cycloidal arc, and the time of swing is independent of the amplitude.

Pendulum Instrument.-See Harmonograph. $[19,26$.

Pendulum, Kater's Reversible Compound.-A compound pendulum, first used by Kater in 1818, for the determination of gravity. It consists essentially of a metal rod, weighted at one end, so that the centre of gravity is much nearer one end than the other, and having two knife-edges, one at either end. In addition, there is some method of adjusting the periods to equality when the pendulum is suspended from either knife-edge.

Pendulum Level.-A plumb level. $[6,24,25,27$.

Pendulum, Mercury, Graham's.-A compensated pendulum in which the ball or "bob" is a cylindrical glass vessel containing mercury. When the temperature rises the rod and stirrup expand downwards, lowering the centre of gravity ; but the mercury, expanding, rises in the cylinder and produces an inverse effect.

Pendulum Myograph.-An instrument for noting, by means of a smoked glass plate forming the bob of a pendulum, the amount and duration of the contraction when electricity is sent through a muscle. See also Myograph. [4.] 
Pendulum, Simple.-An instrument consisting essentially of a light string or wire from which is suspended a heavy mass or " bob," free to swing in a vertical plane.

Pensky-Marten's Flash-Point Apparatus.-See Flash-Point Apparatus. $[15,17$.

Pentagonal Prism.-See Prism. $[1,2,3,8,10,12,13,14,18,20$, $26,27$.

Perambulator.-A very ancient instrument described by Vitruvius as being among the effects of the Emperor Commodus. It was used, by hand or attached to a carriage, to measure distances. $[6,27$.

Perambulator Wheel.-An instrument used in surveying for measuring distances over land or roads. $[2,5,13,15,16$, $17,21,24,26,27$.

Perfect Speed Indicator.-See Speedometer. $[5,6,13,15,17$.

Perfect Speedometer.-See Speedometer. $[5,6,13,15,17$.

Perimeter.-(I) An instrument for the determination of the angle of strabismus. (2) An instrument for determining the area of sensitivity of the retina. $[2,26$.

Periscope.-An instrument, generally in the form of a bent telescope, for viewing objects at a distance from a sheltered position, where direct vision is impossible. $[1,3,5,9,11$, $13,15,16,17,20,21,26,27$.

Periscope, Submarine Vessel type.-A special type of periscope for use on submarine vessels.

Periscopic Lens.-(I) A meniscus lens. (2) A form of nonachromatic photographic lens consisting of two meniscus lenses separated by a considerable interval. $[3,8,10,20$, $26,27$.

Periscopic Spectacles.-See Spectacles. $[20,21,26$.

Permeability Tester.-An instrument for testing the permeability of fabrics used in airships and aeroplanes. [4.]

Permeameter.-Same as permeability tester. [4.]

Perspectograph.-An instrument for the mechanical drawing of objects in perspective.

Petrol Tank Gauge.-For indicating the amount of petrol in the tank of an aeroplane, etc. $[6,15$.

Petroleum Test Apparatus.-See Flash-Point Apparatus. $[15,21$.

Phakoscope.-See Phantascope.

Phanarogrisonmeter.-An apparatus for indicating the presence of dangerous gases in mines.

Phantascope.-An optical instrument for observing the reflected images seen in the human eye when it is being accommodated to a near object.

Phenakistoscope.-An instrument depending, like the thaumatrope and zoetrope (q.v.), upon the persistence of visual impressions on the retina.

Phonautograph.-See Phonograph.

Phoneidoscope.-An instrument for observing the colour figures of liquid films when acted on by sonorous vibrations. 
Phonic Wheel.-See Rayleigh Synchronous Motor. [19.]

Phonograph.-An instrument for recording and reproducing sounds; invented by Mr. T. A. Edison. The record was made on a waxed cylinder by means of a style attached to a membrane acted upon by the sound waves.

Phonometer.-An instrument for ascertaining the number of vibrations of a given sound in a given space of time.

Phonomotor.-An instrument to illustrate the motive power of sound.

Phonorganon.-An instrument designed to imitate vocal sounds of speech ; a speaking machine.

Phonoscope.-An instrument for observing the motions or properties of sounding bodies. An apparatus for testing the quality of musical strings.

Phonoshote.-An apparatus for transformation of sound into light.

Phosphoroscope.-An instrument for measuring the duration of phosphorescence in different substances.

Photodrome.-An apparatus consisting of a large wheel with spokes which, when turning very rapidly, is illuminated by momentary flashes of light passing through slits in a rotating disc.

Photographic Lens.-See Lens. $[1,2,3,8,9,10,17,18,20,22$, 23,26 .]

Photographometer.-An instrument for determining the sensibility to luminous rays of the plates employed in photographic processes.

Photo Heliograph. - A modified form of telescope (q.v.) adapted to taking photographs of the sun. See also Heliograph. $[2,8,13,15,18,20,21,24,25,26,27$.

Photometer.-An instrument for measuring or comparing the intensity of light. There are several forms. $[2,3,10,13$.

Photometer Bench.-A simple optical bench (q.v.) on which the photometer, and other accessories, are mounted. $[3,13$.

Photometer, Box, Lummer Brodhun.-The rays of light, from the two sources, falling on two dials, non-transparent, are reflected on to a prism in such a way that the image of one dial appears enclosed in the image of the other dial, and thus the comparison of the intensities of the light is rendered easy. $[2,3$.

Photometer, Bunsen's. - The two sources of light for comparison are mounted on a simple optical bench (q.v.) on each side of an opaque paper screen with a greased area-the grease spot-in the middle. $[2,10$.

Photometer, Bunsen's Mirror.-A modification of the grease spot photometer in which the grease spot is viewed from both sides by means of an angle mirror.

Photometer, Dibdin's Hand.-A simple and portable photometer for testing street, railway, and school lights. 
Photometer, Fire Damp.-An apparatus for the detection of the presence of photocarbide of hydrogen in the air. It acts by using an electric current to cause the combustion of fire-damp and a photometer for observation of the luminous intensity.

Photometer, Flicker, Simmance-Abady.-A photometer depending upon the principle that, if two sources of light be viewed in rapid alternations, a flickering effect is produced if the intensities are unequal, but that when equality is obtained all that is seen is an apparently motionless disc. By its means light of any colour can be compared with any known standard of light.

Photometer, Prism.-A photometer in which the light rays from - two sources to be compared are brought together by means of two total reflection prisms.

Photometer, Richie's.-A reflecting photometer in which the two reflected images of the two sources of light are viewed in the field of a sliding telescope.

Photometer, Rumford's.-An early simple form of photometer, depending upon the comparison of the two shadows cast by a single rod intercepting the light from the two sources to be compared.

Photometer Thermometer.-See Thermometer. $[13,15$.

Photometer, Wheatstone's.-Based on duration of light. It consists of a brilliant ball or globe fixed on a disc placed eccentrically on a toothed wheel which is geared with the interior circumference of a toothed crown. The apparatus can be used in open daylight.

Photophone.-An instrument for communicating sounds by the agency of a beam of light.

Photoscope.-An instrument for exhibiting photographs. [1.]

Photo-survey Camera.-A form of camera (q.v.) which, by giving a record of compass bearing and horizontal level on the plate when exposed, enables surveys to be made from a series of photographs only.

Photo-theodolite.-A special form of theodolite (q.v.) incorporating a camera, in which the photographs made are used to determine angles not taken by direct observation through the telescope.

Phrenograph.-An instrument for registering the movements of the diaphragm or midriff in respiration. [1.]

Phthongometer.-An instrument for measuring vocal sounds.

Piche's Evaporimeter. - See Evaporimeter.

Pickering's Evaporimeter.-See Evaporimeter.

Picket Pole.-A sighting pole used in surveying for marking off points in the field being surveyed. $[5,13,15,17,21,24,25$, 27.]

Pickets.-See Picket Pole. $[13,15,21,27]$

Picknohydrometer. - A combination of picknometer and hydrometer (q.v.). [21.] 
Picknometer.-See Pycnometer. [21.]

Pickworth's Engine-Power Computer.-See Engine-Power Computer. $[15,31,24$.

Piecework Balance Calculator, Smith-Davis.-A wheel form of calculator for money or time calculations in connection with piecework. [15.]

Piezometer.-An instrument for measuring pressure or the sense of it.

Piezometer.-An instrument for measuring the compressibility of liquids. A gauge connected with a water main to show the pressure at that point. [20.]

Pillar Compasses.-See Compasses. $[2,5,6,13,15,16,17,21$, $24,27$.

Pioscope.-A milk-testing instrument.

Pipette.-A glass measure or tube having a pointed end and small aperture, graduated so as to deliver a fixed quantity of liquid when filled to a definite mark at a definite temperature. $[2,13,17,20,26$.

Pitchometer.-An instrument for determining the pitch of a propeller. $[13,15,17,21$.

Pit Hygrometer.-A portable form of Mason's hygrometer (q.v.) for use in coal mines. $[5,6,13,16,17,21,24,26$.

Pit Thermometer.-See Thermometer. $[5,6,13,16,17,21,24$.

Pit Water Gauge.-An instrument or gauge for taking the airpressure in mines. See Gauge. $[5,13,17,21,24$.

Pitot Tube.-An instrument designed to measure the velocity of flow of gases, consisting essentially of two parts-a tube pointing up-stream and having an opening at the end facing the direction of the air current, and another tube, closed at the end, but with a number of small holes drilled in the surface, which is parallel to the stream-lines. The open ended tube determines the sum of the velocity pressure and the static pressure, and the tube with closed end the static pressure alone. By connecting the two tubes to a suitable manometer the velocity can be determined. $[4,5,6,16$, 17, 21.]

Pivoted Moving Coil Galvanometer.-See Galvanometer. $[4,10$, $16,19$.

Plagiograph.-A pantograph (q.v.) for drawing a copy which is inclined with respect to the original figure.

Plane Table.-A drawing-board on tripod stand with sight rule and trough compass, for field surveying. $[2,13,15,17,20$, $21,24,27$.]

Planetarium.-A working model showing the planets and their movements.

Planigraph.-An instrument for reducing and enlarging drawings. See also Pantograph. $[6,10,13,15,17,21,24,25,27$.

Planimeter.-An instrument for measuring the area of irregular plane figures. $[2,5,6,10,13,15,16,17,21,24,25,27$. 
Planimeter, Coffin Averaging.-A planimeter for working out indicator diagrams. $[10,13,15,16,21,24,28$.

Planisphere.-An instrument to assist in the study of the positions of the heavenly bodies. $[13,15,16,20$.

Plank Rule.-A sliding boxwood calliper $(q . v$.$) used for ascer-$ taining the width and thickness of planks. [15.]

Planometer.-An instrument for gauging or testing a plane surface.

Platinum Resistance Pyrometer.-See Pyrometer. [4.]

Platometer.-An instrument for measuring areas on plans by mechanism. See also Planimeter. $[2,5,6,10,13,15,16$, $17,21,24,25,27$.]

Platymeter.-An apparatus for measuring the inductive capacity of dielectrics.

Plethmograph.-An instrument for determining and registering the variations in the size of a limb, as the arm or leg, and thence the variations of the amount of blood in the limb.

Pleximeter.-A small hard elastic plate, as of ivory, bone, or rubber, placed in contact with the body to receive the blow in examination by medical percussion.

Plumb Bob. - A conoidally or other shaped piece of metal suspended by a cord attached to its upper end and used for determining vertical, or, in connection with a level or straight edge, horizontal lines. See also Plumb Level. $[2,5,16,17$, $21,24,25,26,27$.]

Pluviograph.-A self-recording 1ain-gauge (q.v.). $[13,17,20,2 \%$.

Pluviometer.-An instrument for ascertaining the amount of rainfall in a particular climate or place. See also RainGauge. $[6,13,15,17,20,25,27$.

Pneometer. - A spirometer (q.v.).

Pocket Compasses.-Magnetic compasses that may be placed in the pocket. See Compasses. $[2,5,9,13,15,16,1 \%, 20,21$, $24,26,27$.]

Pocket Dividers.-Folding dividers that may be placed in the pocket. See Dividers. $[2,5,9,13,15,16,17,20,21,24$, $26,27$.

Polar Clock.-An optical instrument, invented by Wheatstone, for ascertaining the time of day by means of polarised light.

Polar Planimeter.-See Planimeter. $[2,13,15,21,24,27$.

Polarimeter.-An instrument for measuring the rotation of the plane of polarisation in polarised light. $[2,13,14,15,17$, 21,26 .]

Polariser.-A crystal, such as tourmaline or calcite, producing polarised light. See Tourmaline Analyser. $[3,26$.

Polarising Apparatus.-Any instrument for producing polarised light. $[2,3,15,17,20,22,26$.

Polariscope.-An instrument consisting essentially of a polariser and an analyser used for polarising light and analysing its qualities. See also Saccharimeter. $[2,3,14,15,17,19,20$, $21,22,26$.] 
Polariscope, Norrenberg's.-A polariscope for exhibiting the interference figures of crystals under convergent polarised light. $[3,26$.

Polemoscope.-An opera or field glass with an oblique mirror arranged for seeing objects that do not lie directly before the eye. [13.]

Polygonoscope.-A form of kaleidoscope (q.v.) [2, 20, 26.]

Polymeter.-A sensitive and accurate form of hair hygrometer $(q . v.) . \quad[2,15,16,17,21,25,26,27$.

Polyoptrum.-A lens, one side of which is plane and the other convex.

Polyphase Slide-Rule. - See Slide-Rule.

Polyscope.-A multiplying lens (q.v.).

Porro Prism Erector.-A pair of right-angle prisms as used in prismatic binocular field-glasses to erect an image in two meridians. Invented by Professor Porro. See Prism, Erecting. $[1,2,3,10,13,15,20,26,27$.

Portrait Lens.-See Lens.

Position-Finder.-An instrument used for ascertaining the position of an object on a map, or the position of a ship on the chart. $[2,13,15,16,26,27,28$.

Position Micrometer.-A micrometer applied to the tube of an astronomical telescope for measuring angles of position in the field of view. $[2,3,13,25,27$.

Positive Eyepiece.-See Eyepiece.

Pot Leather Thermometer.-See Thermometer. $[6,13$.

Potentiometer.-An instrument for measuring the potential between two points in a circuit traversed by an electric current. $[4,16,19$.

Potometer.-For measuring and demonstrating the relative rates of transpiration of the same plant under different external conditions. [8.]

Potometer.-Ganong's.

Potometer.-Pethybridge's.

Praxinoscope.-An instrument for presenting to view or projecting upon a screen images having the natural motions of real objects. [26.]

Pressler Borer.-An instrument for ascertaining the rate of growth of trees. [21.]

Pressure Gauge.-For indicating pressure of steam, etc. See Gauge. $[4,5,6,13,15,16,17,21,26,27,28$.

Pressure Gauge, Air.-See Gauge. [4.]

Pressure Gauge, Bourdon.-See Gauge. [4.]

Pressure Gauge, Edney.-See Gauge. [4.]

Pressure Head.-Another name for Pitot tube (q.v.). $[4,6,17$.

Pressure Thermometer.-See Thermometer. $[4,5,6,13,15,17$. Priaker.-A drawing instrument. $[5,6,13,15,17,20,21,24,27$.

Prime Vertical Transit Instrument.-See Transit. [21, 25.] 
Prism.-In optics a body, of glass, quartz, fluor spar, rock-salt or other transparent substance, bounded by three planes which intersect in three parallel straight lines, used for deflecting light rays either by reflection or refraction. $[1,3$, $8,10,12,13,14,15,20,21$.]

Prism, Ahrens.-A form of polarising prism invented by Dr. C. Ahrens, giving about four times the aperture of the Nicol prism (q.v.). $\quad[2,3,22,26$.

Prism, Amici.-A tetrahedral reversing prism which bends the optic axis through $90^{\circ}$. $[2,3,14,20,26$.

Prism, Achromatic.-A combination of prisms of different substances designed to obtain deviation without much dispersion.

Prism Binocular Glass.-An improved form of binocular glass (q.v.) with double reflecting prism, giving a higher power with larger field. $[2,3,5,9,10,13,15,16,17,18,20,21$, $26,27,28.7$

Prism, Constant Deviation.-A compound prism so designed that the deviation, i.e., the angle between the incident and the emergent beam of light, is constant. $[3,10,13,14$.

Prism, Diatom.-A triangular prism used for illuminating by oblique light small objects in the field of a microscope. $[2,3$.

Prism, Direct Vision.-A compound prism of crown and flint glass giving dispersion without deviation, i.e., an undeviated spectrum. $[2,3,14,20,26$. $]$

Prism, Double Image.-A prism of Iceland spar or other doublyrefracting crystal, giving a double image of an object. [2, $3,13,14,15,20,22,26$.]

Prism, Erecting.-A prism with angles of $45^{\circ}, 45^{\circ}, 90^{\circ}$, giving, by internal reflection of the beam of light, an erect image where, otherwise, there would be an inverted image in the optical projection of an object. $[1,2,3,10,13,20,26,27$.

Prism, Foncault.-A compound prism in which a layer of air takes the place of the cement.

Prism, Fresnel.-A prism with an obtuse angle slightly less than $180^{\circ}$ for producing interference of light images. $[3,14,26$.

Prism Glass.-Any form of telescope, monocular or binocular, in which a double reflecting prism is used. $[3,9,10,13,15$, $18,20,21,26,27$.

Prism, Nachet's. - A form of prism used for conveying an oblique pencil of light upon a microscopic object. $[2,3,26$.

Prism, Nicol's. - See Nicol Prism. [2, 3, 20, 22, 25, 26.]

Prism, Pentagonal.-A five-sided prism, used for range-finding, whose angles are, respectively, $90^{\circ}, 112 \frac{1}{2}^{\circ}, 60 \frac{1}{2}^{\circ}, 66 \frac{1}{2}^{\circ}$, I $12 \frac{1}{2}^{\circ}$, silvered on two surfaces, to deflect a beam of light at a constant angle when the prism is partially rotated. $[1,2$, $3,8,10,12,13,14,18,20,26,27$.

Prism Photometer. -See Photometer. 
Prism, Roof.-A reflecting prism in which one of the reflecting surfaces is replaced by a pair at right angles in the form of the gable of the roof; used to reverse the image in two meridians. $[1,2,3,8,9,12,13,14,15,18,20,23,26$.

Prism, Rutherford's.-A double-image prism used in polarising experiments. $[3,13,26$.

Prism, Thompson.-A polarising prism, invented by Prof. Silvanus Thompson, passing a very wide angle of light. $[2,3$, 22,26 .]

Prismatic Compass.-See Compass. $[2,5,9,10,13,15,16,17$, $18,20,21,24,25,26,27$.

Prisms for Spectroscopes.-Optically worked prisms for use in spectroscopes. $[2,3,8,10,12,13,14,26$.

Process Lens.-A lens (q.v.) used in process reproductions.

Process Prism.-A prism used in process reproduction.

Proell's Pocket Calculator.-A simple form of slide-rule card with an upper sheet of transparent celluloid. $[8,13,15$.

Projection Apparatus.-A magic or optical lantern used for projecting an enlarged image of an llluminated object on a screen of suitable surface. $[2,3,8,10,20,26$. $]$

Proof Glass or Plate.-A glass plate with a perfectly plane or spherical surface for testing the accuracy of surfaces by means of the interference of light; used especially in glasspolishing. $[1,3,8,10,11,20,22,23,26$. $]$

Propeller-speed Indicator.-An instrument for indicating the revolutions of a propeller. See also Speedometer. $[15,17$.

Proportional Compasses.-See Compasses. $[2,5,6,13,15,16$, $17,20,21,24,25,26,27$.]

Protractor.-A mathematical instrument for laying down and measuring angles on paper. $[2,5,6,13,15,16,17,20,21$, $24,25,26,27,28$.]

Protractor.-Set-square pattern. $[5,6,13,15,16,17,20,21$, $24,25,26,27$.

Protractor.-Vernier pattern. A protractor with a radial arm and vernier. $[5,6,13,15,16,20,21,24,25,26,27$.

Protractor, Chart.-A circuliar, semicircular, or rectangular scale divided in degrees for laying off the ship's course on a chart. $[13,15,16,21,28$.

Protractor, Creagh-Osborne.-A specially designed protractor for use with the Creagh-Osborne compass (q.v.). $[13,15,20$, $26,27$.

Protractor, Isometrical.-A protractor constructed for isometrical perspective drawing to give all angles from the horizontal in correct ratio. [27.]

Protractor, Sutherland's.-A special form of protractor designed by Mr. Angus Sutherland. It is used in conjunction with angular instruments in order that the survey may be drawn on the tracing paper attached to it at the actual place of observation. 
Pseudophone.-The name given by Professor Silvanus Thompson to an instrument illustrating the laws of the acoustic perception of space by the illusions it produces.

Pseudoscope.-An instrument which exhibits objects in their proper relief reversed. [26.]

Psychrometer.-A wet and dry bulb hydrometer (q.v.). $[4,5$, $13,15,16,17,20,21,27$.

Psychrometer, Assmann's.-A form of wet and dry bulb hygrometer (q.v.), in which a spring-driven fan is used to draw air over the bulbs of the thermometers. $[6,17,21$.

Pulmometer. - See Spirometer. [21.]

Pulsimeter.-See Sphygmometer. [21.]

Pupilometer.-An instrument for measuring the size of the pupil of the eye. [26.]

Pycnometer.-A specific gravity bottle for measuring and comparing the densities of liquids.

Pyknometer.-See Pycnometer.

Pyrheliometer.-An instrument for measuring the amount of heat radiated from the sun.

Pyrheliometer, Abbe's Silver Disc.

Pyrheliometer, Angström's. - The essential part of this instrument consists of two strips of thin metal, one of which is exposed to the sun's rays and the other, kept in the shade, is heated by an electric current and kept at the same temperature as the exposed slip.

Pyrograph.-A curve indicating measurements of heat. [17.]

Pyrometer.-Instrument used for the measurement of temperatures higher than those for which a glass thermometer is suitable. In its simplest form it depends on the expansion of a solid metal rod or of a gas, but more commonly it consists of an electrical device. The pyrometer in most common use depends on the electrical current generated by a junction of two different metals or alloys when it is heated. This pattern will indicate temperatures up to about $1,35^{\circ}$ or $1,400^{\circ} \mathrm{C}$. For temperatures higher than that, Radiation Pyrometers are used. In this form, the heat is focussed by means of a mirror on to a small thermocouple, or on to a metallic spiral. The instrument, therefore, does not come into direct contact with the hot body. See also Thermometer, Resistance, and Siemens's Water Pyrometer. $[1,2,4,5,6,13,15,16,17,20,21,24,25,26,27$, 28.]

Pyrometer, Hobson's.-A convenient hand pyrometer for testing the temperature of the hot gases in iron furnaces.

Pyrometer, Locomotive.-An electrical pyrometer for use on locomotives using superheaters. $[4,13,16,1 \%$. $]$

Pyrometer, Optical.-A type of radiation pyrometer employing monochromatic luminous radiation. $[4,21,26$.

Pyrometer, Radiation.-A pyrometer operated by the radiant heat emitted by the hot body. $[4,13,16,21,26$. 
Pyrometer, Radiation, Féry.-A pyrometer in which the radiant heat from the body under test is focussed on a small thermojunction, whose temperature is thus raised by an amount depending on the temperature of the hot body. $[4,13,21$.]

Pyrometer, Radiation, Féry Spiral.-In this instrument the radiant heat is focussed by a bi-metallic spiral, the temperature of the hot body being measured by the amount of uncoiling of the spiral. $[4,13,21$. $]$

Pyrometer, Recording.-An instrument which automatically records temperature on a chart. $[4,13,16,20,21,25,26$, 27.]

Pyroscope.-An instrument to measure the intensity of heat radiating from a hot body, or the cooling effect of a cold body. [4.]

Pyroscopes.-See Seger Cones. [17.]

Q.E.D. Chart-Holder.-A device for holding a chart on the charttable. [28.]

Q.E.D. Course-Corrector.-An instrument of the Pelorus type for indicating the true or magnetic course of a vessel and measuring horizontal angles. [28.]

Q.E.D. Rolling Rule.-An improved form of parallel rule for chart work. [28.]

Quadrant.-An instrument for measuring altitudes, variously constructed and mounted for specific uses in astronomy, surveying, gunnery, etc. $[2,13,15,21,27$.

Quadrant, Gunner's.-An instrument for determining the angle of elevation of the gun. $[13,15$.

Quadrant, Hadley's. - A form of reflecting instrument invented by John Hadley for taking angles. By this instrument the observer sees at once the two objects both as touching the same point though distant from each other almost to a semicircle. It is the original of the present form of sextant (q.v.). $[13,15,21$.]

Quadrantal Globes.-The iron spheres used for the correction of the quadrantal deviation on board steel ships. [15.]

Quadriform Group Flashing Light.-A form of lighthouse with four sets of eight lenses with a light in the focus of each set. [7]

Quartz Lenses.-Optically worked lenses made of rock crystal. $[2,3,10,13,14,22,26$.

Quartz Plates.-Rock crystal plates of specified thickness for measuring retardation of polarised light. $[2,3,10,14,20$, 22,26 .]

Quartz Prisms. - Optically worked prisms made of rock crystal. $[2,3,10,13,14,26$. $]$

Quartz Spectrograph.-See Spectrograph. $[10,14,26$.

Quartz Wedge. - A wedge-shape plate of rock crystal used for measuring retardation of polarised light. $[2,3,10,14,20$, 22,26 .] 
Quekett's Forceps.-A long forceps for extracting microscope specimens from deep jars. $[2,3,20,22$.

Quenching Bath Thermometer.-See Thermometer. $[6,13,21$. Quintant.-A special form of sextant enabling a larger angle of reflection to be measured than with the ordinary type of instrument. $[13,15$.

Radiation Pyrometers.-See Pyrometer. $[4,13,16,21,26$. $]$

Radiation Thermometer.-See Thermometer. $[5,13,17,20,21$, 26 .]

Radio-Activity Measurement Apparatus.-For use in connection with an electrometer (q.v.) in measurements and experiments on the radio-activity of substances. It consists of two insulated metal plates, the space between them being occupied by a gas which is ionised by the radio-active substance. The two plates are charged to different potentials, and the rate of leakage of electricity across the plates is determined by an electrometer. $[4,26$.

Kadiograph.-(I) An instrument for the measurement and record of solar radiation. (2) A xylonite or glass plate with circle or semi-circle of degrees on one side and a pencilling surface on the other, for working off two or more observed angles and fixing the ship's position on the chart. $[9,13,15,21$, $25,26,28$.]

Radiometer.-An instrument for indicating the mechanical effect of radiant energy. It consists essentially of four light vanes, blackened on one side and silvered on the other, mounted on a central pillar so as to revolve freely in a vessel nearly exhausted of air. $[13,17,26$.

Radiomicrometer.-A very sensitive modification or application of the thermopile $(q . v$.$) , used for indicating minute changes$ of radiant heat or temperature. $[4,13,21$.

Radio-Micrometer, Boys'-A sensitive radio-micrometer (q.v.) in the form of a modified suspended-coil galvanometer (q.v.), in which the coil consists of a single loop of silver wire with a small bismuth-antimony thermo-couple at its lower end. The radiation to be measured is received on this thermocouple, the consequent heating of which causes a current to flow through the suspended system. [4.]

Radiophone.-An apparatus for the production of sound by the action of luminous or thermal rays.

Radium Buttons.-Containing radium for the treatment of lupus, etc. $[3,26$.

Radium Map-Reader.-A magnifier with a radium illuminator for map-reading. $[15,20,21$. $]$

Rail Tracing Machine.-An instrument for obtaining an accurate tracing of the section of a rail.

Railway Curves.-A set of pearwood curves used by draughtsmen in the setting out of railway lines on plans. $[2,5,6,13,15$, $17,21,24,26,27$.] 
Railway Gauge, Footner's.-See Gauge. $[15,21,27$.

Rain-Gauge.-An instrument for collecting and measuring the rainfall. It consists essentially of a receiver, made of iron or copper, usually of circular form, and of a graduated glass measure accurately calibrated from the area of the receiving surface of the gauge. $[6,13,15,17,20,25,27$.

Rain-Gauge, Balance Pattern.-A rain-gauge with a balance arrangement for automatically recording the rainfall. $[6$, $10,13,15,17,21$.]

Rain-Gauge, Float Pattern.-Any rain-gauge indicating by means of a float. $[2,5,6,10,13,15,17,21,25,27$.

Rain-Gauge, Mountain.-A form of rain-gauge with deep funnel designed for use in very rainy localities and where the gauge can be visited only at rare intervals. $[6,13,15,17,20,21$, $24,25,26$.]

Rain-Gauge, Recording.-A rain-gauge recording on a chart the duration of and the total rainfall during a known period.

Rain-Gauge, Tilting Bucket Pattern.-A special form of selfrecording rain-gauge.

$[6,10,13,15,17,21$.

Rain-Gauge, Totalising.-A rain-gauge recording total rainfall on an outside dial. [15.]

Ramsden Chain.-A specially constructed steel chain devised by Ramsden for Ordnance Survey work. Compound metal rods are now used instead for this purpose. $[8,13$.

Ramsden Eyepiece.-See Eyepiece. $[2,3,8,10,11,13,17,18$, $19,20,21,22,23,24,25,26,27$.

Ramsey's Dividers.-As devised by Sir W. Ramsey for dividing tubes, scales, etc.

Range-Finder.-An optical instrument for finding the distance of the observer from an object, as in gunnery, surveying, etc. $[2,3,6,13,15,17,18,20,21,26,27$.

Range-Finder, H.S.-A simple form of one man range-finder. $[5,20$.

Range-Finder, Weldon.-A portable form of prismatic rangefinder. $[5,20$.

Ranging Poles.-See Picket Poles. $[5,13,15,16,21,26,27$.

Rapid Rectilinear Lens.-See Lens.

Rarefied Air Apparatus.-An apparatus in which the effect of the diminution of atmospheric pressure on living organisms is observed.

Rayleigh Synchronous Motor or Phonic Wheel.-An instrumen't for determining the absolute periodicity of large tuning forks and of alternating electric currents, and for timerecording experiments. [19.]

Reading-Glass.-A large magnifying lens with a handle, used to assist in reading, etc. $[2,5,8,9,13,15,16,17,20,21,24$, $26,27,28$.]

Reading Telescope.-See Telescope. $[1,2,3,10,13,15,17,19$, $21,26,27$. 
Reading Test-Card.-A card containing reading matter set up in various size type for testing the reading capacity of the eye. $[2,21$. $]$

Recoil Dynamometer.-An instrument to measure the recoil of small arms.

Recorder, Sunshine.-See Sunshine Recorder. $[2,4,5,9,10,13$, ik $15,17,21,24,25,27$.

Recording Ammeter.-See Ammeter.

Recording Densimeter.-See Densimeter. $[4,21$.

Recording Galvanometer.-See Galvanometer. [4, 16.]

Recording Pyrometer.-See Pyrometer.

Recording Voltmeter.-See Voltmeter.

Redwood Inflammable Gas or Vapour Detector.-See Inflammable Gas or Vapour Detector. $[13,15$.

Redwood Standard Oil Weight.-See Oil Weight. $[13,15$.

Redwood's Standard Viscometer.-See Viscometer. $[13,15,17$, 21.]

Redwood Water-Finder.-See Water-Finder. $[13,15,16$.

Reeves's Distance-Finder Alidade.-See Alidade. [28.]

Reeves's Endless Tangent Screw.-See Screw. $[13,21$.

Reeves's Tangent Micrometer.-See Micrometer. [6.]

Reflecting Circle.-An instrument for measuring altitudes and angular distances. $[2,27$.

Reflecting Galvanometer.-See Galvanometer. $[4,13,16$.

Reflecting Goniometer.-See Goniometer. [19.]

Reflecting Level.-A simple form of level, sometimes called the Burel Level after its inventor, Col. Burel. See Level. [13, $17,21,25,27$.

Reflecting Microscope.-See Microscope.

Reflecting Telescope.-See Telescope.

Reflector.-An optical instrument by which the rays proceeding from a luminous or heated object are thrown back or diverted in a given direction without being transmitted. [3.]

Reflector, Beale's Neutral Tint.-An instrument to fit on the eyepiece of a microscope, for drawing the magnified image. $[2,3,17,20,22,26$.

Refracting Circle.-An instrument provided with a quadrated circle for measuring refraction. [13.]

Refracting Dial.-See Dial. [13.]

Refractometer.-An instrument for exhibiting and measuring the refraction of light, i.e., determining the refractive index of transparent substances. $[2,13,14,22$.

Refractometer.-Pulfrich's pattern for investigating optical glass. $[14,26$.

Refractometer.-Thornoe's pattern for beer. [14, 26.]

Refractometer, Abbe.-For liquids. [14.]

Refractometer, Butyro and Oleo-- - For the examination of butter, lard, and oils. [14.] 
Refractometer, Dipping.-A critical angle refractometer which is dipped into the liquid the refractive index of which is to be determined. $[14,26$. $]$

Refractometer, Féry.-A direct reading refractometer for taking the refractive index for sodium light of oils, solutions and other liquids. $[14,26$.

Refractometer, Jamin.-A refractometer, for gases or liquids, depending on the principle of interference of light. [14.]

Refractometer Scale, Leach and Lythgoe's. - A slide-rule for use in calculations with the refractometer. [19.]

Refractor.-A refracting telescope. [17.]

Refrigerator Thermometer.-See Thermometer. $[5,6,9,13,15$, $17,21,26,28$.]

Regulator.-The name given to the standard clock used in observations for astronomical work. [15.]

Regulator, Arc.-The apparatus for maintaining the relative distance between the carbons in the electric arc.

Reichert Gas Regulator.-See Gas Regulator. [2, 4.]

Reiset's Apparatus.-For the determination of carbon dioxide in the atmosphere.

Repeating Circle.-A reflecting instrument on the principle of the sextant, for measuring angular distances, and eliminating centreing errors. $[2,10,13,15,27$.

Resistance Pyrometer.-See Pyrometer. [13, 16.]

Resistance Thermometers.-See Thermometer. $[4,13,16$.

Resonator.-An instrument for facilitating the analysis of compound sounds.

Respirometer.-An instrument for indicating the transpiration of a potted plant.

Respirometer, Recording.-Devised by Prof. Blackman and Mr. Paine, for giving a continuous record of the transpiration of a potted plant.

Reticulated Micrometer.-See Micrometer.

Retinoscope.-A form of ophthalmoscope (q.v.) for examining the retina. $[2,10,21,26$.

Revolution-Counter.-An instrument for counting the number of revolutions of a shaft, etc. See also Trocheameter and Variable Speed Recorder. $[4,5,13,15,16.17,19,21,25$, 26.]

Revolution-Indicator.-An instrument for indicating the number of revolutions of an engine, etc. $[5,6,13,15,16,17$.

Revolution-Indicator, Aviation.-A revolution counter specially devised for indicating the revolution speed of an aeroplane propeller. [15.]

Rheochord.-An instrument consisting of a platinum wire mounted on two drums, so that the length of the wire (and hence the resistance) included in an electric circuit may be varied at will.

Rheograph, Abraham Projection.-A type of oscillograph (q.v.) in which the moving systems are formed of small closed 
rectangular rings of aluminium suspended in a magnetic field. Induced currents which follow exactly the variations of the current or E.M.F. under investigation are produced in these rings, which are therefore deflected. The deflections are observed by reflection from a mirror on to a screen. [4.] Rheometer.-An instrument for measuring the force of an electric current. [4.]

Rheomotor.-Any apparatus which originates an electric current. [4.]

Rheoscope.-An instrument for detecting an electric current. [4.] Rheostat.-An instrument consisting of an adjustable resistance for the gradual and continuous regulation of the strength of current in an electric circuit. $[16,19,20,26$.

Rheotome.-An instrument which periodically interrupts an electric current. [4.]

Rheotrope.-An instrument which periodically inverts an electric current. [4.]

Rhinoscope.-A small instrument for use in examining the posterior nares, the rear portion of the nostrils.

Rhomb (Fresnel's). - A rhomb or oblique parallelopiped of crown glass so cut that a ray of light entering one of its faces at right angles shall emerge at right angles at the opposite face, after undergoing within the rhomb at the other faces

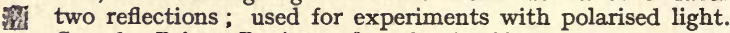
See also Prism, Pentagonal. $[3,14,26$.

R.H.S. Calculator. - A tubular form of slide-rule (q.v.) designed by Prof. R. H. Smith, having a scale line of 50 inches. [15.]

Rhumboscope, Mooney's.-A special form of station pointer for coastal navigation and chart work. [15.]

Rhysimeter.-An instrument for measuring the velocity of fluids or the speed of ships. [13.]

Rhythmometer.-Any instrument for marking time to movements in music.

Richard's Indicator.-An early form of engine indicator (q.v.). $[5,13,15,16,17,21,28$.

Richmond's Slide-Scale.-For the estimation of fat in milk. [26.]

Right-Angle Thermometer.-See Thermometer. $[5,13,15,17$, 21.]

Ripograph.-An instrument for determining the efficiency in flight of an aeroplane. Altitude, velocity, longitudinal inclination, time, engine speed, positions of control levers,

- and rolling movement are indicated. [4.]

Ritchie's Photometer.-See Photometer.

Road-Pen.- A twin drawing-pen for the insertion of roads on plans. $[2,5,6,13,15,17,21,24,25,26,27$.

Road Tracer. - A sighted balance level for taking road gradients. $[6,13,15,17,21,27$.

Robart's Machine-Gun Protractor-A transparent gunnery instrument for range-finding work.

Robinson Anemometer.-See Anemometer. 
Robinson's Centrifugal Force Apparatus.-See Centrifugal Force Apparatus. [19.]

Robinson Magnets.-See Magnets. [19.]

Rod Level.-A level (q.v.) with fitting for use on a vertical or horizontal rod. [21, 27.]

Roller Beam Compass.-See Beam Compass. $[2,6,13,15,20$, $21,24,26,27$.

Rolling Instrument, Mallock's.-A form of parallel rule (q.v.), adapted for drawing parallels on charts on board ship. It has the property of rolling in two directions at right angles to each other. $[13,21$.

Rolling Parallel Rule.-See Parallel Rule. $[2,5,6,13,15,16$, $17,20,21,24,25,26,27,28$.]

Roof Prism.-See Prism. [1, 2, 3, 8, 9, 12, 13, 14, 18, 20, 23, 26.]

Rosenhain Calorimeter.-See Calorimeter. [4.]

Rotameter.-A small wheel instrument for measuring distances on maps or the like. $[5,13,15,17,20,21,24,26,27,28$.

Rotascope.-An instrument on the same principle as the gyroscope (q.v.).

Rousseau's Densimeter.-See Densimeter.

Ruhmkorff's Coil.-An induction coil (q.v.). [26.]

Rumford's Photometer.-See Photometer.

Rutherford's Maximum and Minimum Thermometer. - See Thermometer.

Rutherford Prism.-See Prism. [3, 13, 26.]

Saccharimeter or Saccharimeter Polariscope.-A form of polariscope (q.v.) for testing sugar solutions by polarised light. $[2,3,13,14,15,17,19,20,21,22,26$.

Saccharometer.-See Hydrometer. $[5,6,13,15,17,20,21,25,26$.

Salinometer.-An apparatus for ascertaining the salinity of water or the density of brine in the boilers of marine steam-engines. $[5.6,13,15,16,17,21,26,28$.

Salometer.-See Salimeter. [5.]

Salimeter.-An instrument for measuring the amount of salt present in any solution. $[13,15,17$.

Salinity Recorder.-A development of the recording densimeter (q.v.) for obtaining a record of the changes in the salinity of river or other water. [4.]

Sampling Bottles (Mine Explosions Apparatus) (q.v.).-For extracting samples of gas from the gallery during the explosion. [4.]

Sankey's Metal Bending Tester.-See Metal Bending Tester.

Sapphire Cap.-A metal cap with sapphire setting used in magnetic compasses. $[13,15,16,17,21,24,25,27,28$.

Sceptre Recorder.-An instrument for recording the depth of water under a ship. [28.]

Sceptre Sounding Machine.-See Sounding Machine. [13, 28.]

Schumann Plates. - Sensitised photographic plates sensitive to light of extremely short wave-lengths. 
Scioptic Ball.-The lens of a camera obscura (q.v.). $\quad[20,26$.

Sciopticon.-A magic lantern (q.v.). $\quad[2,17,26$.

Sclerometer.-An instrument for determining with accuracy the hardness of a mineral.

Scotograph.-An instrument for writing in the dark or without seeing.

Scotoscope.-An instrument that discloses objects in the dark or in a faint light.

Screen, Filter. - See Filter (Light).

Screw, Endless Tangent.-A tangent screw acting on a continuous thread cut on the limbs or arc of an instrument, giving an endless motion of the screw. $[13,15$.

Screw, Endless Tangent, Reeves's.-An endless screw for use on sextants and theodolites. $[13,21$.

Screw Gauge Calliper.-A form of callipers (q.v.) with micrometer screw for the measurement of screw gauges and other small diameters or thicknesses.

Screw-Jack Apparatus.-For experiments on the efficiency of a screw-jack. [19.]

Screw-Measuring Machine.-For accurately determining pitch, diameter, angle, etc., in screws. $[2,4,22,23$. $]$

Scribing Iron.-An implement for scribing the marks on timber. [21.]

Searcher.-(I) An instrument for examining the bore of a cannon to detect cavities. (2) A dissecting instrument. [20.]

Searchlight.-A light with lenses or mirrors to produce a powerful beam of light. [\%.]

Searle's Apparatus.-An apparatus for the determination of Young's modulus of wires and deviations from Hooke's Law. Two wires of the same material are used, their ends being connected by a sensitive level with a micrometer screw, so that the extension of one of the wires under varying load can be measured. $[4,8,19$.

Searle's Apparatus.-An apparatus for determining Newton's coefficient of restitution, and for finding the change of energy and momentum on impact. $[4,19$.

Searle and Pye's Revolving Table and Lens System.-For the determination of the focal length of lens system by the nodal point method. [19.]

Searle's Simple Torsion Balance.-For measuring the surface tension of a soap film or of any clear liquid. [19.]

Searle's Total Reflection Apparatus.-For finding the refractive index of a liquid by the method of total internal reflection. See also Refractometer. [19.]

Sea Surface Temperature Thermometer.-See Thermometer. $[6,13,15,17,21,28$. $]$

Sea Wave Counter.-An instrument for counting the number of sea waves breaking on a coast. [4.]

Seconds Pendulum. - A pendulum of which the period of oscillation is one second, with electrical contacts arranged for 
connecting to an ordinary bell or sounder for use in the lecture room. $[10,19$.

Section Cutter.-A microtome (q.v.). $\quad[3,4,10,20,22,26$.

Sectoral Compass.-A special form of drawing compass. $[2,15$, 27.]

Seger Cones or Pyroscopes.-A series of fusible clay cones which melt at various definite temperatures ranging from $590^{\circ} \mathrm{C}$. to $2,000^{\circ} \mathrm{C}$., and can thus be used as temperature indicators. [17.]

Seismograph.-An apparatus for recording and measuring the direction, duration, and force of earthquakes and earth tremors. See also Vibration Recorder. $[13,17,21,26$.

Seismometer.-See Seismograph. $[4,13,17,21,26,27$.

Seismophone.-An instrument for distinguishing and locating subterranean sounds such as that of flowing water, subterranean explosions, etc.

Seismoscope.-A vibration instrument for indicating earthquakes, earth tremors, etc. [17.]

Selenite Stage.-An accessory used in the microscopic examination of chemical and geological specimens under polarised light. It usually consists of a thin section of selenite or gypsum suitably mounted on glass.

Selenite Stage, Darker's.-A brass stage in which mounted selenites of different wave-length can be rotated below a microscopic specimen under polarised light.

Selenite Stage, Mica.-A brass stage containing three selenites of different wave-lengths, any one of which can be slid over a disc of mica, the latter being capable of rotation. For use with polarised light in microscopical examination.

Selenium Eye.-A device for making a model eye blink by the action of light. [26.]

Selenotrope.-A model showing the phases of the moon.

Semaphore.-A signalling device employing moving arms or plates. $[13,15,16,28$.

Sematrope.-An instrument for signalling by reflecting the rays of the sun in different directions.

Semicircumferentor.-A simple mining surveying instrument much used for surface work. $[13,15,17,21,24,25,27$.

Sensitometer.-See Actinometer. [26.]

Separable Socket Thermometer.-See Thermometer. [13.]

Set-Square.-An instrument used by draughtsmen in combination with a tee-square for drawing perpendicular lines or those of specified angles. $[2,5,6,13,15,17,20,21,24,25$, $26,27,28$.

Sextant.-An instrument for measuring angular distances between objects, used especially at sea for ascertaining the latitude and longitude by determination of the altitude of the sun or stars. It is constructed on the same optical principle as Hadley's quadrant (q.v.). $[2,5,6,9,10,13$, $15,16,17,20,21,25,26,27,28$.] 
Sextant, Box.-A pocket sextant made in the form of a flat tubular box. $[2,3,5,6,9,10,13,15,16,17,20,21,24,25$, $26,27,28$.]

Sextant Chronograph.-A small chronograph which can be fitted into the handle of a sextant. $[8,13,15,16,28$.

Sextant, Double.-An improved form of sextant for surveying and harbour work. Two angles can be observed and measured on the one instrument. $[2,10,13,15,20,21,26,27,28$.

Sextant Mirrors.-The index and horizon glasses. $[2,3,10,13$, $15,16,17,21,26,27,28$.]

Sextant, Paget Angle.-A circular dial sextant with a geared index for use with the Station Pointer (q.v.). $[13,15,27$.

Sextant Shades.-Optically worked neutral or coloured glass discs of varying diameters, used in sextants. $[2,3,10,13$, $15,16,17,21,26,27,28$.]

Sextant Stand.-Metal counterpoise stand for sextant. $[10,13$, $15,17,21,26,27,28$.]

Sextant, Stellar.-A special pattern sextant with large mirror and telescope for star observation. $[10,13,15,16,17,25$, 26,28 .]

Shakespear Hydrogen Purity Meter.-See Hydrogen Purity Meter. Sheath Dividers.-Pocket dividers (q.v.), with sheath for protection of the points. $[5,13,15,16,17,20,21,24,26,27$.

Sheppard's Cubing Slide-Rule.-See Slide-Rule. $[15,21$.

Ship's Clock. - A lever spring timepiece for use on ships, to show on the one dial Greenwich and local time. $[13,15,16,17$, 28.]

Ship Curves.-A set of pearwood curves used by naval architects in ship design. $[6,13,15,17,21,24,26$.

Ship's Lamps. [15.]

Ship Log.-See Log. [15.]

Ship's Telescope.-See Telescope. $[3,6,8,9,10,13,15,16,17$, $20,21,23,24,26,28$.]

Shutter, Davis.-A diaphragm used above the objective of a microscope for reducing the aperture. $[2,3,21,22,26$.

Shutter, Photographic.-An apparatus for giving a photographic exposure of definite duration. $[8,20,26$.

Shutter Tester.-An instrument for testing the speed of photographic shutters. [3.]

Side Angle Thermometer.-See Thermometer. $[5,13,17$.

Side Silver Reflector.-An instrument for illuminating opaque objects on the stage of a microscope. $[2,3,22,26$.

Sidereal Clock.-An instrument for showing astronomical time. $[17,18,25,26$. $]$

Sideroscope.-An instrument for detecting minute degrees of magnetism by a delicate combination of magnetic needles.

Siderostat.-An Tastronomical instrument designed to keep a star within the same portion of the field of a telescope for observation. $[6,11,13,18$. 
Siemens's Water Pyrometer.-A calorimetric pyrometer in which temperatures are measured by the heating of the water in a calorimeter consequent upon the introduction of a nickel cylinder which has been allowed to acquire the temperature of the hot body. See also Pyrometer. $[5,13,17,21$.

Sight Clinometer.-A clinometer (q.v.) for use with a gun-sight, more especially the rocking bar sight. $[3,5,13,15,17,21$, $25,27$.

Sight, Dial.--See Dial Sight. $[3,11,13,15,20,21$.

Sight-Rule, Traver's. - A sight-rule for use on a plane table with an adjustable parallel bar. $[13,15,27$.

Sighting Telescope.-See Telescope. $[1,2,3,8,9,11,13,16,17$, $18,20,21,22,23,25,26,2 \%$.]

Signal Station Telescope.-See Telescope. $[1,2,3,8,9,13,15$, $17,18,20,25,26,28$.]

Silver Voltameter.-See Voltameter. [4.]

Silvered Mirrors.-Optically worked glass silvered mirrors. [ 1 , $3,10,11,13,15,17,20,21,26$.]

Simmance-Abady Combustion Recorder.-See $\mathbf{C O}_{2}$ Recorders. [13.]

Simmance-Abady Corrosive Gas Analysers.-Used in paper mills, pyrites, burning plants and chemical works. See Gas Analysis Apparatus. [13.]

Simmance-Abady $\mathrm{CO}_{2}$ Recorders.-See $\mathbf{C O}_{2}$ Recorder. [13.]

Simmance-Abady Dead Beat Gauges.-For recording pressure and vacuum of any range for all purposes. See Gauge. [13.]

Simmance-Abady Lamp Spinner.-See Lamp Spinner. [13.]

Simmance-Abady Ventilating Hygrometer.-See Hygrometer. [13.]

Simple Pendulum.- See Pendulum.

Sine-Galvanometer.-See Galvanometer. [19.]

Sinker, Fairy.-A form of sounding sinker for securing samples of the sea bottom, without the use of the usual tallow arming. $[13,28$.

Siphon Barometer.-See Barometer. $[6,13,16,17,21,28$.

Sismograph.-See Seismograph. [13.]

Sismometer.-See Seismometer. [13.]

Six's Maximum and Minimum Thermometer.-See Thermometer.

Slide-Rule.-A mathematical instrument consisting of two graduated parts, one of which slides upon the other, for the mechanical performance of addition and subtraction, and, by means of logarithmic scales, of multiplication and division. $[2,5,6,10,13,15,16,17,20,21,24,25,27,28$.

Slide-Rule, Anderson.-A slide-rule with the scale in four sections. $[13,15,20$.

Slide-Rule, Atmospheric.-A slide-rule used in gunnery, giving the corrections to apply to the fuse for atmospheric temper ature and pressure. $[13,15,2 \%]$

Slide-Rule, Bain's.-[15.]

Slide-Rule, Beghin.-[15.] 
Slide-Rule, Boucher's Calculating Circle.-A small pocket circ ular slide-rule. $[5,13,15,17,21,24,27$.

Slide-Rule, Chemist's. - A slide-rule specially adapted for chemical calculations. $[13,24$.

Slide-Rule, Davis Lee Bottomley.-A slide-rule having special scales for circle spacing.

Slide-Rule, Davis Martin Wireless.-A slide-rule for use in determinations of wave-length, capacity and self-induction. [21.]

Slide-Rule, Davis Stokes Field Gunnery.-A slide-rule for field gunnery calculations. [21.]

Slide-Rule, Electro.-A slide-rule for electrical calculations. [15.] Slide-Rule, Farmer's Profit-Calculating. [15.]

Slide-Rule, Fuller's Calculating Slide Scale.-A logarithmic sliderule in the form of a cylinder with a special scale on the surface. $[2,13,15,20,21,24,25,26,27$.

Slide-Rule, Gravette.-An early form of slide-rule, invented by M. Gravette. $[21,24$.

Slide-Rule, Hall's Nautical.-A special form of slide-rule for calculations in navigation. [15.]

Slide-Rule, Jakin. $[13,15$.

Slide-Rule, Log Duplex.-A slide-rule for trigonometrical calculations. [15.]

Slide-Rule, Multiplex. - A slide-rule for the direct reading of cubes, cube roots, etc. $[13,21,26$.

Slide-Rule, Polyphase.-A slide-rule for electrical and hydraulic calculations.

Slide-Rule, Sheppard's Cubing.-A slide-rule specially designed for the use of quantity surveyors, timber nerchants, etc. $[15,21$.

Slide-Rule, Stelfox.-A slide-rule with a 5 -in. stock and a ro-in. jointed slide.

Slide-Rule, Whitley.-A slide-rule for calculating altitudes. [13, 15.]

Slide-Rule, Wilson's Double.-A slide-rule for calculating the displacement, registered tonnage, I.H.P., and speed of vessels from the dimensions and coefficients. $[8,13,15$.

Sliding Gauge.- An instrument used by mathematical instrument makers for measuring and setting off distances. $[2,13,17$. 27.]

Slidometer.-An instrument for indicating and recording shocks to railway cars occasioned by sudden stopping.

Smith-Davis Piecework Balance Calculator.-See Piecework Balance Calculator. [15.]

Smith Revolution-Indicator.-See Revolution-Indicator, Aviation. [13.]

Sodeau's Gas Analysis Apparatus.-See Gas Analysis Apparatus.

Solar Attachment.-An attachment to the transit theodolite for the accurate determination of the true or astronomical meridian. $[13,15,17,18,21,24,25,26,27$. 
Solar Diagonal Eyepiece.-See Eyepiece, Diagonal. $[2,3,17,18$, $21,24,25,26,27$.

Solar Intensity Apparatus.-An instrument invented by Padre Secchi for measuring the comparative heat of the sun's rays.

Solar Microscope.-See Microscope. [26.]

Solar Radiation Register.-An apparatus to register automatically the period of sunshine.

Solar Telegraph.-A telegraph in which the rays of the sun are projected from and upon mirrors. [15.]

Solenoid.-A coil of wire the length of which is usually greater than the diameter; wound as cotton is on a reel. When an electric current passes through the wire, the solenoid possesses many of the properties of a magnet. [16.]

Solid Glass Thermometer.-See Thermometer. $[4,5,13,1 \%$.

Sondograph.-A recording sounding apparatus to give a continuous delineation of the bottom of the sea. [16.]

Sonometer.-An instrument consisting essentially of strings or wires stretched on a sounding board, with arrangements for varying the length vibrating and the tension for determining the number of vibrations made by a string emitting a musical sound.

Sounder, Flying.-A name applied to any deep sea sounding apparatus with which soundings can be taken without stopping the ship. $[13,15,16,17,28$.

Sounding Apparatus, Brookes's.-A form of deep sea sounding apparatus invented by Lieut. Brooke, its special feature being the automatic release of the plummet or weight on striking the bottom. $[13,15$.

Sounding-Lead.-The plummet at the end of a sounding line. $[13,15,16,17,24,28$.

Sounding-Line.-The line which holds the sounding lead. [2, $13,15,16,17,21,24,28$.]

Sounding Machine, Hand-Driven.-Apparatus for ascertaining the vertical depth at sea and for taking continuous soundings.

Sounding Machine, Motor-Driven. [15.]

Sounding Machine, Sceptre.-An apparatus for navigational sounding. $[13,28$.

Sounding-Rod.-A graduated iron rod used for ascertaining the depth of water in the well on board ship. $[13,15,21$. $]$

Sounding-Thermometer.-See Thermometer. $[13,15,21,24$.

Sounding Tubes, Chemical. [15.]

Soxhlet's Apparatus.-For milk analysis. [17, 21.]

Soxhlet's Autoclave.-See Autoclave. [2, 26.]

Speciflc Gravity Bottle.-A small glass bottle with a tubulured stopper, used in the determination of the specific gravities of liquids. $[1 \%, 21$.

Spectacles.-A pair of lenses in a frame used to assist or correct defects of vision. $[2,9,13,15,17,20,26$.

Spectacles, Franklin.-Bifocal spectacles with two lense's of different power in each eye. $[2,9,15,20,21$. 
Spectacles, Mydriasis.-Spectacles with blackened discs pierced with small holes for testing chronic dilatation of the pupils. [26.]

Spectacles, Periscopic.-Spectacles having concavo-convex lenses with their curvature nearly parallel with the cornea. [20, 21,26 .]

Spectrograph.-An instrument, consisting essentially of a combined prism spectroscope and camera, for producing, observing and photographing spectra. $[14,26$.

Spectrograph, Concave Grating.-A spectrograph in which a Rowland concave grating is used instead of a prism to produce the spectrum.

Spectrograph, Féry.-A spectrograph in which the collimator and camera lenses are entirely suppressed, the only optical work being the prism itself.

Spectrograph, Quartz.-A spectrograph in which all the optical parts (prisms and lenses) are made of quartz to allow ultraviolet light to be transmitted. $[2,10,11,14,26$.

Spectrograph, Quartz, "Arc" Form.-A quartz spectrograph in which the camera arm is supported by a solid arc with divisions for setting.

Spectrograph, Quartz, Littrow.-A quartz spectrograph specially designed to give a widely-dispersed spectrum with compactness of the instrument.

Spectrograph, Ultra-Violet Glass.-A spectrograph with prisms and lenses of glass for photographing a portion of the ultraviolet spectrum. $[14,26$.

Spectroheliograph.-For producing a monochromatic photograph of the sun's disc. $[4,11,13,14,26$. $]$

Spectrometer.-A prism spectroscope (q.v.) fitted with divided circle, etc., for the accurate measurement of angles and the determination of wave-lengths of spectra. $[2,13,14,19$, 26.]

Spectrometer, Hilger Wave-Length.-A spectrometer in which the collimator and telescope are fixed and a constant deviation prism is rotated. The wave-lengths are read off direct on a drum attached to the screw rotating the prism table. [14.]

Spectrometer, Infra Red.-A spectrometer with mirrors, rocksalt prism and thermopile for the examination of the nonluminous infra red portion of the spectrum. [14.]

Spectrometer, Wave-Length.-A spectrometer in which wavelengths are measured by means of a photographic scale, the reflected image of which is seen in the telescope in juxtaposition to the spectrum. [14.]

Spectrophotometer.-An instrument for comparing and compounding the colours of the spectrum. [14.]

Spectroscope. - An instrument for the production and examination of spectra or absorption phenomena. It consists essentially of a collimator with adjustable slit to transmit a 
parallel beam of the light to be examined, a prism to produce a spectrum, and a telescope to view the spectrum. $[2,3$, $11,13,14,19,20,22,25,26$.]

Spectroscope, Beck-Thorp Pocket Diffraction.-A pocket spectroscope in which a diffraction grating is employed to produce the spectrum.

Spectroscope, Direct Vision.-A spectroscope, with direct vision prism $(q . v$.$) giving an undeviated spectrum.$

Spectroscope, Evershed.-A spectroscope invented by Evershed for the examination of the spectra of star prominences.

Spectroscope Stand.-For small spectroscopes. $[14,26$.

Spectroscope Table.-The rotating table on which the prism stands. [14.]

Speculum.-(I) A mirror or looking-glass; especially a metal mirror. (2) A reflector of polished metal used in astronomical telescopes. (3) In surgery, an instrument for dilating certain of the passages, in order to admit of examinations or access of instruments for operation. $[1,2,3,11,14$. $]$

Speed Recorder.-An instrument for recording the speed of a motor-car, etc. $[5,6,13,15,17$.

Speedometer.-See Speed Recorder. $[5,6,13,15,17$.

Spherograph.-An instrument invented for the mechanical application of spherics in navigation. By its aid with a ruler and index the position of a ship at any place and the distance sailed may be readily and accurately determined. $[13,15$.

Spherometer.-A delicate instrument for measuring the diameter of spherical bodies, and the curvature of spherical surfaces, as of lenses. $[1,2,3,4,17,19,22,25,26$.

Spherometer, Aldis.-An improved form of spherometer, designed by Mr. A. C. W. Aldis, for the determination of the radius of curvature of a lens. [1.]

Spheroscope.-A large model for illustrating and teaching nautical astronomy. [15.]

Sphygmograph.-An instrument used for recording on a chart the character of the movements of the pulse. [21, 26.]

Sphygmometer.-The name for any instrument for measuring and recording the movements of the pulse. [21, 26.]

Sphygmomanometer.-See Sphygmometer. [26.]

Sphygmophone.-An instrument devised to enable a person to determine the rhythms, etc., of the pulse at a distance by means of an electric wire.

Sphygmoscope.-An instrument for rendering the movements of the pulse visible. [26.]

Spinney's Rapid Viewer.-An instrument for repetition examination of interchangeable parts for measuring thickness of material to $0 \cdot 00 \mathrm{r}$ inch.

Spinthariscope.-An instrument for making radium emanations visible to the eye. $[2,3,17,21,26$. 
Spiral Compasses.-A drawing compass for describing spirals. $[13,15,20$.

Spirit Compass.-See Compass.

Spirit Level. - See Level. $[13,15,16,19,21,23,24,27$.

Spirit Level Tester.-A device for calibrating a spirit level in terms of the amount of tilt corresponding to definite movements of the bubble in the level. [21, 25, 27.]

Spirograph.-An instrument for recording the respiratory movements.

Spirometer.-An instrument for measuring the capacity of the human lungs. [21.]

Spline Weights.-An instrument for holding splines in position on the drawing-board. $[13,15,17,21,24,27$.

Splines.-Flexible wooden rods of varying length and section, used for drawing curved lines. $[2,13,15,17,21,24,27$.

Spot Lens.-A condenser (q.v.) for illuminating objects on a black background for examination under a low-power microscope. $[2,3,8,10,12,20,22,26$.

Spotting Telescope.-See Telescope. $[2,3,10,13,20,26,27$.

Sprengel Pump.-A form of air-pump in which exhaustion is produced by a stream of mercury running down a narrow tube in the manner of an aspirator. [20,21.]

Spring Bows.-Small compasses (q.v.) in which the head joint is dispensed with, the sides being tempered steel forming springs.

Spy-Glass.-A small telescope (q.v.). $[3,13,16,17,26,27,28$. Stactometer. - A tube for measuring liquid in drops.

Stadimeter.-A horizontal graduated bar on a staff used as a stadium or telemeter $(q . v$.$) for measuring distances. [13,$ 21.]

Stadiometer.-An instrument designed to show at one reading the measure of any line of sight, curved or broken, on maps. $[13,21,27$.

Stadiometer, Edgeworth's.-A surveying instrument having a round disc plate on which a sheet of paper can be fastened, a divided scale with its edge passing over the centre of the plate enabling the observed distances around the instrument to be plotted to scale. [13.]

Stadiometer Telescope.-A surveying or sighting telescope with an adjustable diaphragm for reading distance from the levelling staff. $[13,21$.

Stage Forceps.-For holding unmounted objects on the stage of a microscope. $[2,3,17,20,21,22,26$.

Stammer's Colorimeter.-See Colorimeter. [17, 21.]

Standard Scale.-A nickel plated divided steel scale, with certificate of accuracy from the National Physical Laboratory. $[21,25$.

Stanhope Lens. -See Lens. $[2,17,20,26$. $]$

Star Diagonal.-See Diagonal Eyepiece. $[2,3,6,21,27$. 
Star Globe.-A sphere indicating the principal stars, for use in star navigation. $[13,15$.

Star Globe, Paget.-An improved star-finding globe. [15.]

Star Photograph Micrometer.-An instrument originally designed to determine the exact co-ordinates of a star or other celestial object upon a photographing plate impressed with a standard réseau. [4.]

Stathmograph.-A contrivance for recording the speed of a railway train.

Station-Pointer.-A nautical surveying instrument for locating positions on charts. $[2,13,15,16,17,21,24,25,26,27,28$. $]$

Station-Staff.-A surveying instrument for taking angles. [2, $13,15,17,27$.

Statoscope.-An instrument for indicating whether an airship or balloon is rising or falling. $[13,17$.

Stauroscope.-An optical instrument particularly designed for investigating the effects of polarised light upon crystals. [26.]

Stead's Gas Analysis Apparatus.-See Gas Analysis Apparatus. [17.]

Steam Gauge.-A gauge (q.v.) for denoting the steam pressure and vacuum in steam boilers and engines, etc. $[5,6,13,15$, $16,17,28$.]

Steel Armoured Thermometer.-See Thermometer. $[4,5,6,15$, 17, 21.]

Steel Mercury Wells.-Steel cups filled with mercury inserted in closed receptacles for obtaining by means of a thermometer the temperature of the receptacle. $[4,5,6,13,15$, $16,17,21,28$.]

Steel Oil-Tape.-A graduated steel tape for measuring the contents of an oil tank. $[15,28$.

Stelfox Slide-Rule.-See Slide-Rule.

Stellar Sextant.-See Sextant. $[10,13,15,16,17,25,26,28$.

Stem-divided Thermometer.-See Thermometer. $[5,6,13,15$, $16,17,21,28$.]

Stencil Plates.-A set of metal plates cut to the shapes of the various letters, figures and designs in common use in architectural and engineering drawings and plans. $[2,10,13$, $15,17,20,21,24,27$.]

Stereometer.-(I) An instrument for measuring the solid or liquid contents of the capacity of a vessel. (2) An instrument for determining the specific gravity of porous bodies, powders, etc.

Stereomonoscope.-An instrument with two lenses by which a stereoscopic effect can be obtained from a single picture.

Stereopticon.-An American name for a magic lantern in which photographic slides are employed. $[17,26$.

Stereoscope.-A binocular instrument for giving to pictures the appearance of solid bodies as seen in nature. $[13,17,20$, 26.] 
Stereoscopic Telescope.-See Telescope. $[2,3,13,20,26$.

Stethometer.-A surgical instrument for measuring the external movement in the walls of the chest during respiration, as a means of diagnosis in thoracic disease.

Stethoscope.-An instrument employed in auscultation for testing the pulsation of the heart and lungs, etc. $[2,26$.

Stevenson Screen.-A stand and screen for out-door thermometers. $[2,6,13,15,17,21,24$. $]$

Stigmatic.-An anastigmat lens (q.v.) having an aperture of $f 6$. The single components are corrected and can be used alone, giving increased focal lengths.

Stokes's Colorimeter.-See Colorimeter.

Stomatoscope.-An instrument for keeping the mouth open for purposes of inspection.

Stonyhurst Sun-Discs.-Specially designed discs for measuring the position of sunspots. $[2,6$. $]$

Storage Cell.-See Accumulator.

Strabismometer.-An instrument for measuring the amount of strabismus. [26.]

Straight-Edge.-A ruler with edge truly aligned. $[2,5,6,13$, $15,16,17,20,21,24,25,26,27$.

Straight-Stem Thermometer.-See Thermometer. $[5,6,13,15$, $16,1 \%, 21$.]

Strain-Measurer.-An apparatus designed to measure directly the strains to which the different parts of any structure are subjected.

Stroboscope.-(I) An instrument for studying or observing the successive phases of a periodic or varying motion by means of light which is periodically interrupted. (2) An optical toy.

Stytometer.-An instrument for measuring columns.

Submarine Camera.-A special form of camera (q.v.) for use under water for submarine photography. [16.]

Submarine Sentry, James.-A special form of sounding machine (q.v.) consisting of a "kite" which is towed after the vessel and, from its construction, submerges and remains at a constant depth below the water. Should the vessel pass into shallow water the trigger, on touching the bottom, is dislodged and the kite rises to the surface, sounding a bell or gong on board. $[13,15,17,28$.

Submarine Telescope.-See Telescope. $[13,15$.

Subsidence Apparatus.-An apparatus for investigating the slow subsidence of a building, etc., or the progress of the effect of a geological fault. [4.]

Substance Diaphragm.-The telescope diaphragm of surveying instrument used to measure distances. [21.]

Sugar-Boiling Thermometer.-See Thermometer. $[5,6,13,15$, $16,17,21$.]

Sulphur Apparatus.-Apparatus for testing the purity of coal gas. 
Suncap.-A tinted glass used between the eye and eyepiece of a telescope when viewing brilliant objects. $[2,3,10,13$, 21,26 .]

Sun-Dial.-An hour-dial with gnomon, the shadow of which, falling on the dial, indicates the time. $[2,6,9,10,13,15$, $16,17,18,20,21,24,26,27$.

Sun-Dial, Universal.-A form of sun-dial which can be set for use in all latitudes. $[13,15,17$.

Sunglass.-A convex lens of glass for producing heat by converging the sun's rays to a focus. $[3,6,13,15,21,26$.

Sunshine-Recorder.-An optical instrument for recording the duration of sunshine by a burning-glass or by a simple form of photographic camera. $[2,4,5,6,9,10,13,15,17,20,21$, $24,25,26,27$.]

Sunshine-Recorder, Campbell Stokes's.-A standard form of sunshine-recorder of the burning-glass type. $[6,10,13,17$, $20,21,26,27$.]

Sunshine-Recorder, Whipple-Casella.-A universal instrument of the burning-glass type, using only one size of card instead of three. [6.]

Superheater Thermometer.-See Thermometer. $[5,13,15,16$, 17, 21.]

Surface Gauge.-An instrument for testing the trueness of a surface.

Surveying Level.-See Level.

Sutcliffe Keratometer.-See Keratometer.

Sutherland's Protractor.-See Protractor.

Switch.-A mechanical device for passing an electric current to another circuit. $[16,26$.

Switch Scale.-A transparent scale divided to 6,00o yards, on scale of I/Io,000 with a pinhole of scale; for pivoting over gun position; used for gunnery work. Also a boxwood scale for use with radian arcs. [2.]

Sygmograph.-See Cardiosygmograph. [21.]

Sympalmograph.-An instrument for making Lissajou's soundcurves.

Sympiesometer.-An instrument for measuring the weight of the atmosphere by the compression of a column of gas. See also Barometer, Boylean Mariotte. $[13,27,28$.

Syphon Barometer.-See Barometer. $[6,10,13,17,21,26,27$, 28.]

Tabor Indicator.-See Indicator, Engine. $[13,15,16,24$.

Tacheometer. - A transit theodolite (q.v.) having a distancereading device in the telescope. $[2,13,15,17,18,21,24$, $25,26,27$.]

Tachograph.-A recording tachometer. [13.]

Tachometer.--(I) An instrument for measuring the velocity of machines. (2) An instrument for measuring speeds without timing. $[5,13,15,17$. 
Tally Counter.-A pocket instrument used in tallying cargo, etc。 $[5,13,15,17,28$.

Tally Register.-An instrument for counting vehicles, people, cattle, etc. $[5,13,15,17,21,26$. $]$

Tangent Galvanometer.-See Galvanometer. $[19,20,21$.

Tape Measures.-In use by surveyors for measuring. $[5,9,13$, $15,16,17,21,25,26,27,28$.

Taseometer.-An instrument for measuring the strains to which the different parts of any structure may be submitted.

Tasimeter.-An instrument for measuring very minute variations of pressure, temperature, moisture, etc. [13.]

Tautness-Meter, O'Gorman.-An instrument for measuring the stresses or tensions of cables, stays and wire ropes in aircraft. $[4,6,21$.

Taximeter.-An instrument for measuring the distance travelled by a vehicle. $[13,15$.

Tee-Square.-A drawing instrument used for making horizontal and (with the aid of a set-square) vertical lines. $[2,5,6$, $13,15,17,20,21,24,26,27,28$.]

Teinoscope.-An optical instrument, consisting of prisms so combined that the chromatic aberration of the light is corrected, and the linear dimensions of objects seen through them are increased or diminished. [13.]

Telautograph.-An electrical device for transmitting autographs or copying designs.

Telectograph.-An apparatus for reproducing by telegraph the images obtained in the camera obscura.

Telegraph.-An apparatus for communicating intelligence rapidly between different points, electrically, by a code of signals. [13.]

Telegraph, Engine.-A mechanical arrangement on ships for the transmission of orde1s from the bridge to the engine-room.

Telegraph, Needle.-A telegraph in which the indications are given by the deflections of a magnetic needle.

Teleiconograph.-A combination of the telescope and camera lucida (q.v.).

Telemeter.-An instrument for determining the distance of an object from the observer. $[2,3,13,20,21,26,27,28$.

Telemeter, Military.-A pocket range-finder (q.v.).

Telemicrophone.-A combined apparatus simultaneously producing the effects of the microphone and the telephone, and reversible like the latter.

Telengiscope.-An instrument combining the powers of the telescope and microscope.

Telephone.-An instrument for transmitting sounds, especially articulate speech, at a distance. [16.]

Telephote. - An instrument for conveying messages or images by the transmission of light.

Telephoto-Lens.-See Lens. 


\section{I65}

Telepolariscope. - A polariscope arranged to be attached to a telescope. $[8,14$.

Telescope.-An optical instrument for " magnifying" distant objects, so as to make them look nearer to the eye than they actually are. There are two principal forms-refracting telescopes and reflecting telescopes. The optical system of a refracting telescope, in its simplest form, consists of two co-axial lenses: the object-glass or objective (q.v.), to produce a real image of the distant object, and the eyelens, through which this image is viewed. In reflecting telescopes the image is formed by means of a concave mirror of large radius. $[1,2,3,5,6,8,9,11,13,14,15,16,17,18,20,21$, $23,24,26,27,28$.]

Telescope, Achromatic.-A form of refracting telescope in which achromatic lenses are used to avoid chromatic aberration. $[2,3,8,9,10,11,13,15,17,18,20,21,22,23,25,26,27,28$. $]$

Telescope, Astronomical.-A refracting telescope in which the objective forms a real, inverted image which is viewed through a convergent eye-lens, acting as a magnifying glass.

Telescope, Binocular.-An instrument, compounded of two similar telescopes, by which an object is viewed simultaneously with both eyes. $[2,3,5,9,13,15,17,18,20,21,26$, 27.]

Telescope, Cassegrain's.-A reflecting telescope in which the concave mirror is pierced with a small central aperture and a subsidiary, small, convex reflector forms a secondary image which is viewed through the aperture in the large mirror by means of an eyepiece. $[3,11,13,18$.

Telescope, Catadioptrical. - A combined reflecting and refracting telescope.

Telescope, Catoptric.-A reflecting telescope.

Telescope, Coastguard.-A 30-in. refracting telescope, strongly mounted, with a power of $25 .[2,3,5,8,9,13,15,16,17$, $18,20,23,24,25,26,27$.

Telescope, Day and Night.-A refracting ship's telescope with a power of 12 or 25 . $[3,5,8,9,10,13,15,16,17,20,26$, $2 \%, 28$.]

Telescope, Dioptric.-A refracting telescope. $[1,3,11,13,17$. 20.]

Telescope, Equatorial.-A telescope mounted in such a manner that, by suitable mechanism, it follows the apparent motion of the observed star, due to the rotation of the earth. [2, $3,6,8,9,11,13,17,18,20,21,25,26,27$.

Telescope, Floating Photographic.-An observatory photographic telescope floating on a liquid for observing absolute zenith distances of stars within 80 of the zenith. [13.]

Telescope, Galilean.-A refracting telescope in which the eyelens is divergent, giving an erect image. It is shorter than an astronomical telescope of equal magnifying power. $[1,3,6,8,10,11,13,15,16,17,18,20,21,26,27$. 
Telescope, Gregorian.-A reflecting telescope in which the concave mirror is pierced with a small central aperture, and a subsidiary, small, concave mirror forms a secondary image which is viewed through the aperture in the large mirror by the aid of an eyepiece. $[11,18$.

Telescope, Herschellian. - A reflecting telescope, designed by Sir $\mathrm{Wm}$. Herschel, in which the axis of the concave mirror is slightly inclined to the incident rays and the image is thus thrown to one side of the axis, and observed directly by means of an eyepiece at the front end of the telescope. [11, 18.]

Telescope, Naval.-A refracting signalling telescope, with taper body and having a sliding tube for focussing, in several sizes, ranging in power from 20 to 50 . $[1,2,3,5,6,8,9$, $10,13,15,16,17,18,20,21,23,24,25,26,27,28$.]

Telescope, Newtonian.-A reflecting telescope, invented by $\mathrm{Sir}$ Isaac Newton, in which the eyepiece views at right angles to the axis the image formed by the main speculum, by means of a speculum (or a totally reflecting prism) set at $45^{\circ}$ to the axis close to the focal point. $[2,3,11,13,18,26$.

Telescope, Officer of Watch.-A regulation, hand, refracting telescope, as used by officers in the Royal Naval Service. Power I5. $[2,3,5,9,13,15,16,17,20,21,23,24,25,26$, 2\%, 28.]

Telescope, Oscillating Prism.-

Telescope, Reading.-A small refracting telescope used for reading at a distance a scale of, for example, a galvanometer. $[1,2,3,10,13,15,17,19,21,26,2 \%$.]

Telescope, Ship's.-Known generally as the Day and Night Telescope (q.v.). $\quad[3,6,8,9,10,13,15,16,17,20,21,23$, $24,26,28$.]

Telescope, Sighting.-A refracting telescope with an index, or graticule, used for sighting guns. $[1,2,3,8,9,11,13,16$, $17,18,20,21,22,23,25,26,27$.]

Telescope, Signal Station.-A high power, signalling, refracting telescope, with tripod, as used at signalling stations. $[1,2$, $3,8,9,13,15,17,18,20,21,22,23,25,26,27$.]

Telescope, Spotting.-A binocular, refracting telescope, giving greatly increased stereoscopic vision for estimating distances. $[2,3,10,13,20,26,27$.

Telescope, Submarine.-A special form of refracting telescope, with a large plane object-glass, which is submerged beneath the surface of the water. $[13,15$.

Telescope, Variable Power.-A telescope in which parts of the eyepiece are made to move conformably so as to vary the power continuously while keeping the object in focus.

Telespectroscope.-An instrument, compounded of the telescope and spectroscope, for observing the light from the planets and fixed stars, for ascertaining their physical condition, and the composition of their atmospheres. [11.] 
Telestereoscope.-An instrument for producing an appearance of relief in the objects of a landscape at moderate distances.

Telethermometer.-An apparatus for determining the temperature of a distant point, as by a thermo-electric current or otherwise. See also Pyrometer, Thermometer. $[4,13,16$.

Telewriter.-A telegraphic apparatus for reproducing writing at a distance.

Tellurian.-A working model for showing the revolution of the earth round the sun.

Temperature Control Apparatus.-For maintaining constant temperature baths for standard cells and coils. See also Thermostat. $[4$.

Templets.-Arcs of large radii cut in wood, used as a guiding edge in drawing arcs. [21.]

Tennant's Nitrometer.-See Nitrometer.

Tension Meter.-An instrument for measuring the tautness of aeroplane fabrics.

Terrascope.-Model of the earth and sun. [15.]

Terrestrial Globe.-A sphere representing the earth, and having the seas, continents, and islands, etc., indicated thereon. $[15,21$.

Test-Gauge, Duplex Standard.-A double reading standard gauge used in the testing of gauges. $[5,13,15,17,28$. $]$

Test Plate (Abbe). - A silvered glass plate with rough edged lines ruled upon it. Used for testing microscope object-glasses. $[2,3$.

Test Types.-Printed type on card for eyesight testing. [2, 26.]

Tetanometer.-An electrically controlled apparatus used in physiological experiments for stimulating a nerve by rapid concussion.

Tetragonal Prism. - The same as Corner Cube Prism (q.v.).

Thacker's Calculating Instrument.-See Calculating Instrument. $[13,27$.

Thacker's Slide-Rule.-A surveying instrument. $[13,21,27$.

Thaumatrope.-An optical toy depending for its effects upon the persistence of vision.

Theodolite.-A surveying instrument for accurately measuring both horizontal and vertical angles by the aid of a telescope and graduated circles. It is usually mounted on a strong tripod and is provided with compass, level, etc., and verniers for reading the circular scales. See also Dunbar-Scott Auxiliary Top and Side Telescope. $[2,5,6,9,10,13,15$, $16,17,20,21,24,25,26,27$.]

Theodolite, Lean's Miners'.-A special form of theodolite for mining work. $[6,13,18,21,25$.

Theodolite, Transit.-A theodolite in which the telescope may take a complete revolution upon its horizontal axis. In the "plain" theodolite the telescope moves through an arc of about $45^{\circ}$ upwards or downwards from the horizontal plane. $[2,5,13,15,16,17,20,21,24,25,26,27$. 
Theodolite, Transit, Hoskold's.-A special form of theodolite or tacheometer for mining and underground railway work. $[13,25,2 \%$. $]$

Theodolite, Transit, Mountain.-A theodolite designed for geographical exploration and for making sketch surveys. [2, $6,13,17,21,24,25,26,27$.

Thermal Conductivity of Copper (Searle's Apparatus).-For the absolute measurement of the thermal conductivity of copper.

[19.]

Thermatelephone.-A telephone dependent for its action on the difference in temperature of the surface of a diaphragm, when it is convex or concave, as measured by a thermopile. Thermetograph.-A self-registering thermometer, especially one that registers the maximum and minimum during long periods. See also Thermometer. $[13,17,20,21$. $]$

Thermo-Ammeter, Duddell's.-An instrument for the measurement of very small currents. The current to be measured passes through a heater, which becomes heated in consequence and warms a thermo-couple, causing a current to flow through a coil turning in a magnetic field and carrying a pointer. [4.]

Thermo-Barometer.-An instrument for measuring altitudes by means of determining the boiling point of water. See also Barometer, Hypsometer. $[6,13,17,27$.

Thermo-Couple.- Two wires of dissimilar metals joined at one end and forming part of an electric circuit. When the junction is heated, a current flows in the electric circuit; hence, if this current is measured by a galvanometer, it is possible to employ thermo-couples as a means of measuring temperatures. See Thermo-Electric Pyrometer. $[4,16$.

Thermo-Couple Potentiometer. - A potentiometer (q.v.) for measuring the potential of thermo-couples. [16.]

Thermo-Electric Pyrometer.-See Pyrometer. $[4,16$.

Thermo-Electrometer.-An instrument for ascertaining the heating power of an electric current. [13.]

Thermo-Galvanometer, Duddell's. - An instrument for the measurement of extremely small alternating or continuous electric currents to a high degree of accuracy. It consists of a resistance which is heated by the current to be measured, some of the heat thus generated heating the thermo-junction of a Boys' radio-micrometer (q.v.). [4.]

Thermograph.-An instrument for automatically recording on a chart variations of temperature. $[2,4,5,9,13,15,16$, $17,20,21,27,27,28$.]

Thermo-Hydrometer.-A thermometer and hydrometer combined in one instrument. $[5,13,16,17,20,21$.

Thermometer. - An instrument for the measurement of temperature, commonly founded on the principle that changes in the temperature of a body are accompanied by 
proportional changes in its volume or linear dimensions. The term usually denotes a thermometer of glass, in which the thermometric substance is mercury, but it includes instruments in which other fluids than mercury may be used and other vessels than glass, and also instruments depending upon changes of electrical resistance or other electrical properties with changes of temperature. See also Pyrometer. $[2,4,5,13,15,16,17,20,21,24,25,26,27,28$.

Thermometer, Alarm.-A thermometer used for giving a signal when the temperature rises or falls to a given temperature, at which point an electrical circuit is completed so as to ring a bell or light a lamp. See also Balance Thermometer. $[4,6,13,15,16,17,24$. $]$

Thermometer, Bake-oven.-Range, $200^{\circ}-750^{\circ} \mathrm{F}$. $[4,5,13,15$, $16,17,21,26$.]

Thermometer, Baker's Temperating.--Range, $30^{\circ}-160^{\circ} \mathrm{F} . \quad[4,5$, $9,13,15,20,21$.]

Thermometer, Balance.-A thermometer mounted as a balance so that the movement of a mercurial column changes the inclination of the tube. With the aid of electrical or mechanical attachments, it is used for the automatic regulation of the temperature of rooms warmed artificially, or as a fire-alarm. See also Alarm Thermometer. $[4,6,13$, $15,16,17,20,21,24$.

Thermometer, Banana.-A special thermometer for use in the holds of vessels carrying bananas. $[4,5,6,13,15,17,20$, 21.]

Thermometer, Beckmann.-A sensitive mercurial thermometer designed to give within a limited range, which is adjustable, a very considerable expansion of the mercury column. Used for indicating only small differences of temperature. Estimations to one-thousandth of a degree Centigrade can be made with the aid of a lens.

Thermometer, Blind Scale.-A thermometer without any scale, but with a single mark to indicate a particular temperature. $[4,5.6,13,15,16,17,20,21$.

Thermometer, Chemical.-Any thermometer, usually mercurial for use in chemical operations. The scale is either wholly encased in glass or engraved on the stem itself, so that the instrument may be plunged into caustic or corrosive liquids. $[2,5,6,15,16,17,20,21,25$.

Thermometer, Clinical.-A form of maximum thermometer for obtaining the temperature of the human body. $[2,5,6,9$, $13,15,16,17,20,21,24,25,26,27,28$.]

Thermometer, Coal Tar Still.-Range, $200^{\circ}-75^{\circ}$ F. $[5,6,16$, 17, 21.]

Thermometer, Condenser.-Range, $30^{\circ}-160^{\circ} \mathrm{F}$. $[5,6,13,15$, $17,20,21$. 
Thermometer, Confectioner's.-For chocolate-melting: Range, $60^{\circ}-120^{\circ}$ F. For sweets-making: Range, $200^{\circ}-400^{\circ} \mathrm{F}$. For vacuum pans: Range, $100^{\circ}-35^{\circ} \mathrm{F}$. $[5,6,13,16,17$, 20,21 .]

Thermometer, Copper Case.-Any form of thermometer fitted in a copper case, usually applied to the thermometers used in brewing. $[13,15,16,17,20,21,27,28$.

Thermometer, Deep Sea.-A thermometer for ascertaining the temperature of the sea at any depth. The instrument is automatically reversed at any given depth and the temperature recorded by the mercury column broken at the moment of reversal. $[6,13,15,17,20,21$. $]$

Thermometer, Dial.-A thermometer with a scale in the form of a circular dial. The tube may be made of glass or metal. Thermometer, Differential.-An instrument, invented by Sir J. Leslie, having two air bulbs connected by a bent stem containing coloured sulphuric acid. It usually indicates, without measuring, differences of temperature of the two bulbs. $[13,15,16,17,20,21,25$.

Thermometer, Distance.-A thermometer used for indicating or recording temperatures at a distance, usually electrically operated. See Pyrometer.

Thermometer, Economiser.-Range, $50^{\circ}-400^{\circ} \mathrm{F} . \quad[5,6,13,16$, 21.]

Thermometer, Electrical Distance.-See Distance Thermometer. $[4.6,13,16$.

Thermometer, Feed Water.-Range, $40^{\circ}-240^{\circ} \mathrm{F} . \quad[5,13,15,16$, $20,21,28$.]

Thermometer, Flour Hopper.-Range, $30^{\circ}-100^{\circ} \mathrm{F} . \quad[5,6,13,15$, $17,21$.

Thermometer, Gasworks. - Two standard types. Ranges, $30^{\circ}-$ $160^{\circ} \mathrm{F}$ and $70^{\circ}-240^{\circ} \mathrm{F}$. $[4,5,13,15,16,17,21$.

Thermometer, Gum Melting.-Range, $200^{\circ}-70^{\circ}$ F. $[5,15,21$.

Thermometer, Hand-Testing.-Range, $0^{\circ}-120^{\circ} \mathrm{F} . \quad[5,6,13,15$, $16,17,21$.]

Thermometer, Immisch's. - A form of special pocket thermometer. It contains a crescent-shaped, thin, metallic vessel filled with a highly-expansible liquid. $[20,21,26$.

Thermometer, Incubator.-A special form of thermometer for use in incubators. $[2,5,15,17,21,26$.

Thermometer, Index.-See Dial Thermometer. $[4,16,21,25$.

Thermometer, Jam Boiling.-Ranges, $200^{\circ}-240^{\circ} \mathrm{F}$. and $180^{\circ}-$ $270^{\circ} \mathrm{F}$. $[5,6,13,15,16,17,21,26$.

Thermometer, Linseed Oil.-Range, $60^{\circ}-150^{\circ} \mathrm{F}$. $[5,13,15,16$, 21.]

Thermometer, Loaf-Testing.-Ranges up to $400^{\circ} \mathrm{F}$. $[1,5,13$, $15,16,17,21$.]

Thermometer, Maximum.-A thermometer provided with an index showing the maximum temperature reached during a given period. The index may form part of the mercury 
column of the thermometer, or may consist of a small index of iron which is pushed by the mercury column. $[2,5,6$, $13,15,16.17,20,21,24,25,26,27$.

Thermometer, Maximum and Minimum, Six's.-A combined maximum and minimum thermometer, employing alcohol and mercury as the thermometric liquids.

Thermometer, Minimum.-A thermometer, usually with alcohol as the liquid, for registering the minimum temperature reached during a given period. The index is of glass or enamel. $[2,5,6,13,15,17,21,24,25,26,28$.

Thermometer, Molten Metal.-A glass thermometer encased in a metal frame for dipping into metals, such as type metal, with comparatively low melting points. Ranges, $200^{\circ}-$ $75^{\circ} \mathrm{F}$., and $200^{\circ}-\mathrm{I}, 000^{\circ} \mathrm{F}$. $[5,6,15,16,17$.

Thermometer, Obtuse Angle.-A steam thermometer with the lower or bulb end set at an obtuse angle to the stem. $[5,13$, 15.]

Thermometer, Oil-Boiling.-Range, $200^{\circ}-650^{\circ} \mathrm{F}$. $[5,13,15,16$, $17,21$.

Thermometer, Oil Fuel.-Range up to $10^{\circ} \mathrm{F}$. $[13,15,16,17$, 21,28 .]

Thermometer, Oil-Tempering Bath.-Range, $200^{\circ}-650^{\circ}$ F. $\quad[5$, $6,13,15,16,17$.

Thermometer, Oxide-Testing.-Range, $60^{\circ}-200^{\circ}$ F. $[13,15,21$. Thermometer, Photometer.- [13.]

Thermometer, Pit.-A portable form of thermometer for use underground. $[5,6,13,15,16,17,21,24]$

Thermometer, Platinum Resistance.-See Resistance Thermometer. [4.]

Thermometer, Pot Leather.-Range, $100^{\circ}-300^{\circ}$ F. $[6,13,15$.

Thermometer, Pressure.-A thermometer for the measurement of temperature under pressure. Range, $200^{\circ}-350^{\circ} \mathrm{F}$. and I-100 lbs. per square inch pressure. $[4,6,15,17$.

Thermometer, Quenching Bath.-Ranges, $30^{\circ}-220^{\circ}$ F. and $100^{\circ}-$ $250^{\circ} \mathrm{F}$. $[6,13,21$.

Thermometer, Radiation.-A thermometer specially adapted for indicating the radiation of heat from grass or from the sun. See Solar Radiation Thermometer. $[5,13,15,17,20,21,26$. Thermometer, Refrigerator. - Range, $0^{\circ}-90^{\circ}$ below zero $\mathrm{F}$. [5, $6,9,13,15,17,21,26,28$.]

Thermometer, Resistance.-A temperature-measuring instrument depending on the principle that the electrical reistance of a wire increases with the rise of temperature. The wire usually employed is of platinum. See also Distance Thermometer and Pyrometer. $[4,13,16$.

Thermometer, Right Angle.-A steam or vat thermometer with the lower or bulb end at right angles to the tube scale. [5, $13,15,17,21$.]

Thermometer, Sea Surface.-Range, $26^{\circ}-95^{\circ}$ F. $[6,13,15,17$, $21,28$. 
Thermometer, Separable Pocket.-A steam or vat thermometer with a detachable socket cup. $[13,15$.

Thermometer, Side Angle.-A steam or vat thermometer with the lower end bent sideways. $[5,13,15$ 17. $]$

Thermometer, Solar Radiation.-A mercurial thermometer for measuring the maximum temperature attained in the full rays of the sun. The tube has a blackened bulb and is enclosed in a glass jacket from which the air has been removed. $[15,21$. $]$

Thermometer, Solid Glass.--Range up to $500^{\circ} \mathrm{F}$. $[4,5,13,15,17$. Thermometer, Sounding.-An electrical balance thermometer to ascertain the temperature of the ocean at any depth. $[13$, $15,21,24$.]

Thermometer, Steel Armoured.-A chemical or steam thermometer, encased in a steel sheath. $[4,5,6,15,17,21$.

Thermometer, Stem Divided.-Range up to $1,000^{\circ} \mathrm{F}$.; those from $600^{\circ} \mathrm{F}$. are nitrogen-filled. $[5,6,13,15,16,17,21,28$.

Thermometer, Sugar-Boiling.-Range, $200^{\circ}-400^{\circ}$ F. $[5,6,13$, $15,16,17,21$.]

Thermometer, Superheater.-Range, $200^{\circ}-750^{\circ}$ F. $[5,13,15$, $16,17,21$.

Thermometer, Terrestrial Radiation.-A spirit thermometer for measuring the maximum temperature reached in consequence of the radiation from the earth at night. $[13,15,1 \%$.]

Thermometer, Varnish Maker's.-Range, $200^{\circ}-650^{\circ} \mathrm{F}$. $[5,13$, $15,16,17,21$.]

Thermometer, Vulcaniser.-Range, $200^{\circ}-350^{\circ} \mathrm{F}$. $[5,13,15,17$.

Thermometer, Water.-A thermometer filled with water instead of mercury.

Thermometer, Wet and Dry Bulb.-See Hygrometer.

Thermometrograph.-See Thermograph. $[13,15,20,21$.

Thermomultiplier.-An instrument for measuing small variations of temperature due to radiant heat. [21.]

Thermophone.-An instrument in which sonorous vibrations are produced by the expansion of heated bodies connected with an electro-magnet.

Thermopile.-An instrument consisting essentially of a number of thermo-couples (q.v.) in which all the odd junctions are presented together at one end and all the even junctions at the other, so as to yield a thermo-electric current. The electromotive force obtained with a given difference of temperature between the ends of the pile is proportional to the number of junctions.

Thermo Regulator. - See Thermostat. [4.]

Thermoscope.-An instrument for indicating, but not measuring, changes of temperature.

Thermostat.-A self-acting apparatus for maintaining a constant, or nearly constant, temperature by the unequal expansion of different metals, liquids, or gases by heat. $[2,4,21,23$, $26,27$. 
Thermostat, Electric. - A thermostat in which the temperature is kept constant by the automatic regulation of the amount of current traversing a heating coil. $[4,13$.

Thermostat, Lowry's New Pattern.-An apparatus designed by Dr. Lowry to supply a rapid stream of hot water at a constant temperature.

Thermostat, Ostwald's Water.-A thermostat consisting of a felt-covered copper vessel with gas regulator, Méker burner, and stirring arrangement.

Thomas Sinker.-An improved form of sounding sinker (q.v.), with large tallow reservoir. $[13,28$.

Thompson Prism.-See Prism. $[2,3,22,26$.

Thomson Calorimeter. - See Calorimeter. $[4,15,21$.

Thomson Deflector.-See Deflector.

Thomson Galvanometer.-See Galvanometer. $[4,16,19,21$.

Thomson's Quadrant Electrometer.-See Electrometer. $[16,21$.

Thorp Diffraction Grating.-See Diffraction Grating. [3, 17.]

Thorp Diffraction Spectroscope.-A spectroscope (q.v.) in which the dispersion is produced with a Thorp diffraction grating. $[3,17$.

Thread Recorder.-See Galvanometer. [4.]

Threlfall Micromanometer.-See Micromanometer. [4, 21.]

Thrust and Torque Dynamometer. -See Dynamometer. $[4,16$.

Thunderstorm Recorder.

Thurston's Oil-Tester.-See Oil-Tester. [13.]

Thurston's Recording Oil-Tester.-See Oil-Tester. [13.]

Tide-Dial. - A dial to exhibit the state of the tides at any time. $[13,15,17$.

Tide-Gauge.-An instrument to measure the rise and fall of the tides. See Gauge. $[13,15,16,17,21,24,26$.

Tide-Indicator, Lenthall-Baugh.-An instrument for giving the height of the tide above low-water level of ordinary spring tides at any hour between high and low water, and also the time from high water that the tide should be at any given height. [13.]

Tide-Predicting Machine.-See Harmonic Analyser.

Tide-Recorder.-A tide-gauge which gives continuous records of the rise and fall of tides. $[4,6,13,15,16,17,21,26$.

Tide-Recorder, Field and Cust.-An improved form of tidegauge, worked by compressed air, for use on a coast or on a ship.

Tide Table.-Capt. Grant's "De Plano" model. A table for giving immediately the time of high water at the most important ports throughout the world.

Timber Contenting Rule.-A slide-rule for denoting the content of timber in cubic feet. $[15,21$.

Timber Rod.-A jointed deal rod with hook at one end, for ascertaining the length of standing timber. $[15,21,24$. 
Time-Marker.-An instrument for recording to the tenth of a second the time of fall of a body through a known distance. [4.]

Tintometer.-An optical colour-testing instrument, used by dyers and printers. See also Colorimeter. $[2,17,21,26$.

Tintometer, Lovibond's.-An instrument for denoting tints and colours by reference to standard coloured glasses, used for ascertaining the strengths of solutions by means of their colours. $[3,5,13,17,21,26$.

Tithonometer.-An instrument for noting the tithonic or chemical effect of the rays of light.

Titrating Apparatus.-An apparatus used in plant physiology.

Tonometer.-(I) An instrument for determining the rate of vibrations in tones. (2) An apparatus for studying and registering the action of various fluids and drugs on the excised heart of various animals. (3) An instrument for measuring tension, especially that of the eyeball.

Tonophant.-A modification of the kaleidophone (q.v.) for showing composition of acoustic vibrations.

Topophone.-An instrument to determine the direction of a source of sound.

Totalising Rain-Gauge.-See Rain-Gauge. $[13,15,17,20,21$, $25,27$.

Tourmaline.-A mineral occurring usually in three-sided or six-sided prisms terminated by rhombohedral or scalenohedral planes. $[2,26$.

Tourmaline Analyser or Polariser.-A crystal used for polarising light. See also Polariser. [3, 26.]

Tracer.-A drawing instrument used for copying purposes. [15, $24,27$.

Tracheotomy Tube.-A tube placed in an opening in the trachea to permit passage of air to the lungs in the case of obstruction of the larynx.

Trajectograph.-A simplified form of ripograph, for recording altitude and velocity. $[13,20$.

Trammel.-An ellipsograph consisting of a cross with two grooves which form guides for two pins on a beam compass. $[2,17,21$.

Transit.-An instrument resembling a large theodolite used by surveyors and engineers, and especially for ascertaining correct time of passage of heavenly bodies over the meridian. $[2,10,11,13,15,17,21,24,25,26,27$.

Transit Circle.-A transit instrument with a graduated circle attached, used for observing the time of transit and declination at one observation. $[11,13,17,21,25,26,27$.

Transit Instrument.-A telescope mounted at right angles to a horizontal axis, on which it revolves with its line of collimation in the plane of the meridian; used in connection with 
a clock for observing the time of transit of a heavenly body over the meridian of a place. $[2,3,10,11,13,15,17,21$, $25,26,27$.

Transit Photograph Apparatus.-A device for moving the photographic plate instead of the telescope to allow for the rotation of the earth in star photography. [11.]

Transit, Prime Vertical.-A transit instrument, the telescope of which revolves in the plane of the prime vertical. Used for observing the transit of stars over the circle. $[21,25$.

Transit Theodolite.-See Theodolite. $[2,5,13,15,16,17,20,21$, $24,25,26,27$.]

Transmitter.-In the telephone, the funnel for receiving the voice and conveying the waves of sound upon the thin iron diaphragm. [16.]

Traver's Sight-Rule.-See Sight-Rule. $[13,15,27$.

Trechometer.-A kind of odometer $(q . v$.$) or contrivance for$ ascertaining the distance run by vehicles. [21.]

Trestles for Drawing-Boards.-Drawing office equipment. [2, $15,17,20,21,24,27$.

Trial Frame.-A spectacle frame into which trial lenses can be placed for testing sight. $[2,17,20,21,26$.

Trial Sight Case.-A case of spectacle lenses for testing the sight. $[2,17,20,21,26$.

Triangular Beam Compass.-See Beam Compass. $[2,13,15,17$, $20,21,26,27$.

Triangular Compasses.-See Compasses. $[2,5,13,15,16,17,20$, $21,24,26,27,28$.]

Triangular Scales.-Drawing scales triangular in section, containing scales on each of the three sides. $[2,5,13,15,17$, $20,21,24,26,27$.

Tribometer.-An instrument resembling a sled, used in estimating the friction of rubbing surfaces.

Tribrach, Quicksetting.-A special form of mounting for engineer's field instruments, designed to save time in setting up. $[13$, $15,21,24,25,26,27$.

Trichinascope.-An apparatus for the detection of trichinæ in the flesh of animals, as of swine. [2.]

Triple Aplanat Magnifier.-See Magnifier. $[1,2,3,12,13,15$, 23, 26.]

Triple Nib Drawing-Pen.-A drawing-pen for ruling a heavy or broad line. $[2,13,15,27$.

Trocheameter.-A revolution-counter (q.v.), for fixing to the wheel of a vehicle. $[4,5,13,15,16,17,19,21,24,25,26$.

Trochometer.-An instrument for computing the revolutions of a wheel; an odometer (q.v.). [13.]

Tromometer.-An instrument for measuring earth tremors. See also Seismograph. [21.]

Trough Compass.-A compact form of magnetic compass used where the magnetic north and south only is required. 


\section{6}

Tubular Compasses.-Compasses with pen and pencil mounted on a tube. $[2,5,13,15,17,21,24,26,27,28$.

Turbidimeter.-An instrument for measuring the turbidity of water.

Turn-Table.-A revolving table used in mounting microscopic objects. $[2,26$.

Twaddell's Hydrometer.-See Hydrometer. $[5,13,15,17,21,28$.]

Udometer. - A rain-gauge (q.v.). $\quad[13,15,17$.

Ullage Rod.-A rod for determining the quantity of liquid required to fill a cask partly filled. $[5,13,15,17$.

Ullage Rule.-A rule for use with the Ullage $\operatorname{Rod}(q . v.) . \quad[5,13$, 15. 17.]

Unifilar Magnetometer.-See Magnetometer. $[13,15,17$.

Universal Portable Electrometer.-See Electrometer. [4.]

Universal Sun Dial.-See Sun Dial.

Vaccine Apparatus.-Apparatus for the preparation of vaccines for injection in the treatment of diseases.

Vacuum Gauge.-See Gauge. $[5,13,15,16,17,21,28$.

Vacuum Tube.-See Geissler's Tube and Crookes's Tube.

Valentine Knife.-A two-bladed knife for making at a single stroke a thin section of a tissue, for microscopic examination. $[20,26$.

Valvograph.-A simple instrument, made in transparent celluloid, for solving without calculation various problems relating to valve diagrams. $[13,15,21$.

Vaporimeter.-An instrument for measuring the volume or the tension of any vapour. [13.]

Vaporimeter, Archbutts'.-An instrument for determining the vapour-tension of oils. [13.]

Variable Power Telescope.-See Telescope.

Variable Speed Recorder.-A type of recording drum which can be connected to a machine to enable the speed of rotation to be determined. See also Revolution Counter. $[4,5,13,16$, $17,19,21,25,26$.]

Varnish-Maker's Thermometer.-See Thermometer. $[5,13,15$, $16,17,21$.]

Velocimeter.-An apparatus for measuring and ascertaining the speed of machines, etc. See also Revolution Counter.

Velometer.-An air-speed indicator for aeroplanes. $[15,17$.

Verascope.-A stereoscopic hand camera invented by Jules Richard.

Verner Rapid Sketcher.-A combination instrument for military work, designed by Major W. Verner; combining a clinometer, compass, sighting rule, protractor, and plotter.

Vernier Calliper.-See Calliper. [25.]

Vernier Compass.-A Service pattern marching compass (q.v.). $[16,20.21,27$. 
Vernier Model.-A model used in navigation schools for teaching the reading of the vernier. [15.]

Vernier Reading Theodolite.-A theodolite (q.v.) with vernier reading device. $[21,24,25$.

Vertical Drawing Compasses.-See Compasses. [15, 21.]

Vertical Iluminator.-An apparatus for illuminating metal surfaces for examination with the microscope by throwing the light down through the objective. $[2,3,20,21,22,26$.

Viameter.-An odometer (q.v.), called also a viatometer. [21.]

Viatometer.-See Viameter.

Vibration Recorder.-See Seismograph. $[4,13,17,21,26,27$.

Vibrometer.-A special form of vibration table used for testing compasses and instruments for the effects of vibration. [16.]

Vibrometer, Tuned-Reed Pattern.-An instrument fitted with vibrating reeds of adjustable natural frequencies and arranged to show the extent of, and the plane in which, vibration is present in a turbine or other machine.

Vibroscope.-An instrument for graphically recording the vibrations of a tuning-fork.

Vicat Needle.-An accurate instrument for determining the time taken by cement in setting. See Cement Needle Apparatus. $[17,21$.

View-Finder.-See Finder.

Vignetter.-An apparatus for printing photographs with a margin gradually fading away. $[3,20$.

Vinometer.-A form of hydrometer (q.v.) for measuring the strength of wine. $[13,21$.

Viscometer.-An instrument for measuring the viscosity of liquids. $[13,15,1 \%$. $]$

Viscometer, Boverton Redwood's.-A viscometer for determining the viscosity of oils. [15.]

Viscometer, Engler's.-A standard form of viscometer designed by the Petroleum Congress. [15.]

Viscometer, Glue.-A viscometer for testing the viscosity of glue. [21.]

Viscometer, Redwood's Standard.-Admiralty pattern. A viscometer for the determination of the viscosity of lubricating oils. $[13,15,1 \%, 21$.

Viscosimeter. - See Viscometer. $[13,17$.

Visiometer.-An instrument by which to determine the power of lenses (spectacles).

Vitrographine Ink.-Ink for writing on glass with steel pen.

Vivascope.-A telescope for viewing objects at close ranges. 13.]

Voltaic Battery.-A galvanic battery. See Battery. [26.]

Voltameter.-An instrument for measuring the strength of a current by means of electrolysis.

Voltameter, Silver.-A voltameter in which the current strength is measured from the deposition of silver from an electrolyte 
of a silver salt. The anode consists of a plate or rod of pure silver and the cathode of a platinum bowl. [4.]

Voltmeter.-Any instrument for measuring the pressure, electromotive force, or difference of potentials at the ends of an electric current. $\quad[10,16,21$.

Voltmeter, Electrostatic.-A voltmeter for the measurement of the potential difference between two points, by means of the electrostatic forces between moving and fixed elements, but no current flows through the instrument itself.

Voltmeter, Recording.-A voltmeter giving a continuous and visible record on a chart of variations of potential.

Volumescope.-An instrument, consisting essentially of a glass tube, provided with a graduated scale for exhibiting to the eye changes of volume of a gas resulting from chemical action or the like.

Voluminometer.-An instrument for measuring the volume of a body, especially a solid, by means of the difference in tension caused by its presence and absence in a confined portion of air.

Vulcaniser Thermometer.-See Thermometer. $[5,13,15,17$.

Wallis's Barometer Adjunct.-A small reading microscope (q.v.). $[6,13$.

Walpole's Colorimeter.-See Colorimeter.

Warm Stage.-A contrivance for keeping a specimen at an even temperature when examining under a microscope. [2, 3, 22,26 .]

Watchmaker's Eyeglass. - A magnifying lens mounted for fixing in one eye. $[2,3,15,17,20,21,22,26$. $]$

Water-Analysis Apparatus.-Any apparatus for the analysis of water.

Water-Barometer.-See Barometer. $[13,17$.

Water Finder, Redwood.-An instrument for determining the amount of water at the bottom of an oil tank. $[13,15,16$.

Water-Gauge Glasses.-Glass tubes fitted to boilers, etc., to indicate water level. $[5,15,17$.

Water Hammer.-A vessel partly filled with water, exhausted of air, and hermetically sealed; when reversed or shaken, the water, being unimpeded by air, strikes the sides in solid mass with the sound like that of a hammer. $[17,21$. $]$

Water-Testing Apparatus.-For testing the hardness of water.

Water Thermometer.-See Thermometer.

Watkin Clinometer.-See Clinometer. $[13,15,21,25,26,27$.

Watkin's Heat-Recorder.-Consists of a small block of refractory material, having circular recesses sunk into top face, into which are placed fusible pellets of definite composition and melting point. See also Seger Cones.

Wattmeter.-An instrument for directly measuring, in watts, the work-rate, or electrical power, of an electric current in. a circuit. It is usually a form of electro-dynamometer $(q . v$.$) .$ 
Wattmeter, Recording.-A wattmeter giving a continuous and visible record of the work-rate of an electric current.

Wealemefna.-A form of space runner; a convenient instrument for measuring distances on maps in prospecting. See also Rotameter. $[13,15,17,21,24,26,28$.

Weather-Glass.-A barometer (q.v.). $[5,6,13,15,16,17,20$. Weldon Range-Finder.-See Range-Finder. $[13,15,17,21,27$. Weston Normal Cell. - A type of cadmium cell used as a standard of electromotive force. $[4,16,19$.

Wheatstone Bridge.-A network, arranged in a particular way, of six electrical conductors. Used, together with a galvanometer and battery, in electrical measurements of E.M.F., resistance, etc.

Wheatstone's Photometer.-See Photometer.

Wheel of Life.-See Zoetrope.

Whipple Temperature Indicator.-Used with resistance thermometers. The instrument is a form of Wheatstone bridge (q.v.) calibrated to give readings in degrees of temperature. [4.]

White Cloud Illuminator.-A plaster of Paris reflector to put over a mirror of a microscope to give a diffused reflected light. $[3,26$.

Whitley Slide-Rule.-See Slide-Rule. $[13,15$.

Wide-Angle Lens.-See Lens.

Wilson-Kaye Electrometer.-See Electrometer. [4.]

Wilson's Chromometer.-See Chromometer.

Wilson's Double Sliding-Rule.-See Slide-Rule. $[8,13,15$.

Wind-Corrector, Notcutt.-A celluloid instrument giving range and line corrections at sight for a ro ft. per second wind. [15.]

Wind-Dial. - A dial to show the direction of the wind. $[6,13$, 15, 17.]

Wind-Gauge.-An instrument for measuring the velocity and force of the wind ; an anemometer (q.v.). $[6,13,15,16,17$, $20,21,24,25,26$.]

Wire Extension and Rupture Apparatus.-For measuring the extension of wires to the point of rupture. See also Extensometer. [19.]

Wollaston's Double-Image Prism.-See Prism. $[3,13,14,22,26$.

Wright's Finder.-See Finder. $[2,10,22,26$.

Wynne's Actinometer.-See Actinometer.

X-Ray Machine Apparatus.-Apparatus for generating Röntgen rays. [26.]

XY Chart-Frame.-A chart-frame with a transparent xylonite top. $[13,15$.

XY Rolling Parallel Rule, Field's.-A rolling rule with a xylonite blade or rule for chart work.

$[13,15,16,20,27$. 
Yacht Curves.-A set of curves for boat or yacht designing. [13, 15, 21, 24, 27.]

Yeast-Testing Apparatus.-Apparatus for estimating the amount of $\mathrm{CO}_{2}$ evolved from yeast.

Y-Level.-A surveyor's level with Y-supports for the telescope, enabling the latter to be reversed. $[2,6,9,13,15,16,17$, $21,24,25,26,27$.

Young's Modulus Apparatus.-For the determination of Young's modulus of elasticity. See also Searle's Apparatus. $[4,19$.

Zenometer.-An instrument for measuring the angle of depression from a ship's bridge, and getting the distance of a buoy or other object. Can be fitted to any sextant. [15.]

Zoetrope.-An optical toy, also known as the "Wheel of Life." A circular series of pictures representing moving figures, etc., in successive phases is placed vertically in a revolving cylinder and viewed through narrow slots cut in the circumference of the cylinder. A life-like appearance of motion is apparent to the observer. The germ of the modern cinematograph.

Zollner Spectroscope--See Spectroscope. $[2,13,14,26$.

Zoogyriscope.-A form of kinematograph or animatograph.

Zoophyte Trough.-A small glass trough used for examining small aquatic objects under the microscope. $[2,3,20,22$, 26.]

Zoopraxinoscope.-An instrument similar to and the same as a phenakistoscope, by means of which pictures projected upon a screen are made to exhibit the natural movements of animals and birds.

Zymoismeter.-An instrument for ascertaining the degree of fermentation occasioned by the mixture of different liquids and the degree of heat which they acquire in the process of fermentation. 


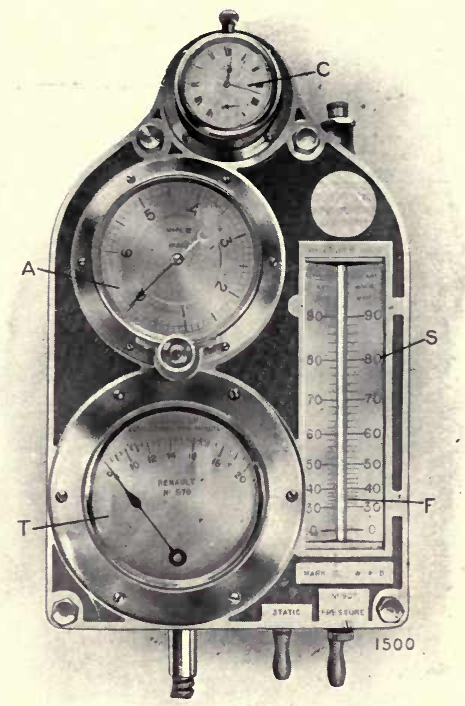

Fig 1.-Aeroplane Instrument Board.

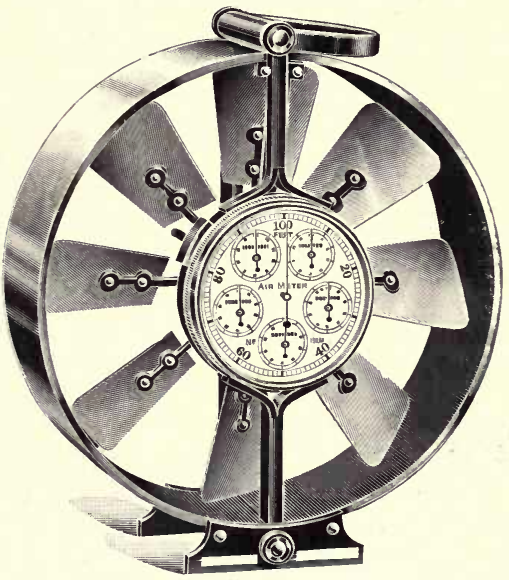

Fig. 2.-Air Meter, Biram's. 


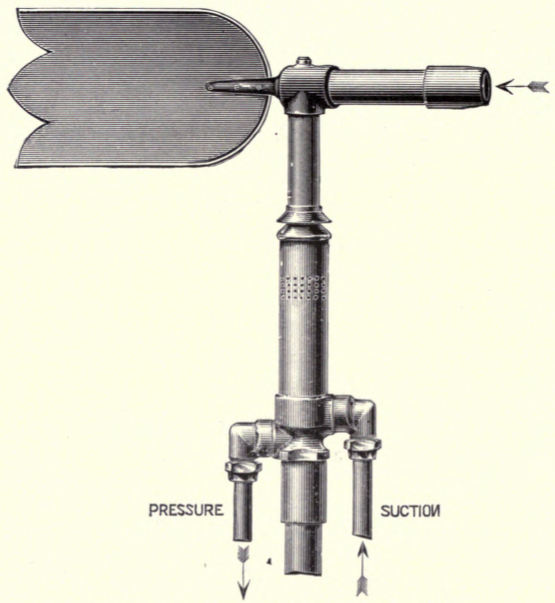

Fig. 3.-Anemometer, DyNe's.

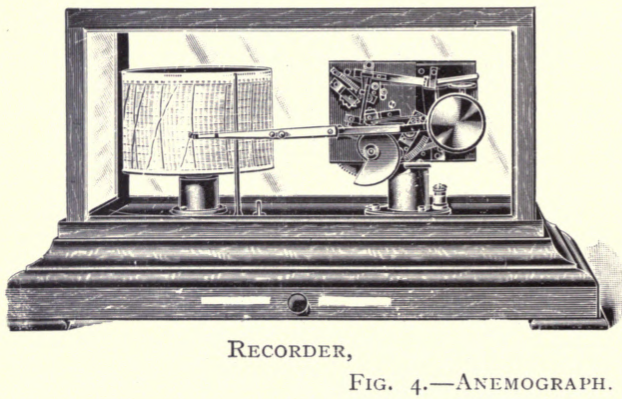




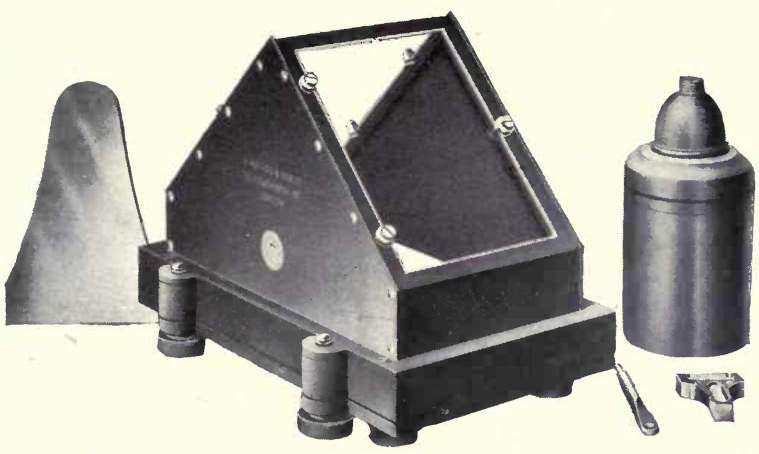

Fig. 5.-Artificial Horizon, Admiralty Pattern.

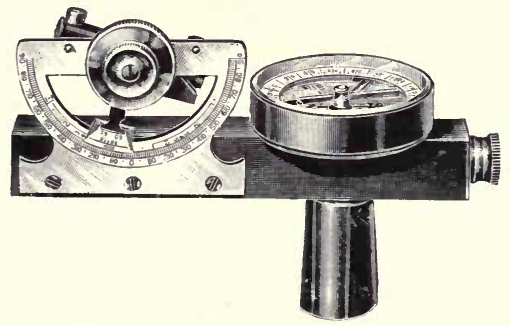

Fig. 6.-Alidade and Abney Level.

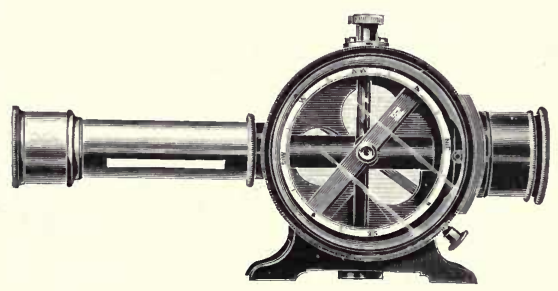

Fig, 7.-Altazimuth for Surveying. 

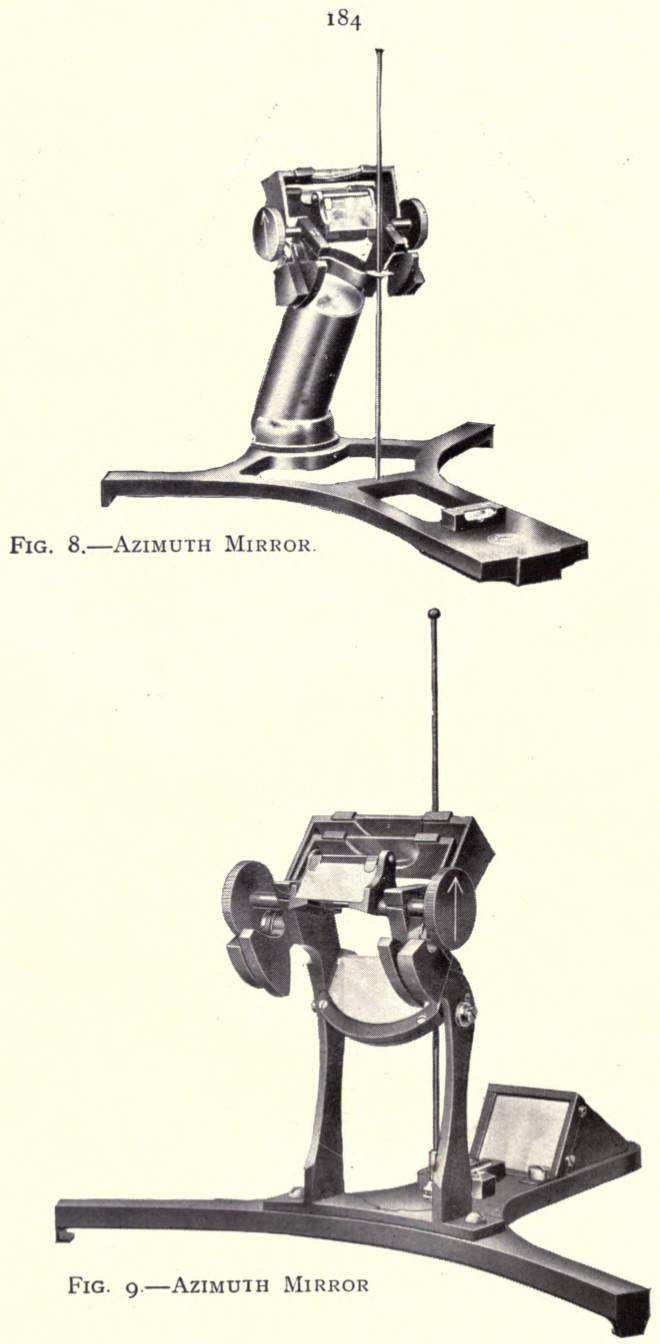


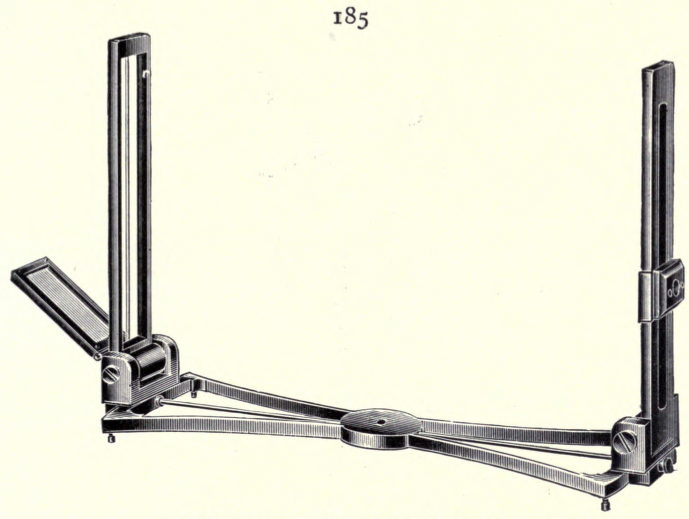

Fig. io.-Azimuth Sight.

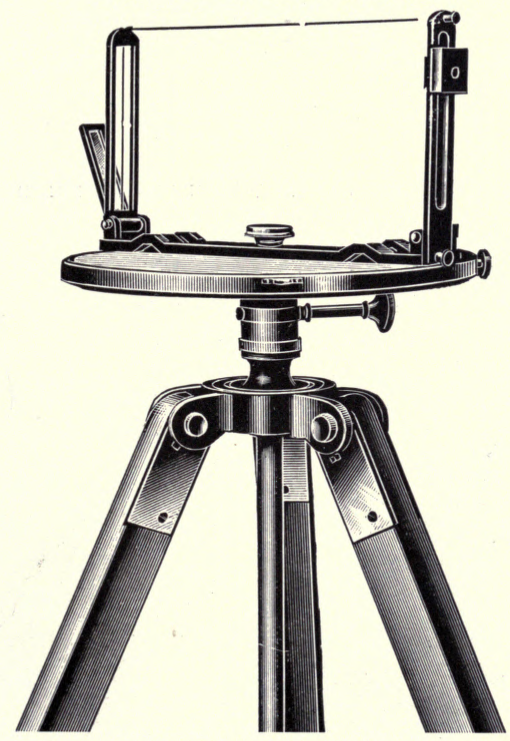

Fig. il.-Adjusting Dial. 


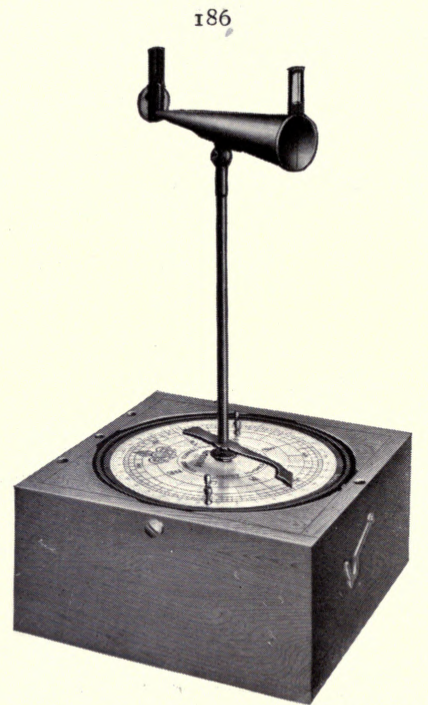

Fig, i2.-Azimuth Dial, Course Corrector

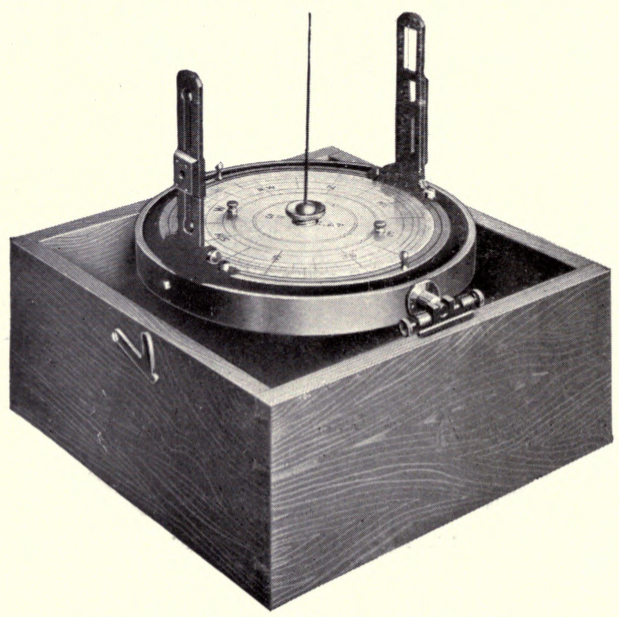

Fig. I3.-Azimuth Dial, Pelorus. 


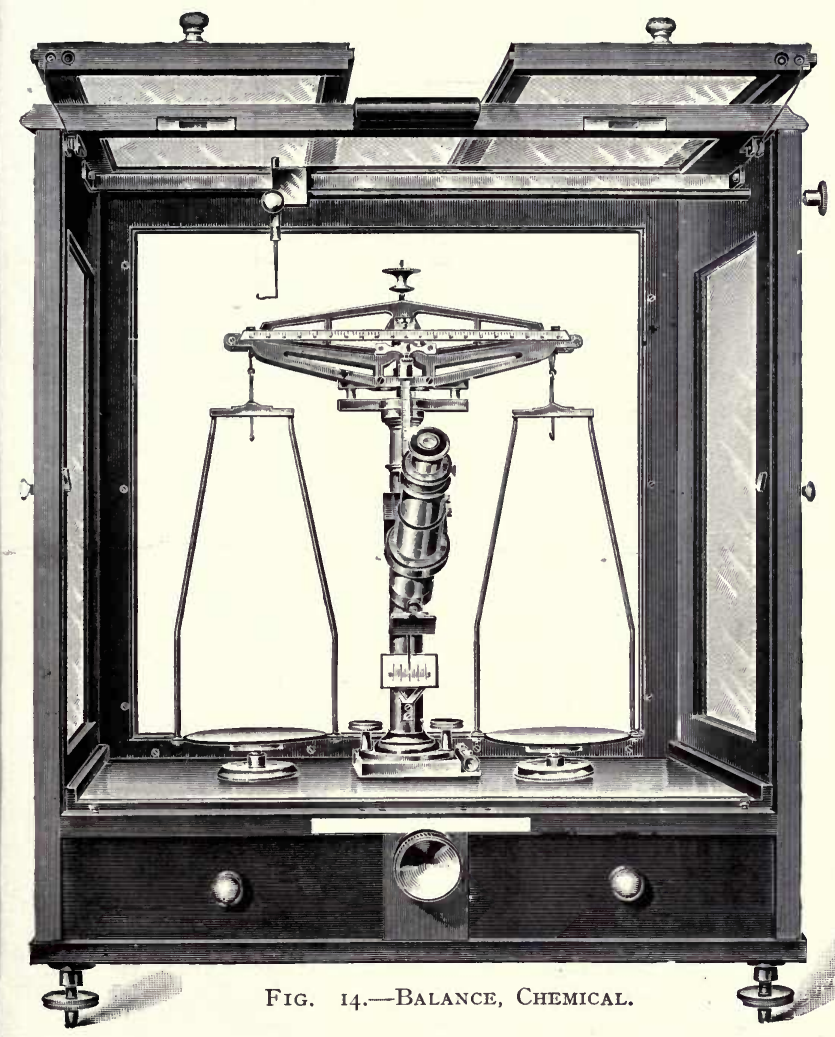




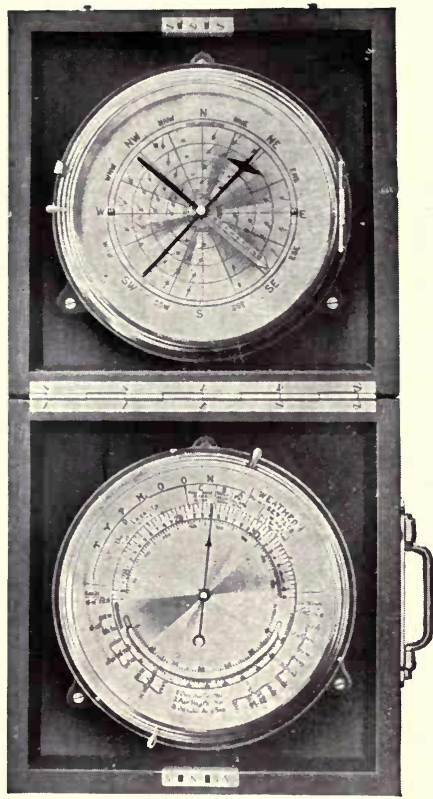

Fig. I 5.-BARocyclonometer.

$a^{2}=-4 \times 4=20$

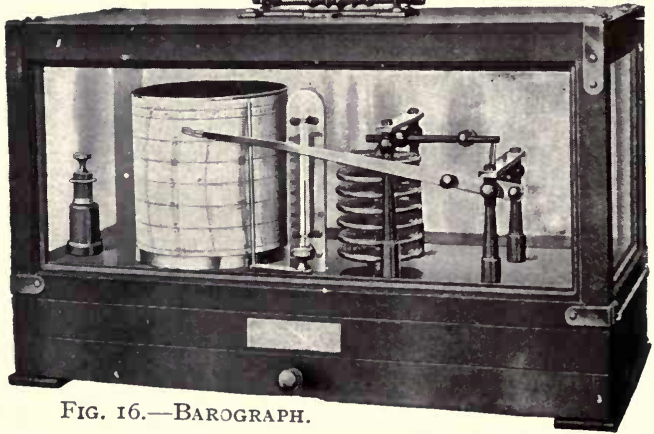




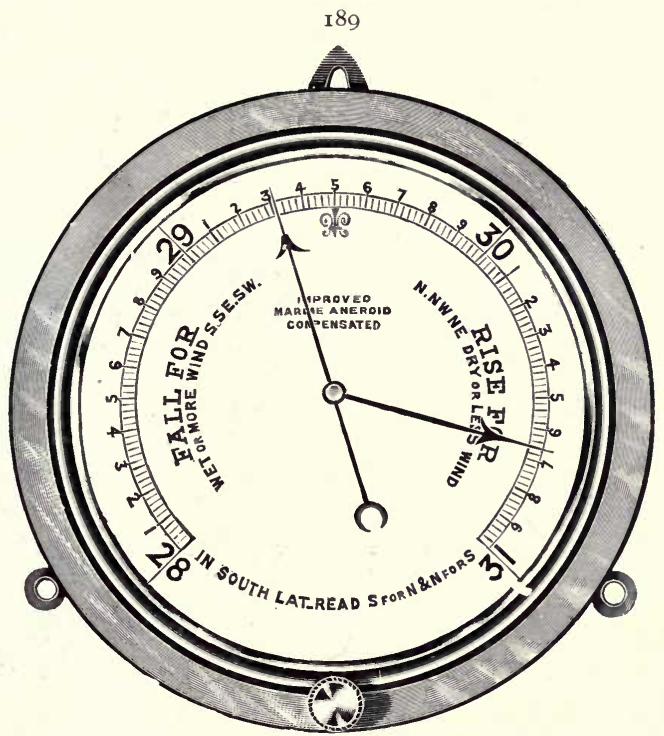

Fig. I7.-BArometer, Aneroid.

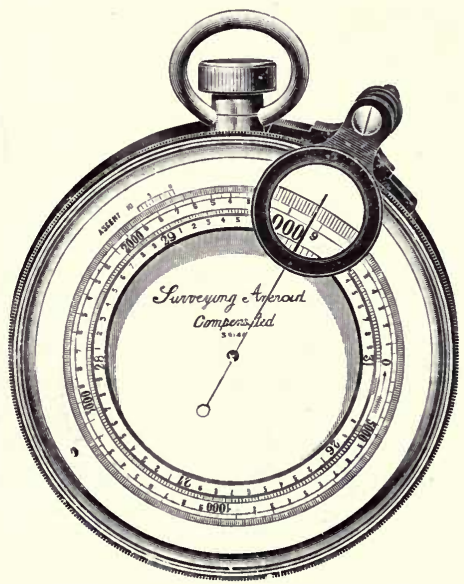

Fig. 18.-Barometer, Aneroid, Surveying Pattern. 


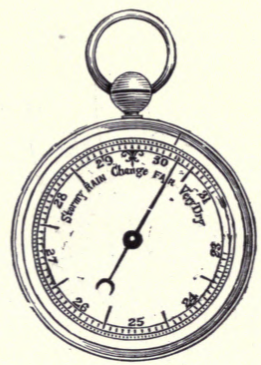

Fig. I9.-BARometer, Aneroid. Pocket Size.

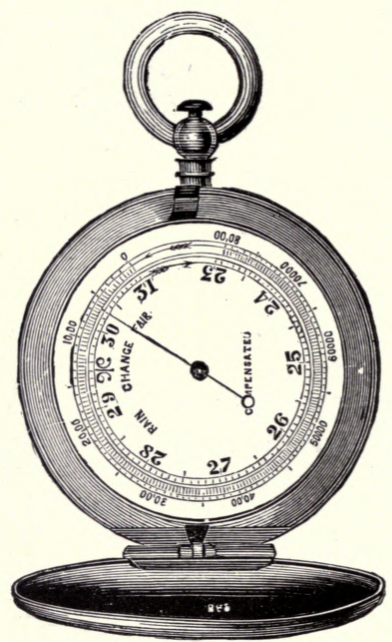

Fig. 20.-BAROMETER, Aneroid. Hunter Case.

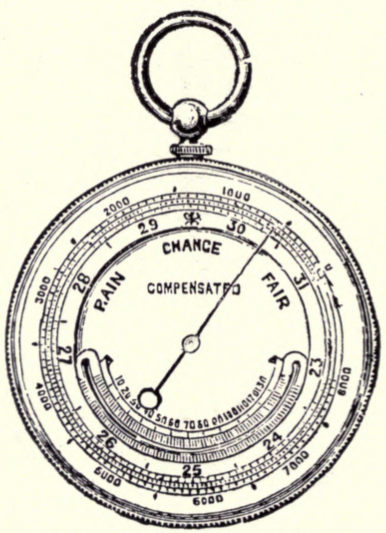

Fig. 21.-Barometer, Aneroid, Surveying Pattern. 


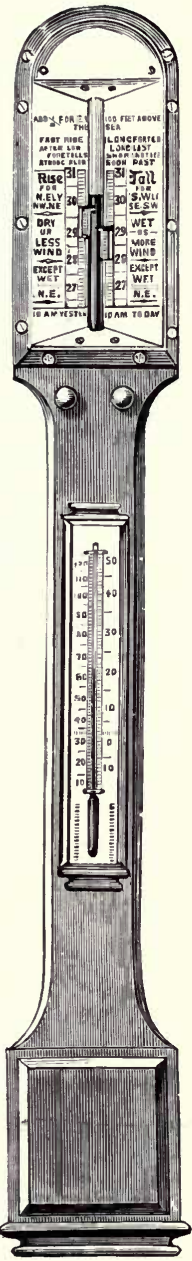

FIG. 22.-BAROMETER, Fitzroy Pediment.

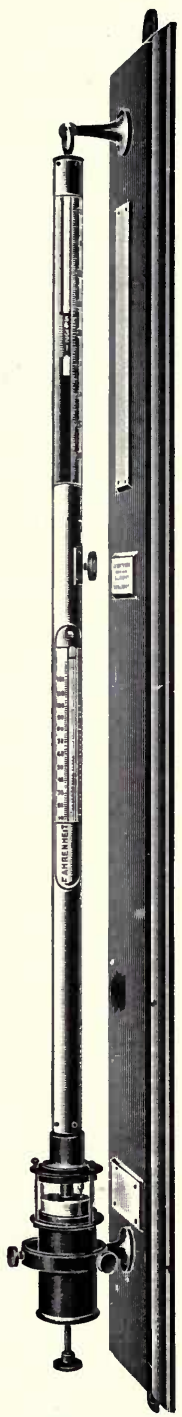

Fig. 24.-Barometer, Fortin Standard. 


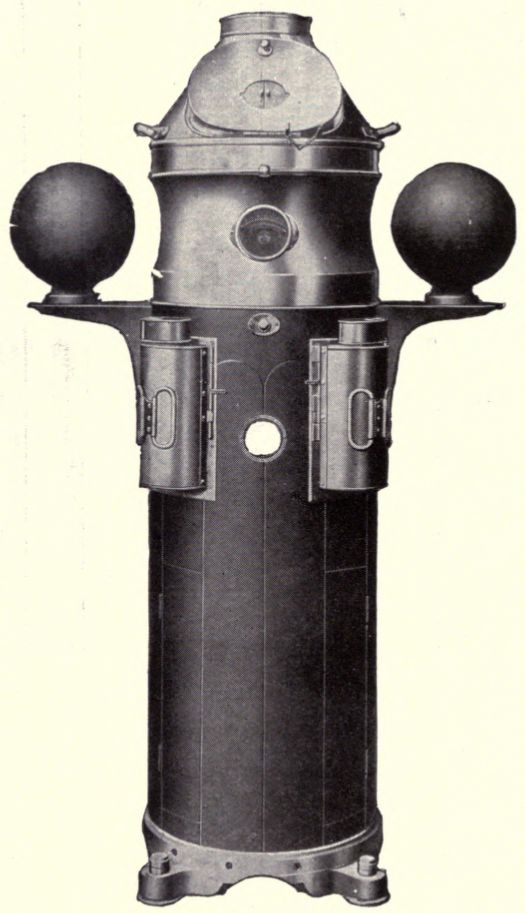

Fig. 25-Binnacle, Standard. 


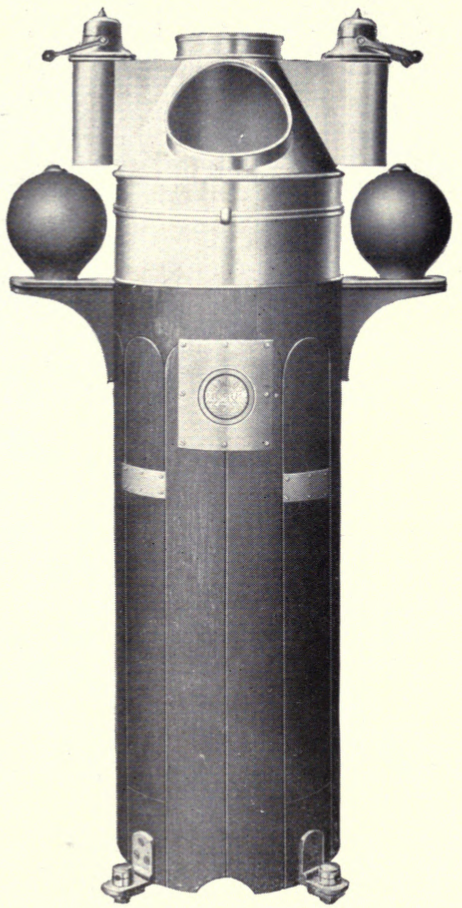

Fig. 26 -Binnacle, Trawler Standard 


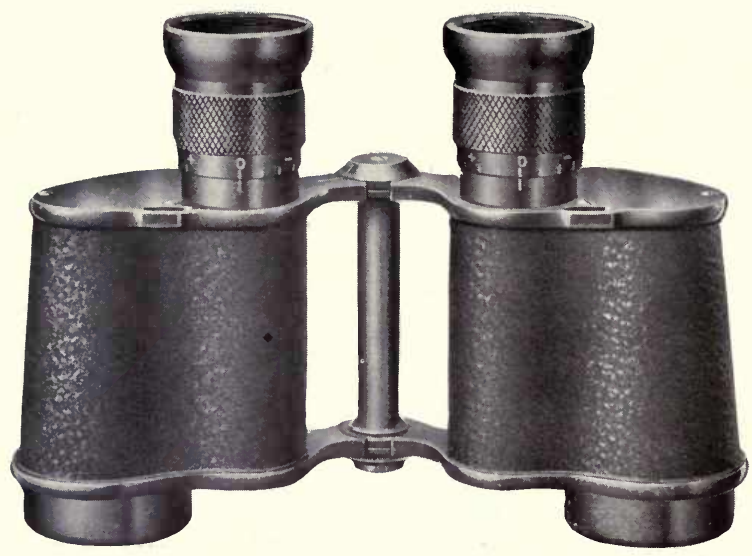

Fig. 27.-Binocular, Prism, Marine.

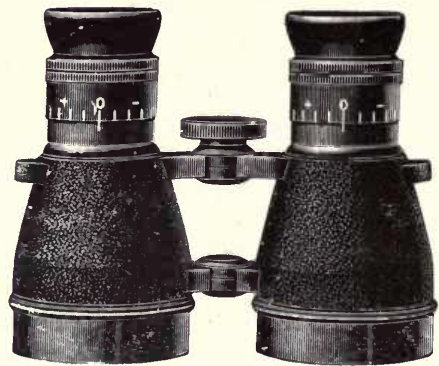

Fig. 28.-Binocular, Galilean, Eye-Focussing Marine. 


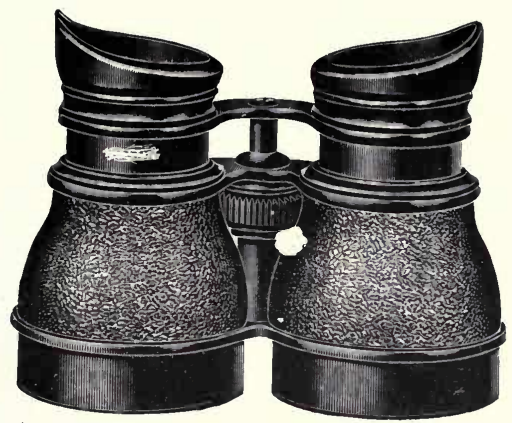

Fig. 29.-Binocular, Galilean, Marine Night Glass.

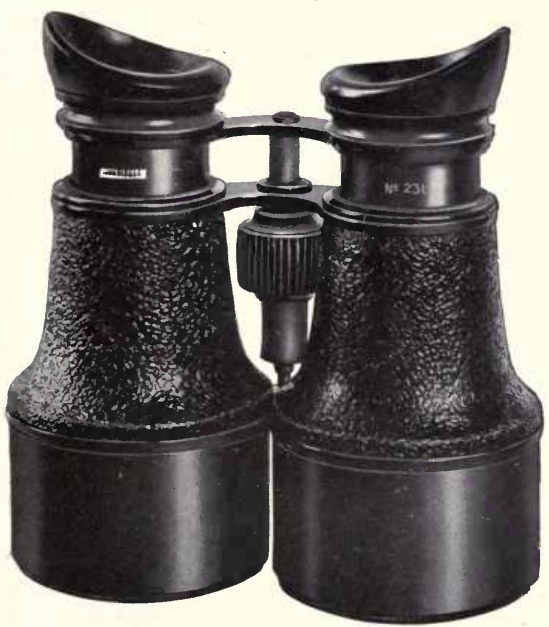

Fig. 30.-Binocular, Galitean, Marine Night and Day Glass. 


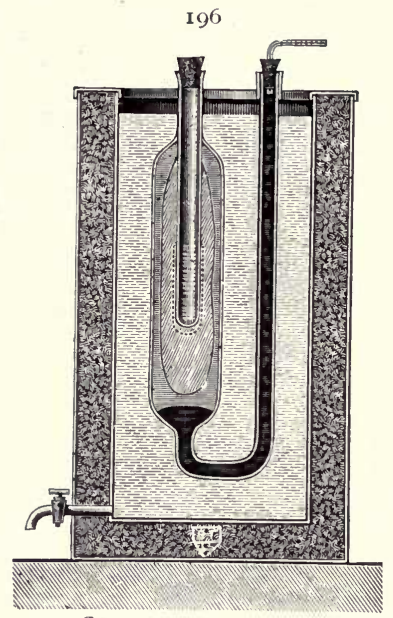

Fig. 3i.-Calorimeter, Bunsen's Ice.

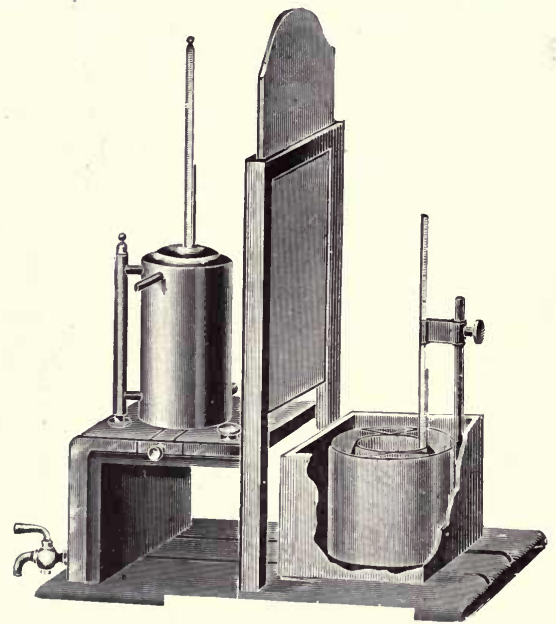

Fig. 32.-Calorimeter, Glazebrook's. 


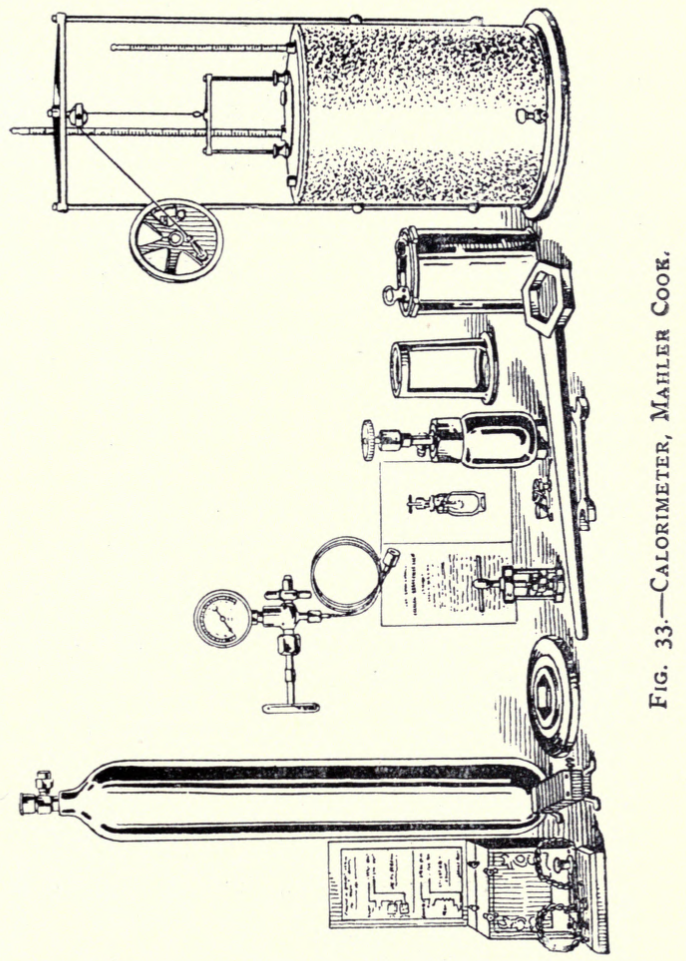




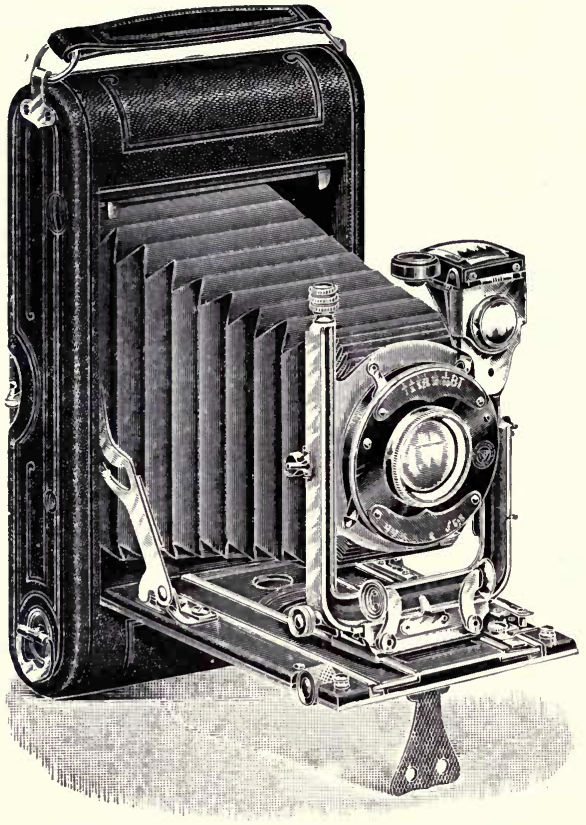

Fig. 34.-Camera, Hand. 


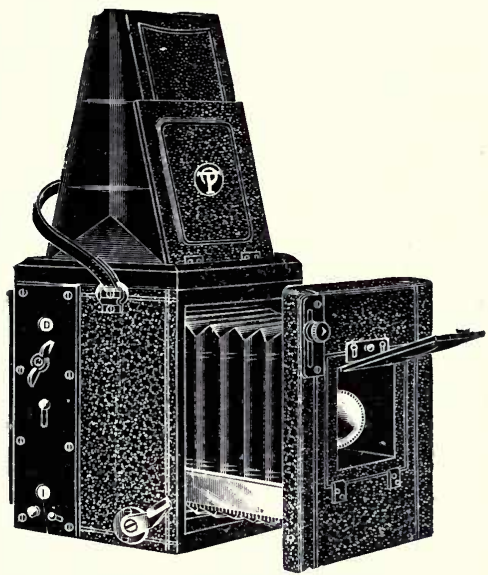

Fig. 35.-Camera, Reflex.

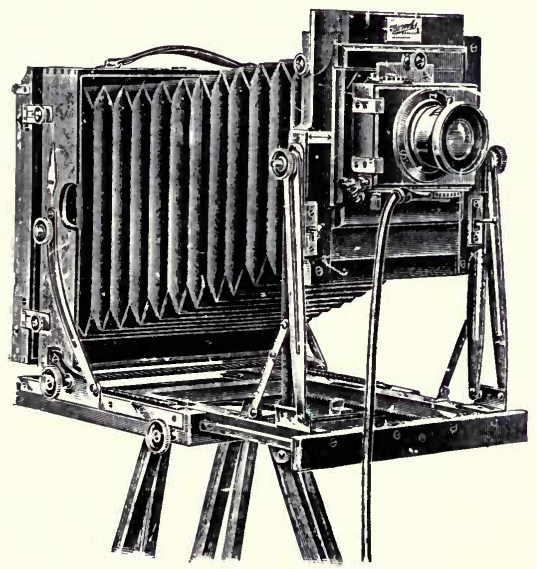

Fig. 36.-Camera, Stand, 


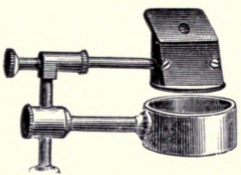

Fig. 37.-CAmera Lucida, Vertical.

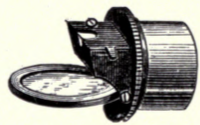

Fig. 38.-Camera Lucida, WOLLASTON's.!

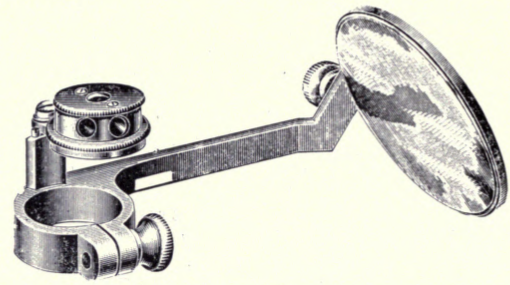

Fig. 39.-Camera lucida, Abbé.

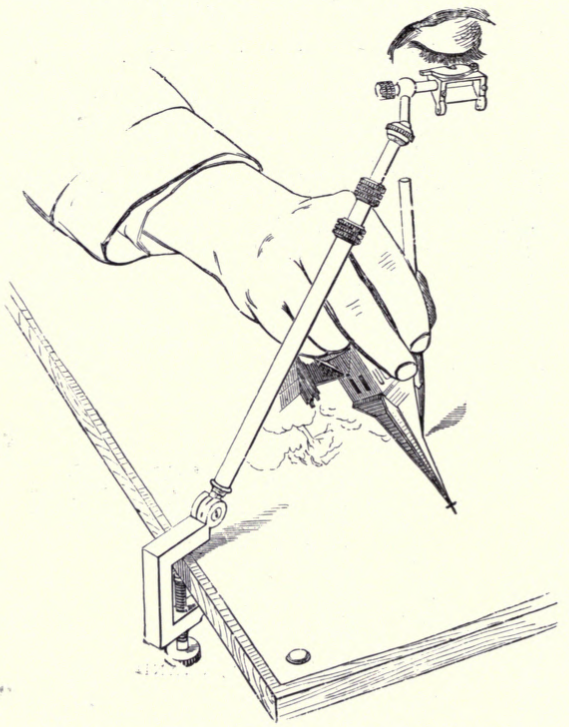

Fig. 40.-Camera Lucida, Sketching. 


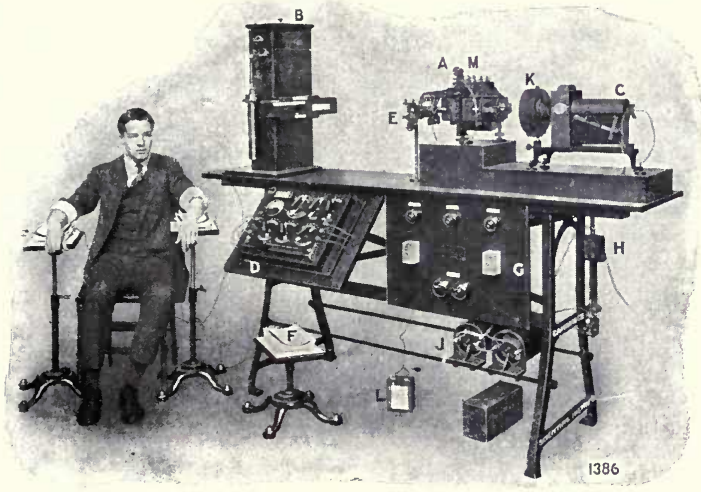

FIG. 4I.-CARDIOGRAPH 


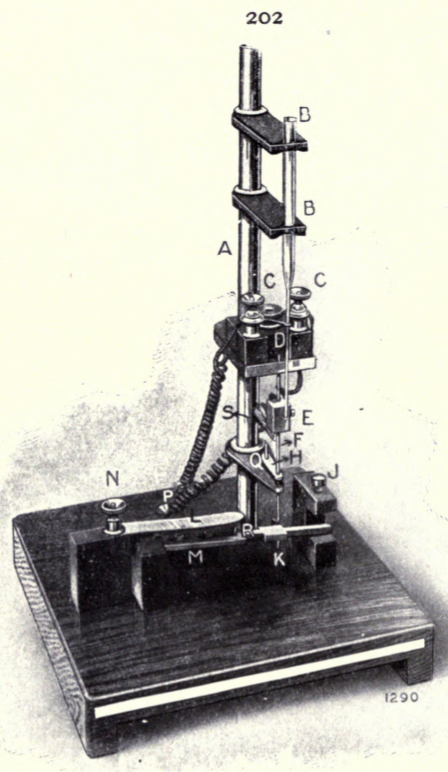

Fig. 42.-Capillary Eifctrometer.

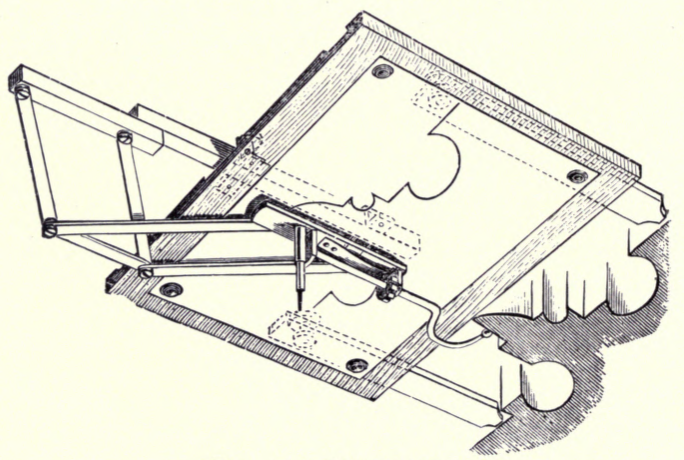

Fig. 43.-CyMOGRAPH. 


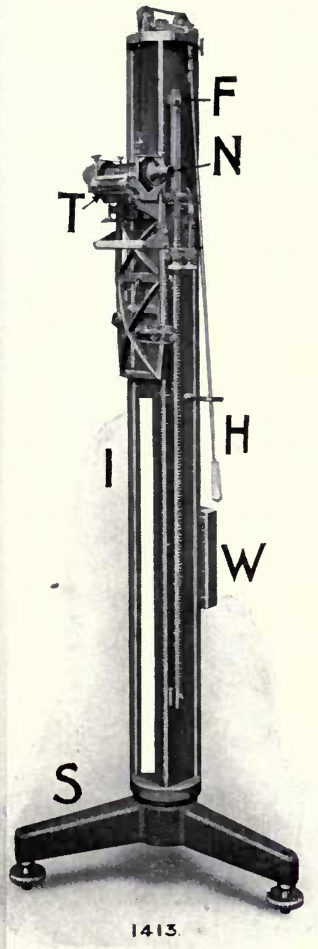

Fig. 44.-CATHetometer.

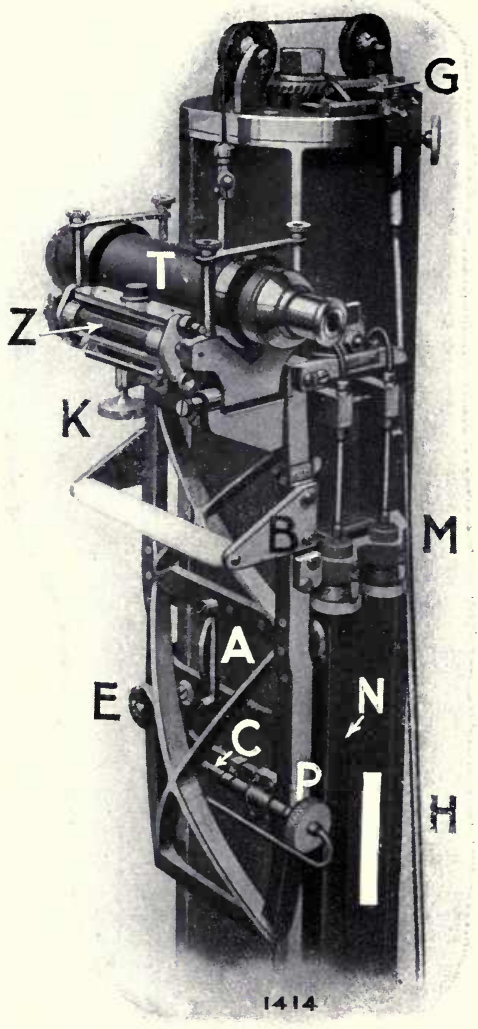

Fig. 45-Cathetometer. 


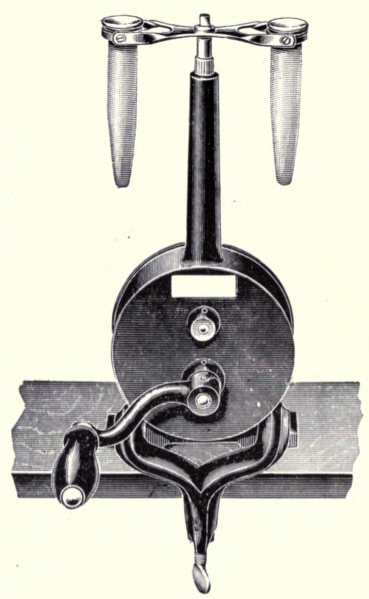

Fig. 46.-Centrifuge.

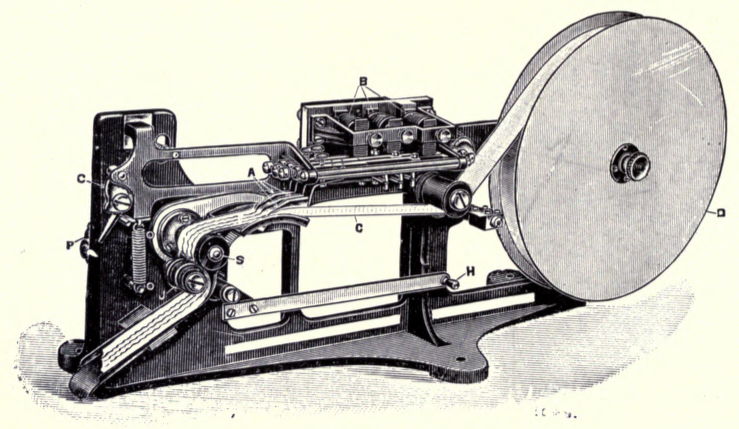

FIG. 47.-ChRONOGRAPH. 


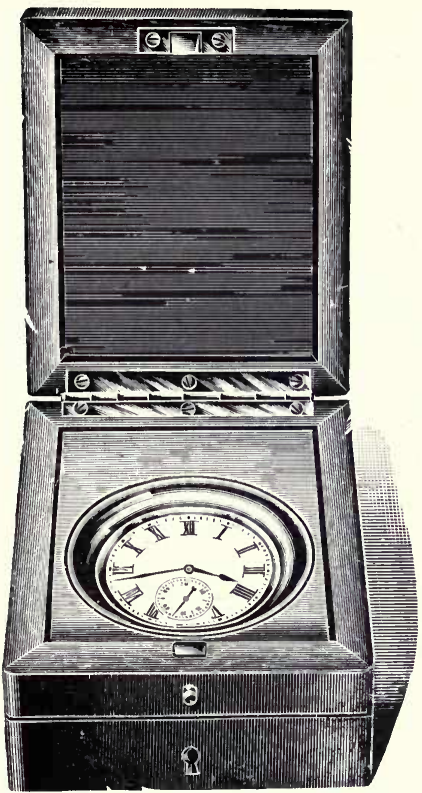

Fig. 48.-Chronometer DeCK WATCH.

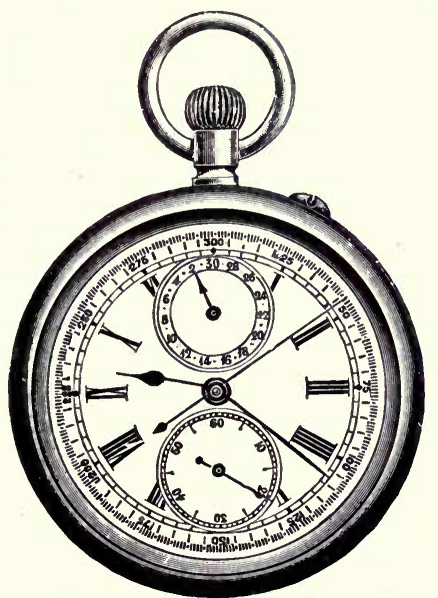

Fig. 49 -Chronograph Watch. 


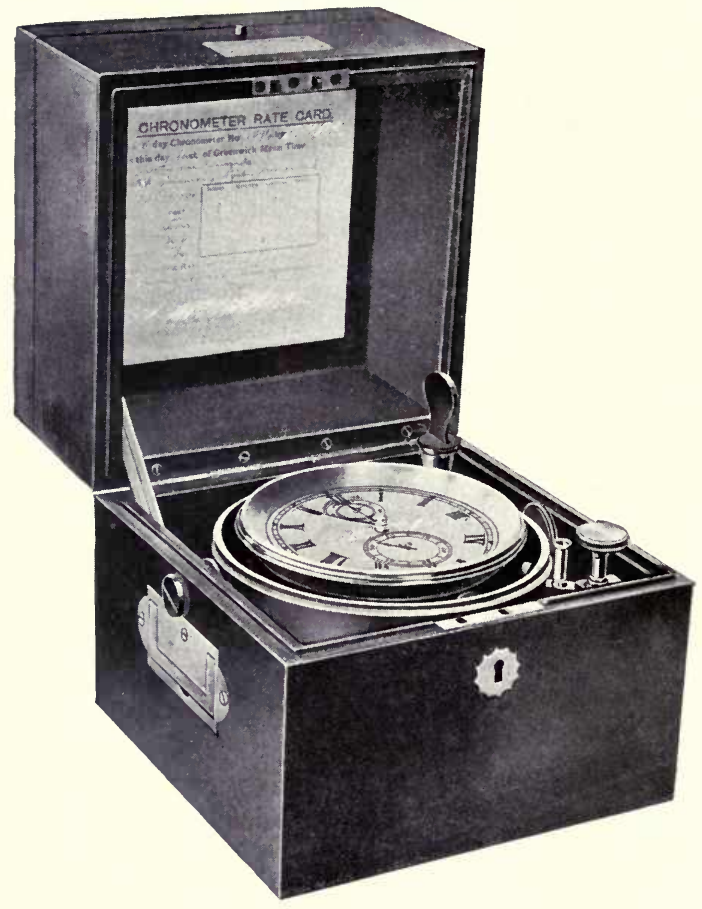

Hig. 50.-Chronometer, Marine. 


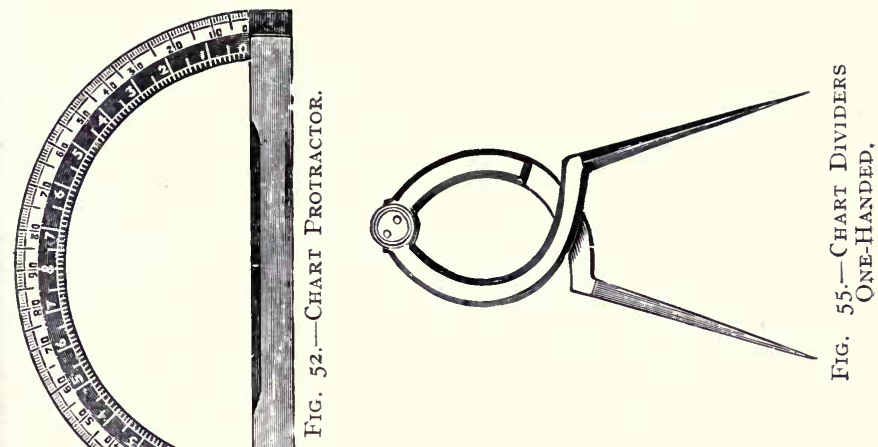




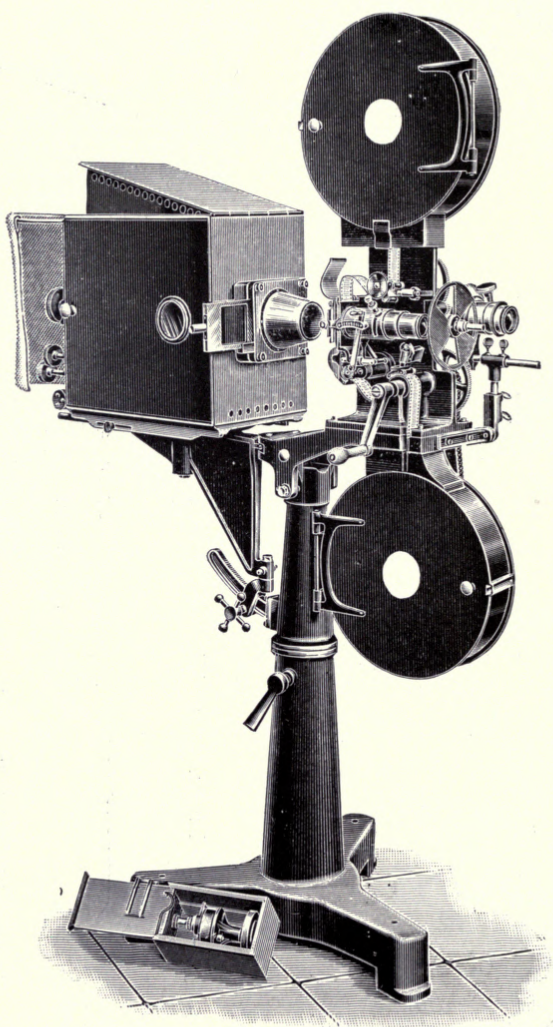

Fig. 56-Cinematograph. 


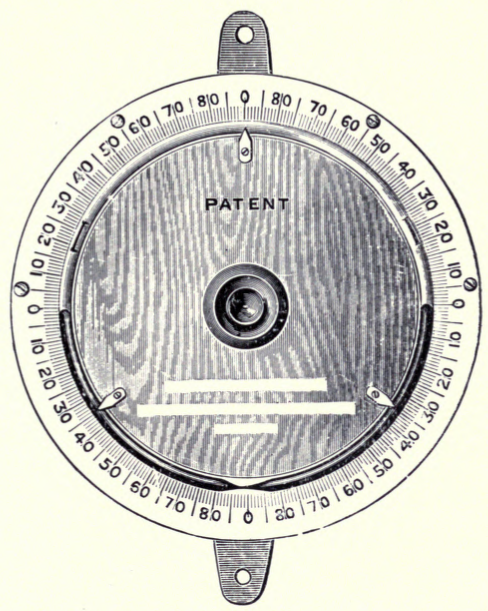

Fig. 57-Clinometer, Marine Mercury.

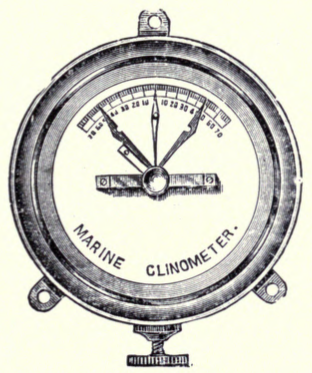

Fig. 58.-Clinometer, Marine Dial. 


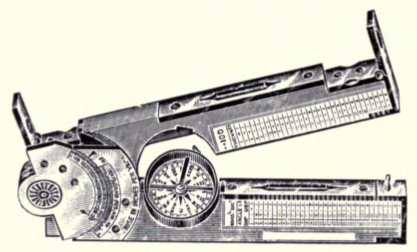

Fig. 59.-Clinometer, Rule and Compass.

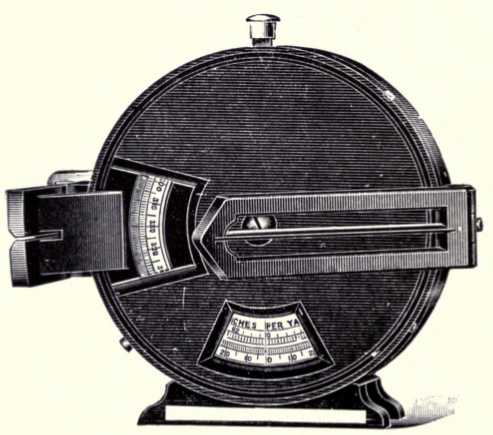

Fig. 6o.-Chinometer and Prismatic Compass, 
2 I 1

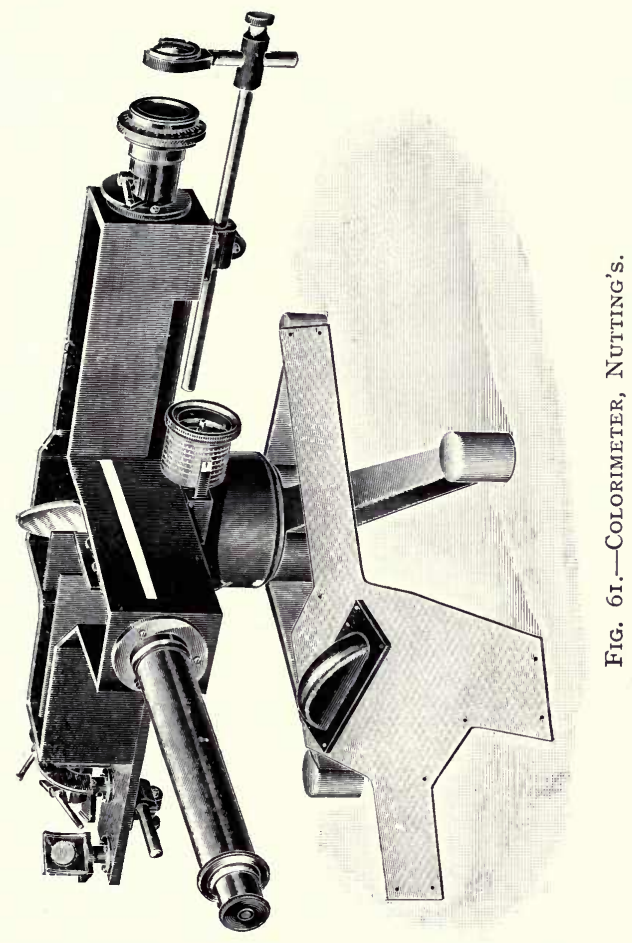


2 I2

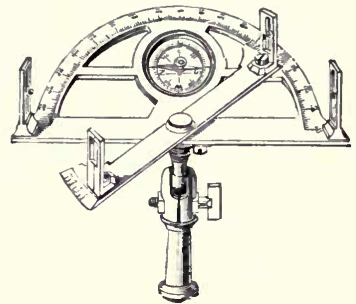

FIG. 62.-CIRCUMFERENIOR.

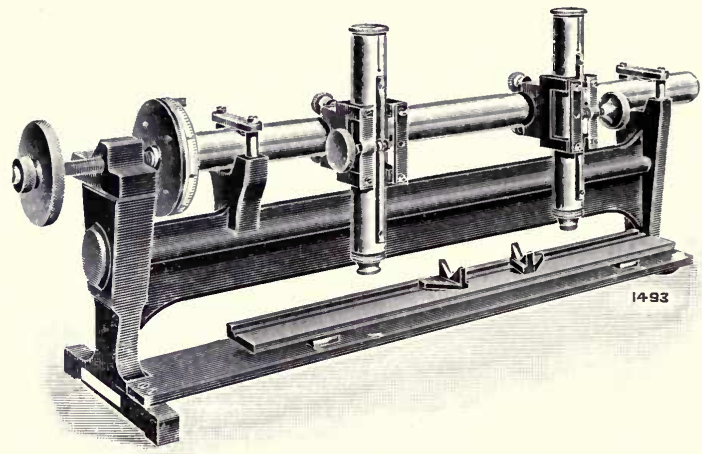

Fig. 63.-Comparator.

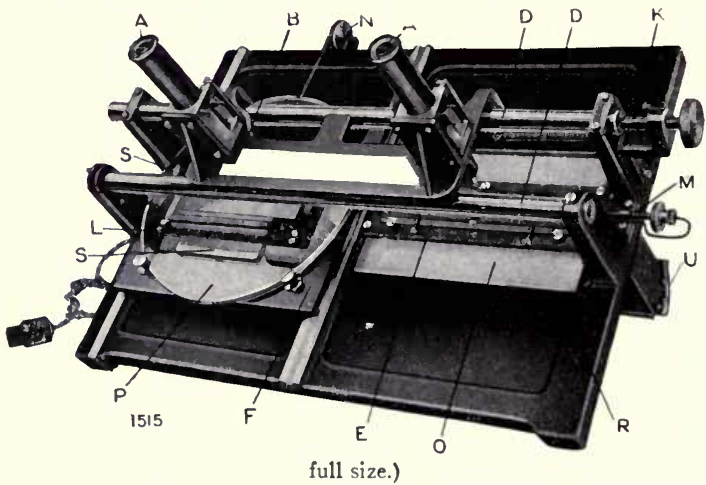

Fig. 64-Comparator, Co-ordinate. 


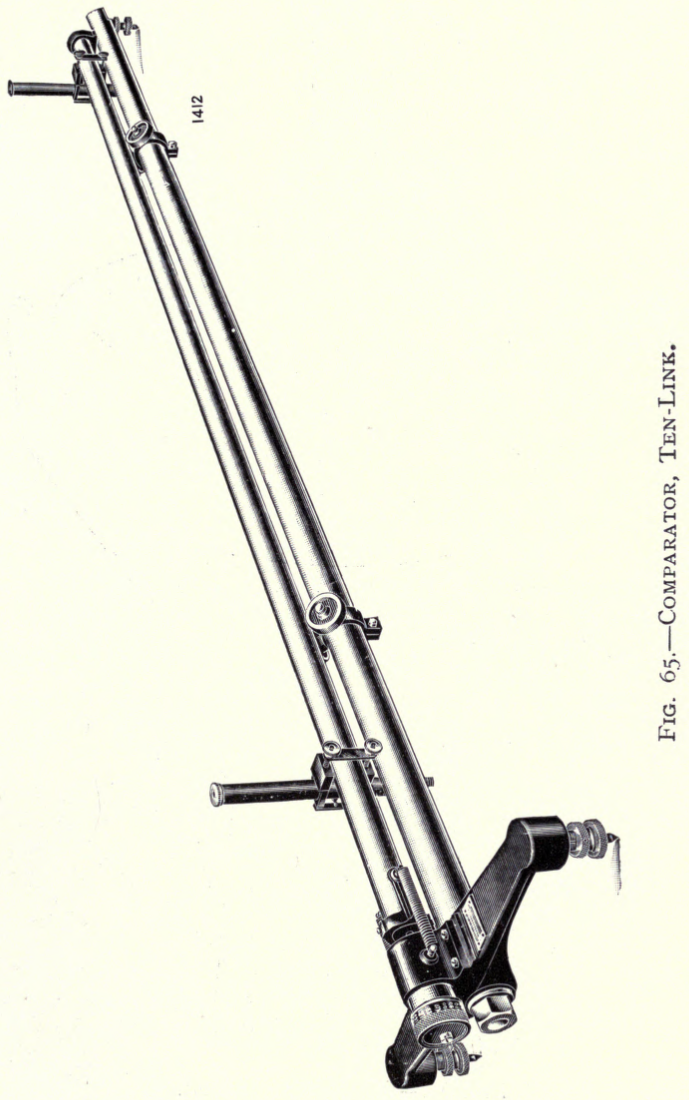




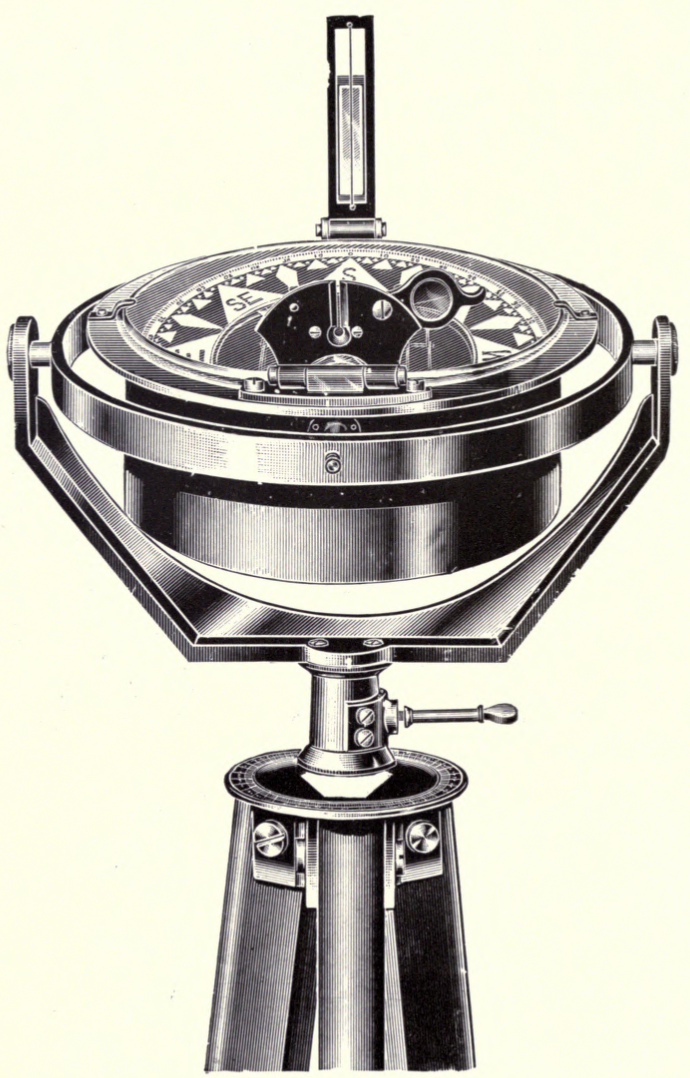

Fig. 66.-Compass, Azimuth. 


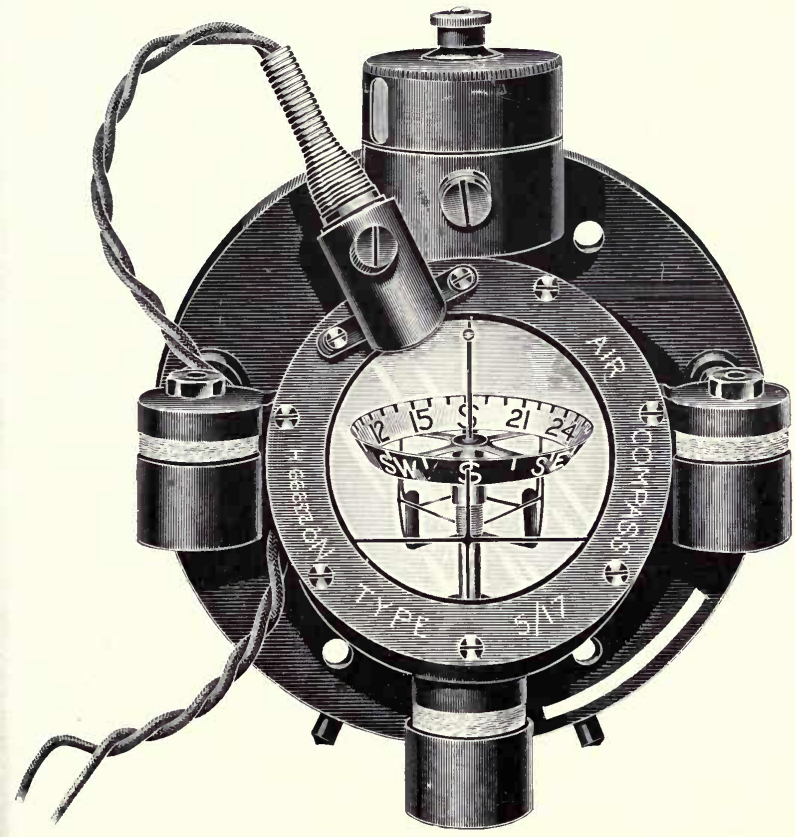

Fig. 67.-Compass, Aeronautical. 


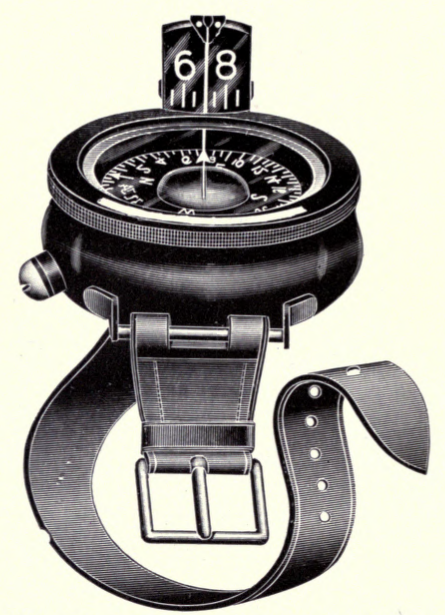

FIG. 68.-Compass, CREAGH-Osborne.

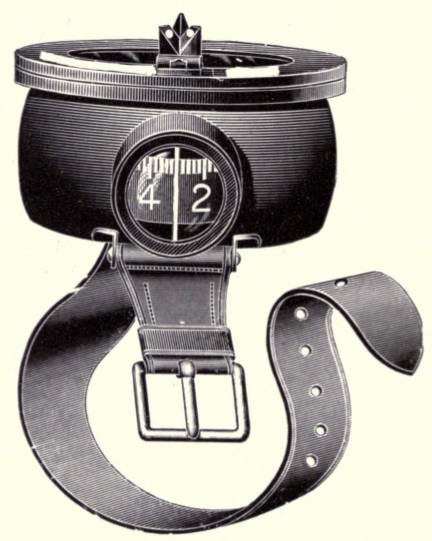

Fig. 69.-Compass, Creagh-Osborne. 


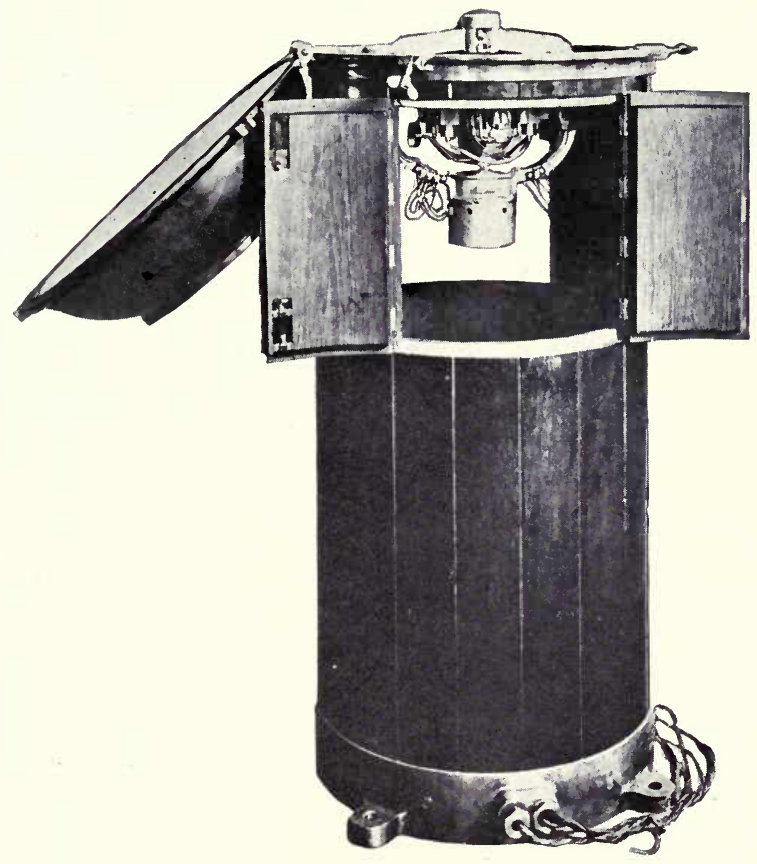

Fig. 70.-Gyroscopic Compass in Binnacie. 

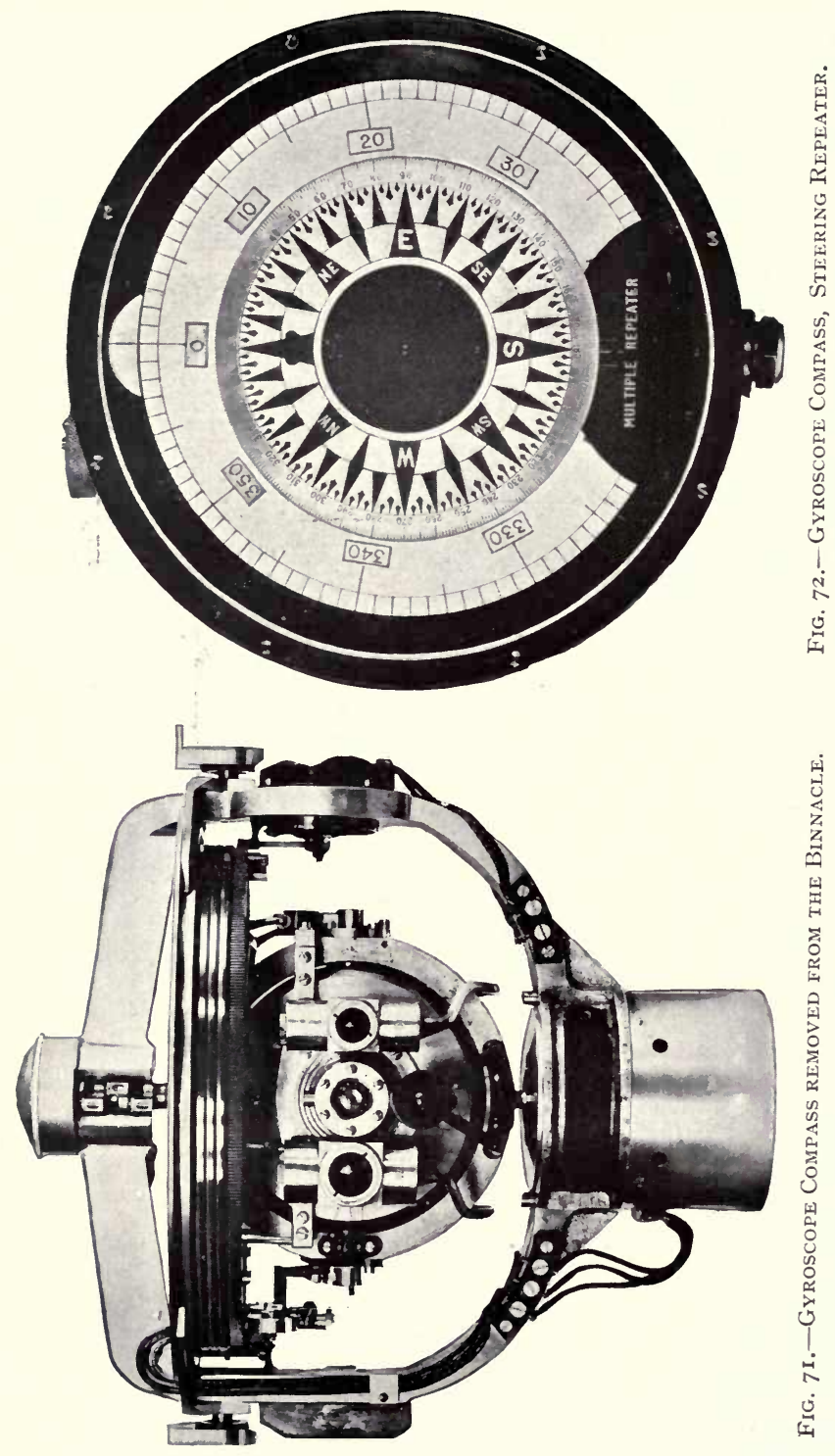

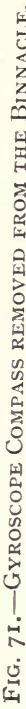




$$
\frac{9}{a}
$$




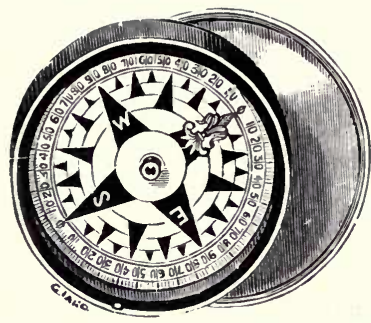

Fig. 75.-Compass, Pocket.

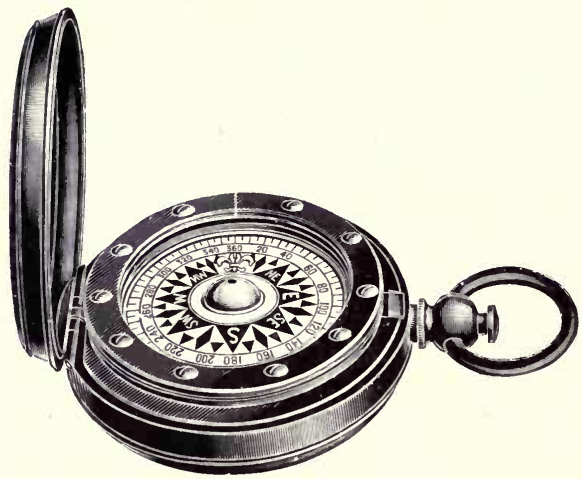

Fig. 77.-Compass, Pocket, Liquid.

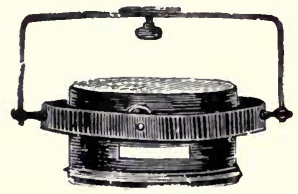

Fig 78.-Compass, Tell Tale.

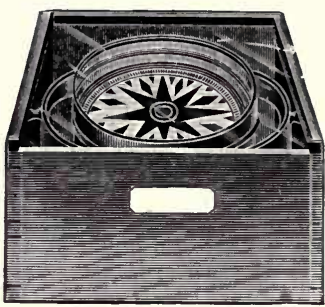

Fig. 76.-Compass, Box. 



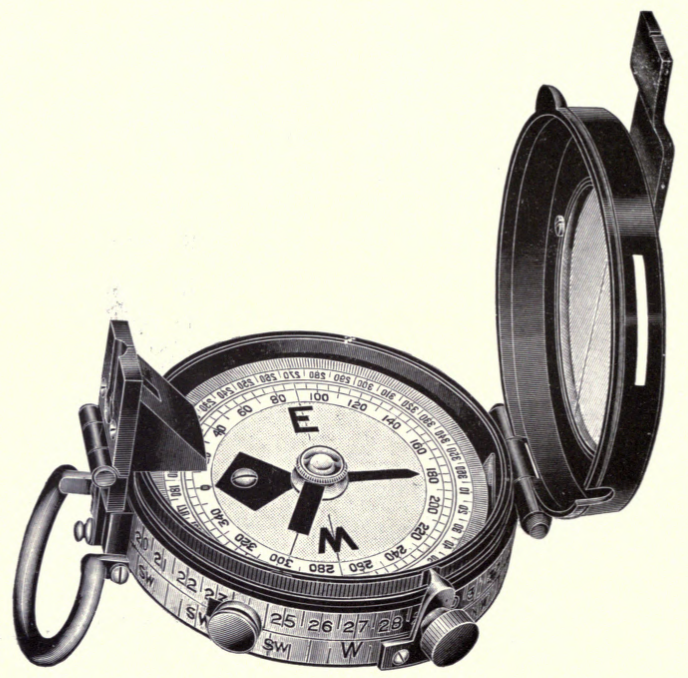

Fig. 8I.-Compass, Prismatic.

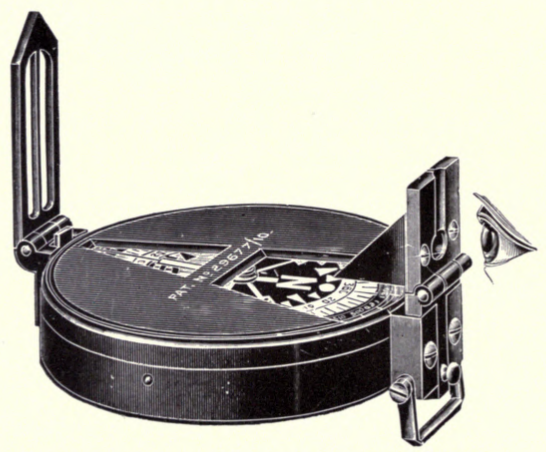

Fig. 82.-Compass, Prismatic. 


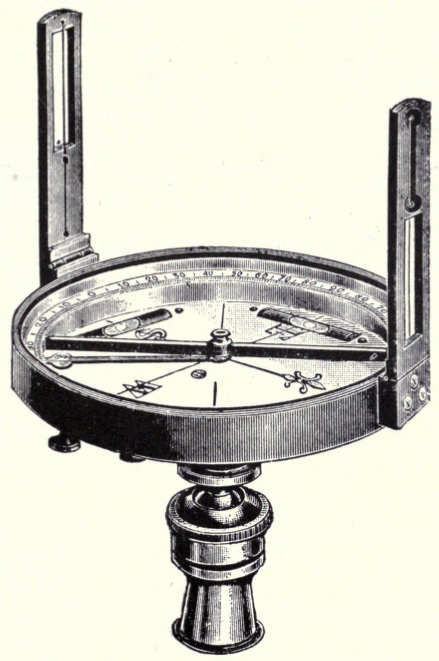

Fig. 83.-Compass, Surveying.

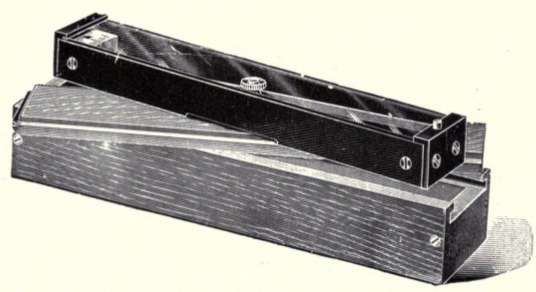

Fig. 84.-Compass, Needle. 


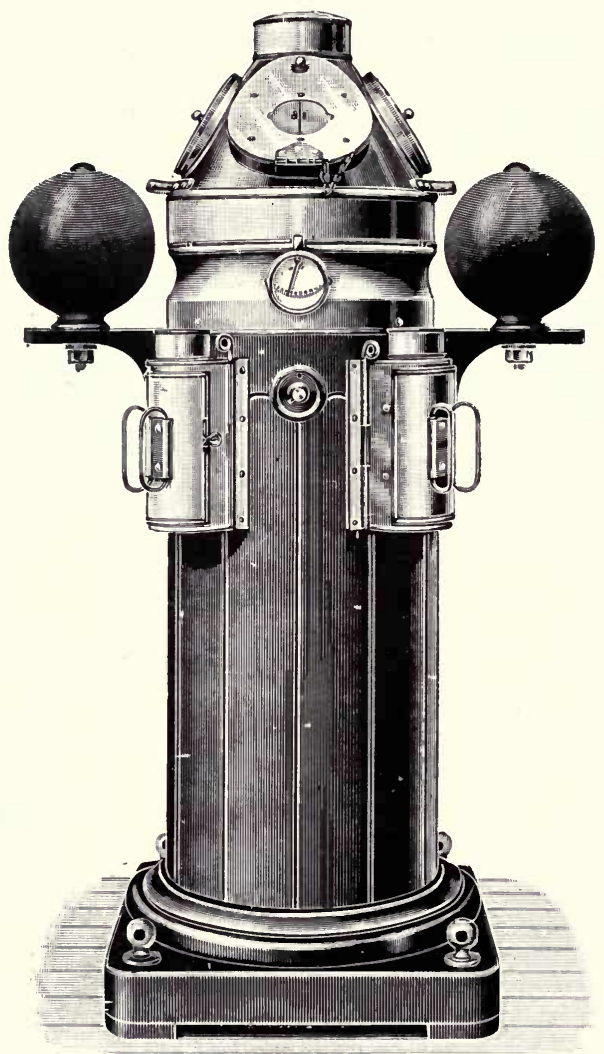

Fig. 85.-Compass, Standard. 


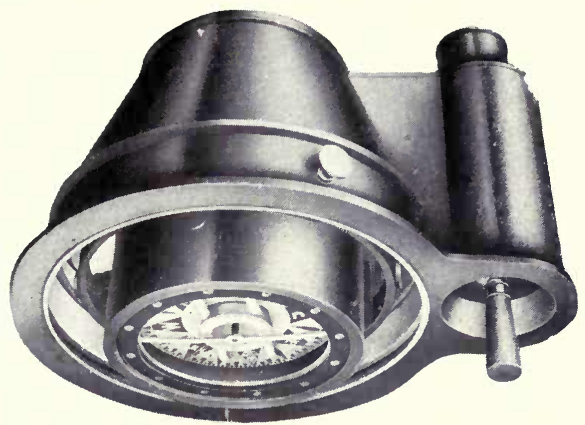

Fig. 86.-Compass, Overhead.

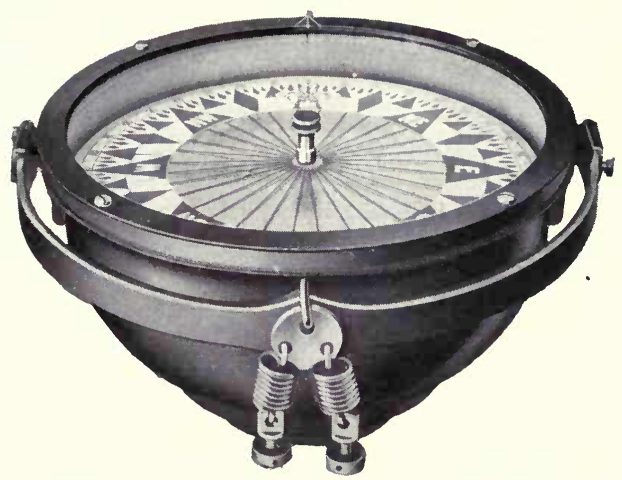

Fig. 87.-Compass, Standard, Light Card.

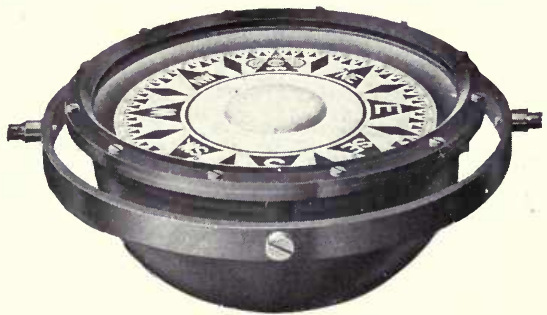

Fig. 88. - Compass, Liguid Form. 


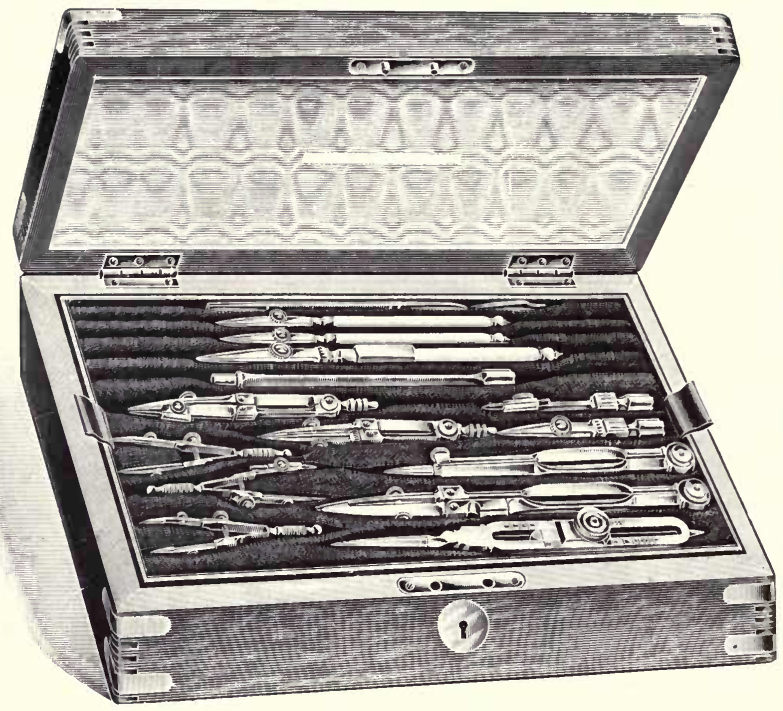

Fig. 89.-Compasses, Drawing.
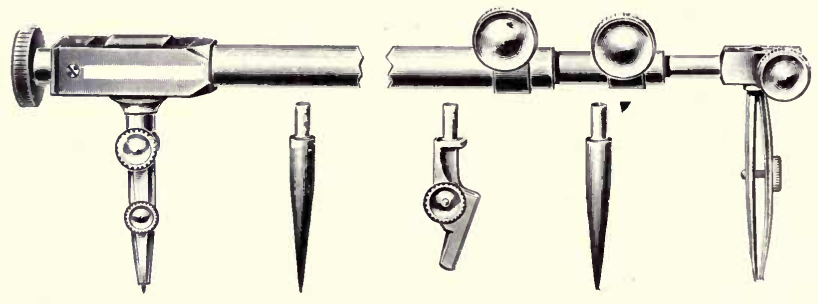

Fig. 90.-Compass, Beam. 

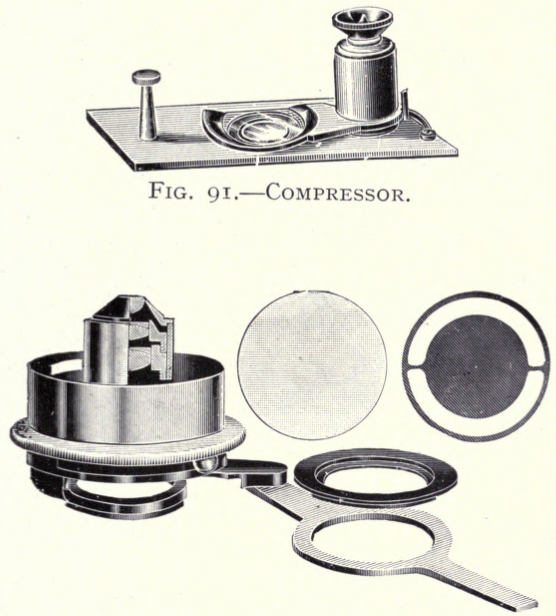

Fig. 92.-Condenser, Achromatic.

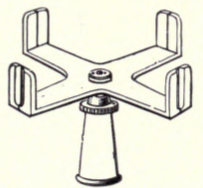

Fig. 93.-Cross Staff.

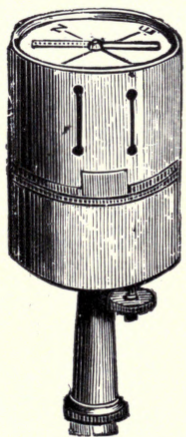

Fig. 94.-Cross StafF. 


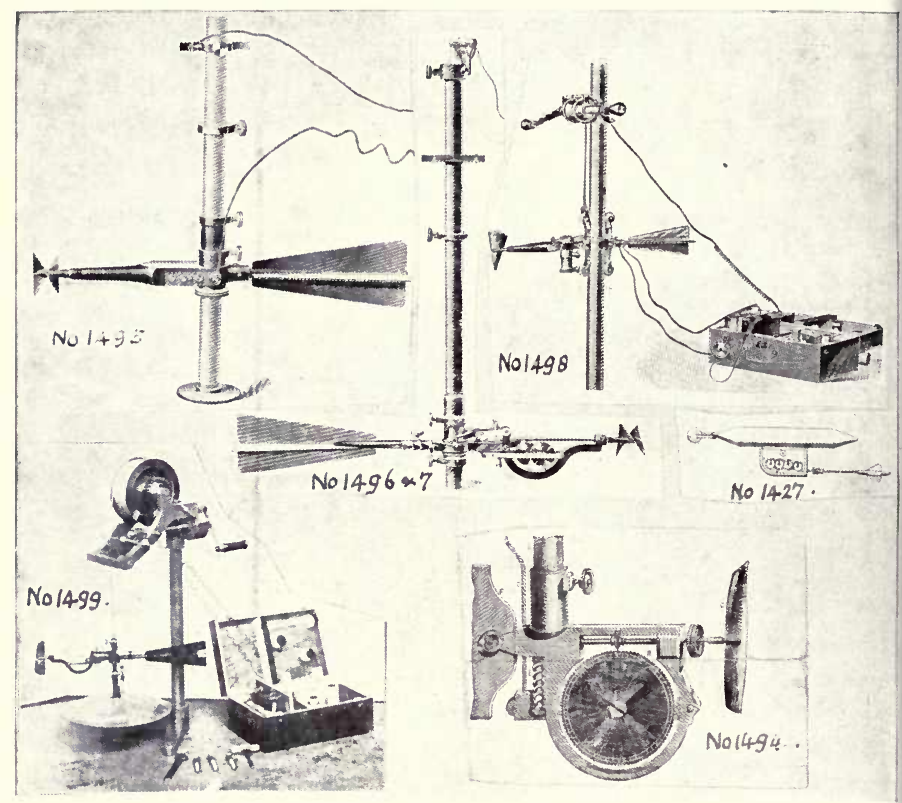

Fig. 95.-CUR RENTMETERS.

I 427. Currentmeter, Tidal Log.

I 494. Currentmeter.

I 495. Amsler Currentmeter, Pattern III.

$\begin{array}{lllll}\text { I } 496 . & \text {, } & \text {, } & \text {, } & \text { I. } \\ \text { I } 498 . & \text { ", } & \text { " } & \text {, } & \text { IV. } \\ \text { I } 499 . & \text {, } & \text {, } & \text {," } & \text { VI. }\end{array}$




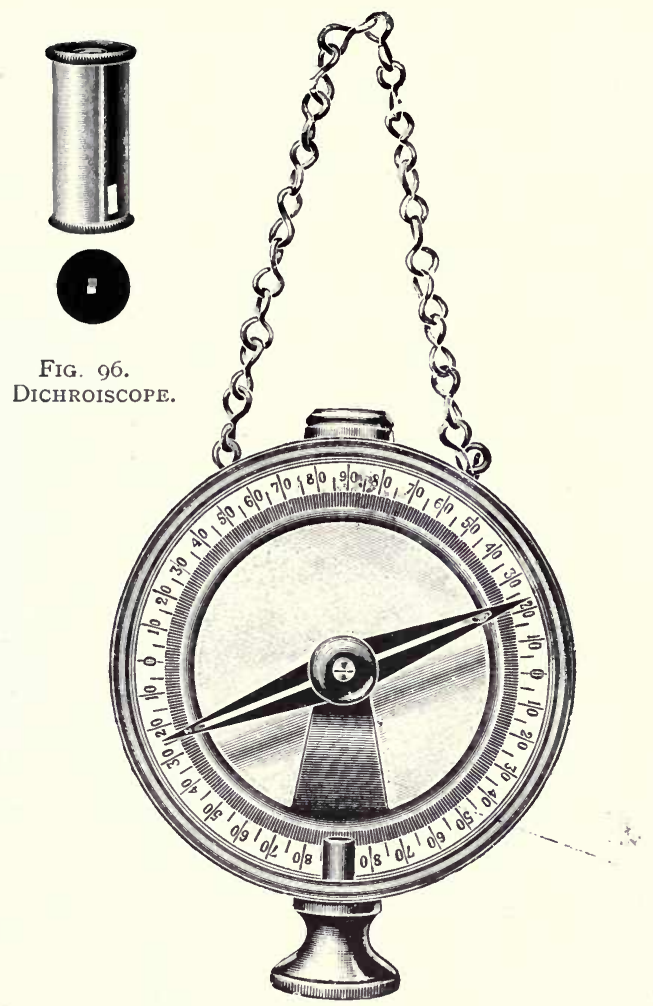

FIG. 97--DiP NEEdLE.

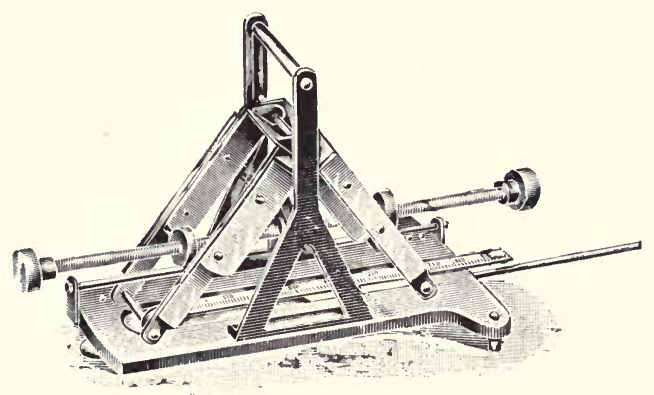

FIG. 98.-DEFLECTOR. 


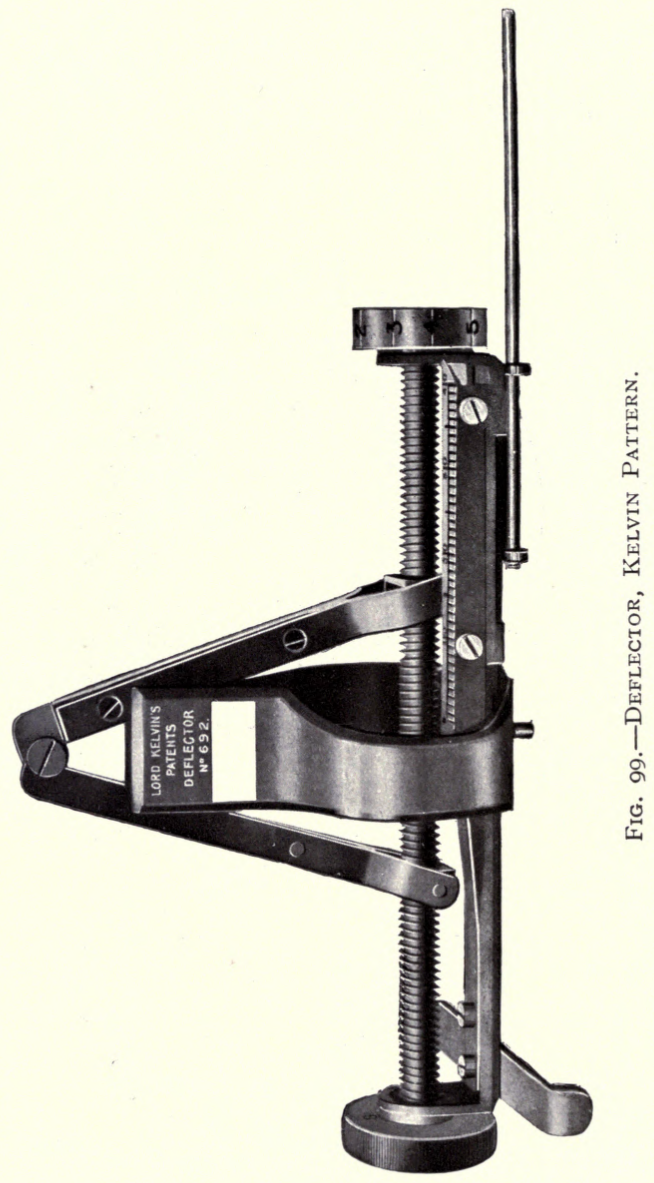


23I

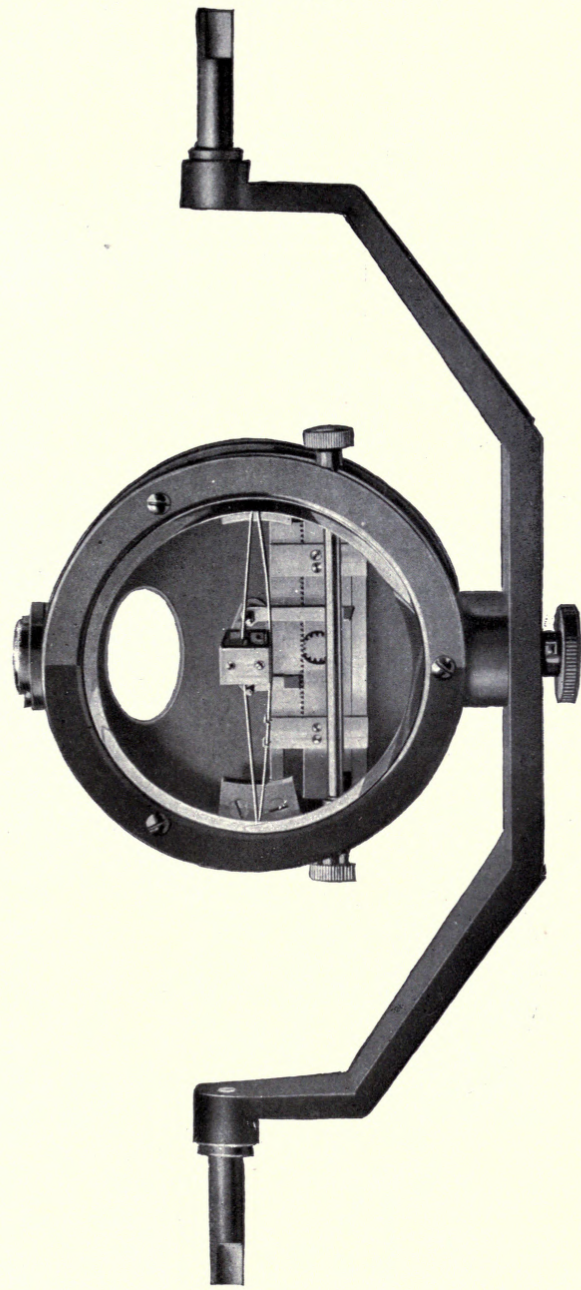

宽

됭

논

'

됩

空

A

금

氠

됙

定

Q 2 


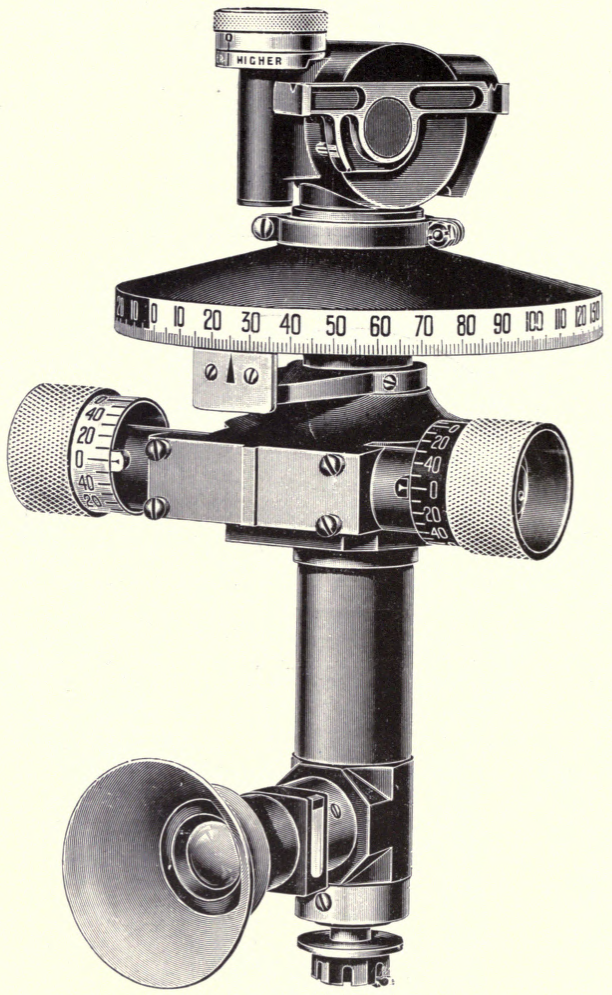

Fig, IOI.-Dial Sight. 


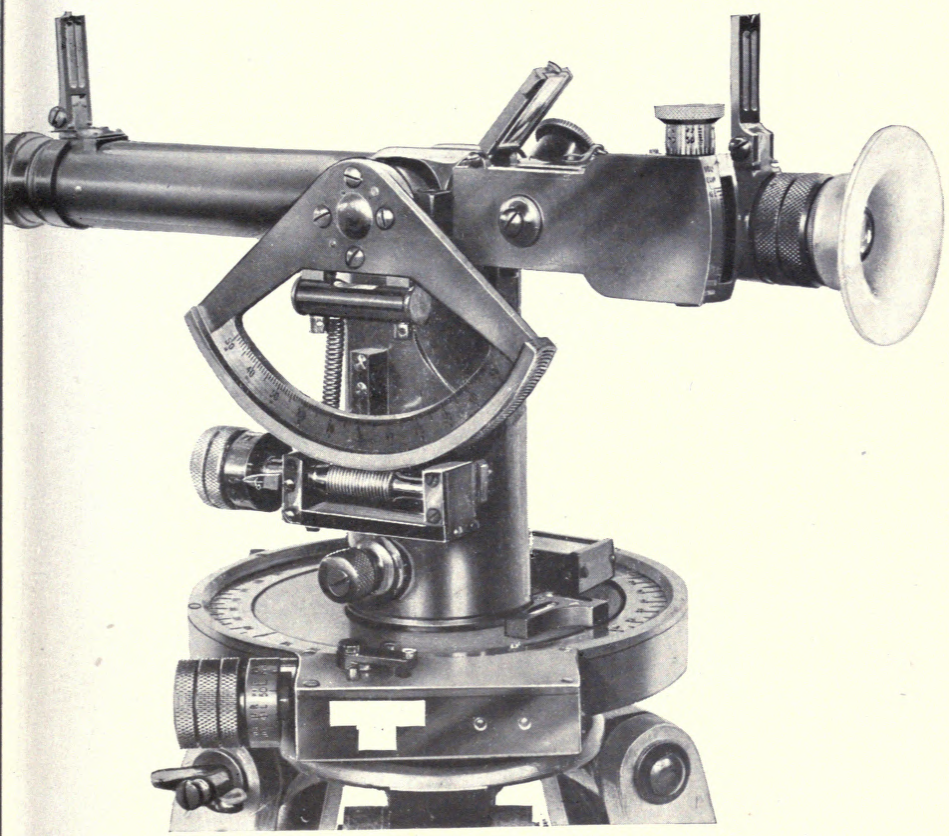

Fig. IO2.-DIRECTOR.

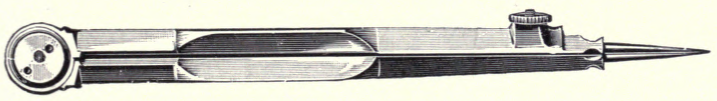

Fig. IO3-Divider, Hair. 


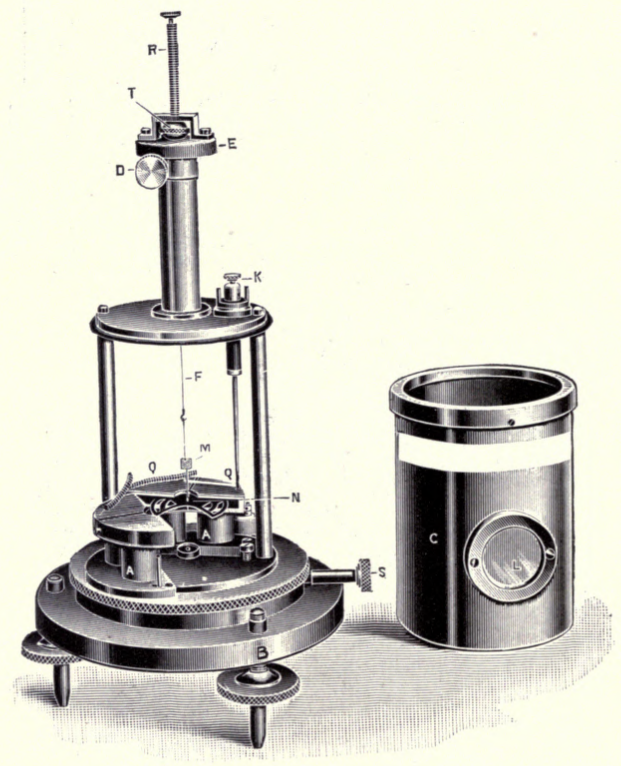

Fig. io4.-Electrometer, Dolezalek.

Fig. I05.-Dotting Pen. 


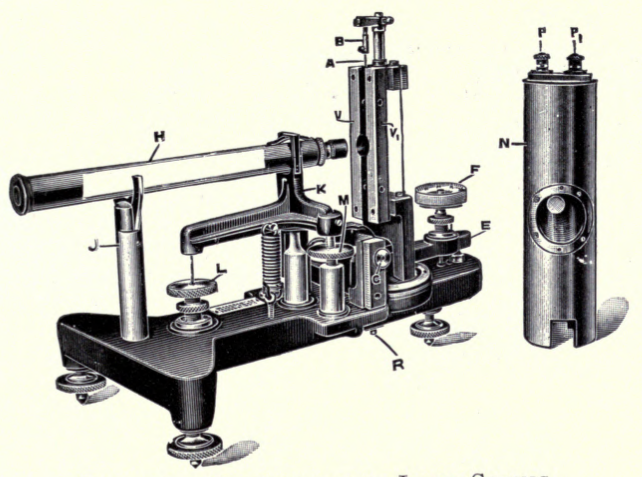

Fig, io6.-Electrometer, Laby String.

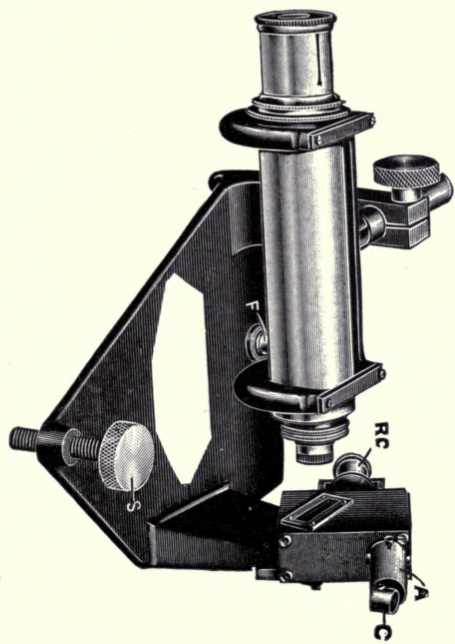

Fig. io7.-Electrometer, Wilson Kaye's Tilted GOLD LEAF. 

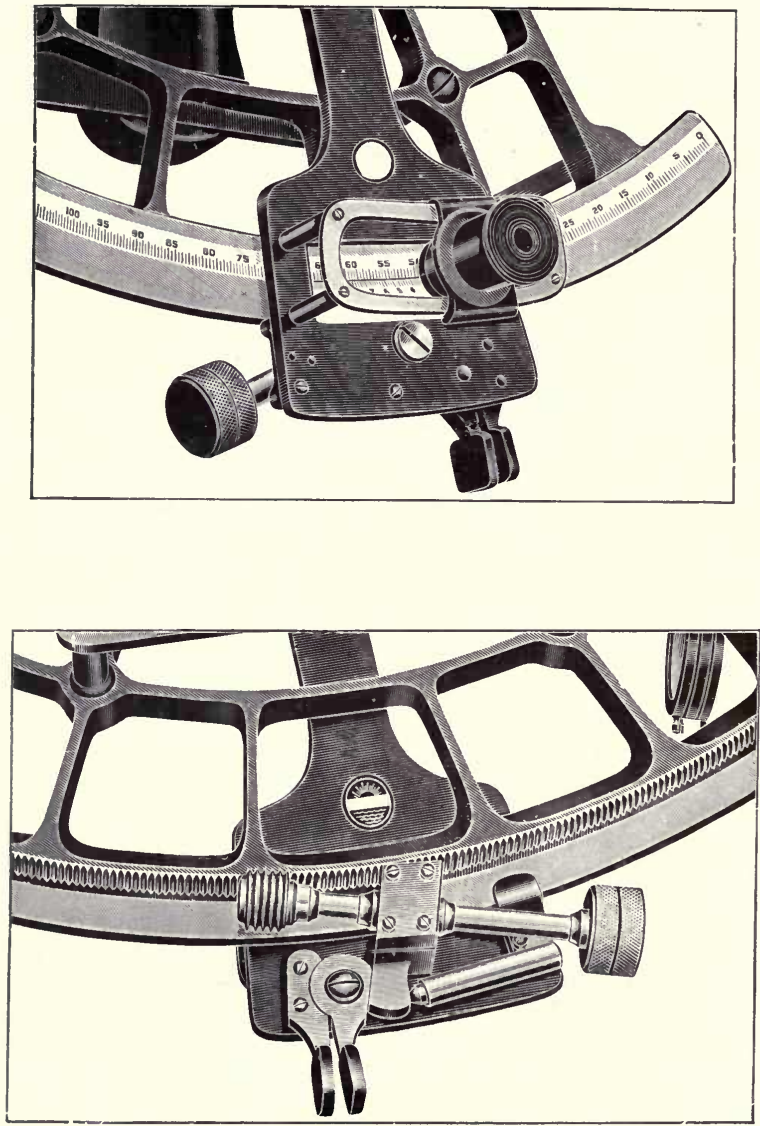

Fig. I08.-Endless Tangent Screw on Sextant. 


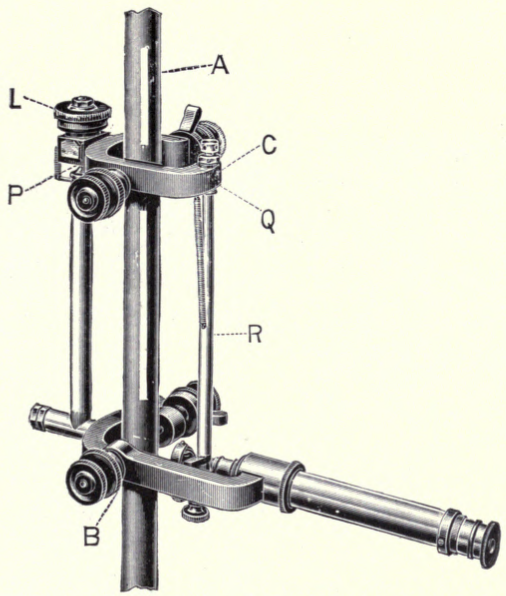

Fig. I09.-EXtensometer.

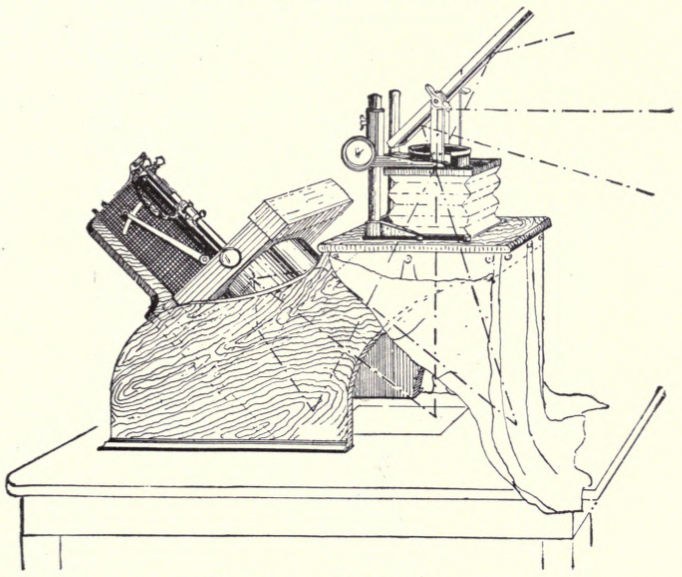

Fig. IIO.-EPIScope. 


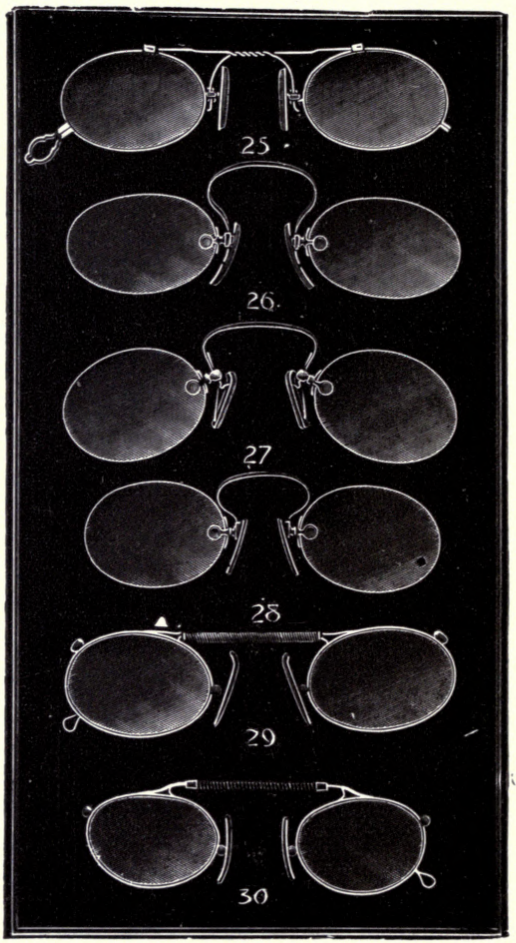

Fig. ili,-Eyeglasses, Folding Pattern. 


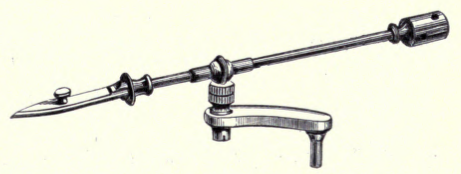

Fig. II2.-Forceps for Microscope.

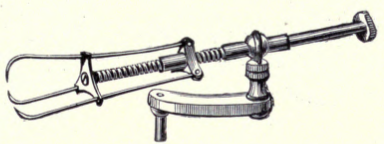

Fig. II3.-FoRCEPS, 3-PRONG.

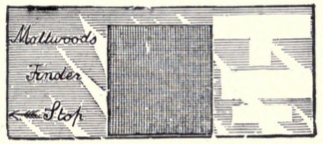

Fig. II4.-Finder, Maltwood's.

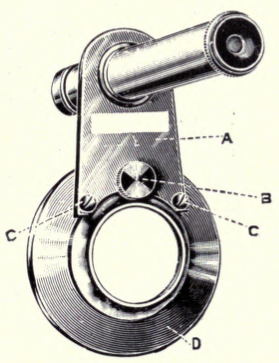

Fig. II 5.-Finder, Telescope. 


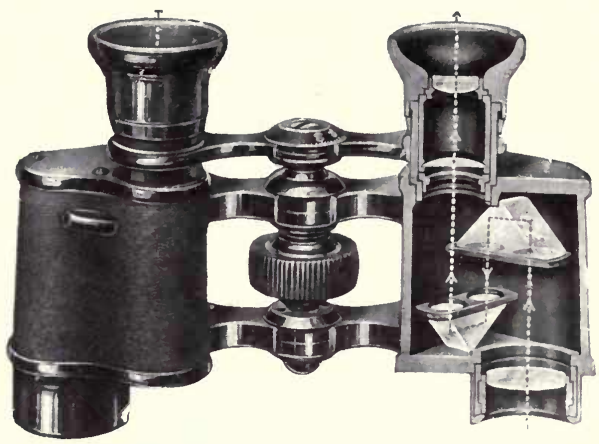

Fig. Ii6.-Field Glass, Prism.

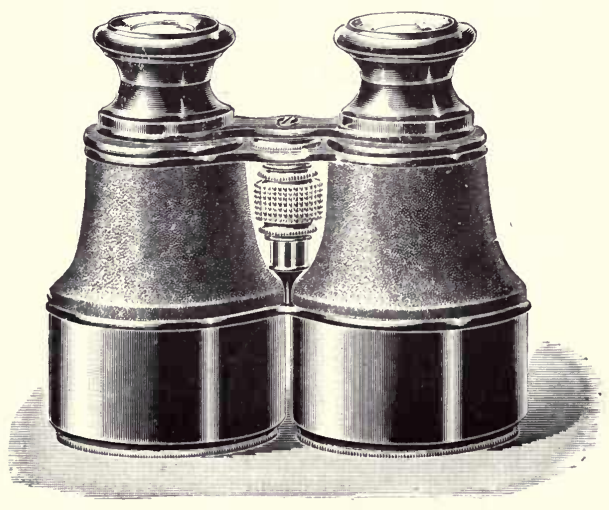

Fig. Ii 7.-Field Glass, Galilean. 
241

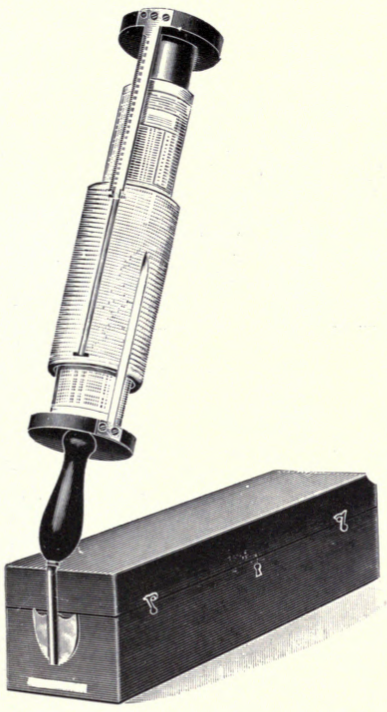

Fig, ir8.-Fuller Calculating Slide-Rule.

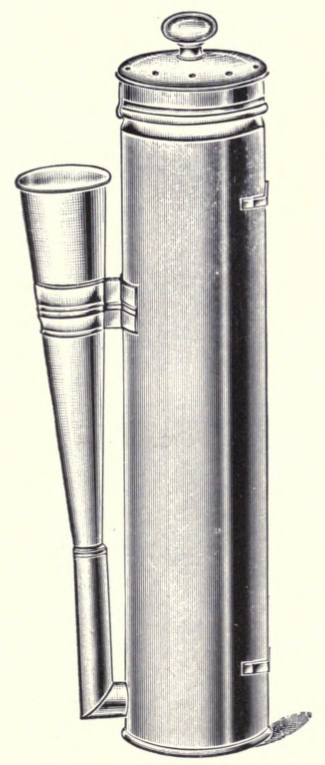

FIG. II9.-FOG HORN. 


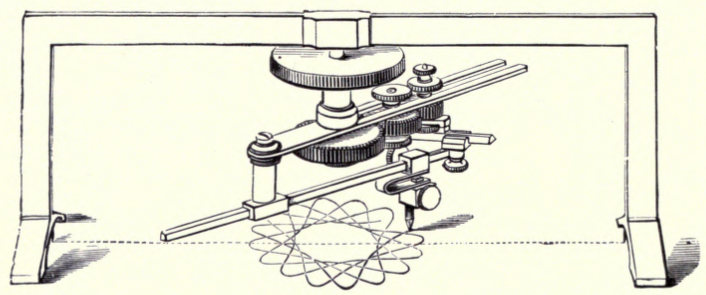

Fig. I20.-Geometric Pen.

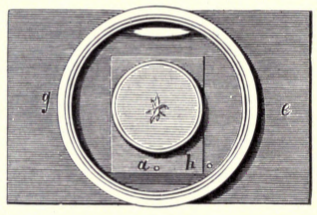

Fig. I2I.-Growing Cell for Microscopes.

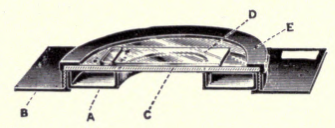

Fig. 122.-Growing Cell for Microscopes. 


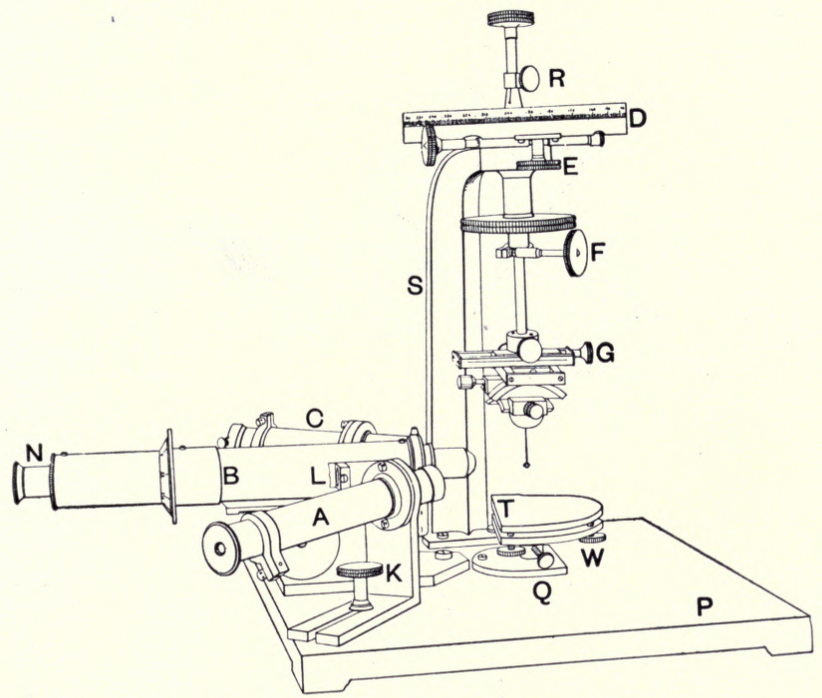

Fig. I23.-Goniometer, Dr. Hutchinson's.

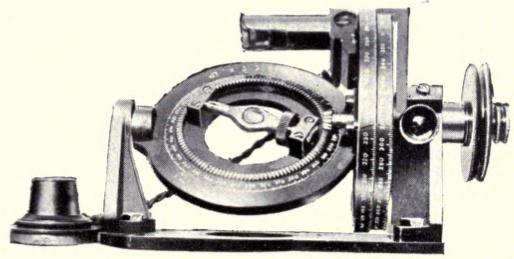

Fig. I24.-Goniometer For Microscope. 


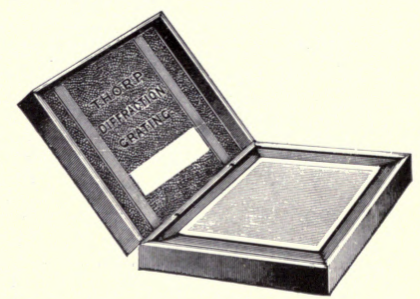

Fig. I25-Grating, Diffraction.

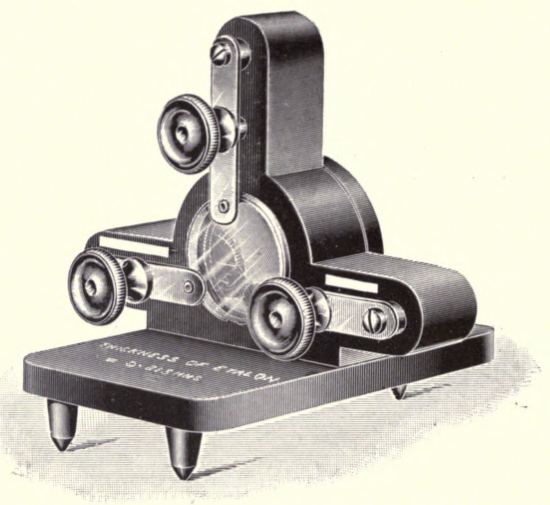

Fig. I26.-Grating, Étalon. 


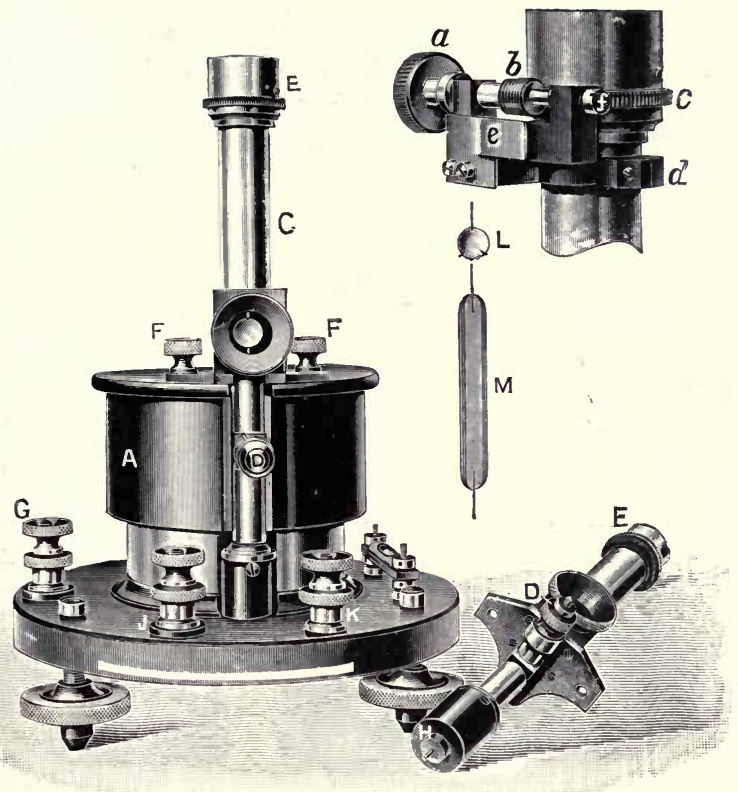

Fig. 127.-Galvanometer, Ayrton-Mather. 

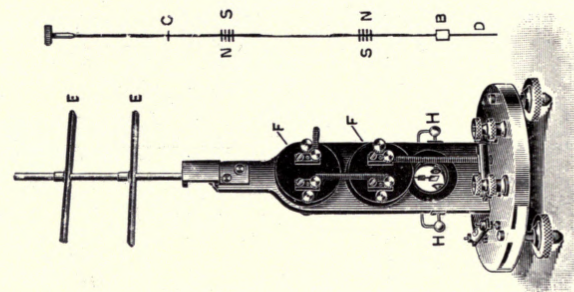

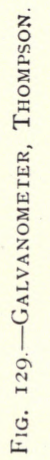

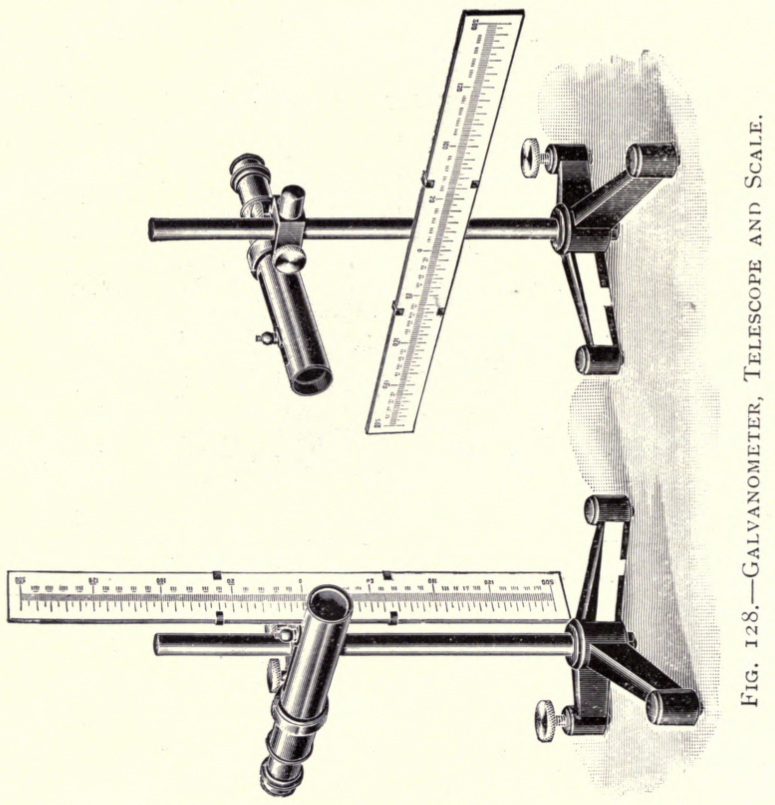




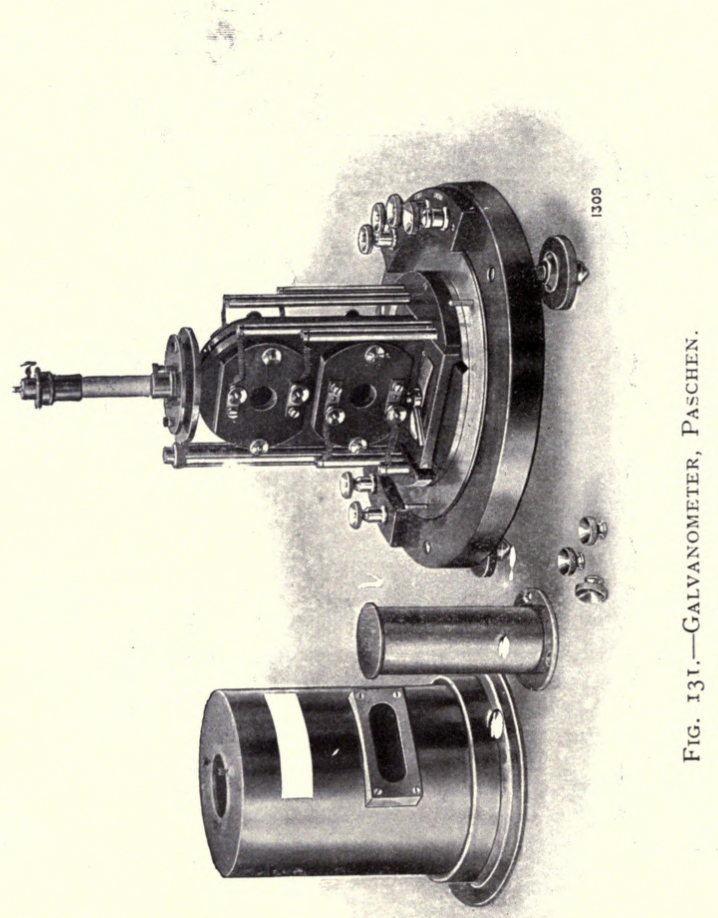




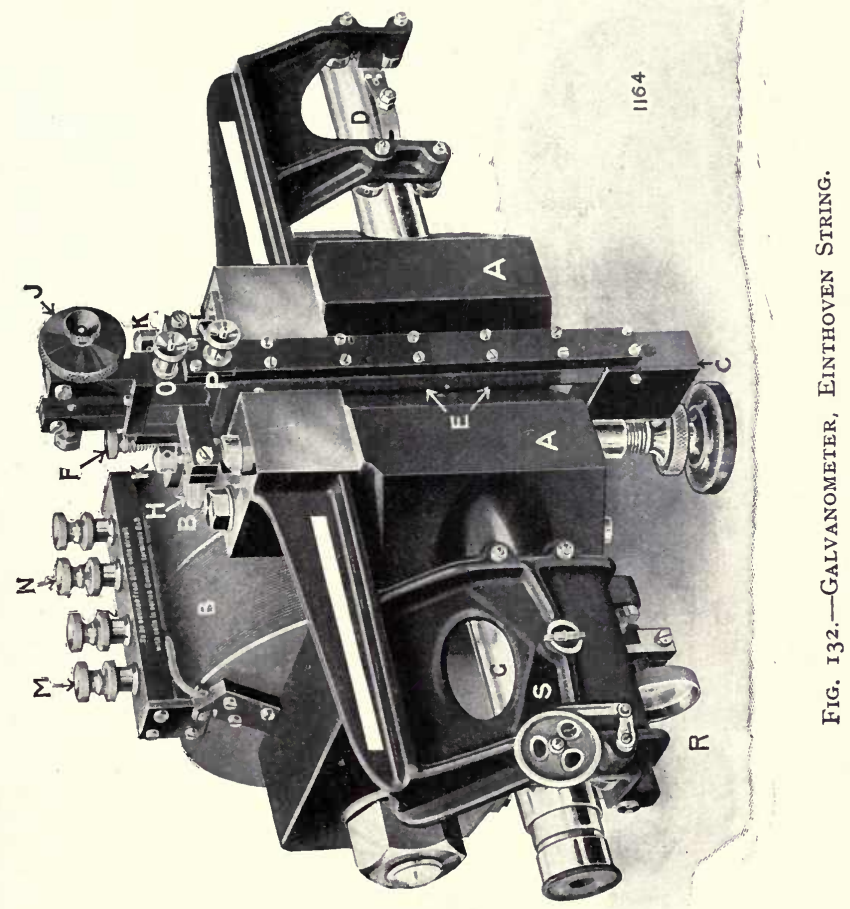


250

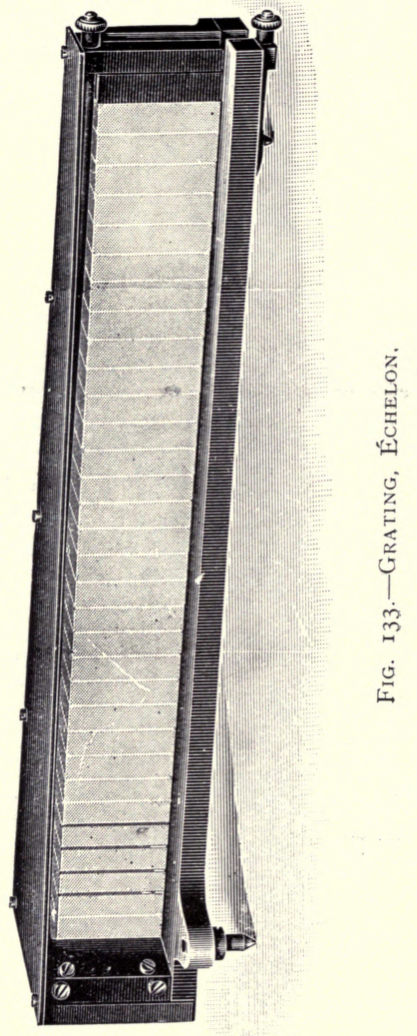



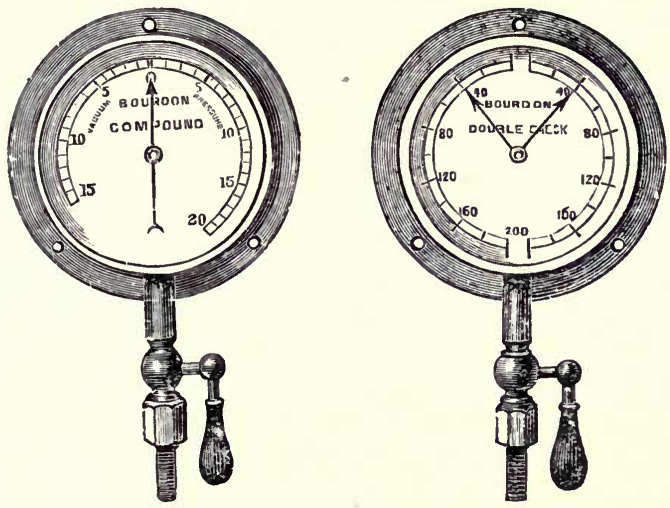

Figs. $134 a$ and $b$.-Gauges, Vacuum and Pressure.

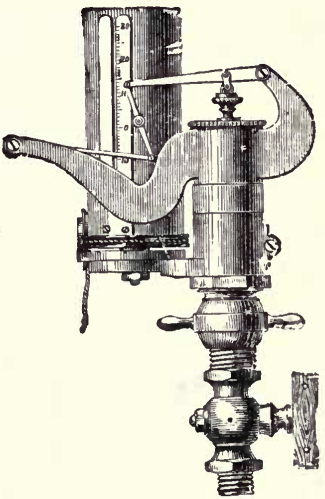

Fig. 135.-INDICATOR: RICHARDS'S

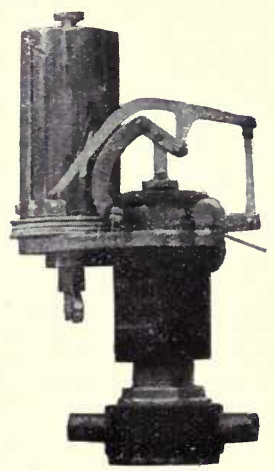

Fig. 136.-INDicator. High Speed. 
252

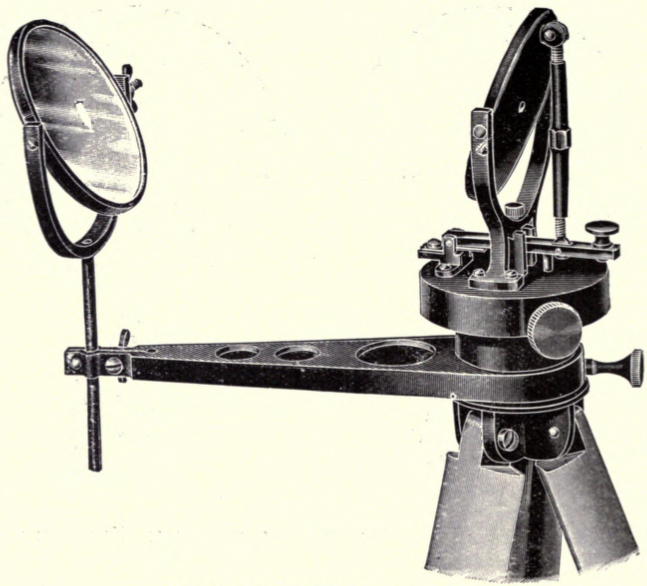

Fig. I37.-Heliograph.

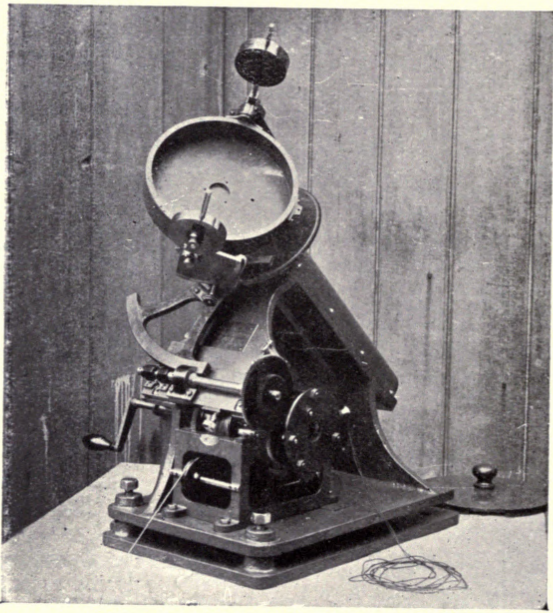

Fig. 138.-Heliostat. 


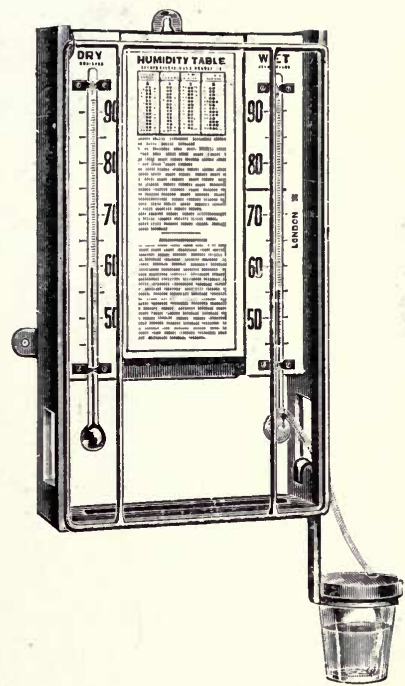

Fig. I39.-Hygrometer, With Humidity Tables.

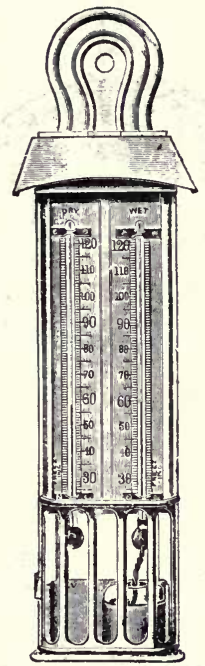

FIG. I 40.-HYGROMETER, AdmRalty Pattern. 


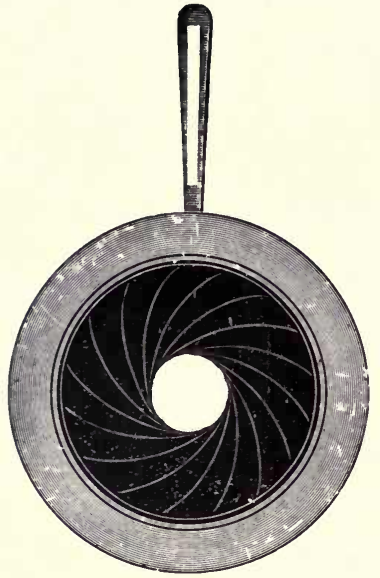

Fig. I4I.-IRIS Diaphragm.

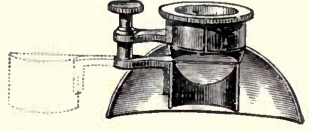

FIG. I42.-SORBY'S PARABOLIC ILLUMINATOR.

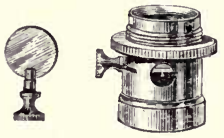

Fig. 143.-Illuminator, VERTICAL.

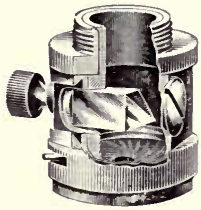

Fig. I44-Illleminator PRISM.

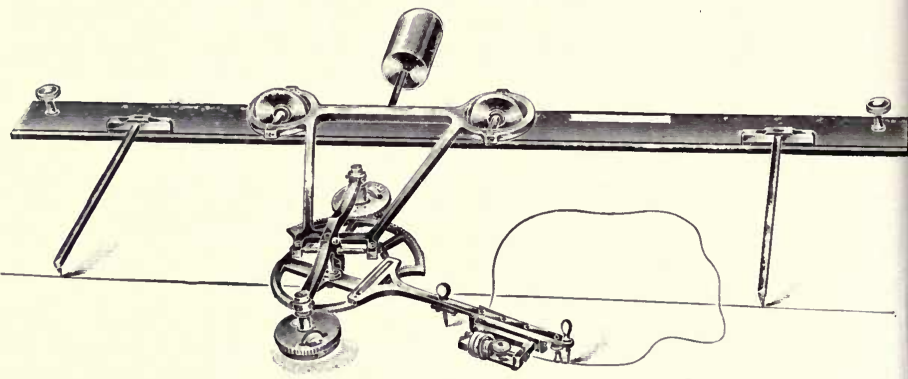

Fig. 145.-Integrator. 


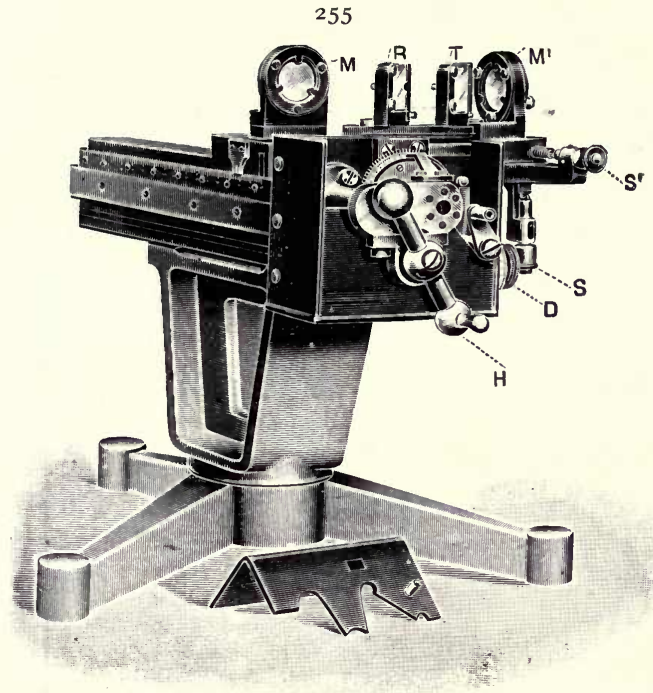

Fig. I46.-Michelson's Interferometer.

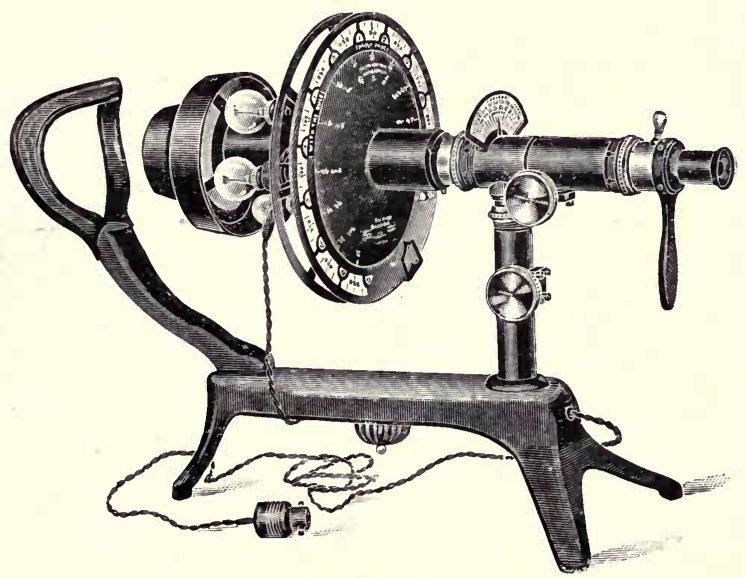

Fig. 147.-KERATOMFTER. 


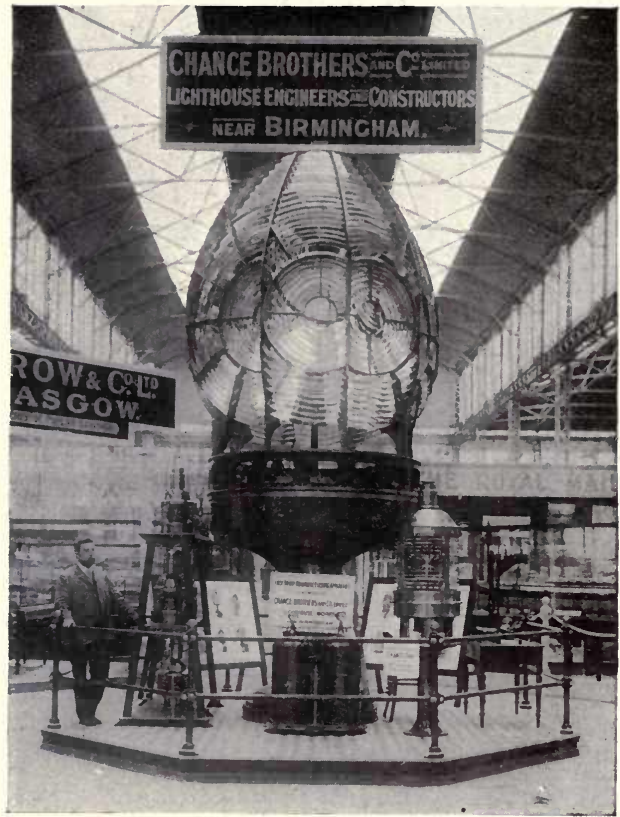

Fig. I4 8.-Lamp, Lighthouse.

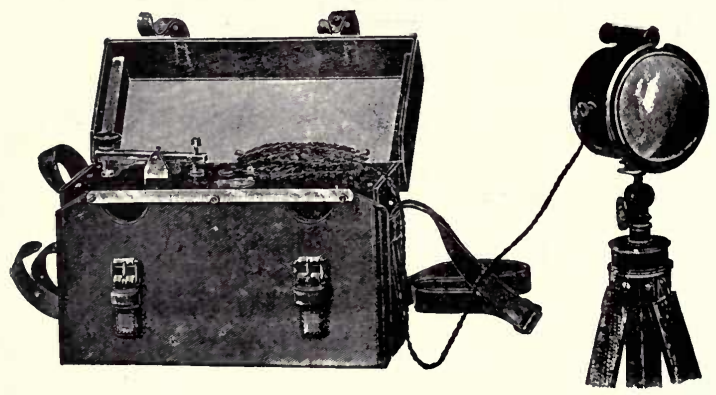

Fig. I49.-IAmp, Signalling. 


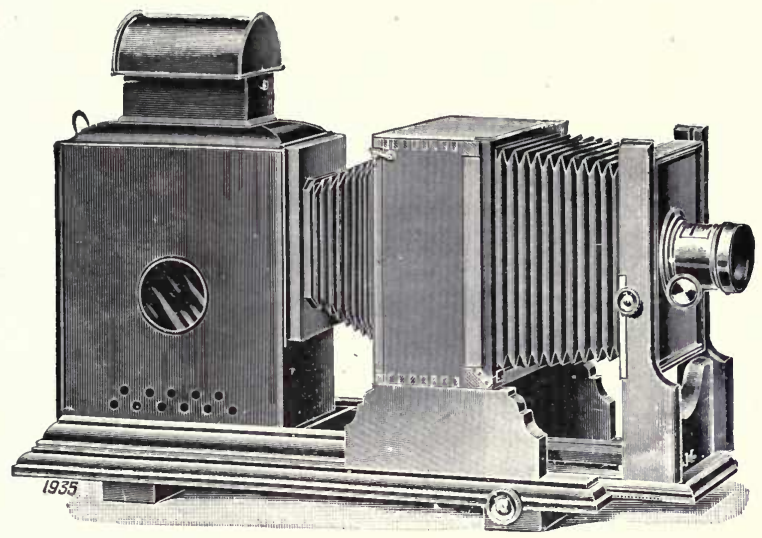

Fig. I50.-LANTERN, ENLARging.

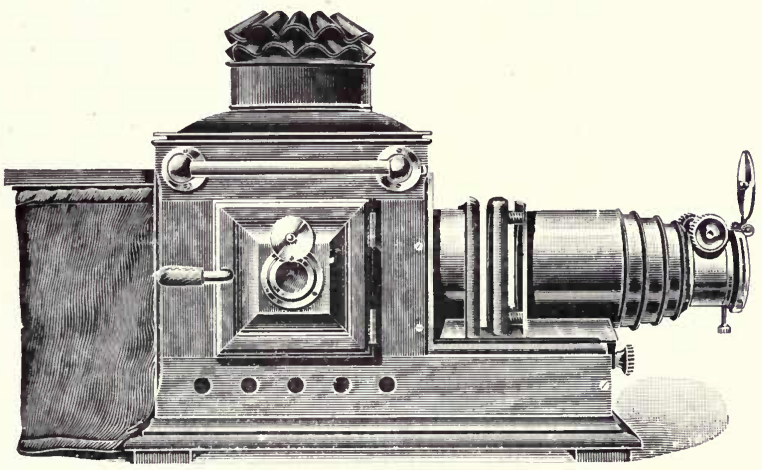

Fig. I5I.-I,ANTERN, Optical. 


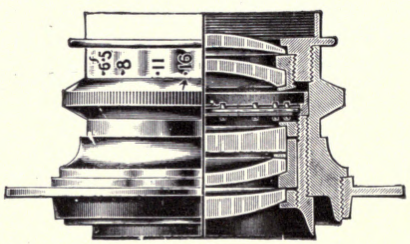

Fig. I 52.-Lens, Photographic.

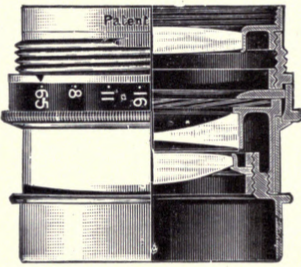

Fig. I53.-Lens, РнотoGRAPHIC.

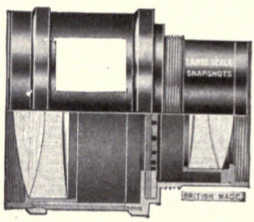

Fig. I54.-Lens, Telephoto.

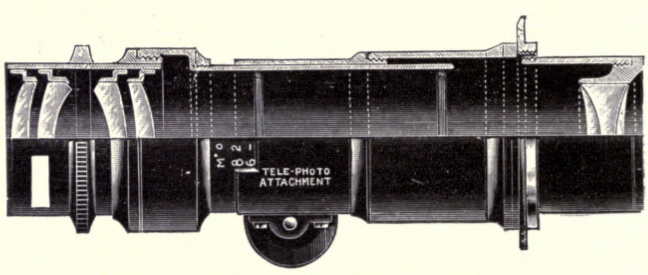

Fig. i55-Lens, Telephoto. 


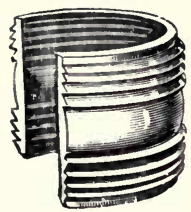

FIG. 156.-LAMP I.eNS.

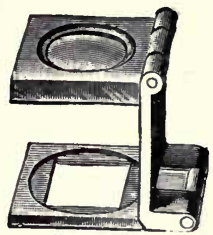

Fig. I57.-Linen Prover
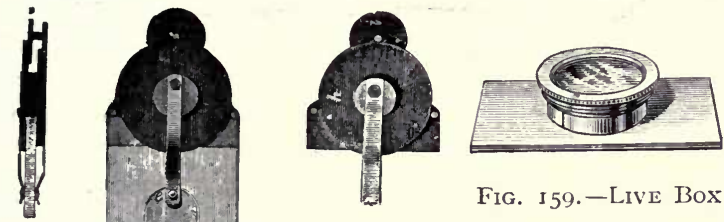

Fig. I59.-Live Box.
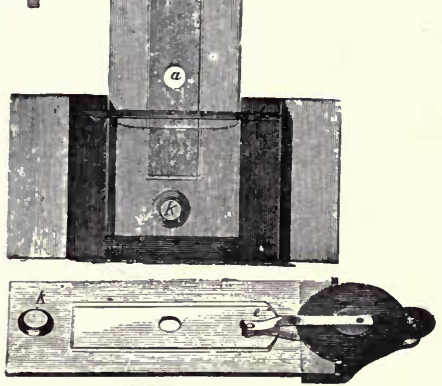

Fig. "I6o.-LiEBERKUHN

FIG. I58.-LIVE TRAP.
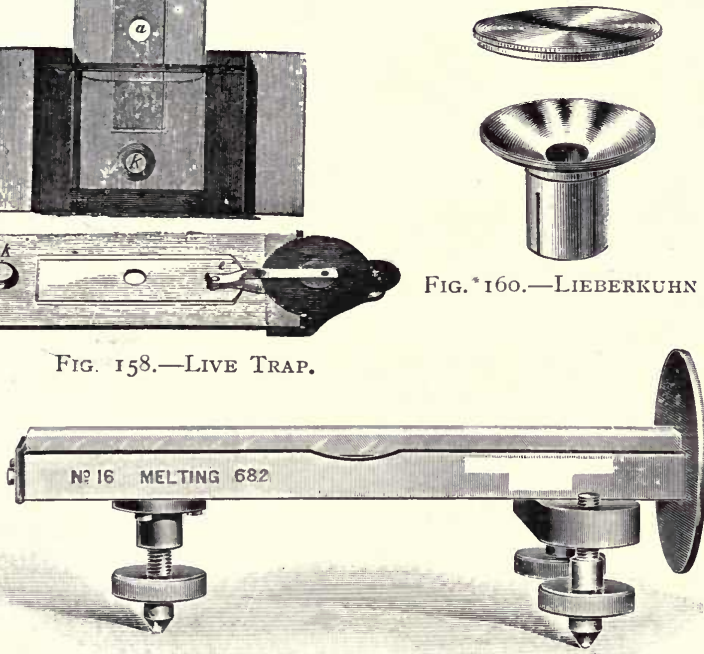

Fig. I6r.-Lummer-Gehrcke Plate. 


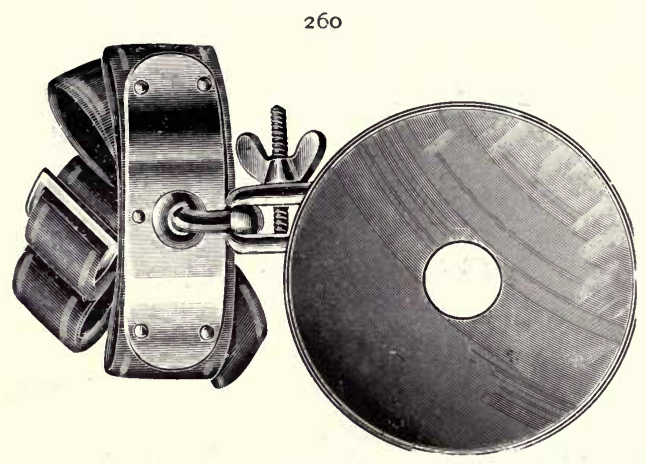

Fig. I62.-LARYNGOSCOPE.

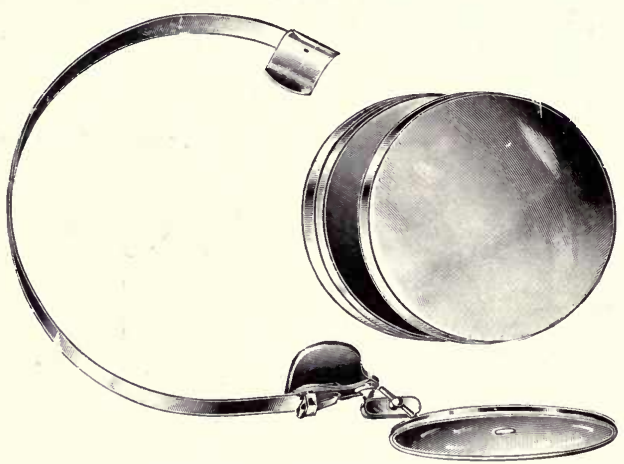

FIG. I63.-LARYNGoSCOPE.

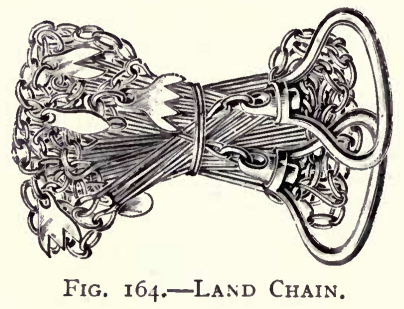




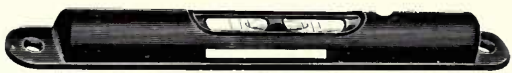

Fig. 165.-Level, Spirit.

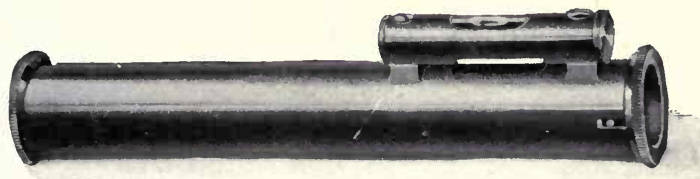

Fig. I66.-Level, Plain Reflecting.

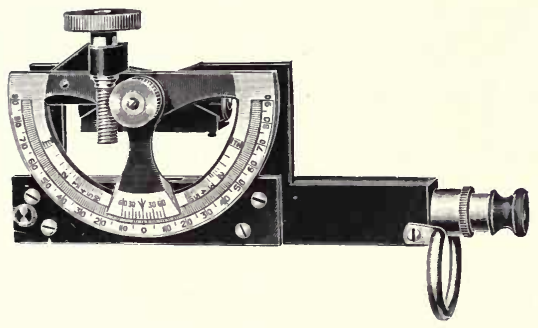

Fig. i67.--Level, Abney.

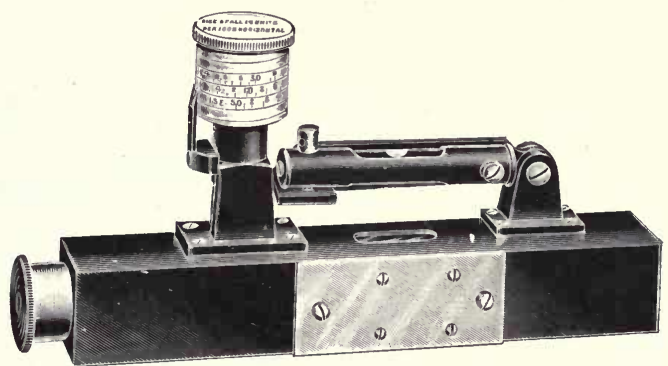

Fig. i68.-Lenel, Abney, Micrometer Pattern. 


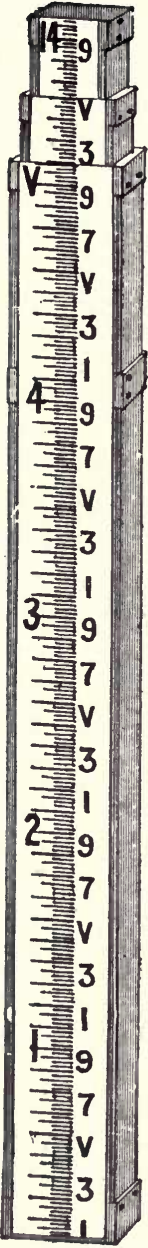

FIG. I 70 .

LEVELLING

Staff.
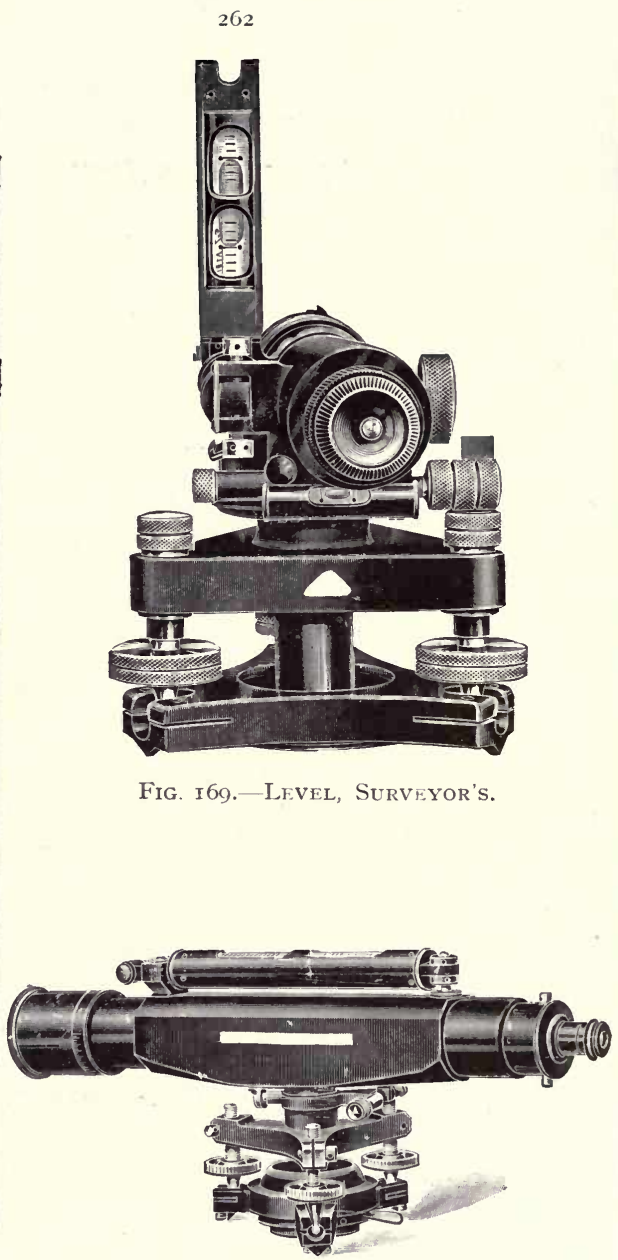

Fig. I7 I.-LeVel, Surveyor's. 


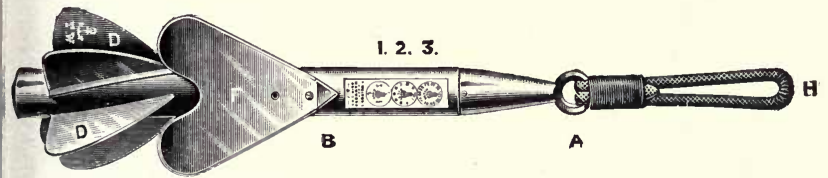

Fig. I72.-Log, Towing Patiern.

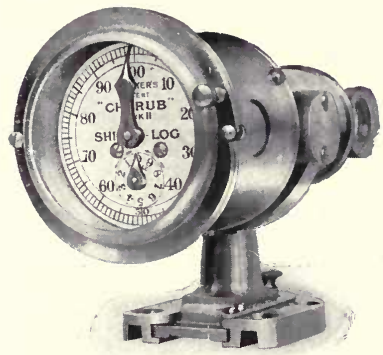

Fig. I73--Log, The Cherub Rail Register.

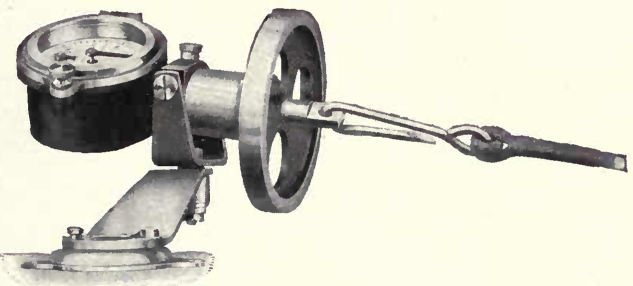

Fig. I 74.-Log, Excelsior; For Motor-BoAts. 


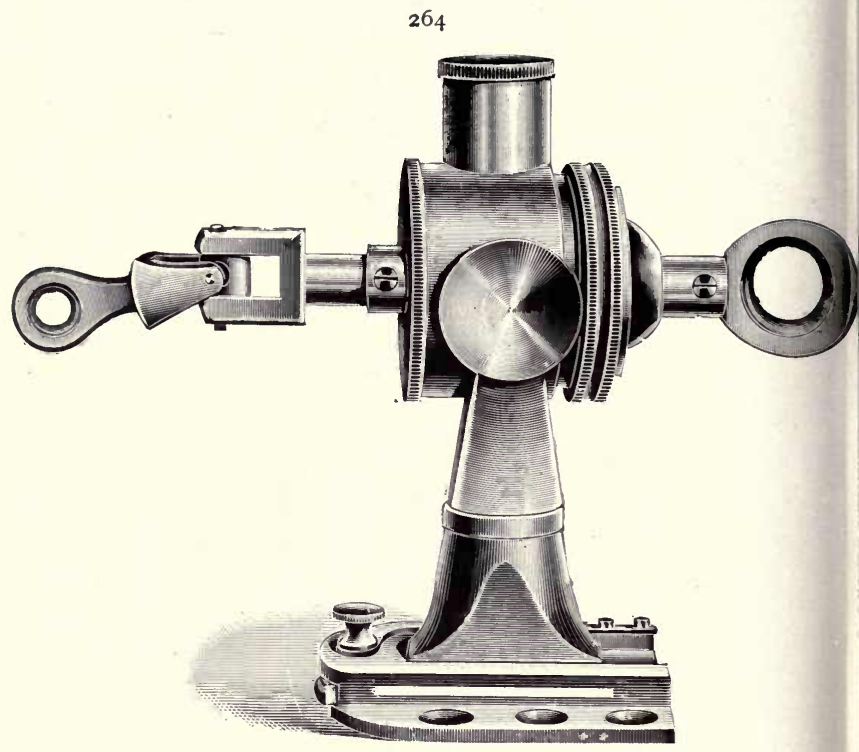

Fig. I75--Log, BRIDGe Connection.

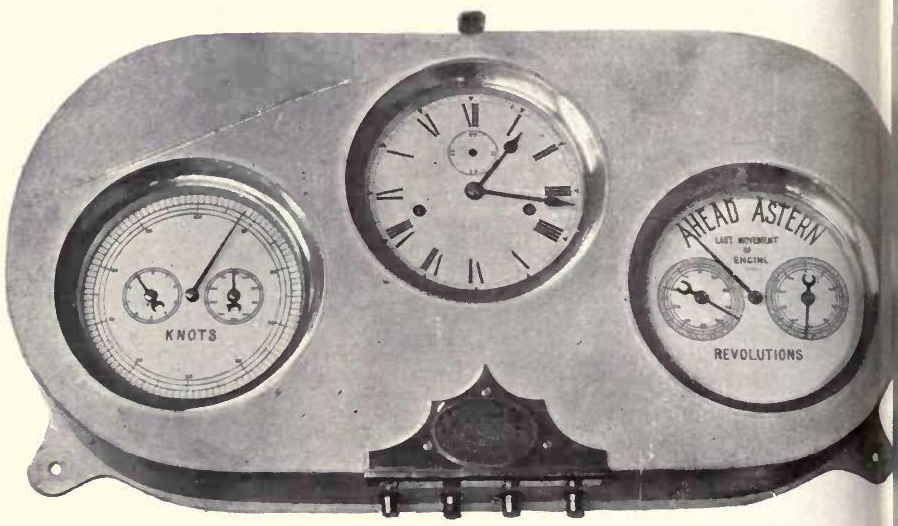

Fig. 176.--Log, Bridge Indicator Dial. 


\section{5}

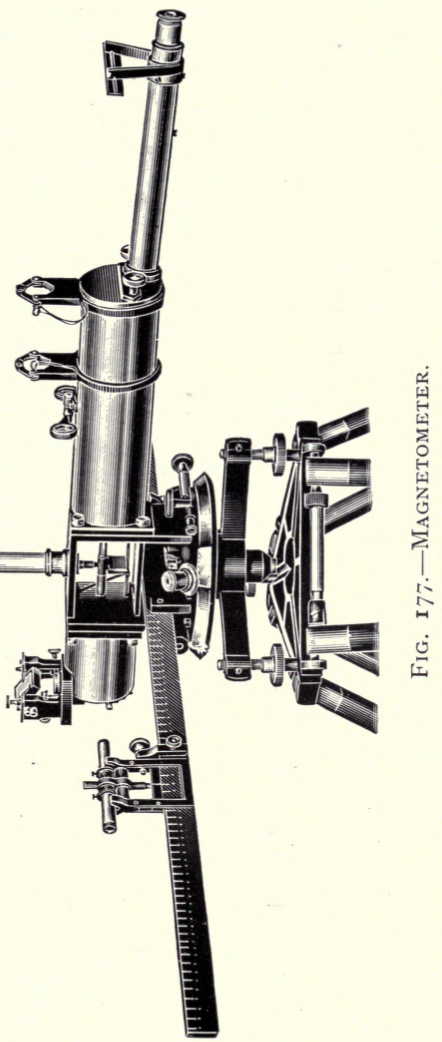




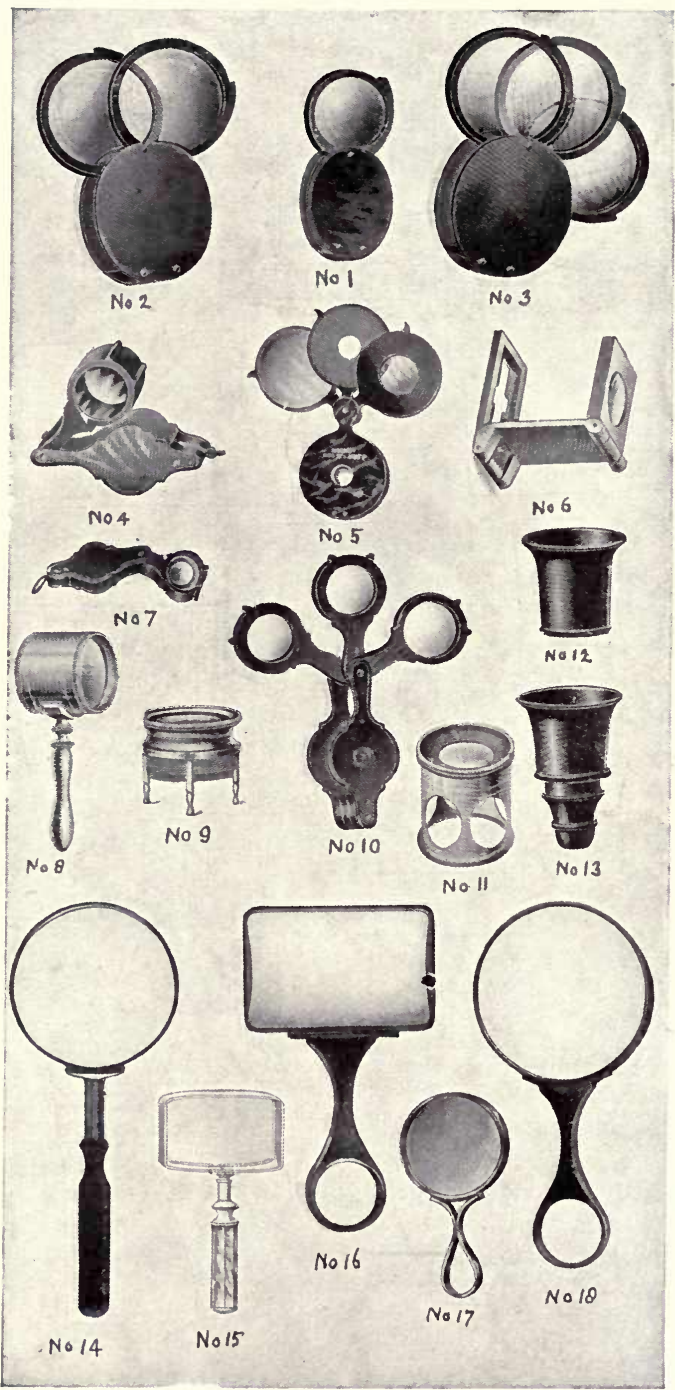

Fig. I78.-Magnifying Lenses, Hand and Pocket. 
267
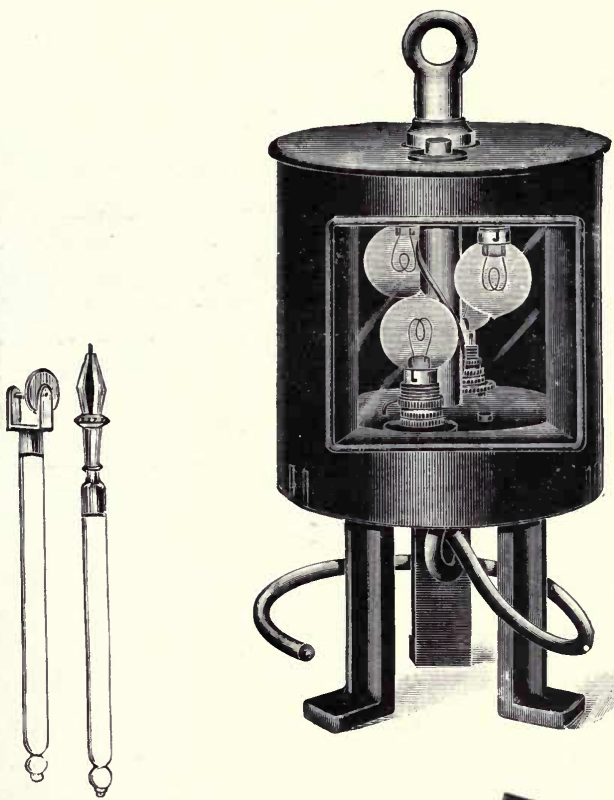

FIG. I79.

Map Measurer.

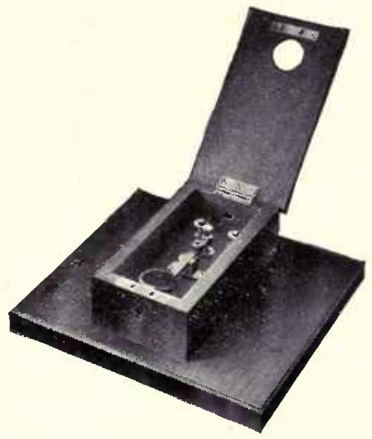

Fig. I80.-Morse Signalling

LAMP AND TAPPER. 


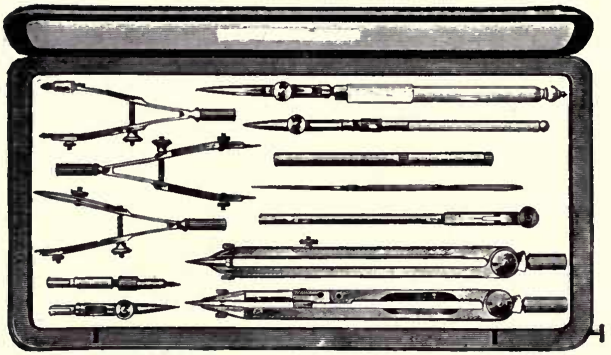

Fig. I8I.-Mathematical Instruments.

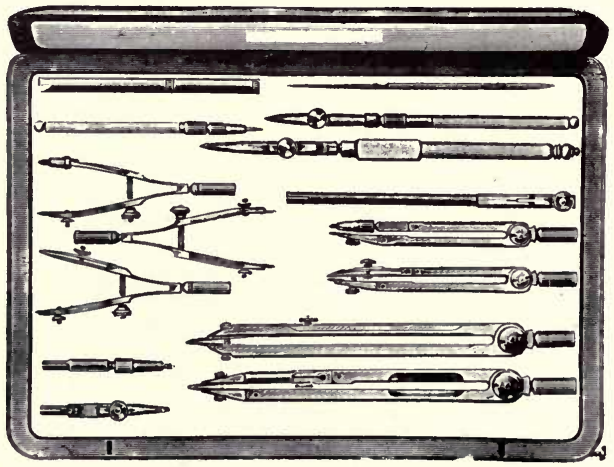

Fig. I 82,-Mathematical InStRUMents. 
269

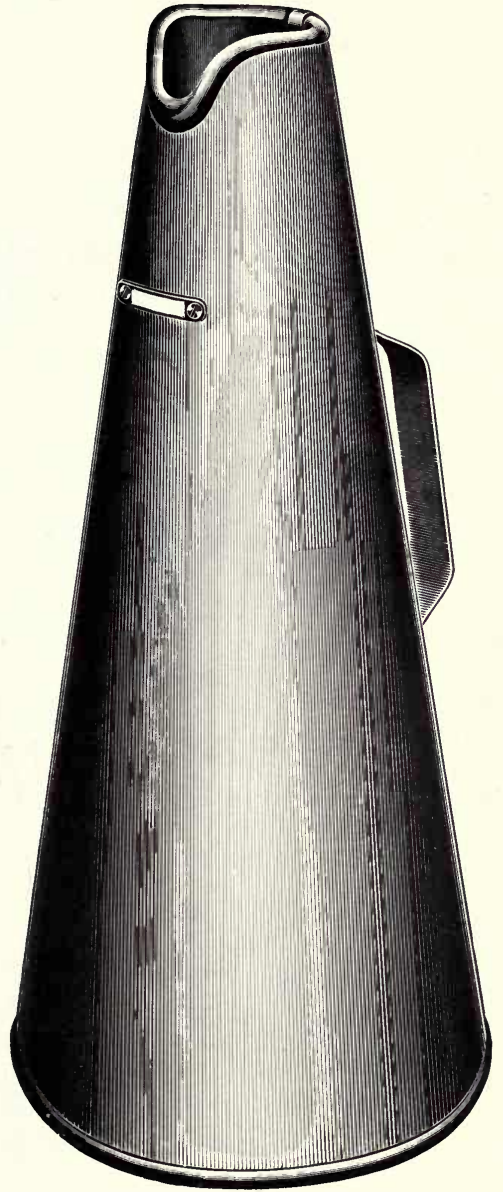

Fig. I83.-MEgaphoNe. 


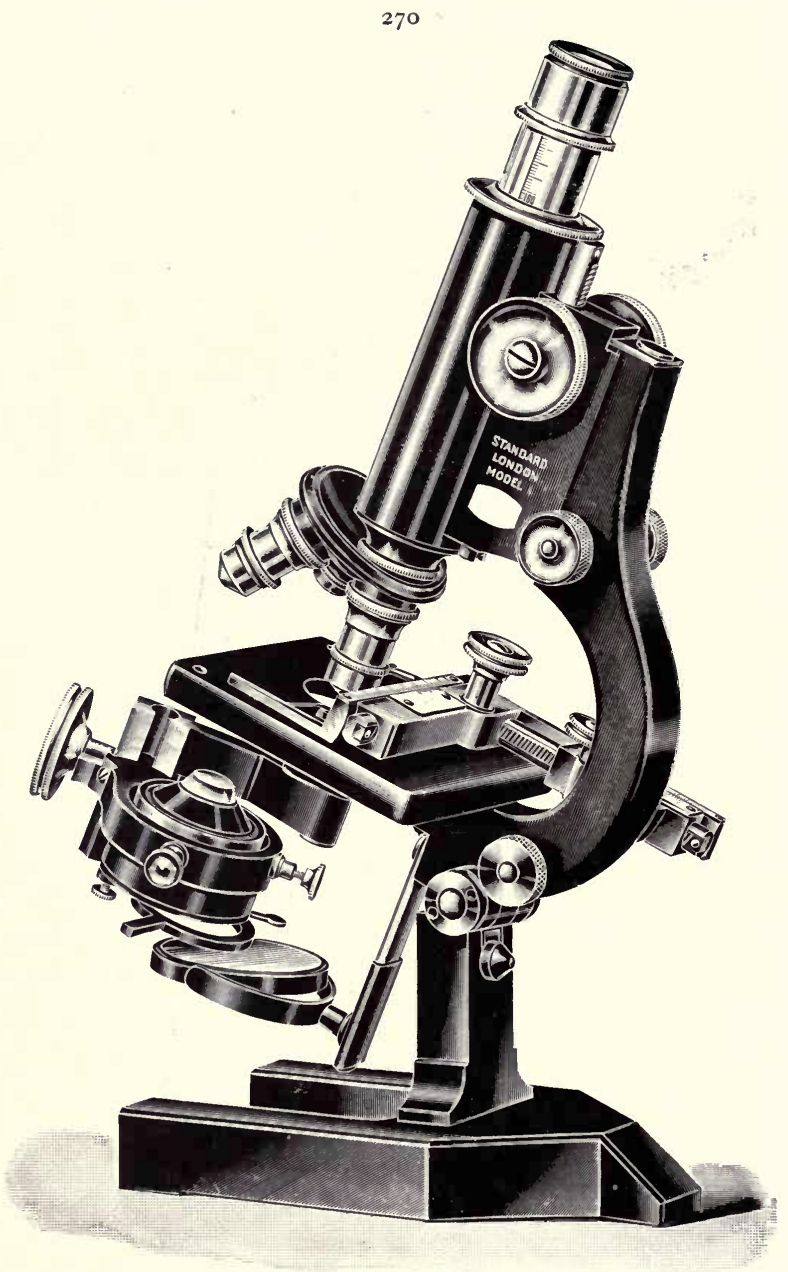

Fig. I84.-Microscope, Bacteriological. 


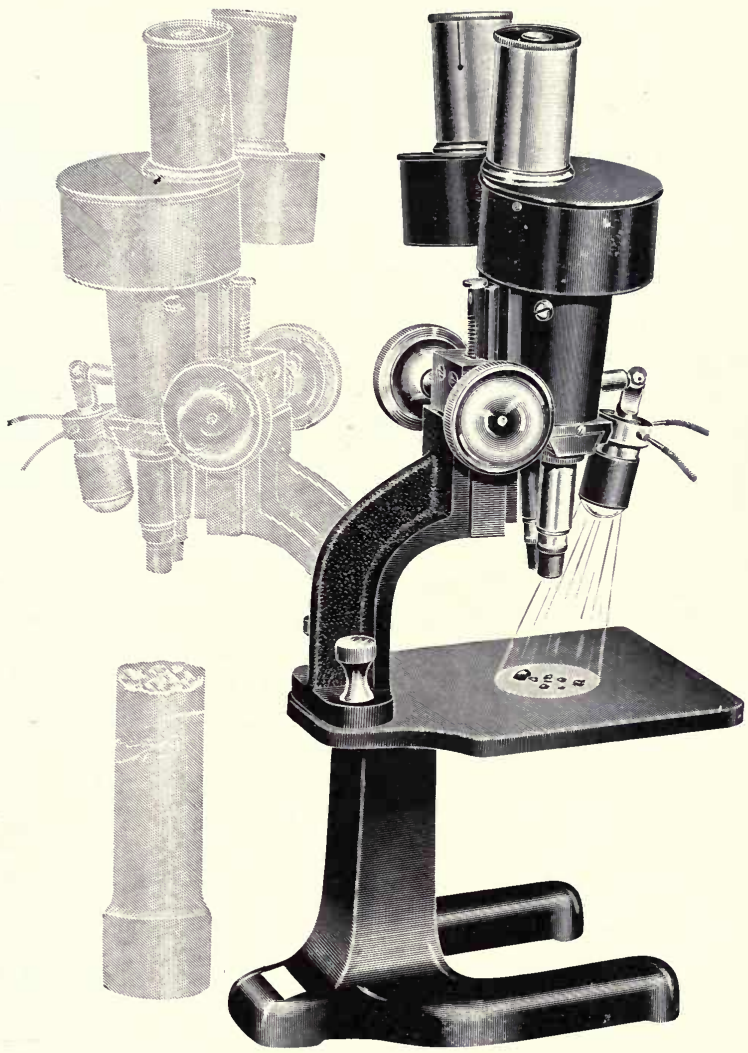

Fig. i 85.-Microscope, Binocular. 


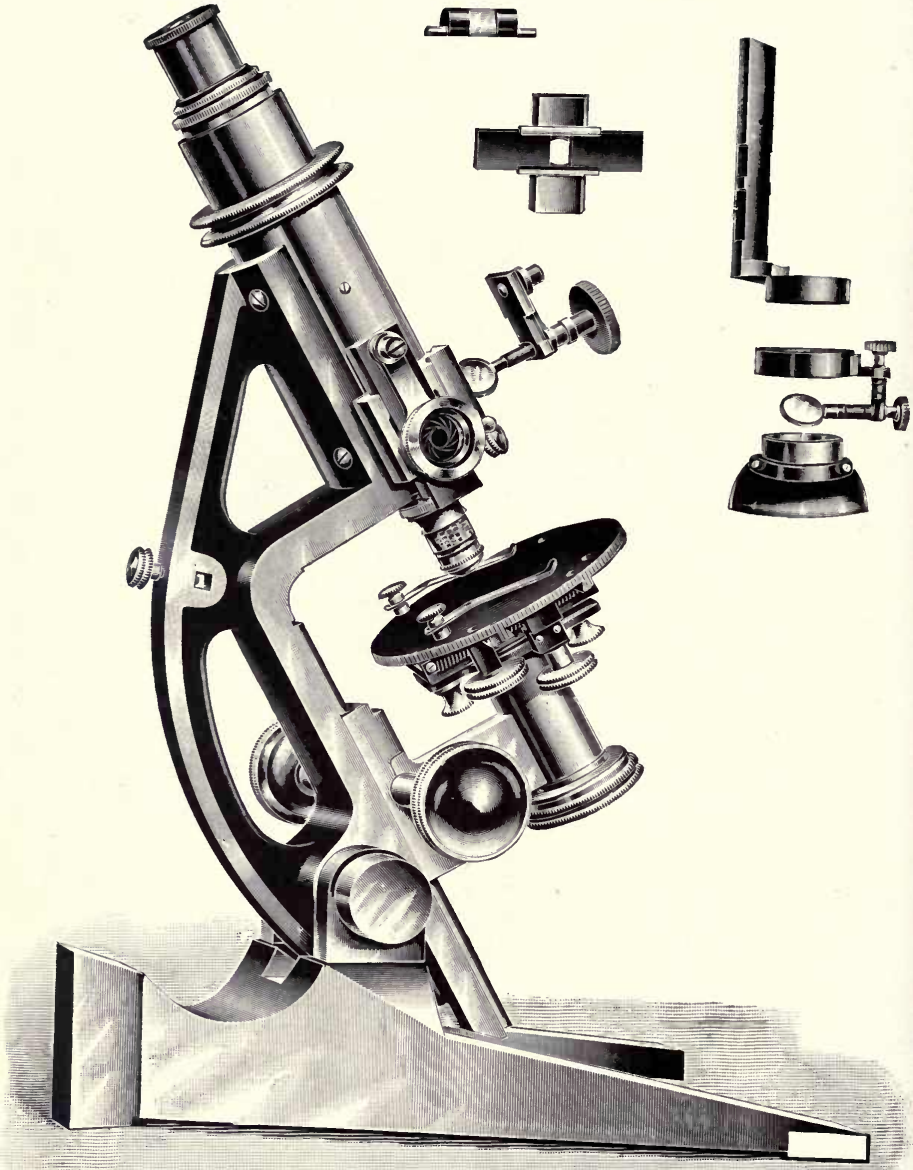

Fig. I 86.-Microscope, Metallurgical. 


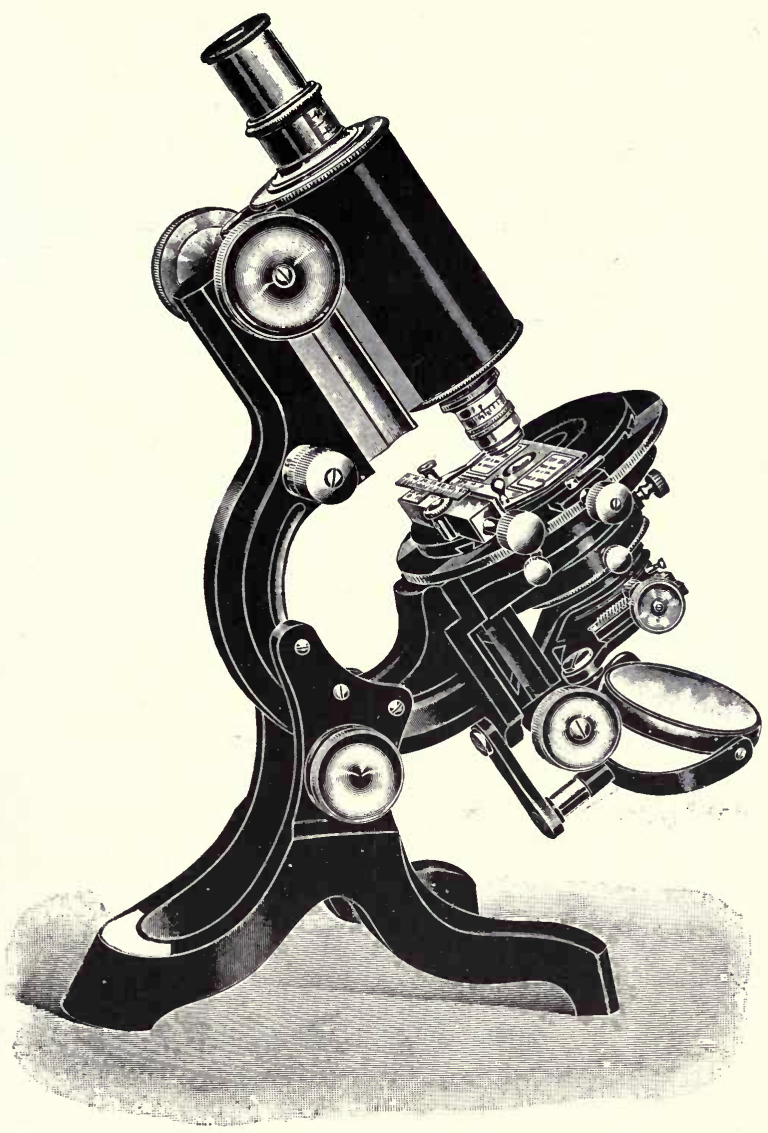

Fig. I 87.-Microscope, Research. 


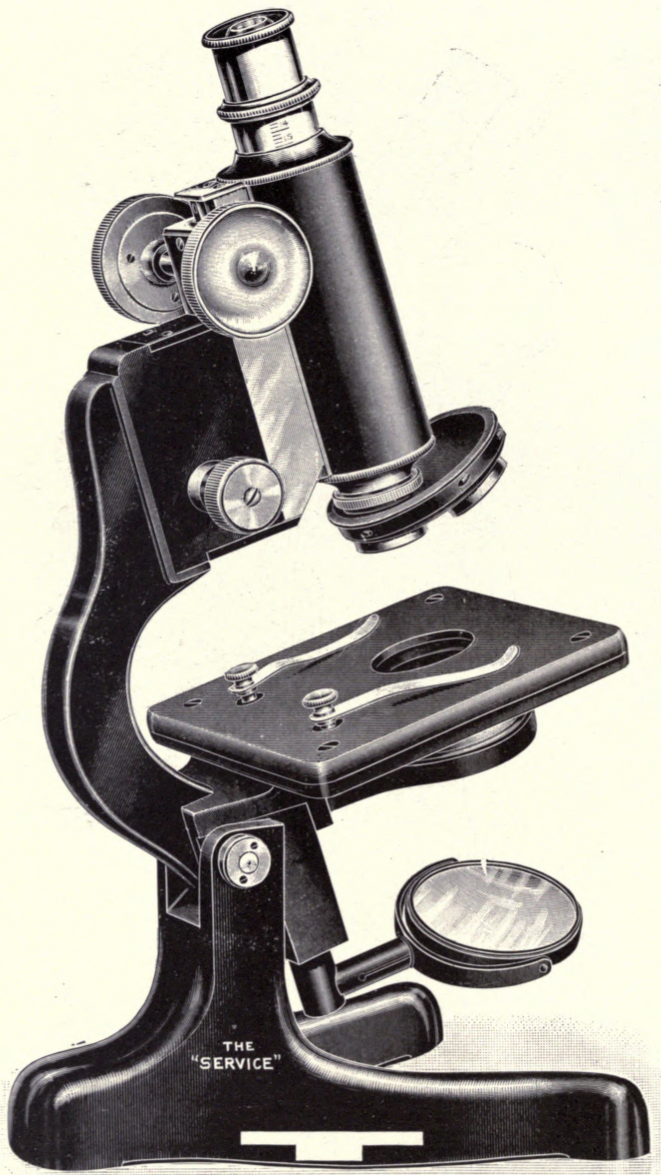

Fig. I 88.-Microscope, Standard. 


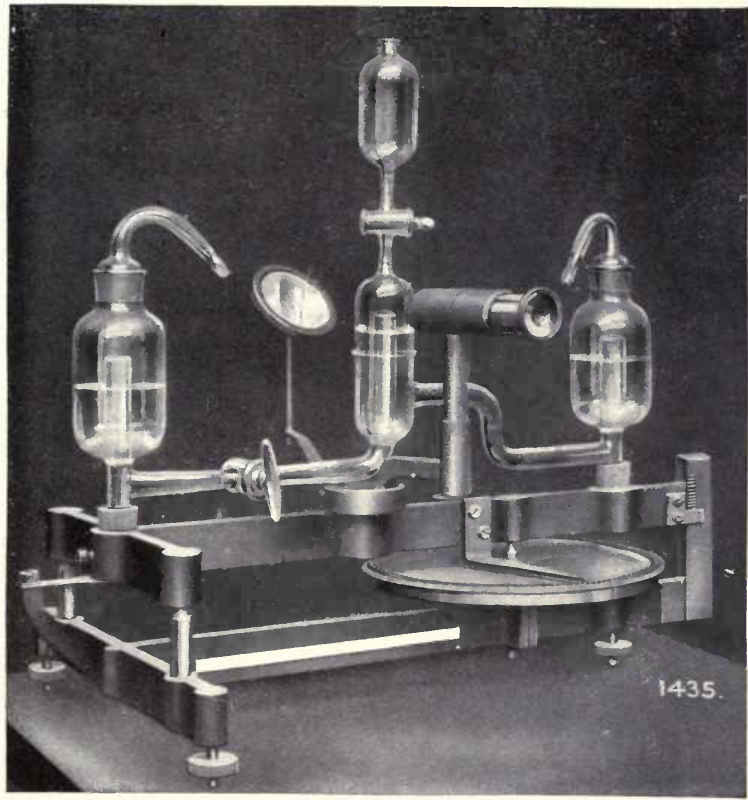

Fig. I89.-Micromanometer, Chattock Tilting.

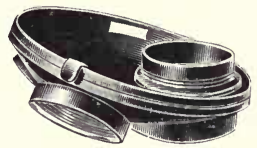

Fig Igo - Microscope. Nosepiece, Revolvixg. 


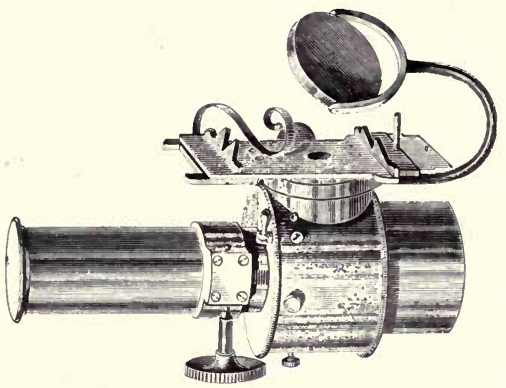

Fig. i91.-Micro-Spectroscope.

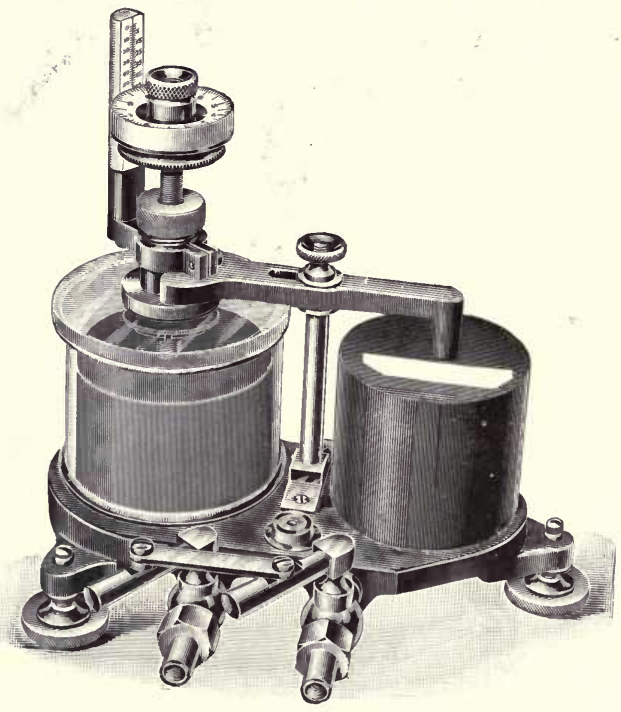

Fig. 192.-Micromanometer, Thrfifal. 


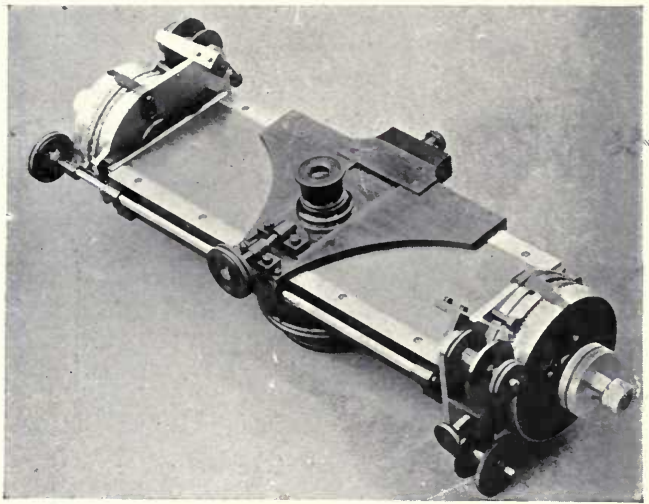

Fig. I93.-Micrometer, Bi-Filar.

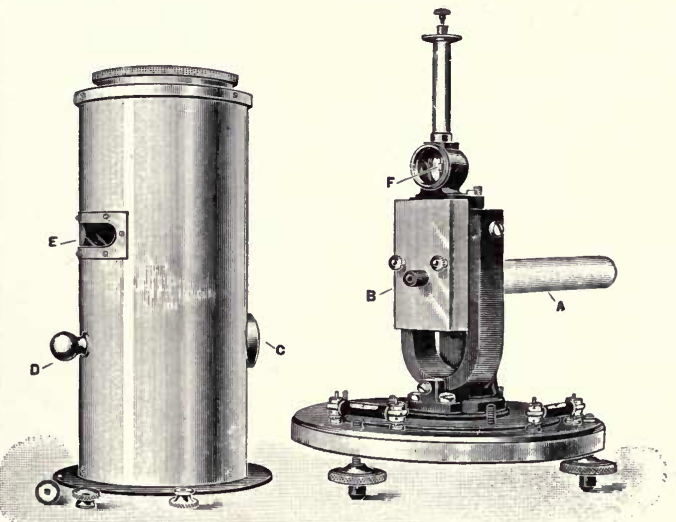

Fig. r94.-Micromlter, Buys' Radio. 
$27^{8}$

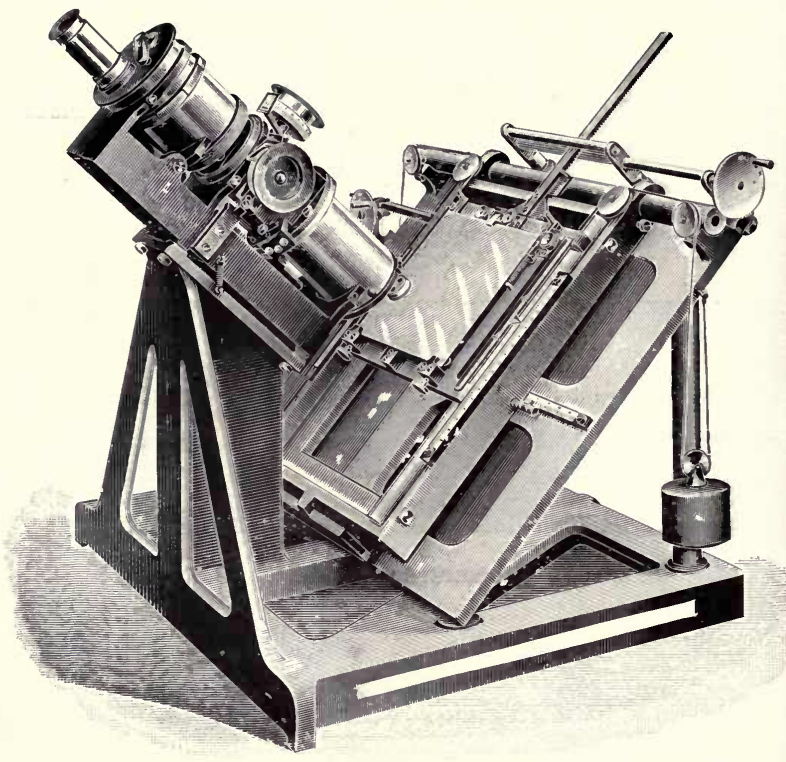

Fig, 195.-Micrometer, Star Photographic.

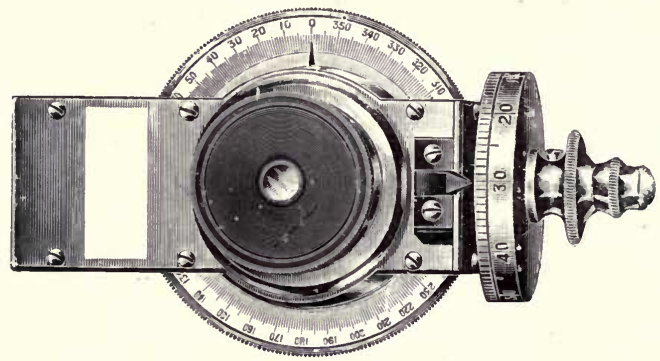

Iitg. I96.-Micrometer, F:Lar. 
279

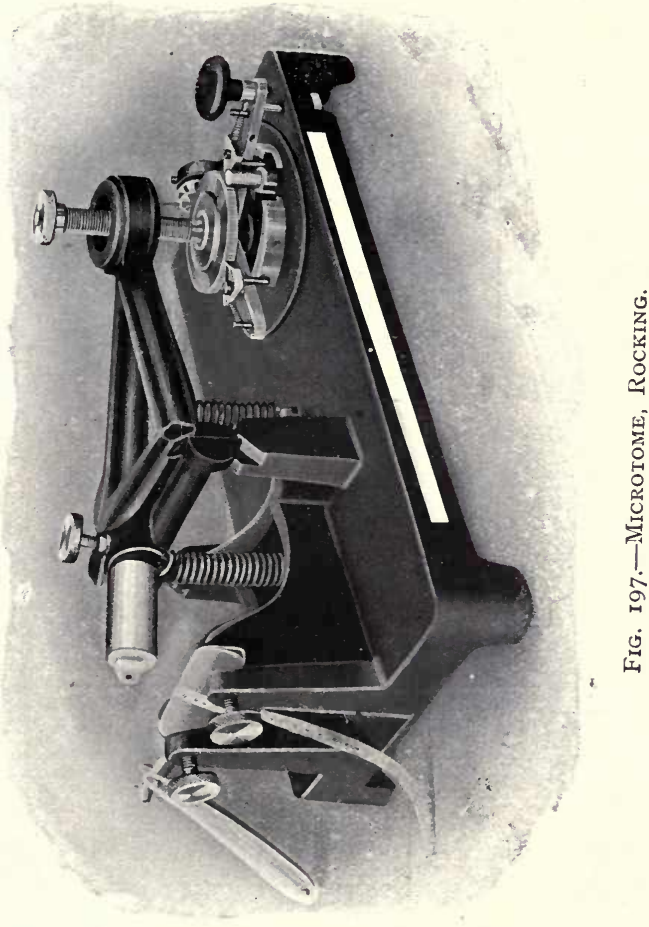

T 2 
280

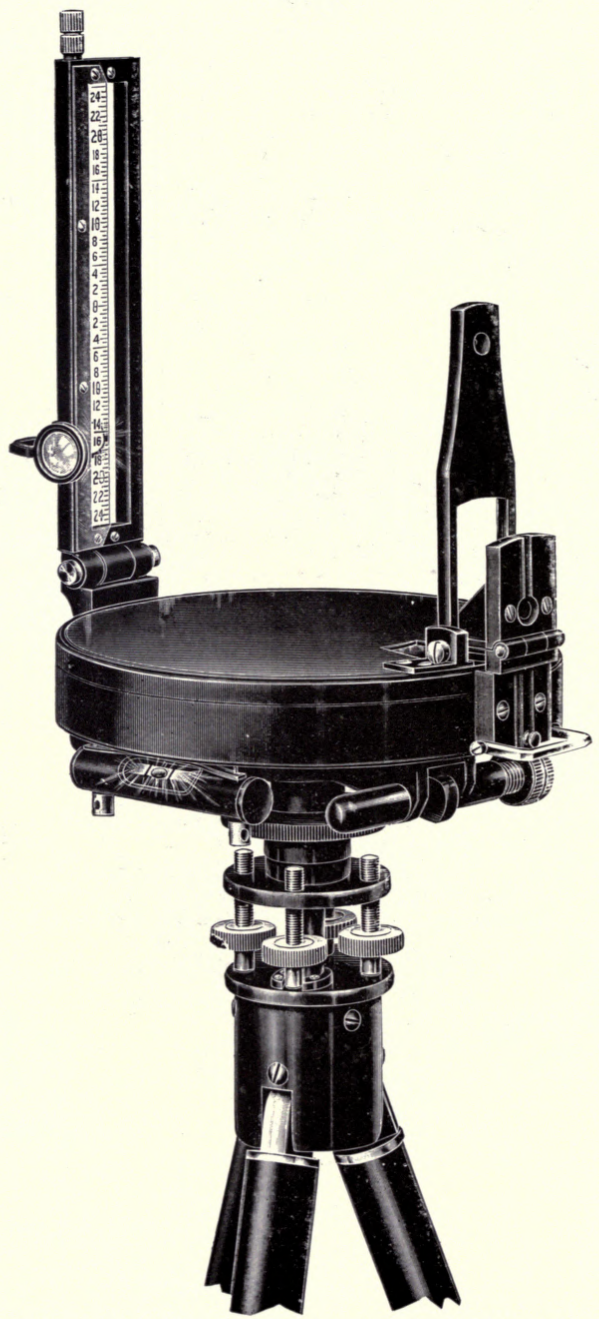

Fig. I98.-Mining Compass, Luminous Scales. 


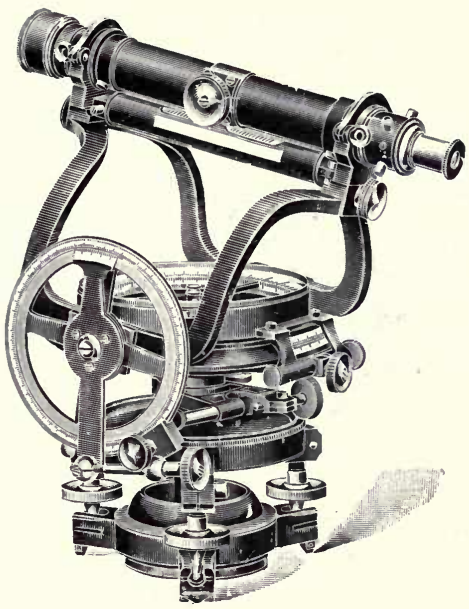

Fig. I99.-Mining Dial.

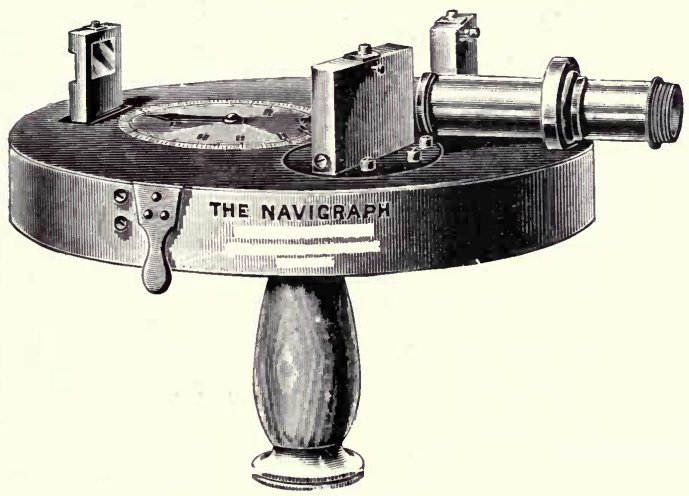

Fig. 200.-Navigraph Instrument. 
282

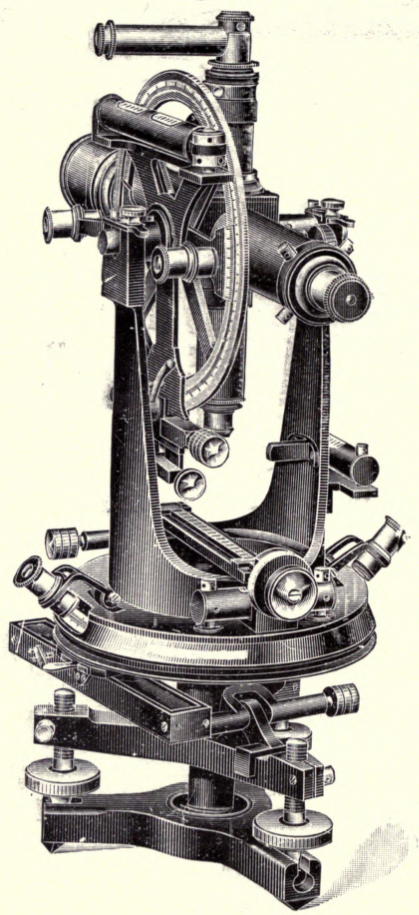

Fig. 2OI -Omnimeter, Theodolite. 
$28_{3}$

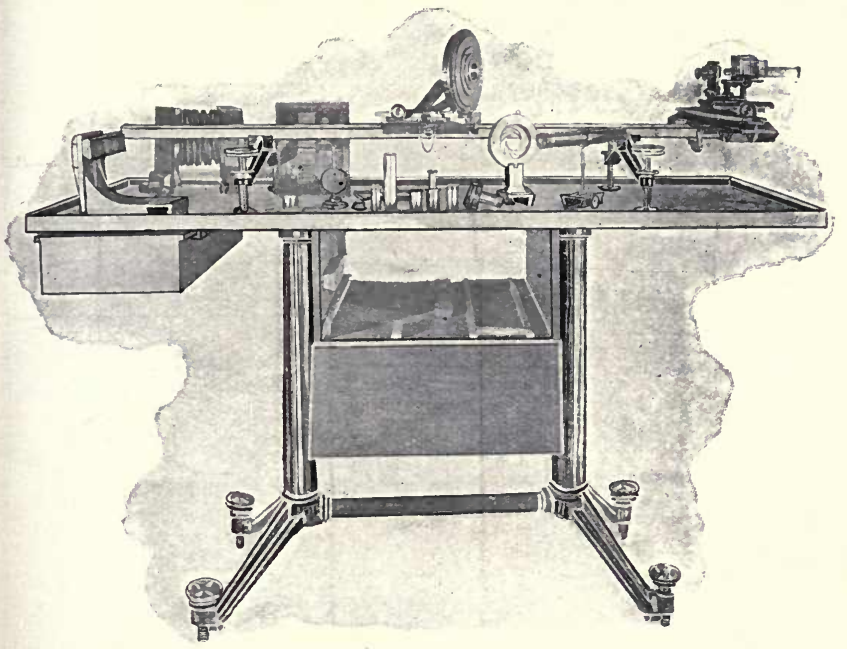

Fig. 202.-Optical Bench, Lens Testing.

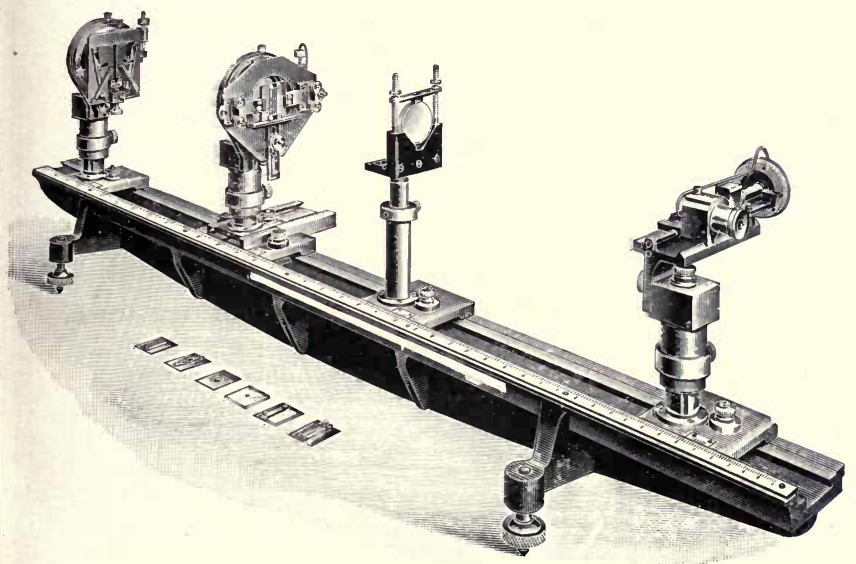

Fig. 203.-Optical Bench. 
284

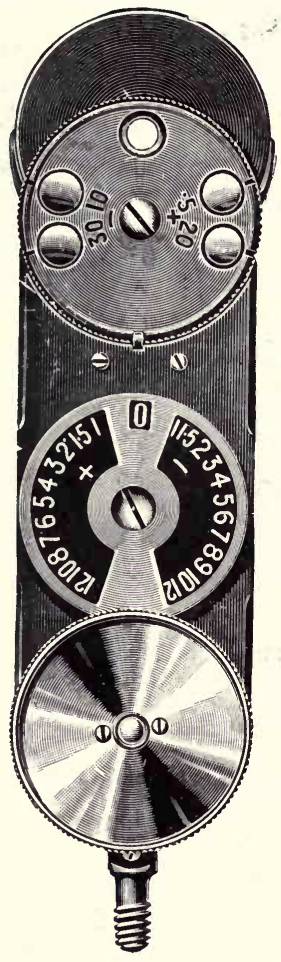

Fig. 204:-OPhthalmoscope.

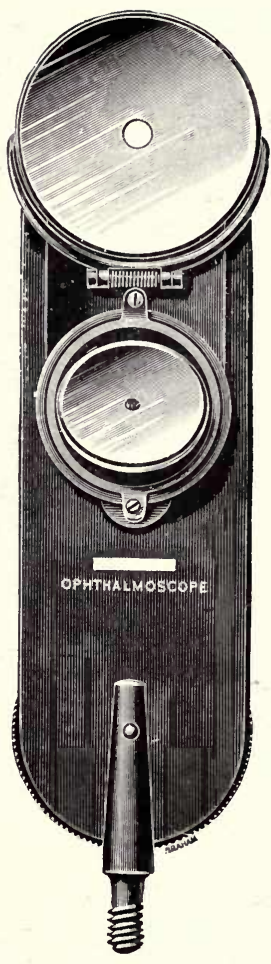

Fig. 205--Ophthalmoscope.

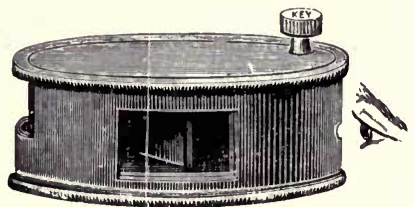

Fig. 206.-Optical Square. 


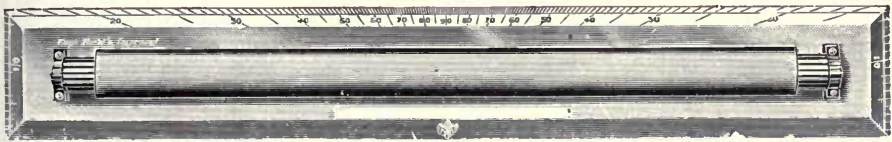

Fig. 20\%.-Parallel Ruler, Metal, Field's Rolling.

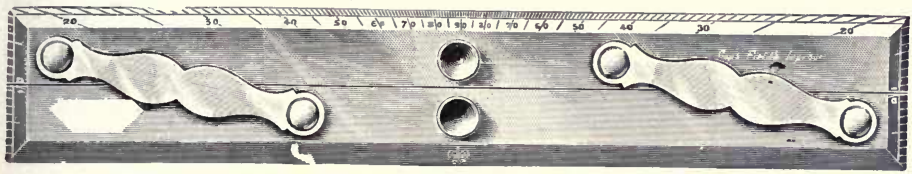

Fig. 208.-Paralilel_Ruler, Metal, Field's Pattern.

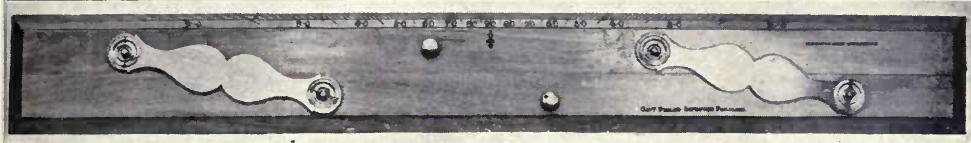

Fig. 209.-Parallel Ruler, Field's Pattern.

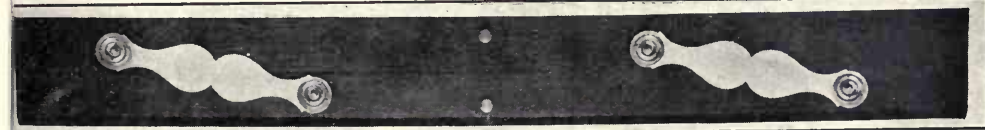

Fig. 2io.-Parallel Ruler.

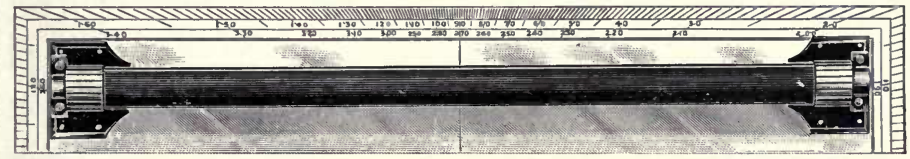

Fig. 2it.-XY. Rolling (Field's) Parallel Rule. 


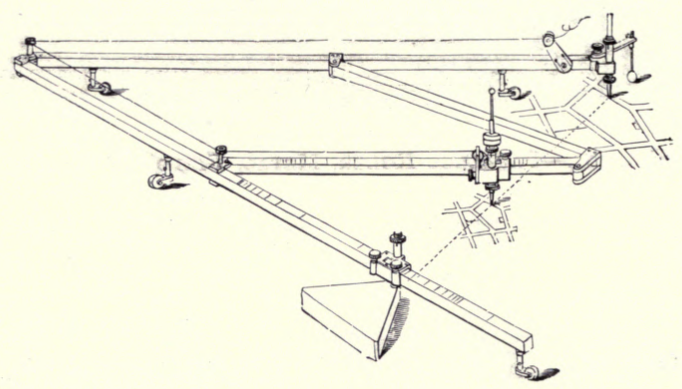

Fig. 21 2.-PANTOGRAPH.

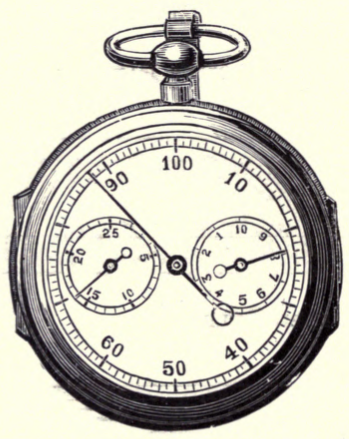

Fig. 2I3.-PASSOMEter.

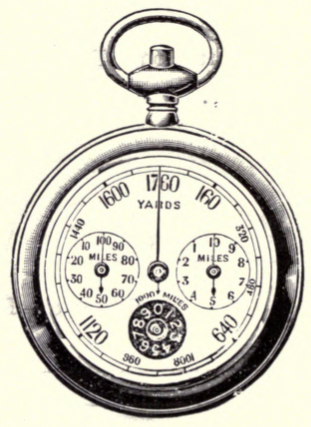

Fig. 2I4.-Pedometer. 


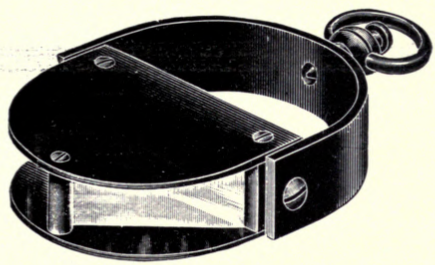

Fig. 215.-Optical Souarf.

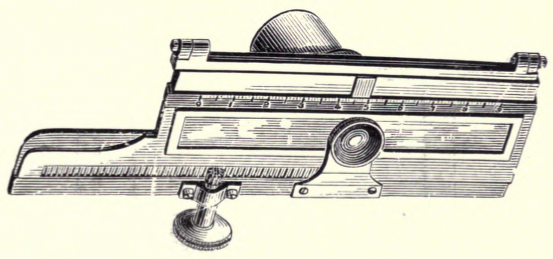

Fig. 2I6.-Photometer Wedge.

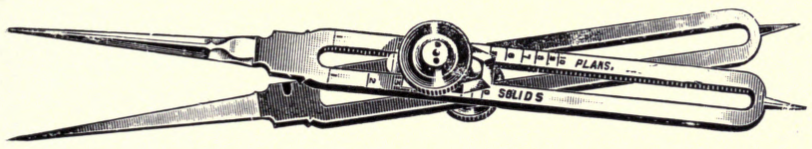

Fig. 2i 7.-Proportional. Dividers. 


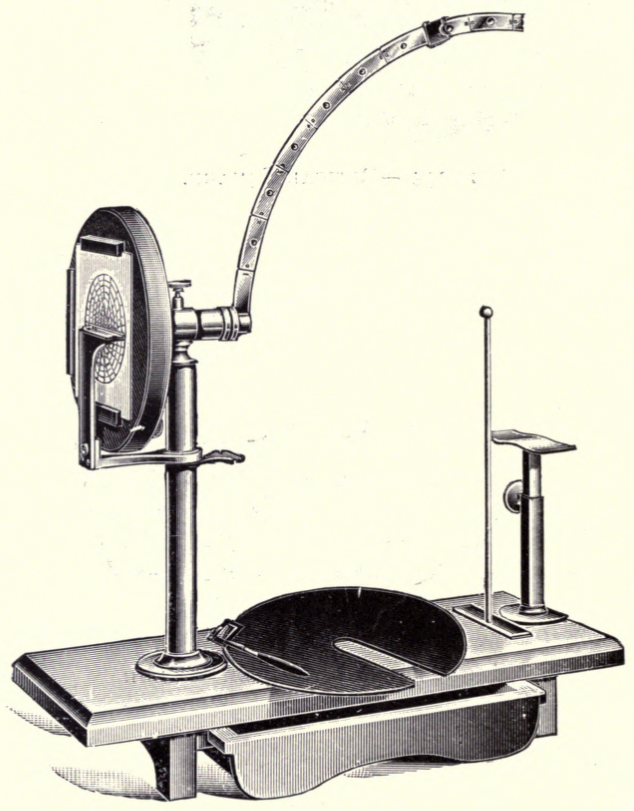

Fig. 2I 8.-PERIMEter. 
.289

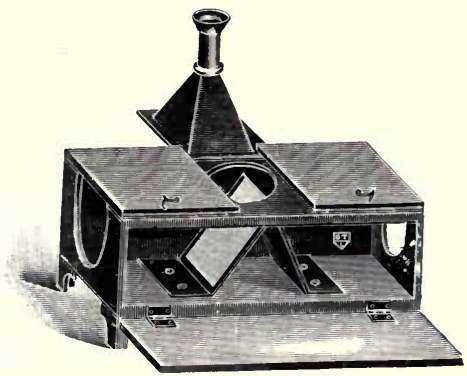

Fig. 2i9.-Рhotometer, Ritchie's.

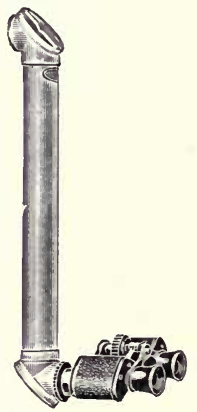

FIG. 220.-PERISCOPE, WITH PrISM Binoculars.

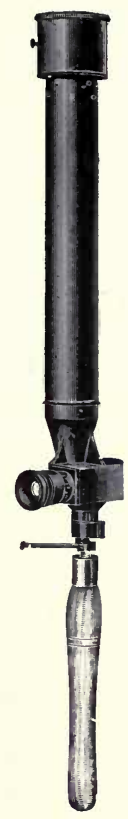

FIG. 22I.-PERISCOPE TRENCH.

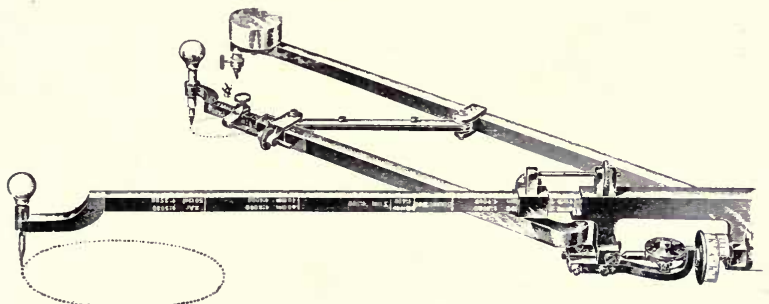

Fig. 222.-Planimeter. 

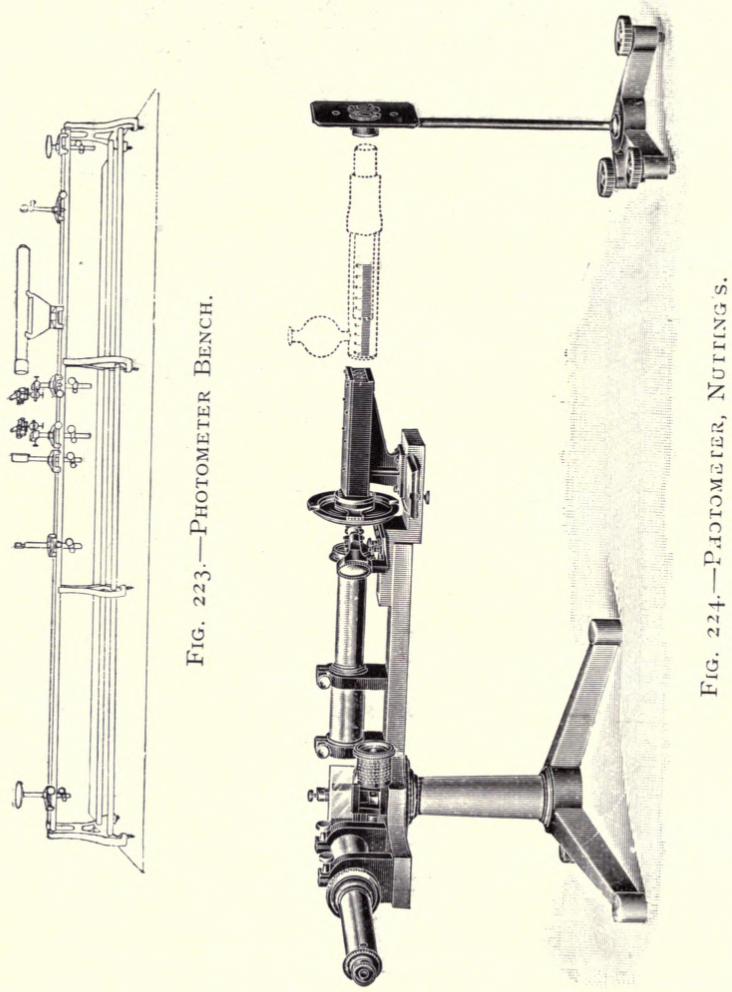


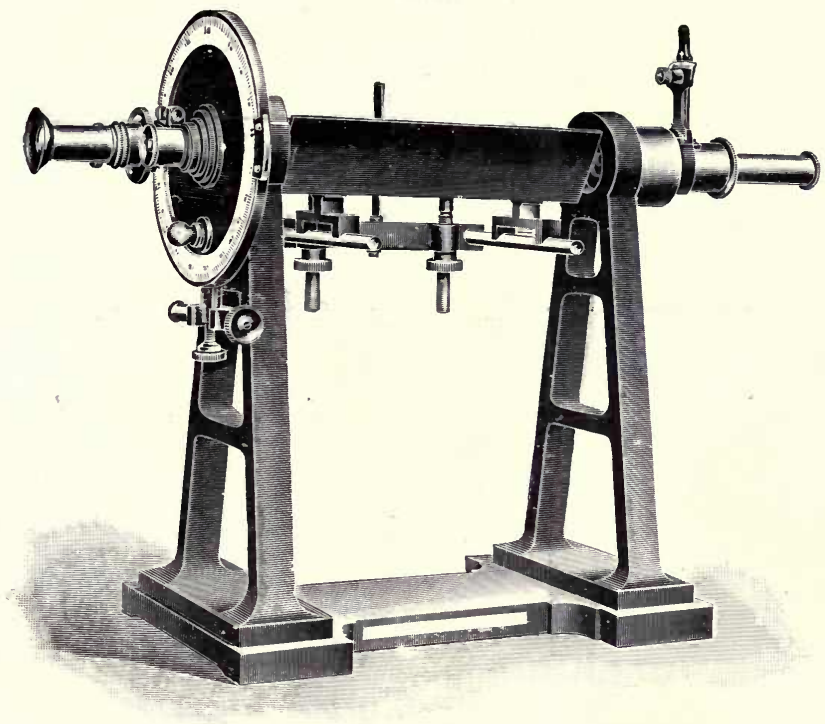

FIG. 225.-Polarimeter.

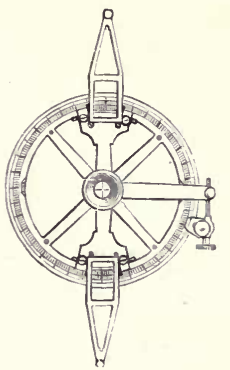

Fig. 226.-PROTRACIOR.

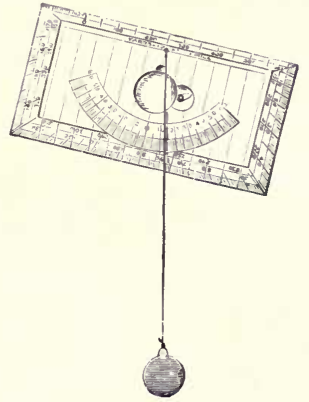

Fig. 227.-PROTRACTOR. 


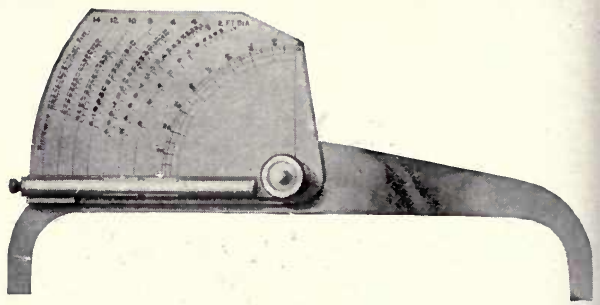

A. The Instrument.
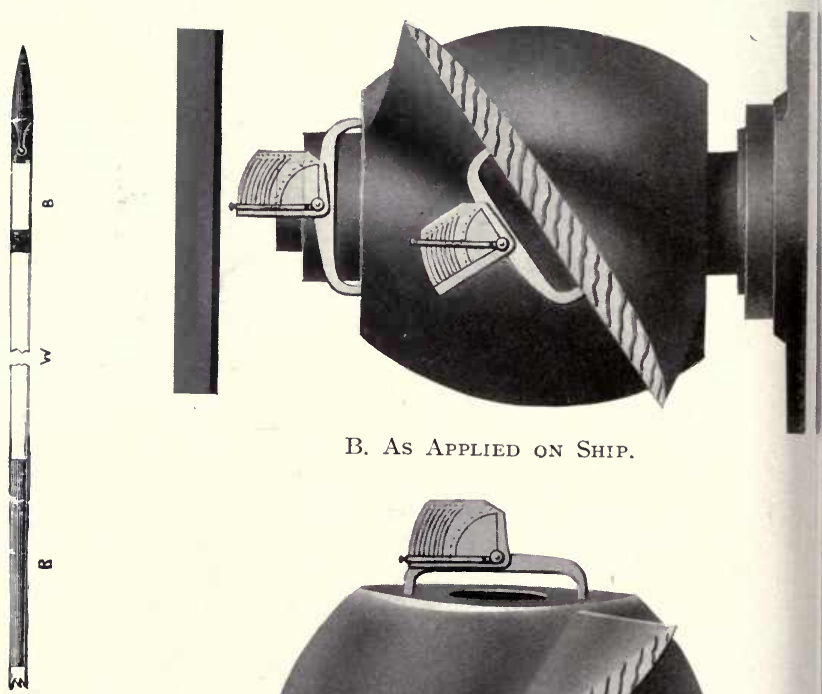

B. As Applied on Ship.

Fig. 228.-Picker Poles

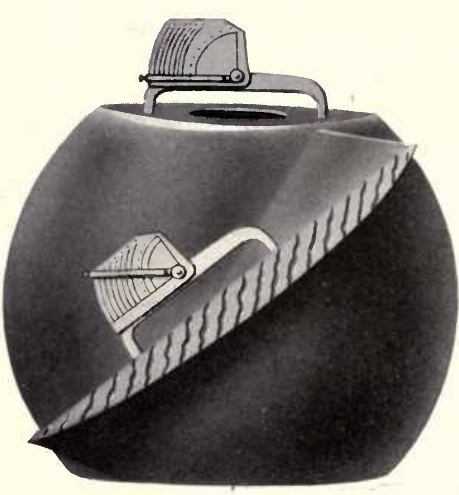

C. As Applied in Shop.

Fig. 229.-Pitchometer. 

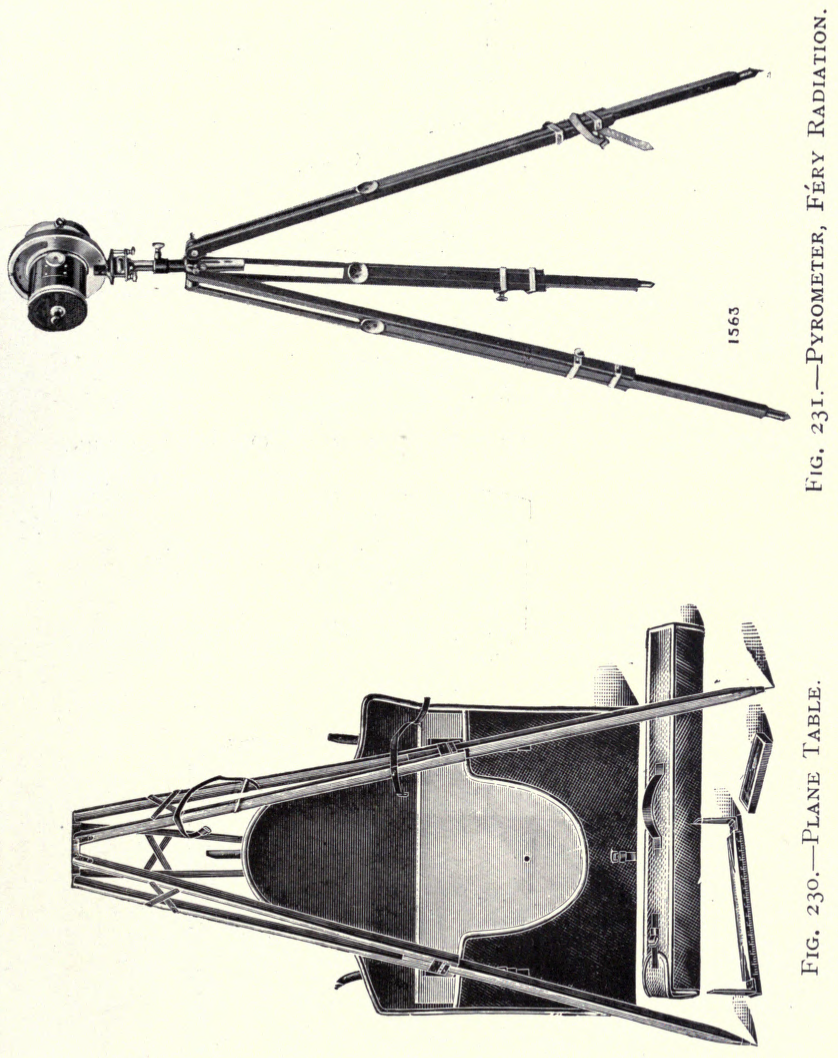


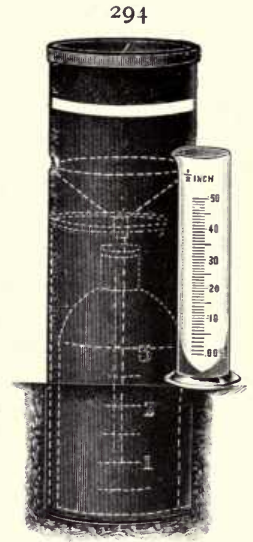

Fig. 232.-Rain-Gauge, Metallurgical Office Pattern.

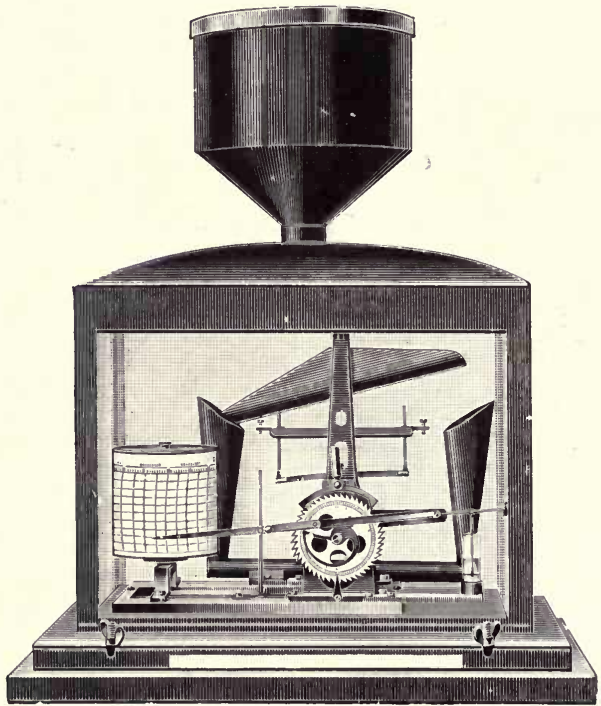

Fig. 233.-Rain-Gauge, Tiliting Bucket. 


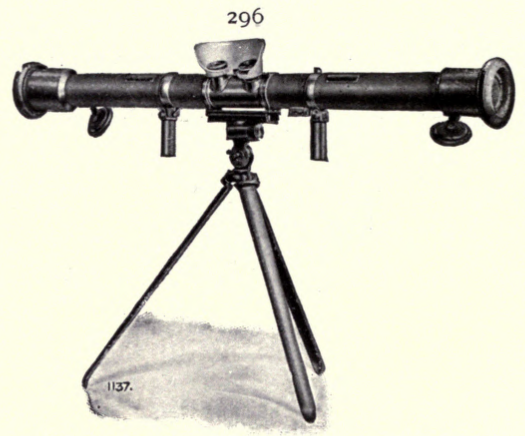

Fig 236.-Range-Finder, Infantry.

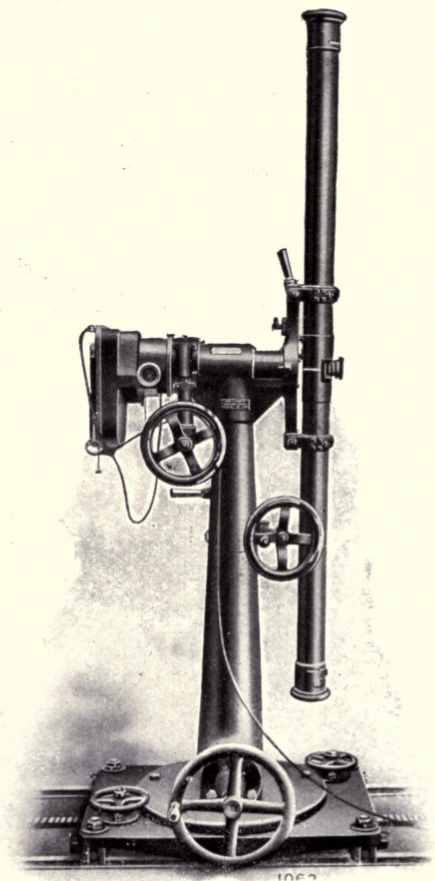

Fig. 237.-RAnge-Finder, Anit-Aircrafi. 


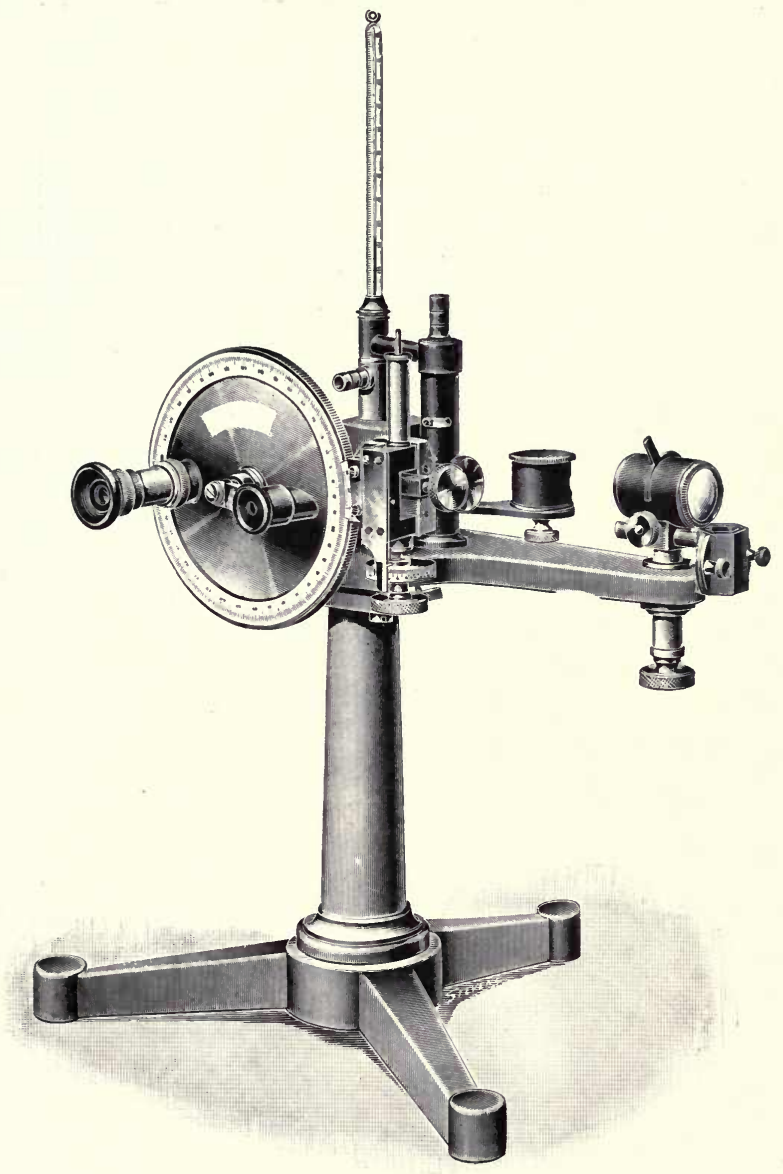

Fig. 238.-Refractometer, Pulfrich. 


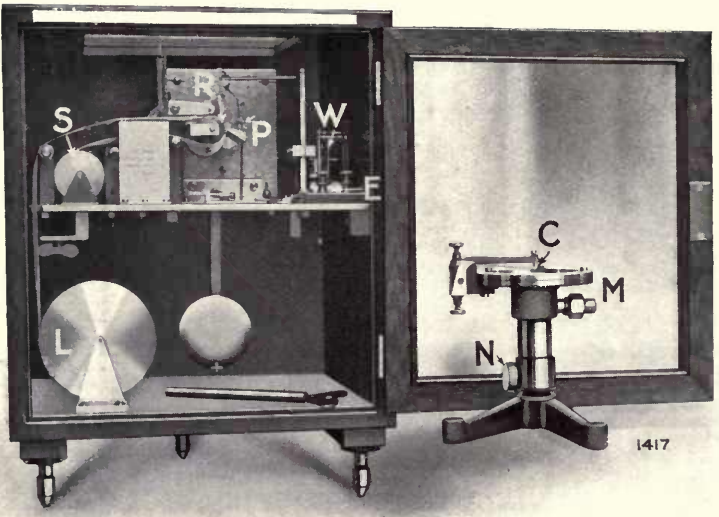

Fig. 239.-SeA Wave Counter.

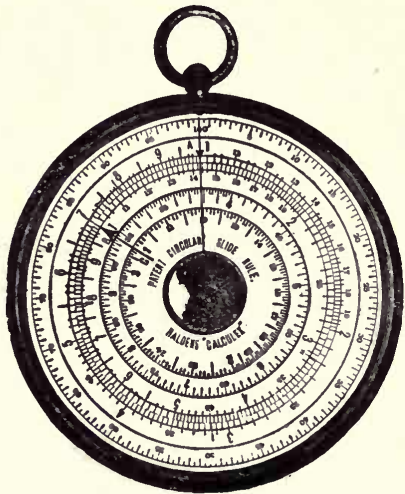

Fig، 240,-Slide-Rule, Calculating Circle. 


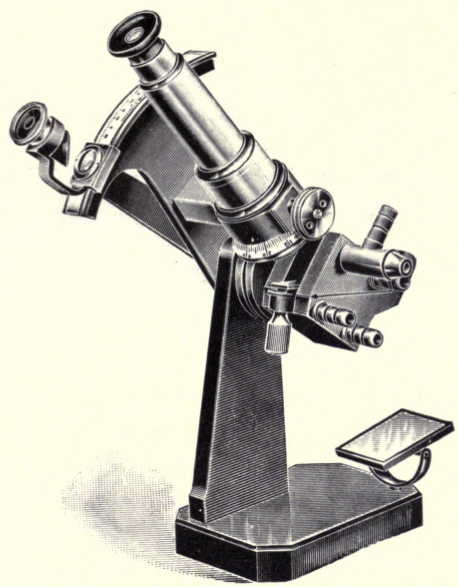

Fig. 24I.-Refractometer, AbBé

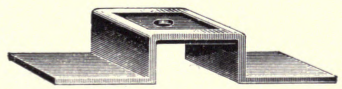

Fig. 242.-SAuver's Bridge (Microscope Object-holder.)

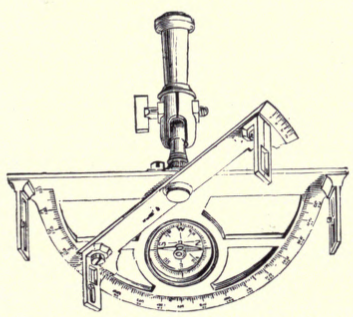

Fig. 243.-Semi-Circumferenter. 


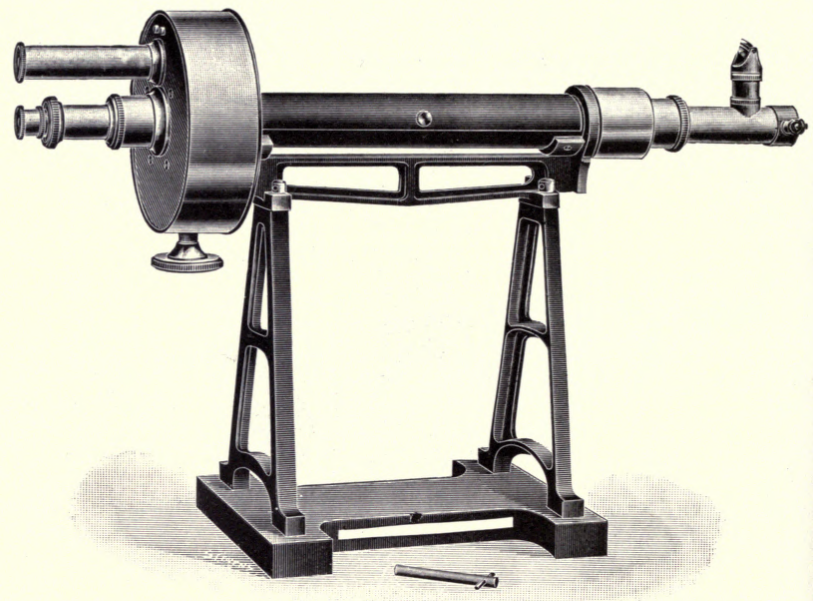

Fig. 244.-SACCHARIMETER.
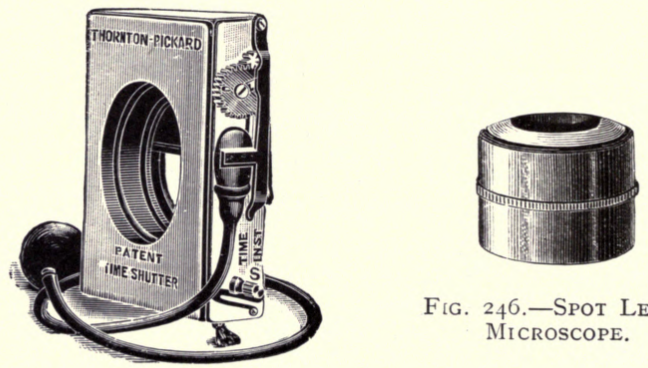

Fig. 246.-SPOT Lens, Microscope.

Fig. 245.-Shutter, Photographic. 


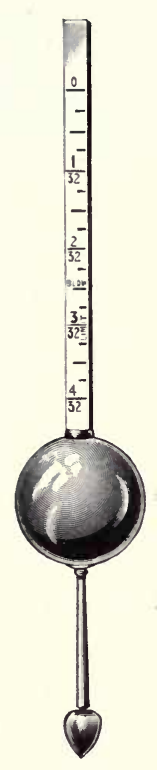

FIG. 247.

SALINOMETER.

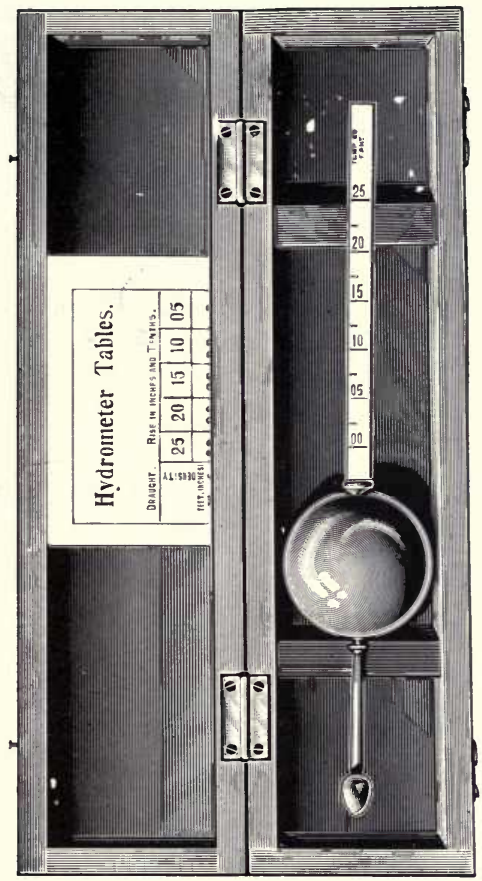

Fig. 248.-SEa-Water Hydrometer, B.T. PATtern. 


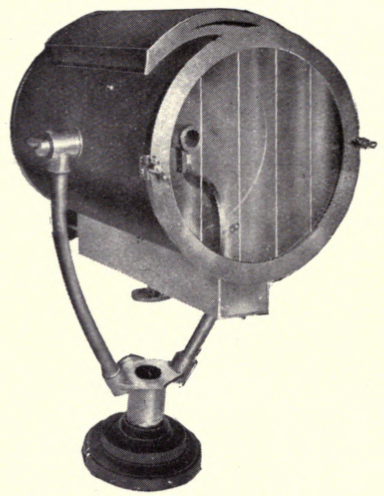

FIG. 249.-SeARChlight

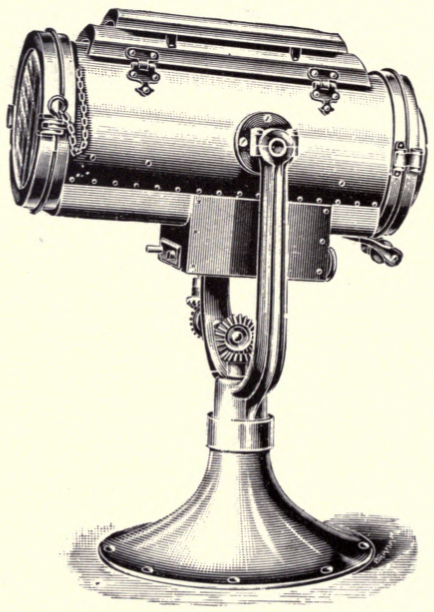

FIG. 250.-SEARChLIGH r. 


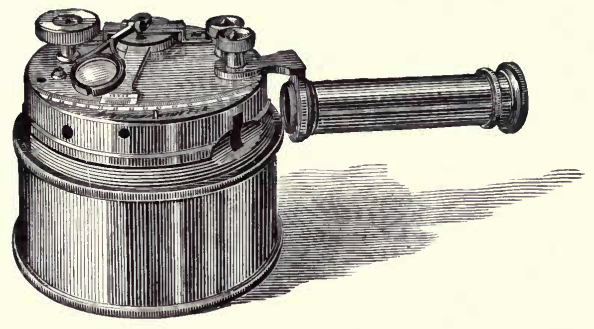

Fig. 25I.-Sextant, Box.

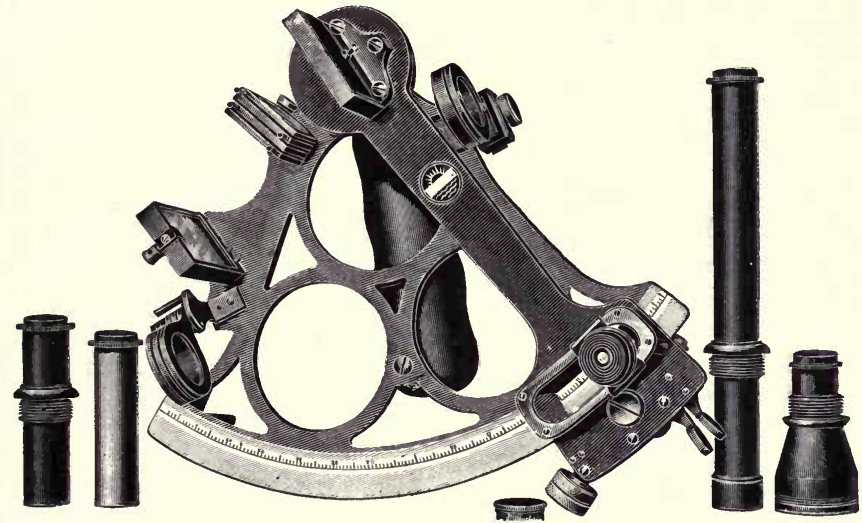

Fig. 252.- Sextant, Nautical. 


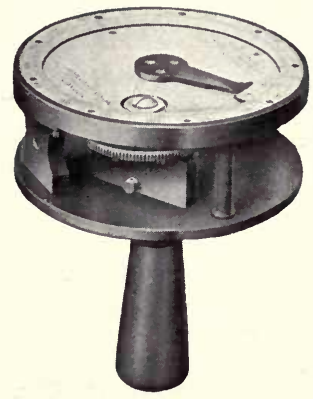

Fig. 253.-Sextant, Paget Angle.

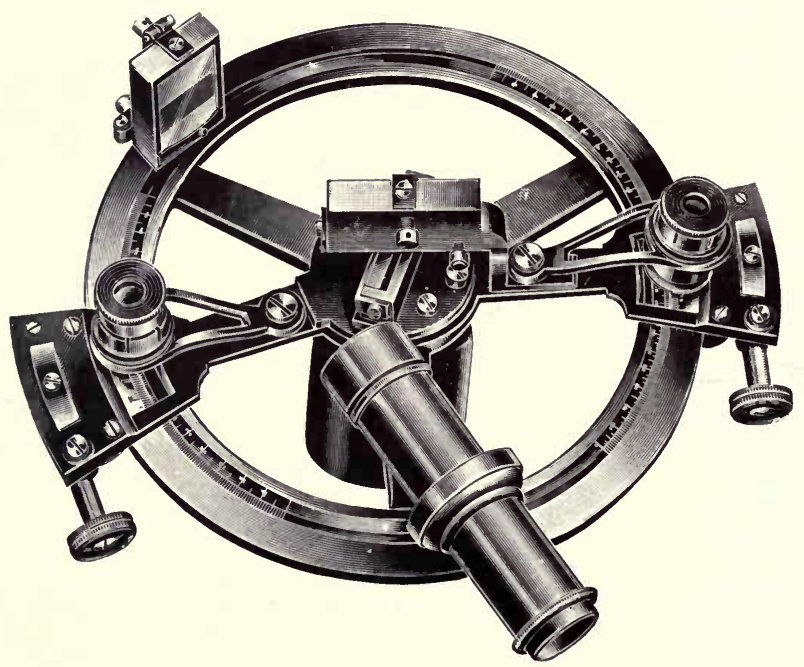

Fig. 254.-Sextant, Paget Double. 
305
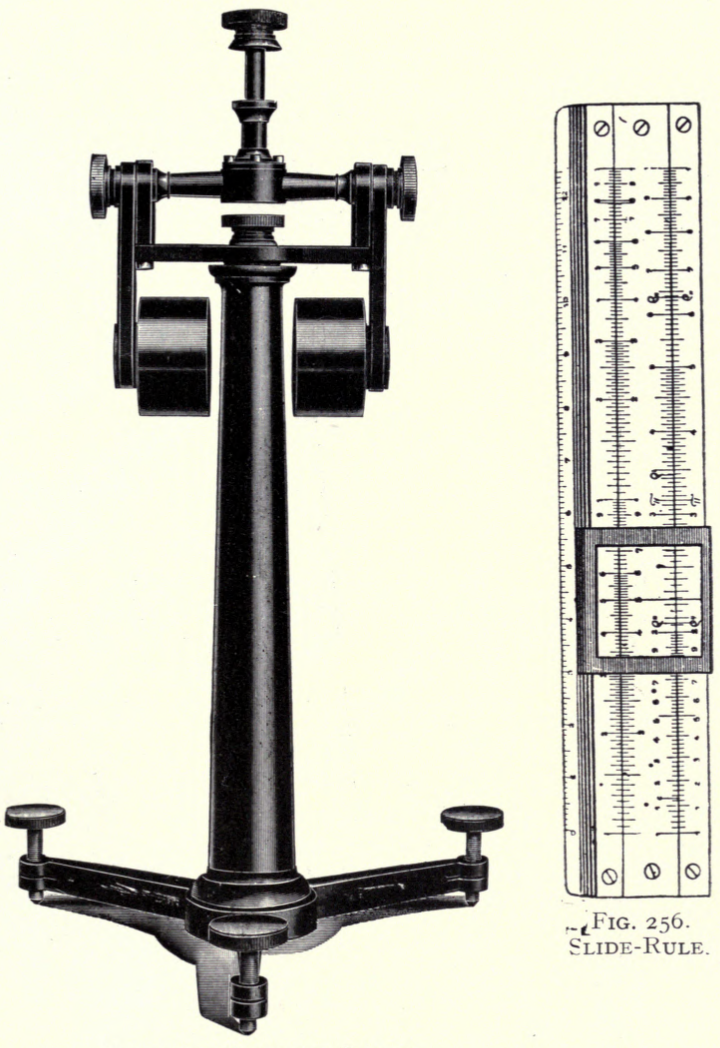

SLIDE-RULE.

Fig. 255.-Sextant Stand. 

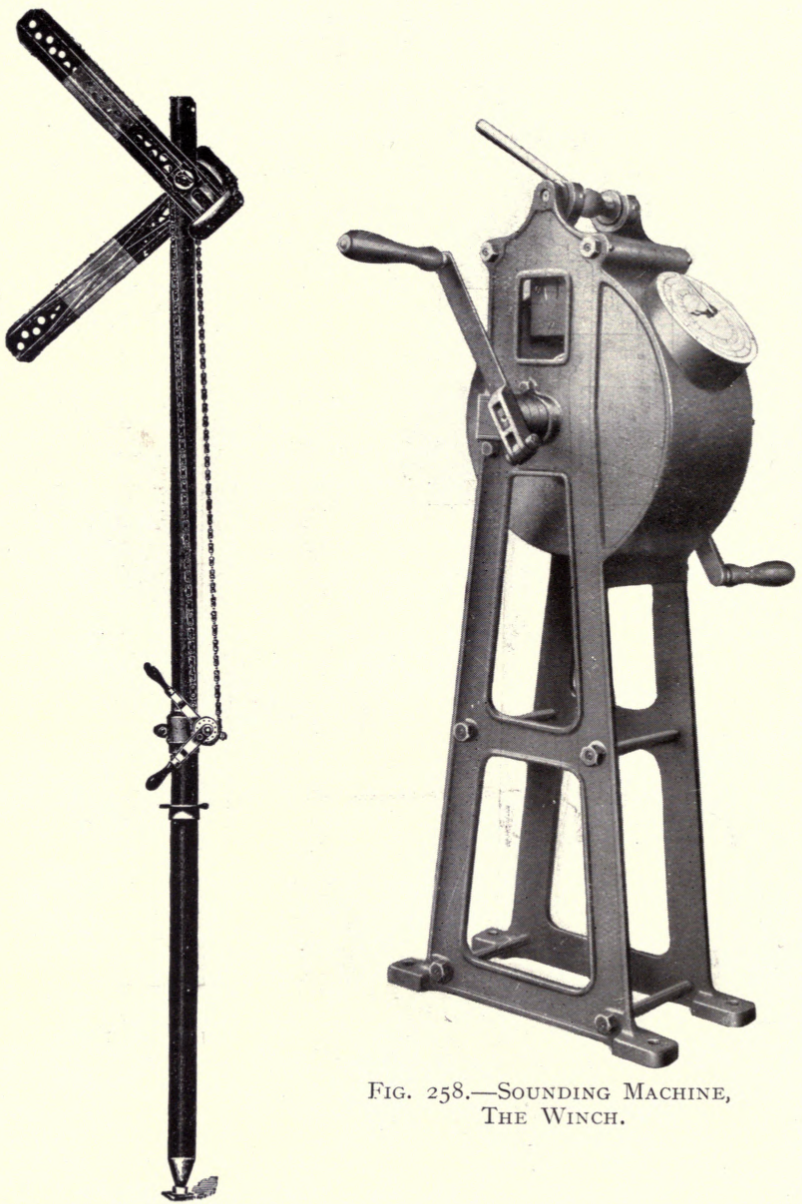

Fig. 258.-Sounding Machine, ThE WINCH.

Fig. 257.-SEMAPHORE. 


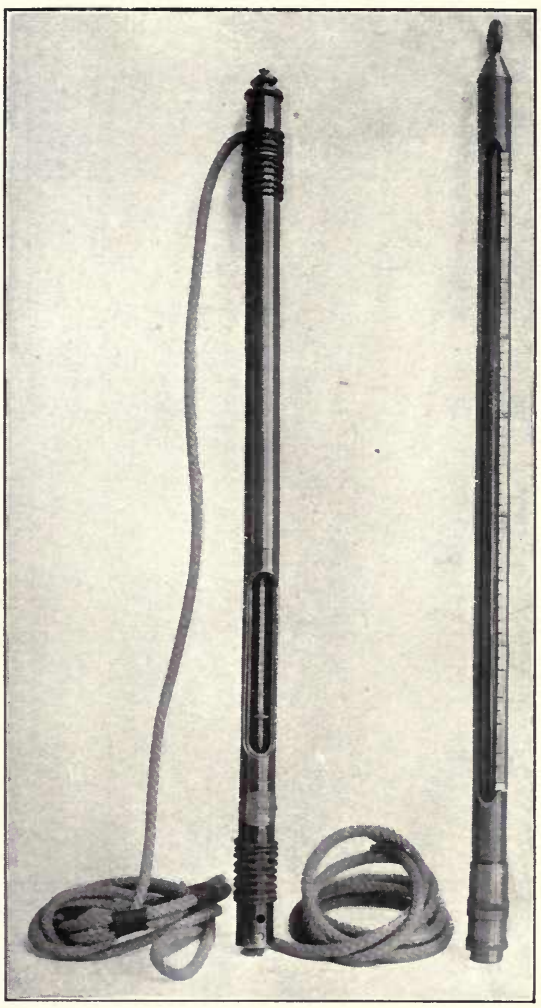

Fig. 259.-Sounding or Depth Gauges.

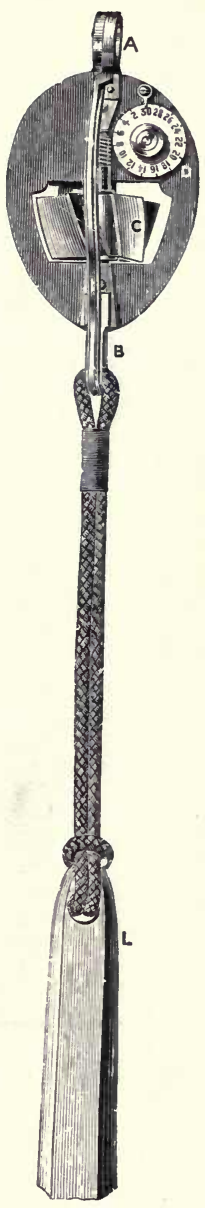

FIG. 260.

Sounding Machine AND LOAD. 


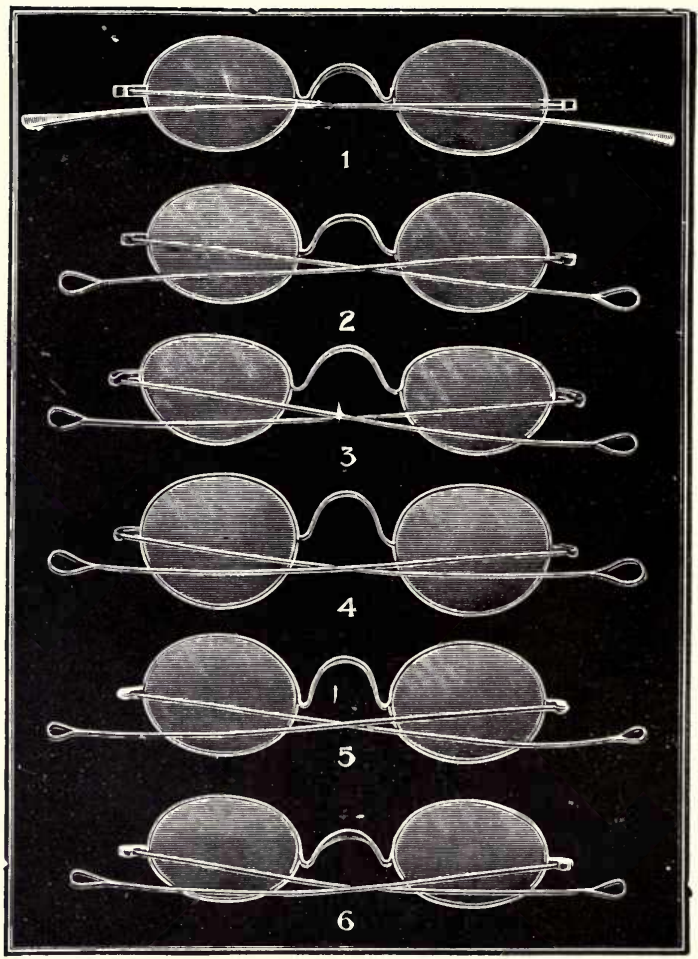

Fig. 261.-Spectacles. 


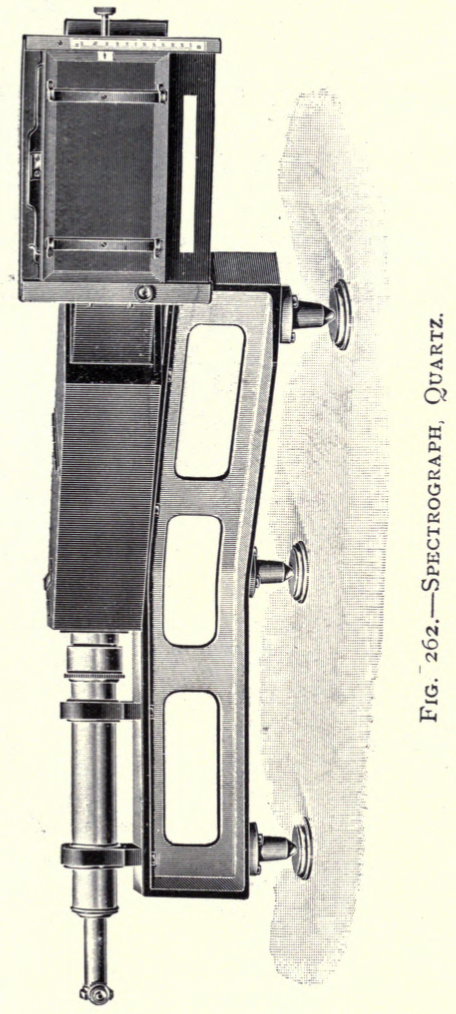




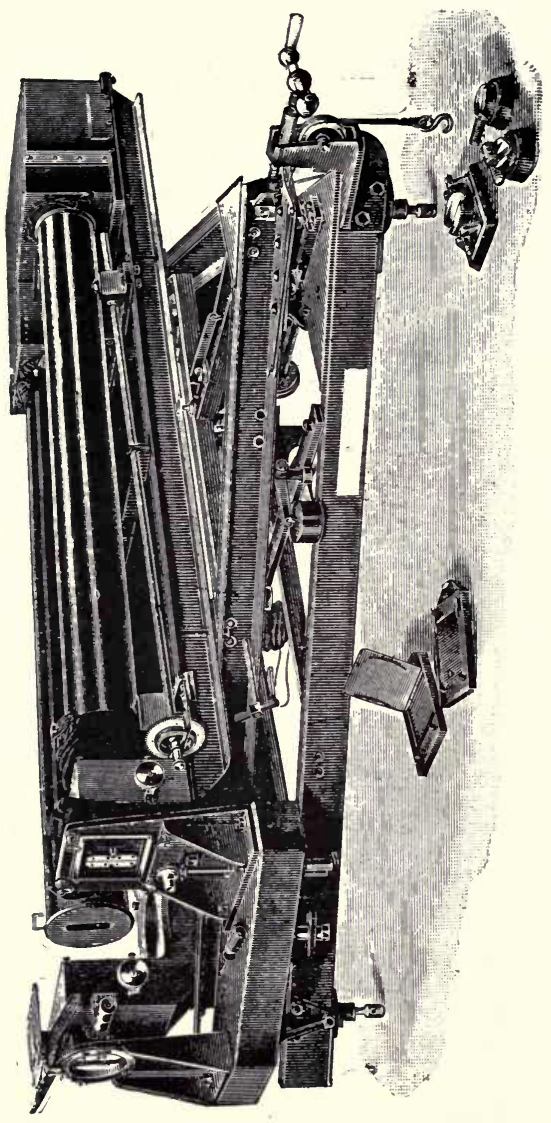

密 


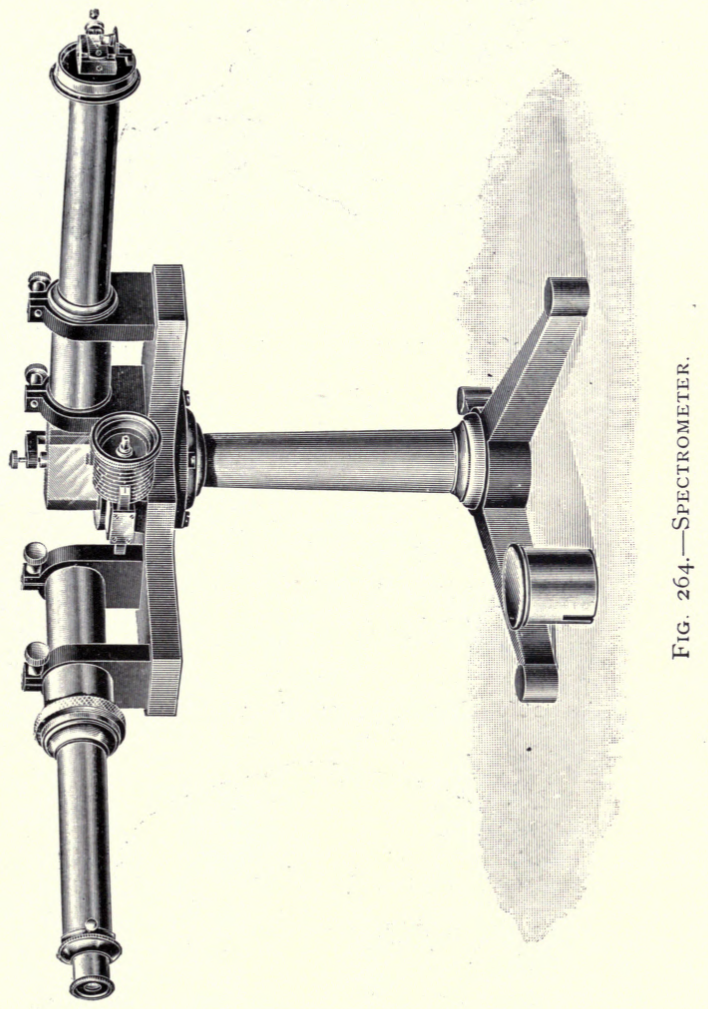




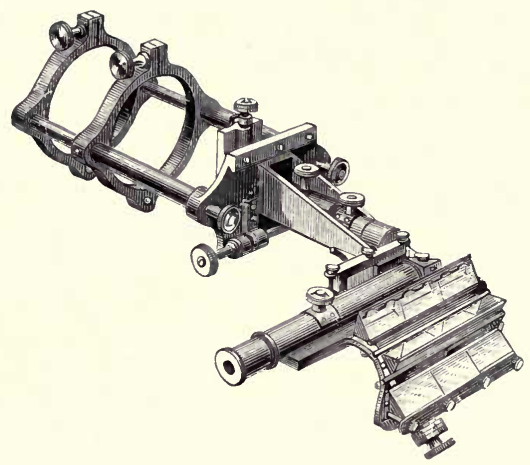

Fig. 265.-Spectroscope, Astronomical.

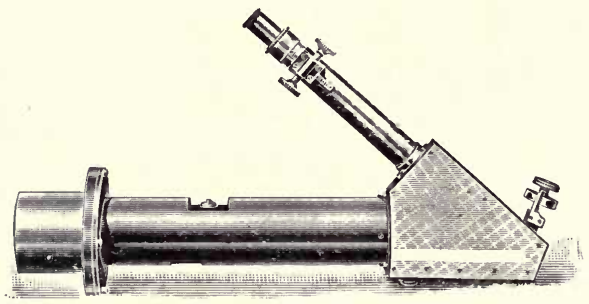

Fig 266.-Spectroscope, Solar Prominencf.

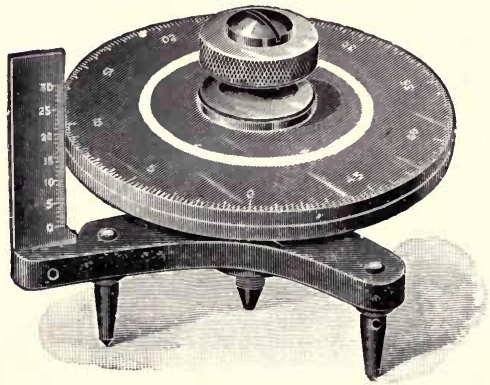

Fig. 267.-Spherometer. 


\section{I 3}

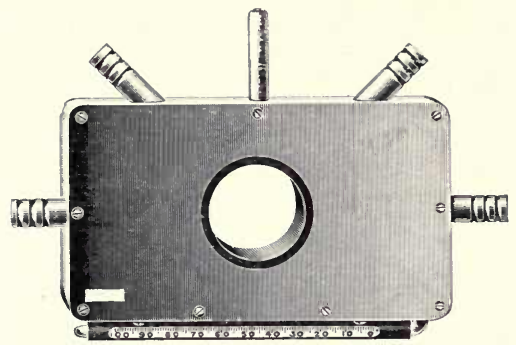

Fig. 268.-Stage, Warm, for Microscope.

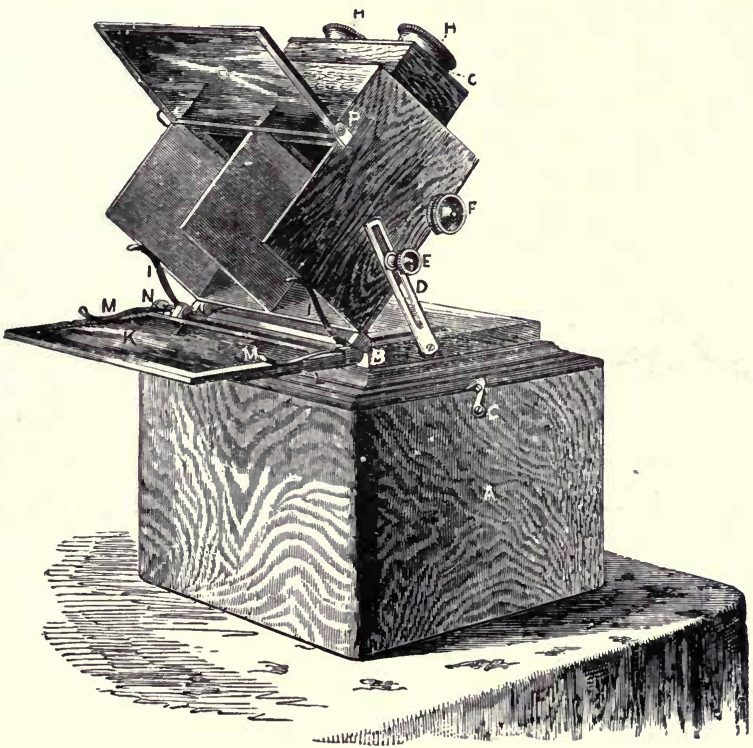

FiG. 269.-Stereoscope. 


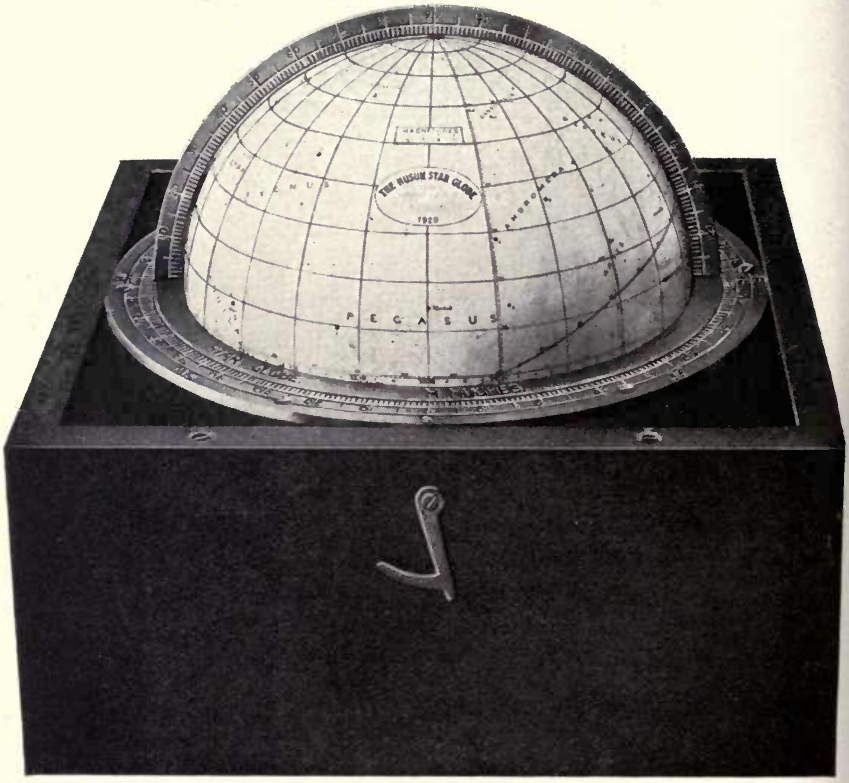

Fig. 270.-Star Globe, Paget. 


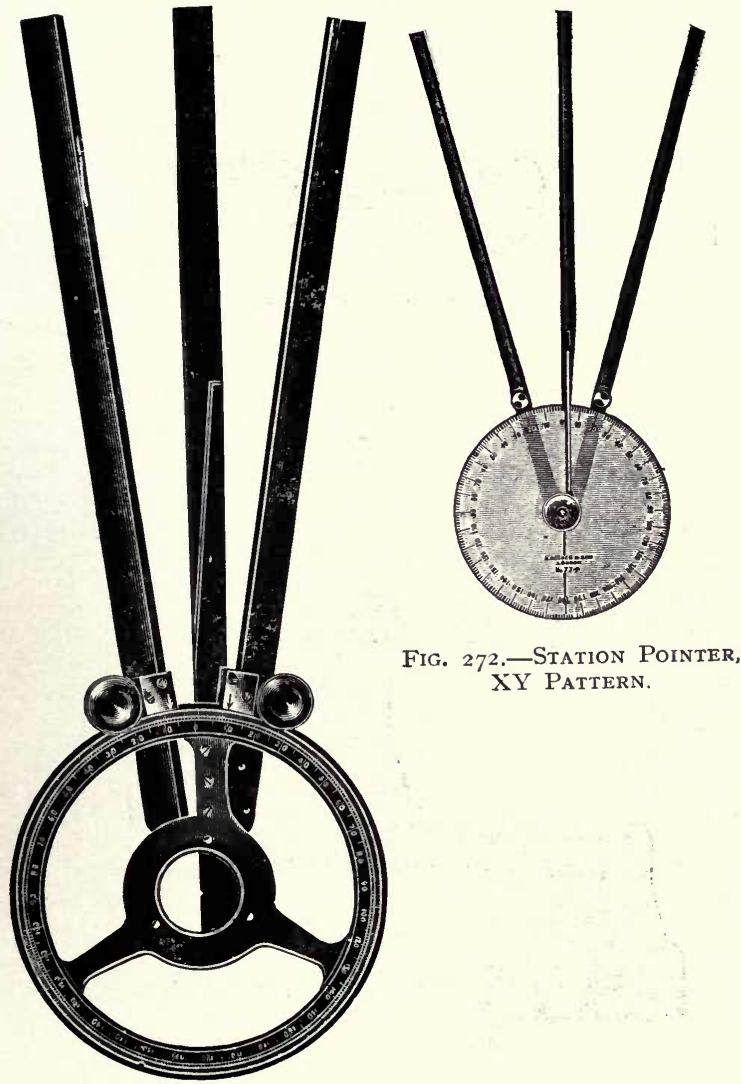

Fig. 271.-Station Pointer, Admiralty Pattern 


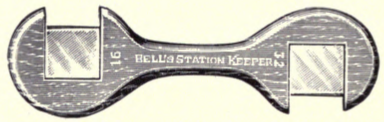

Fig. 273.-Station Kefper, Bell's.

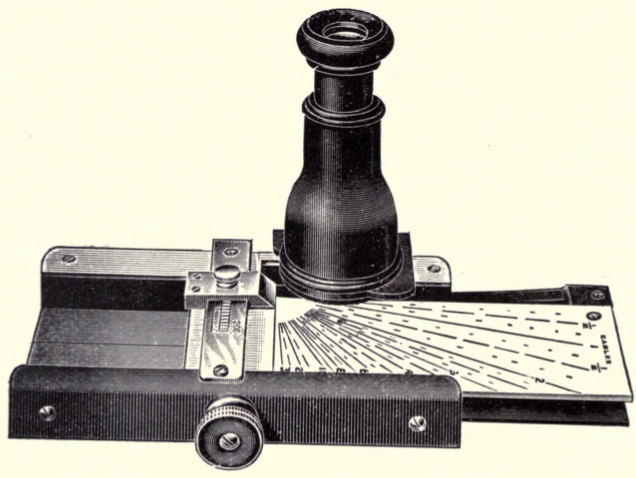

Fig. 274.-Stewart's Distance-Finder. 


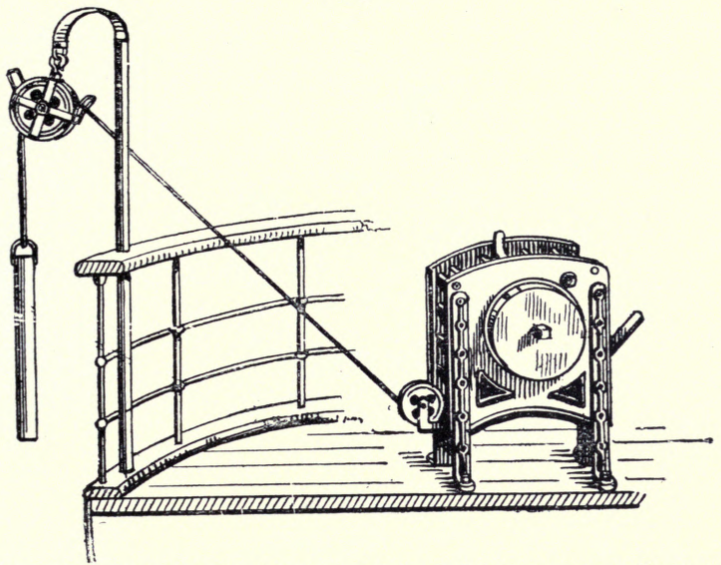

Fig. 275--Submarine Sentry Winch, Fatrlead and Sinker.

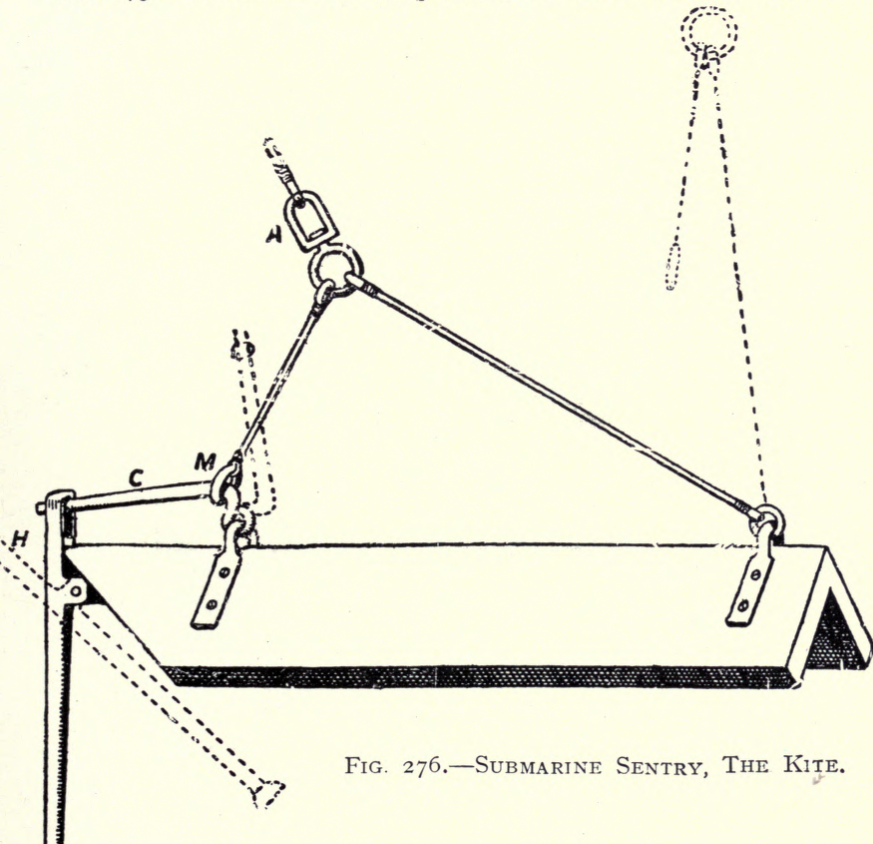




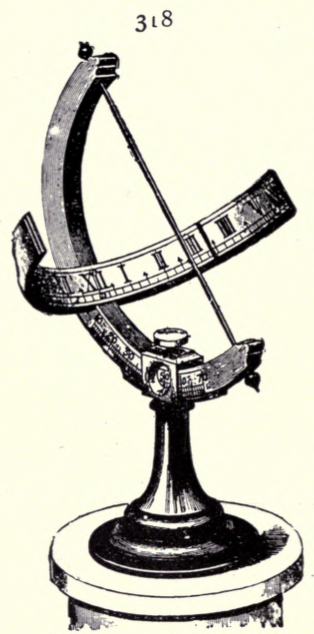

Fig. 277.-SUNdial, EQUATORIAL.

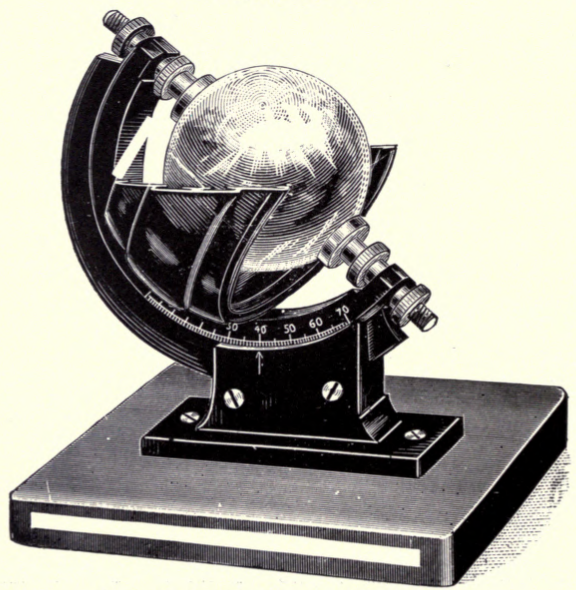

Fig. 278.-Sunshine Recorder. 

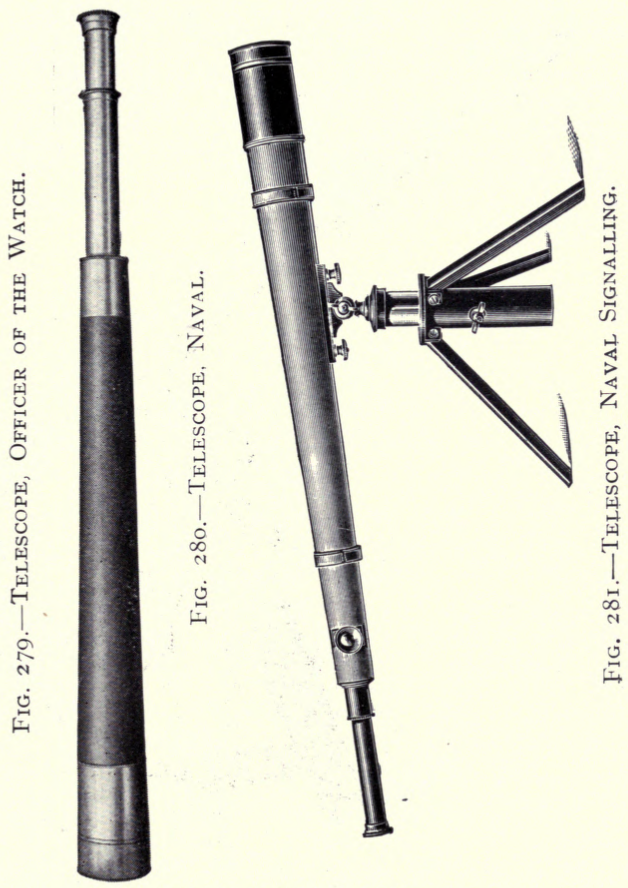


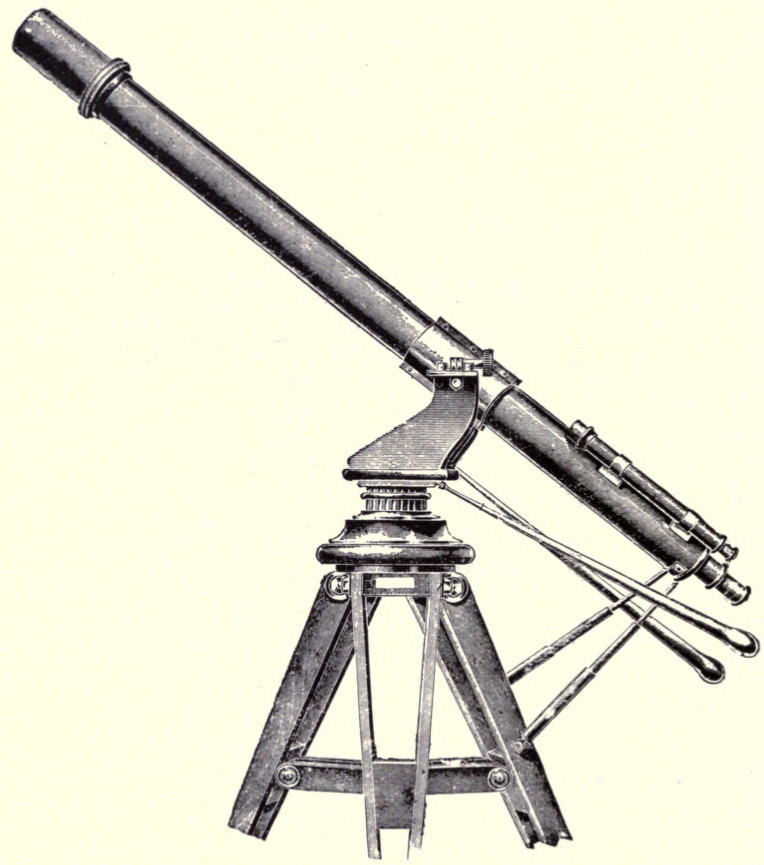

Fig. 282.-Telescope, Altazimuth. 


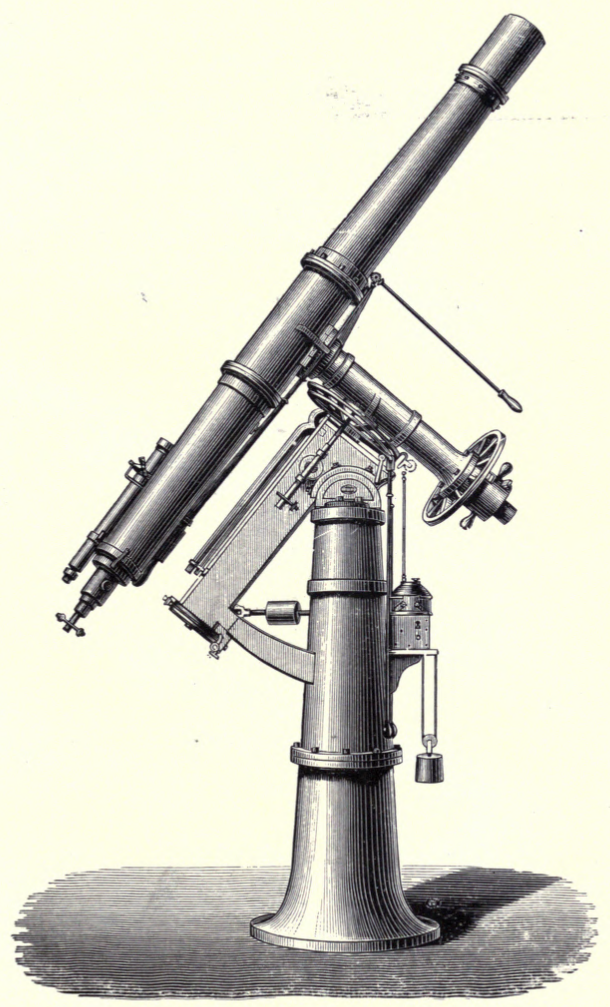

Fig. 283.-Telescope, Equatorial. 


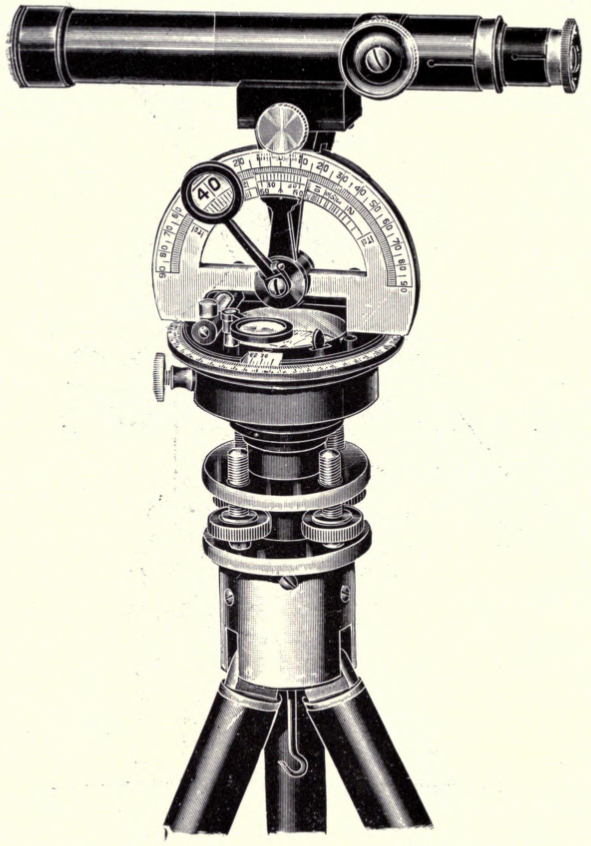

Fig. 284,-Theodolette. 


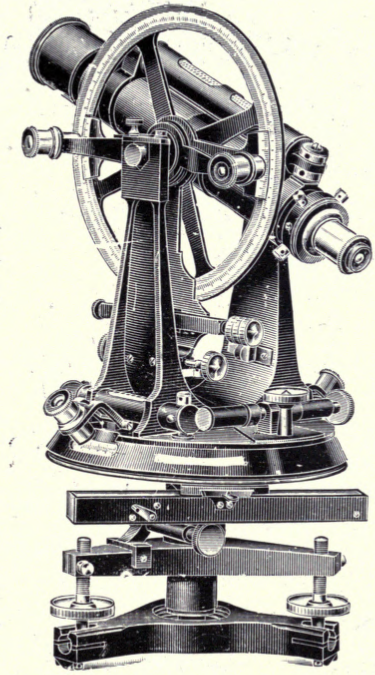

Fig. 285.-Theodolite, Transit, for General Surveying. 


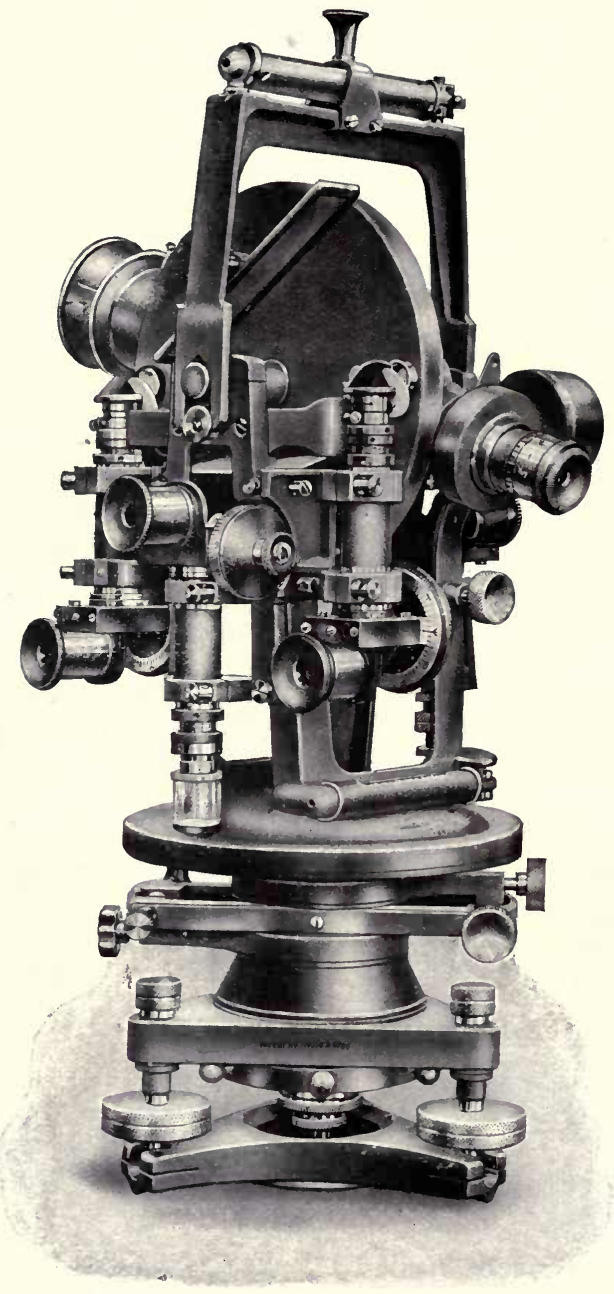

Fig. 286.-Theodolite, Micrometer. 


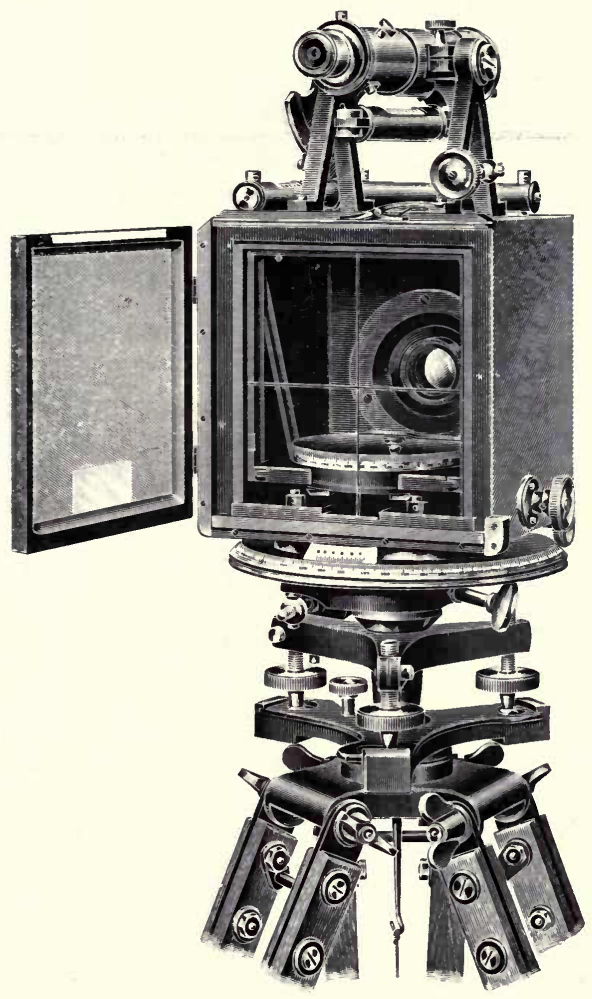

Fig. 287.-Theodolite, Phoio. 


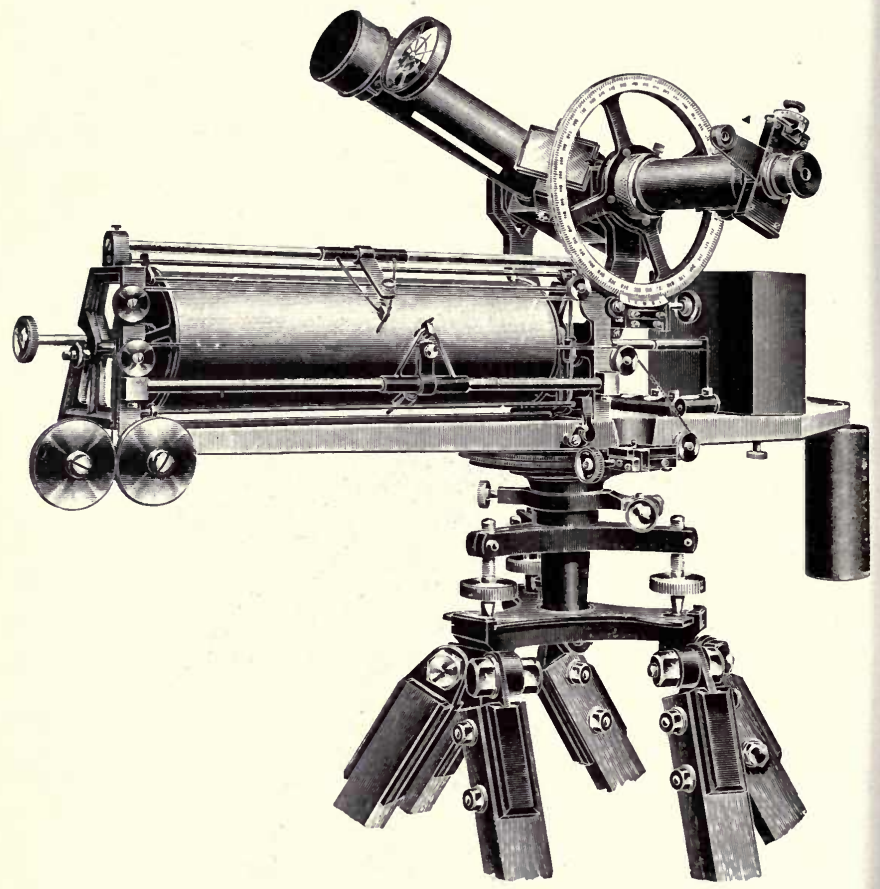

Fig. 288.-Theodolite, Recording. 


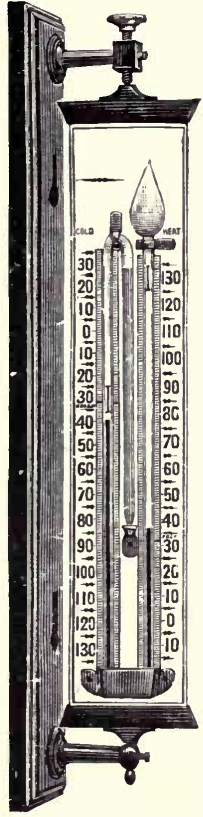

FIG. 292.

THERMOMETER (Six's Maximum and Minimum).

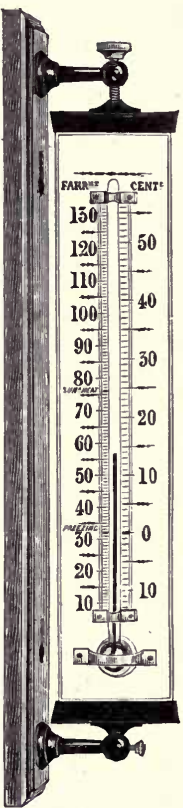

FIG. 293.

THERMOMETER, Window.

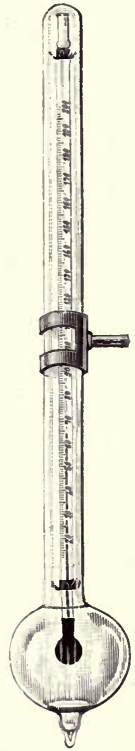

F1G. 294.

THERMOMETER, SOlAR RADIATION.

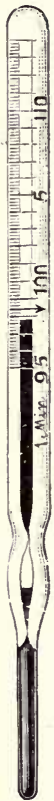

FIG. 295.

THERMOMETER, Clinical. 


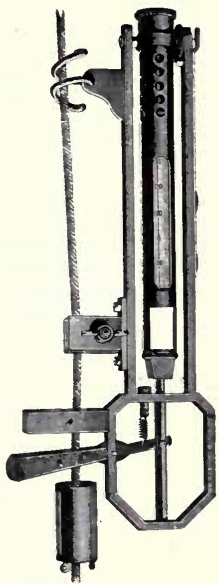

FIG. 296.

THERMOMETER

(in Scottish pattern Frame).

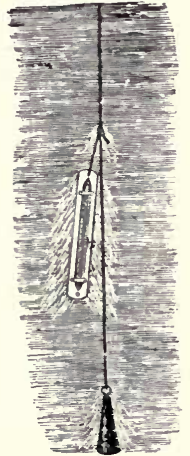

FIG. 297.

THERMOMETER

(in Wooden Mount, ascending).

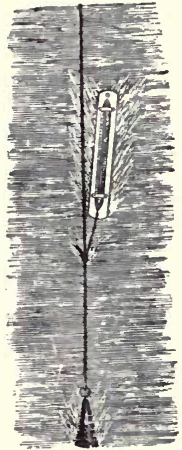

FIG. 298.

THERMOMETER

(in Wooden Mount, descending).

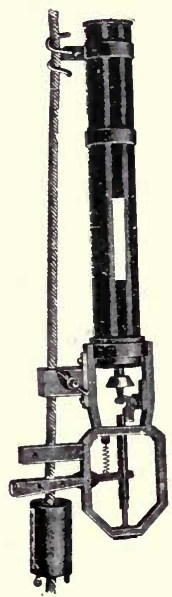

FIG. 299.

DEEP SEA

IVATER-BOTTLE.

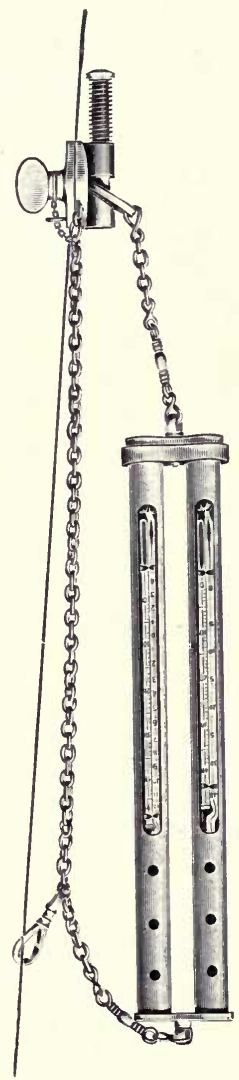

FIG. 300.

THERMOMETER, Reversing Frame. 


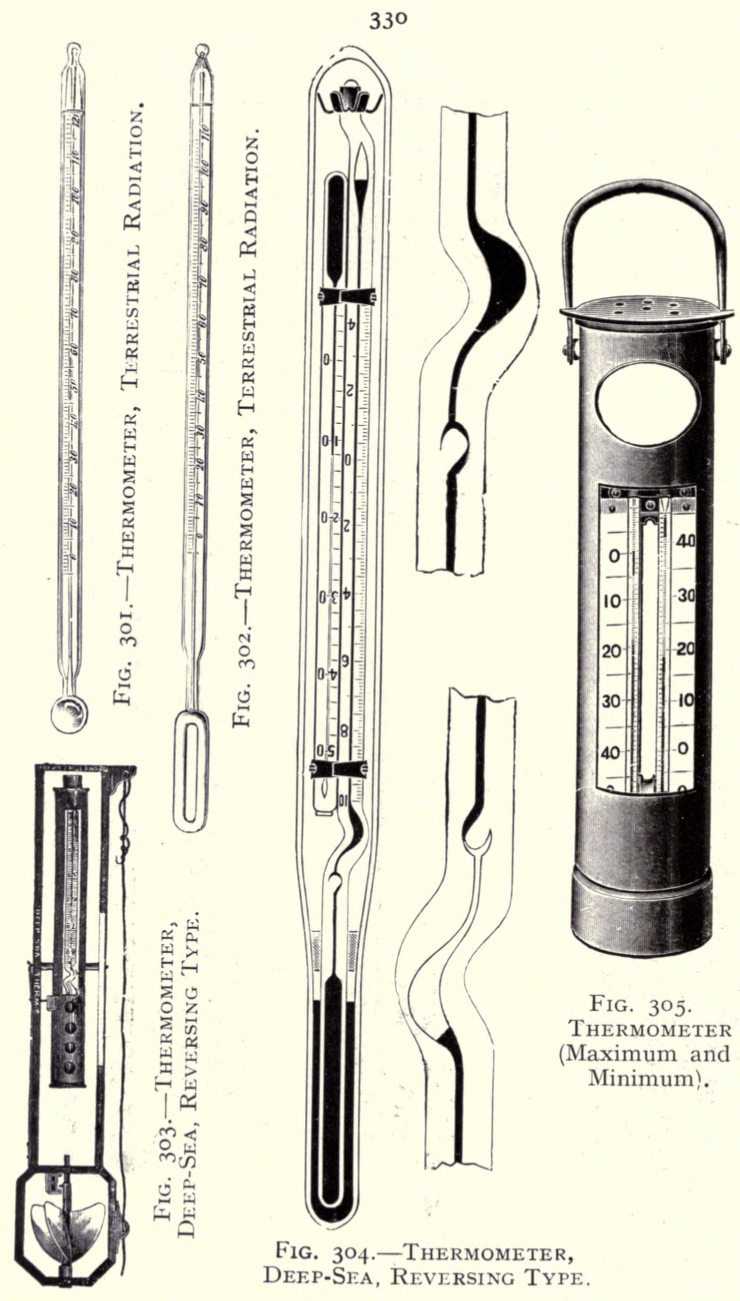




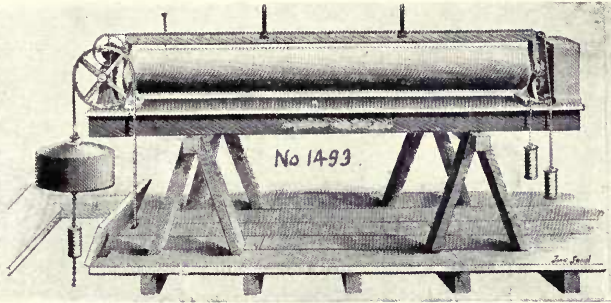

Fig. 306.-Tide-Gauge, India Office Pattern.

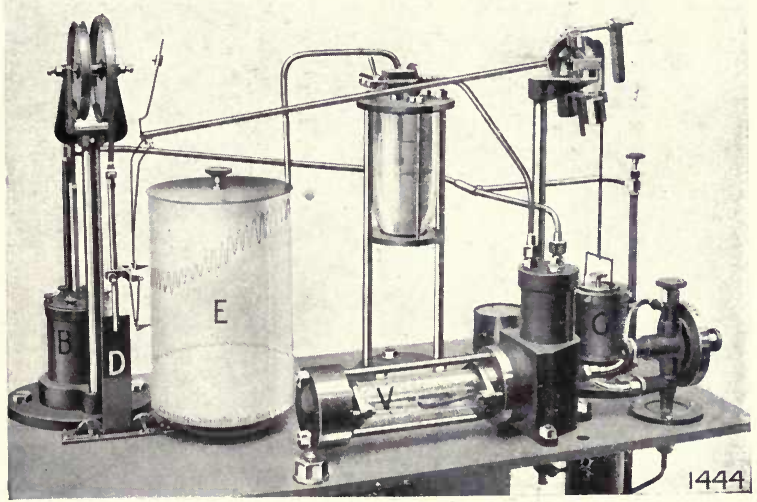

Fig. 307.-Tide-Recorder，Field \& Cust. 


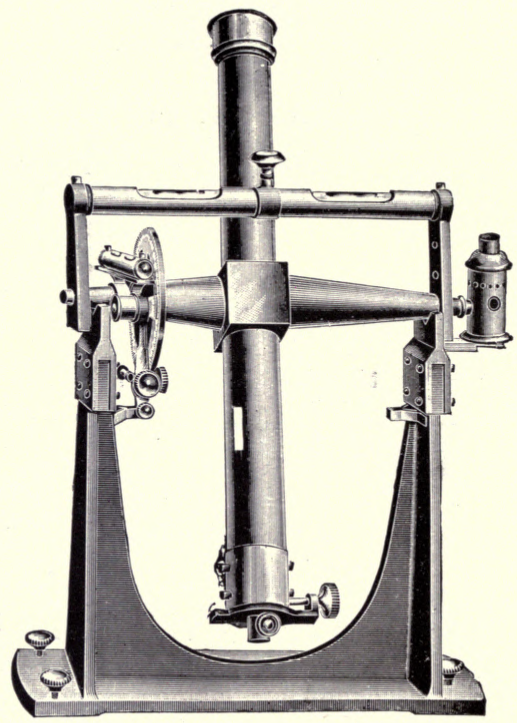

Fig. 308.-Transit Instrument.

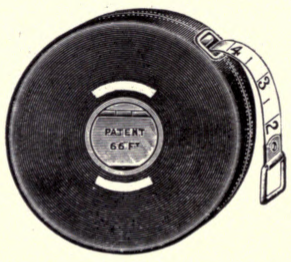

Fig. 309-TApe Measure. 


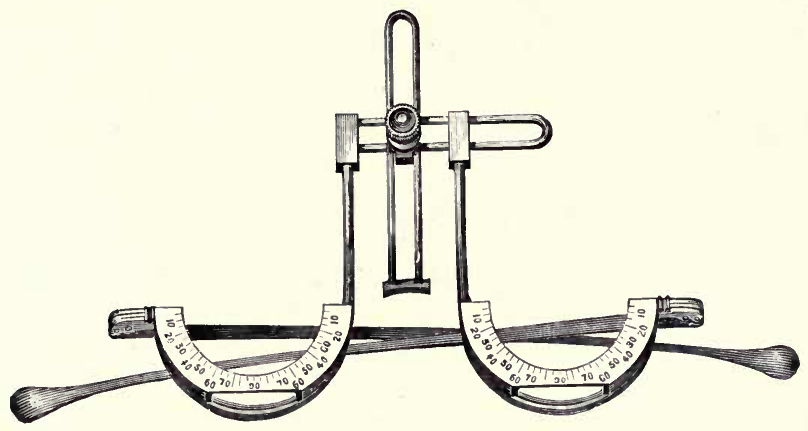

Fig. 3io.-Trial Sight Frame.

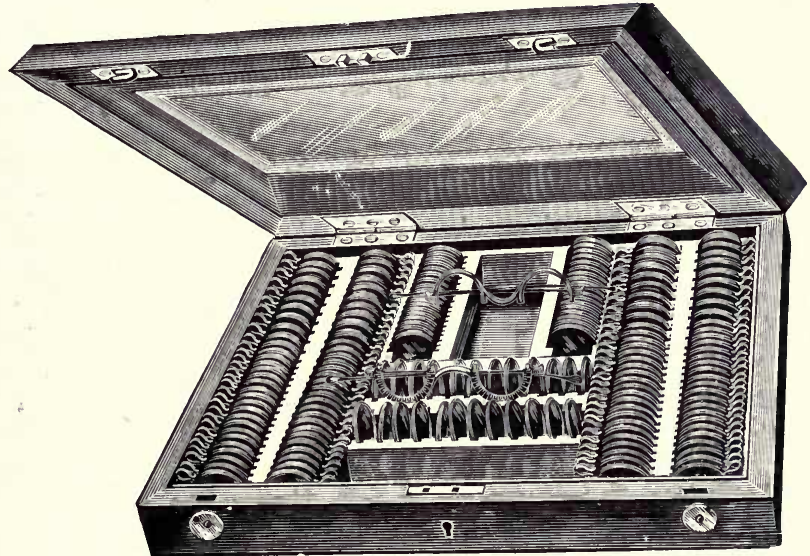

Fig. 3il.-Trial Sight Case. 

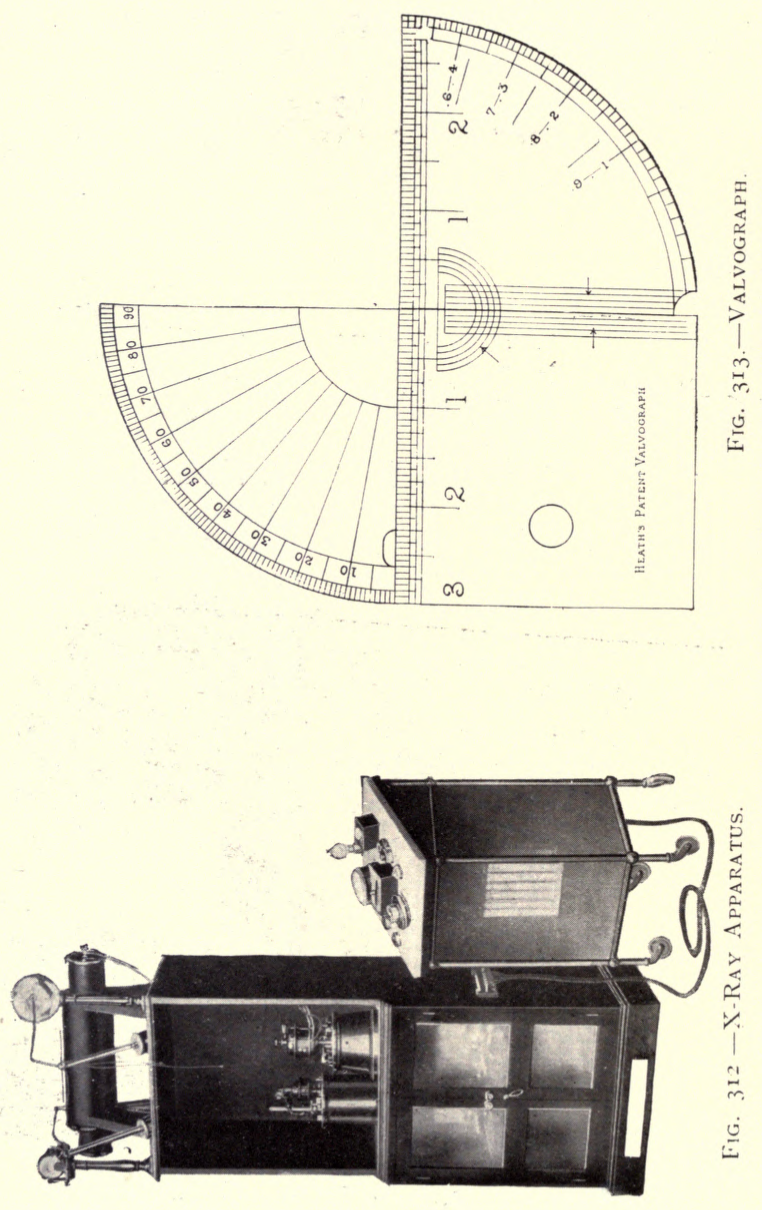
NOTES. 
(3) 








$$
\frac{D}{\omega}
$$






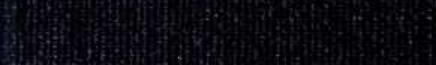

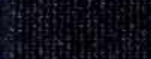

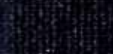

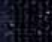

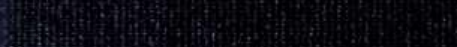

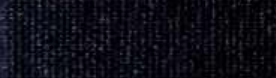

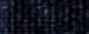

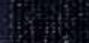

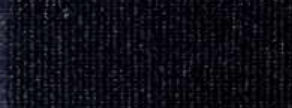

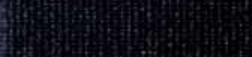

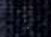

蜼 to:

数

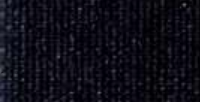

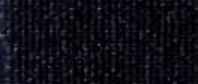

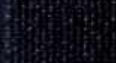

34

3. 